Universidad de Lima

Facultad de Administración

Carrera de Negocios Internacionales

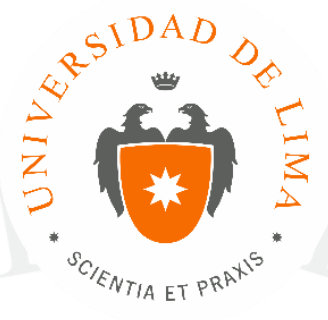

\title{
EXPORTACIÓN DE GRANADAS FRESCAS AL REINO UNIDO
}

Trabajo de investigación para optar la licenciatura en Negocios Internacionales

\section{Carla Alejandra Rubio Valla \\ Código 20081973}

Asesor

William Arteaga Donayre

Lima - Perú

Setiembre de 2015 


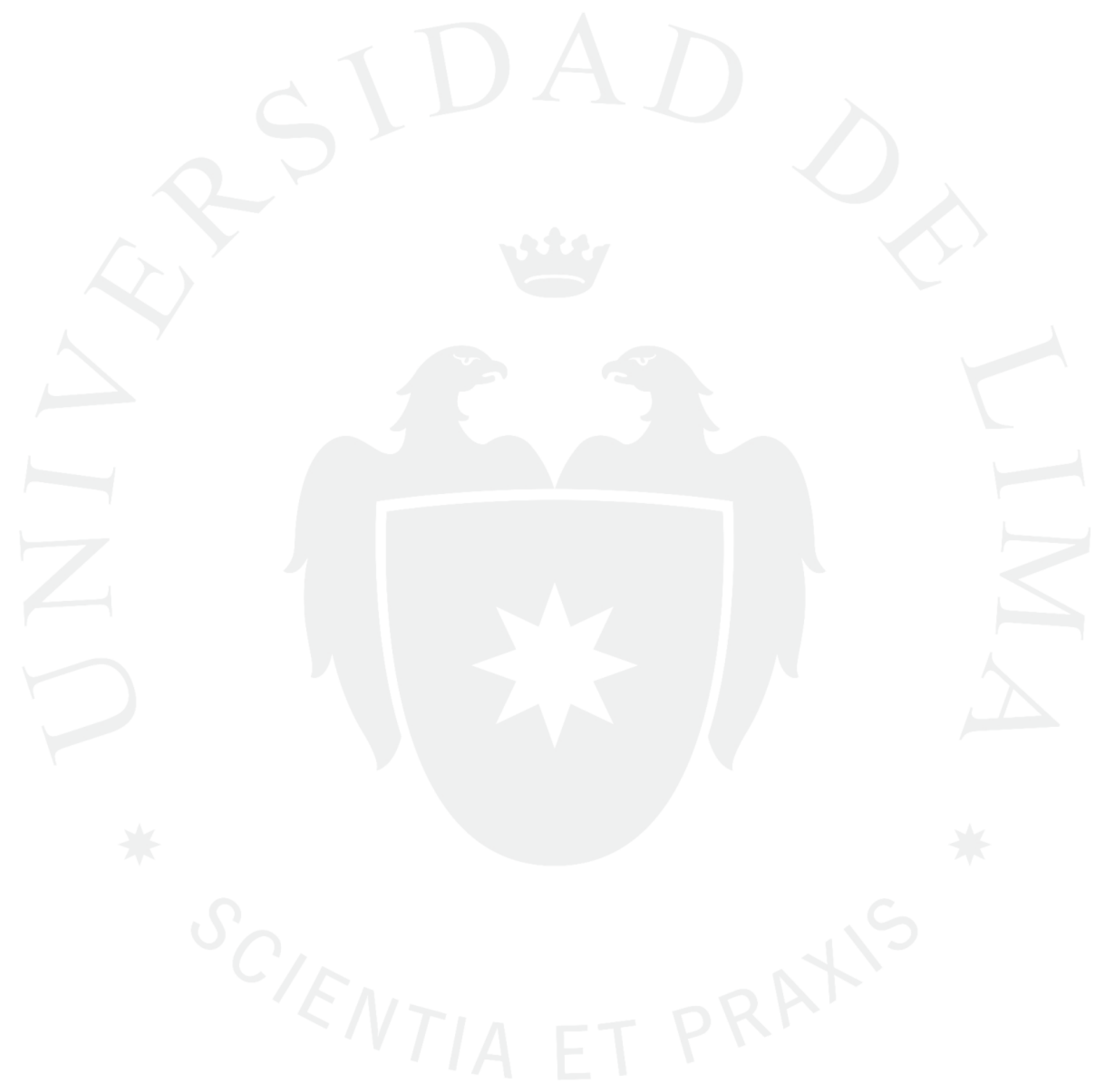




\section{EXPORTACIÓN DE GRANADAS FRESCAS AL REINO UNIDO}




\section{ÍNDICE}

INTRODUCCIÓN .............................................................................................14

1.1 Planteamiento del Problema................................................................... 16

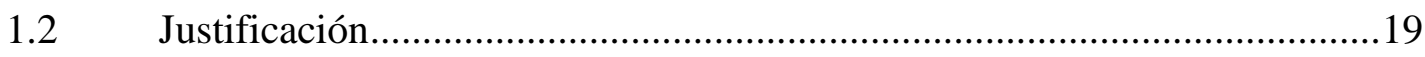

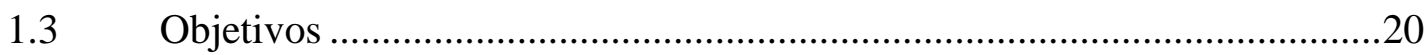

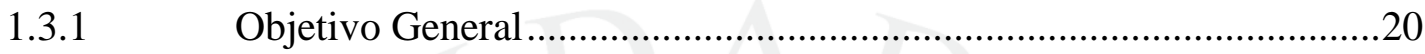

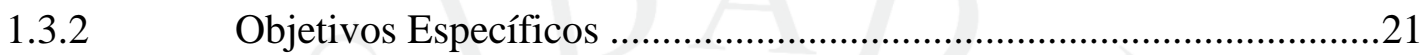

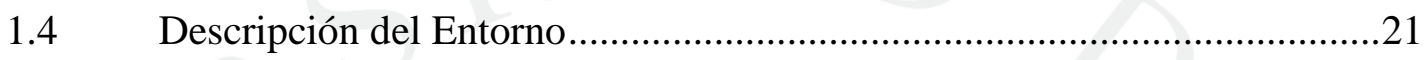

1.4.1 Sector Agroindustrial Perú - Reino Unido ...................................22

1.4.2 Análisis del Mercado destino como potencia mundial ......................24

a) Potencial del consumo en el Reino Unido .................................24

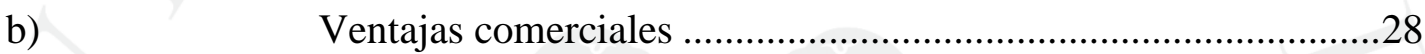

CAPÍTULO II: MARCO TEÓRICO ....................................................................32

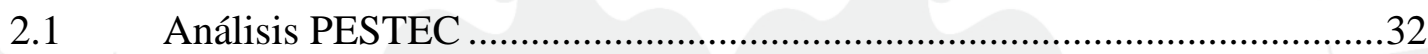

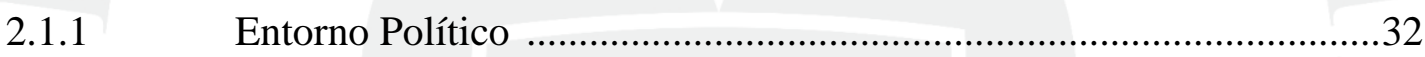

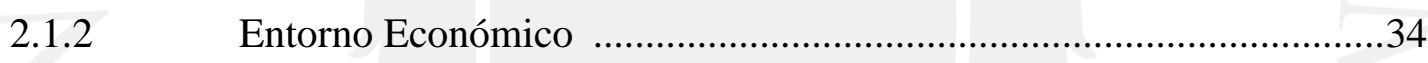

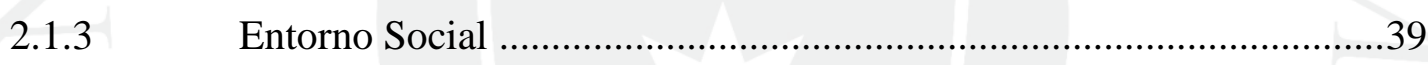

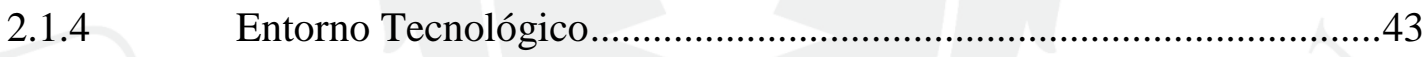

2.1.5 Entorno Económico y Competitivo …...............................................47

2.2 Diamante competitivo de Porter.............................................................50

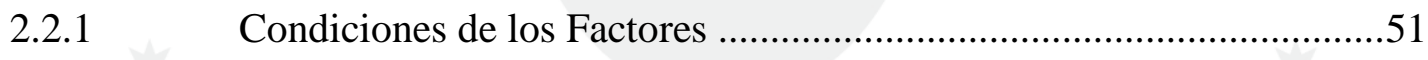

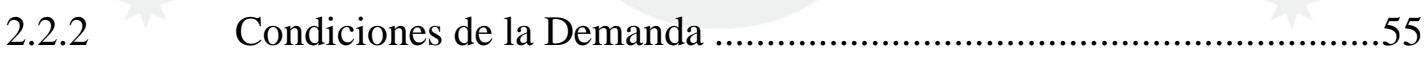

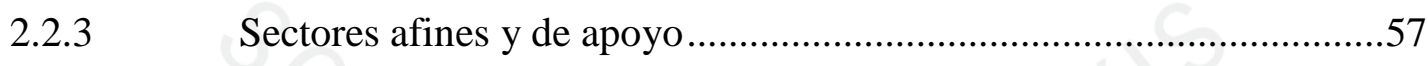

2.2.4 Estrategia, estructura y rivalidad de la empresa ...............................59

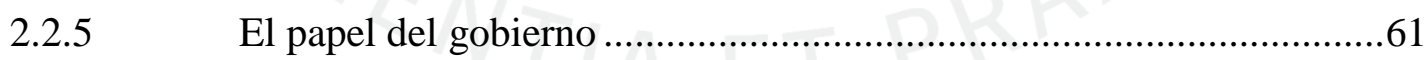

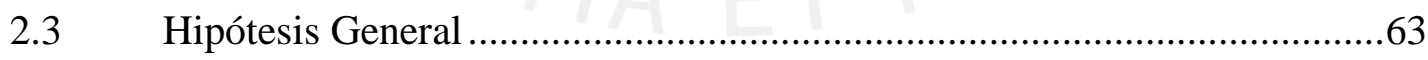

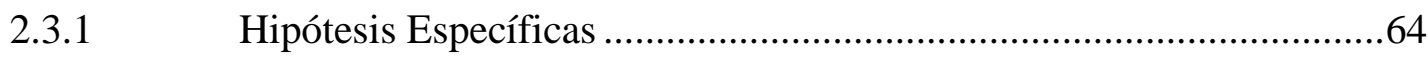

CAPÍTULO III: PLAN DE NEGOCIOS ................................................................65

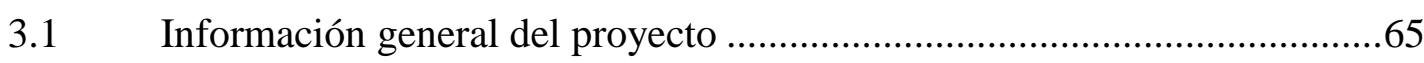

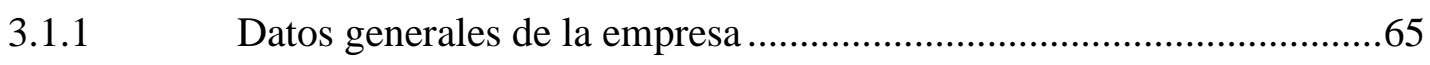

3.1.2 Identificación de la oportunidad de negocio .....................................66

3.1.2.1 Propiedades Beneficiosas de la Granada ....................................68 


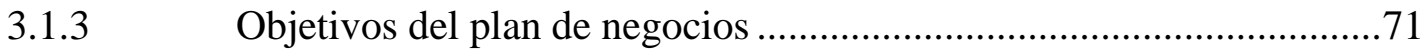

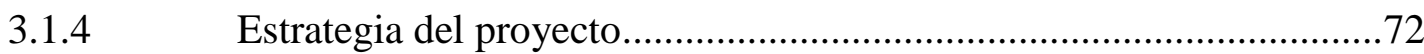

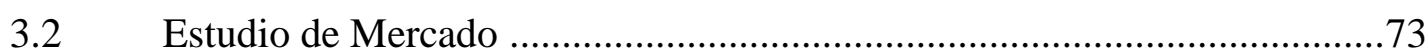

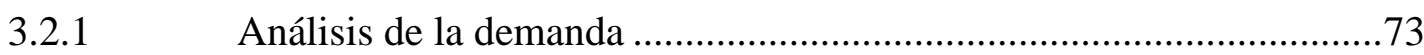

3.2.1.1 Definición del producto ............................................................73

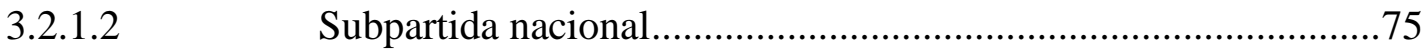

3.2.1.3 Producción del producto en el Perú ............................................76

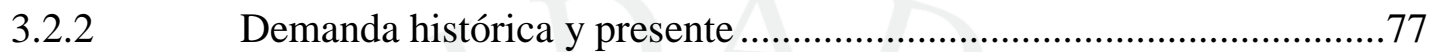

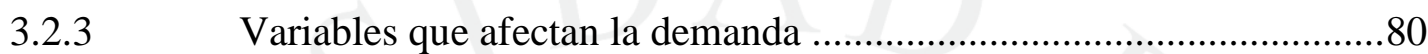

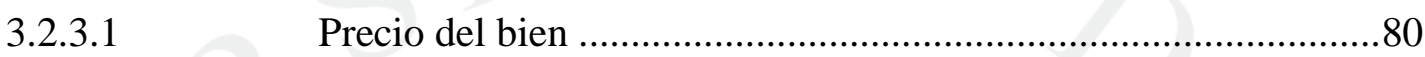

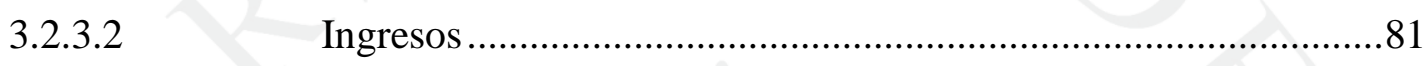

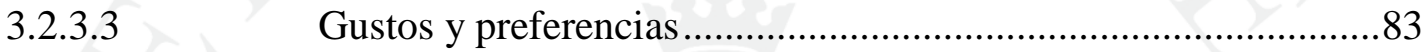

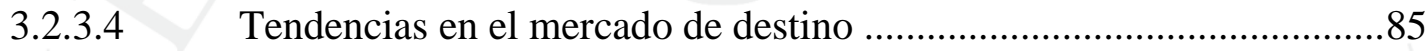

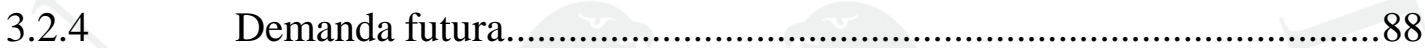

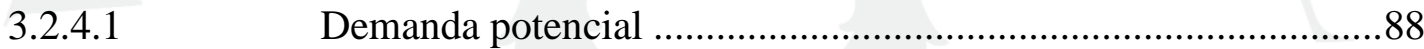

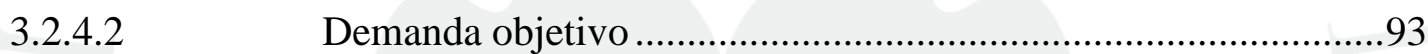

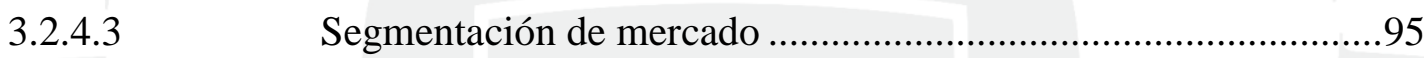

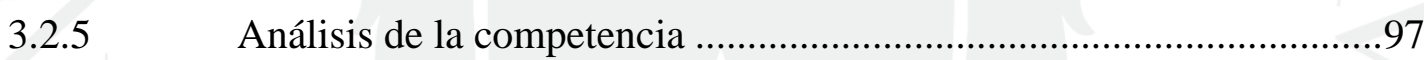

3.2.5.1 Análisis de la competencia local............................................97

3.2.5.2 Principales empresas exportadoras peruanas .............................97

3.2.5.3 Análisis de la competencia internacional...................................100

3.2.5.4 Principales proveedores mundiales..........................................100

3.2.5.5 Principales proveedores del producto al mercado destino ..........103

3.2.5.6 Tendencia de la competencia ....................................................105

3.2.5.7 Marco legal de la competencia ..............................................111

3.2.5.8 Mix comercial de la competencia ...........................................112

3.2.6 Análisis FODA de la competencia.................................................117

3.2.6.1 Análisis de la comercialización ..................................................117

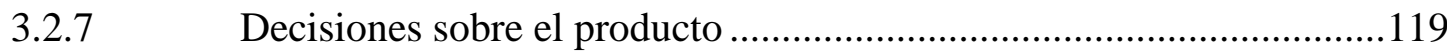

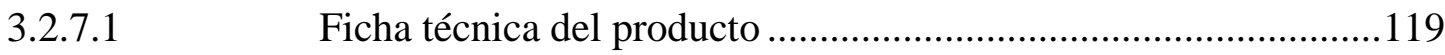

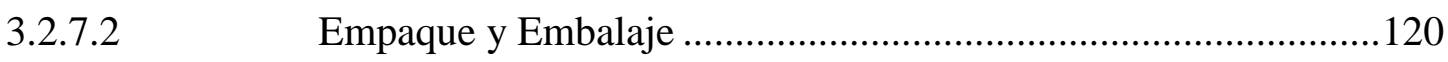

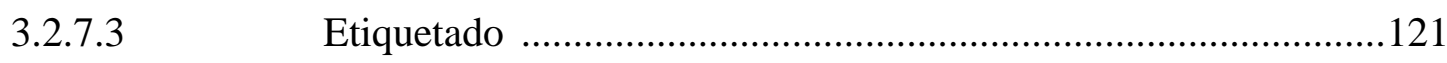

3.2.7.4 Información Adicional ..........................................................122 


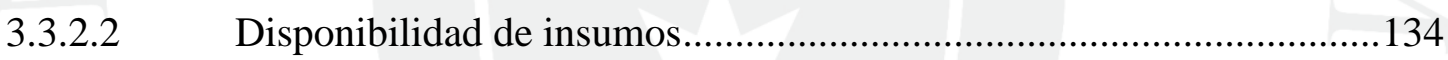

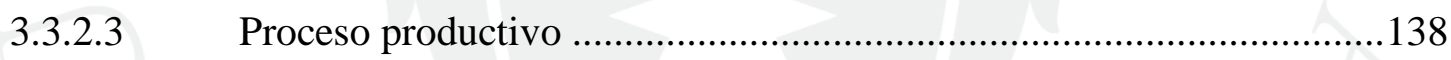

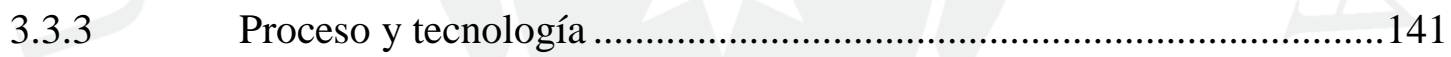


3.5 Estudio legal.

3.5.1.2 Flujograma de creación de la empresa.............................................153

3.5.2 Legislación arancelaria - tributaria..................................................154

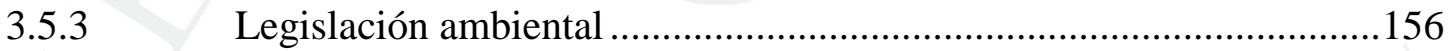

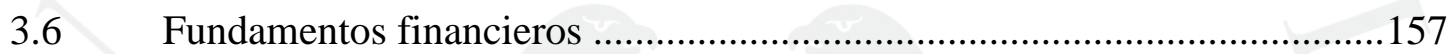

3.6.1 Evaluación Económica Financiera...................................................157

3.6.1.1 Inversión en activos fijos ......................................................157

3.6.2 Estructura de costos fijos y variables.............................................. 158

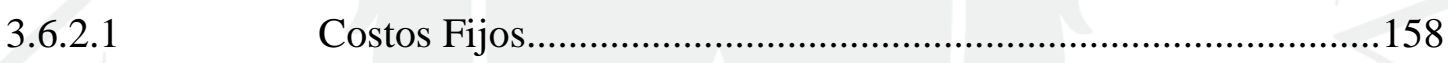

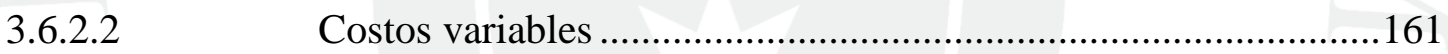

3.6.3 Margen y determinación del precio de venta.....................................163

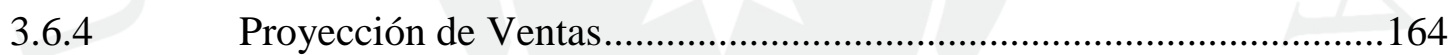

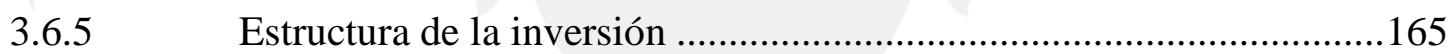

3.6.5.1 Depreciación de Activos Fijos ..................................................167

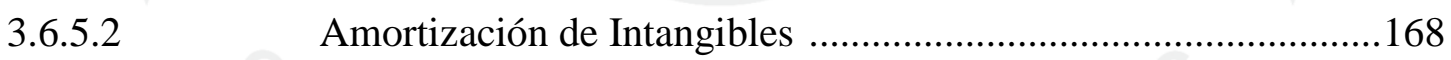

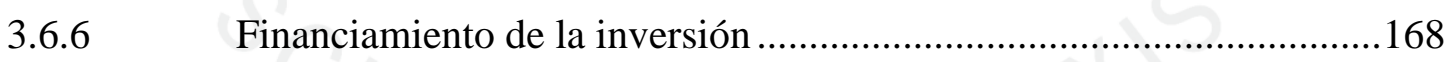

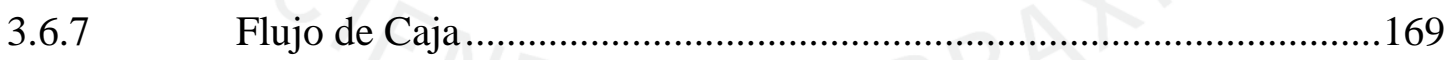

3.6.7.1 Flujo de Caja Económico...........................................................169

3.6.7.2 Flujo de Caja Financiero ........................................................ 170

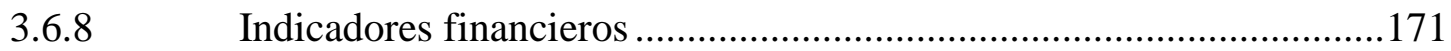

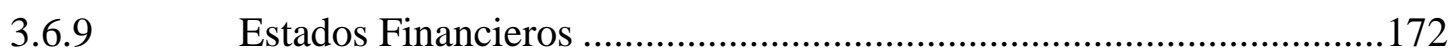

3.6.9.1 Estado de Ganancias y Pérdidas ..............................................172

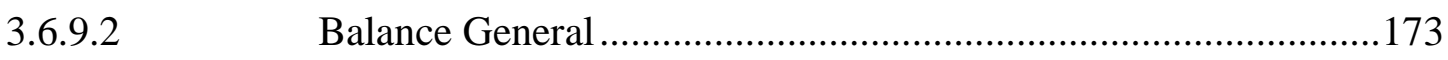

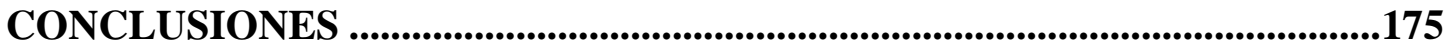

RECOMENDACIONES .......................................................................177 


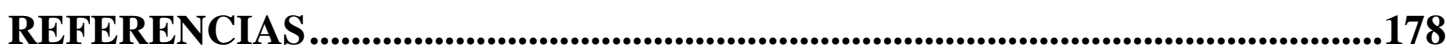

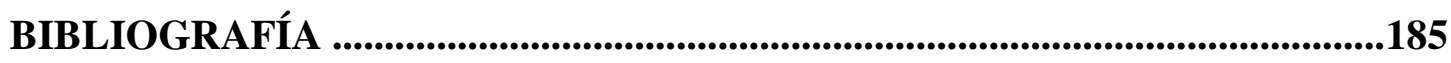

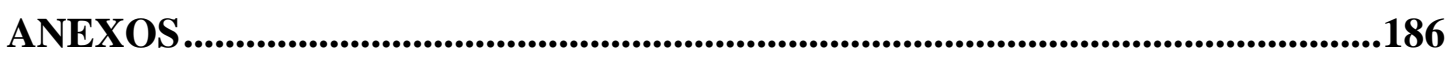

\section{ÍNDICE DE TABLAS}

Tabla 1: Principales Destinos De Exportación: Granada (Valor Fob US\$)..............16

Tabla 2: Principales Destinos De Exportación: Granada (Peso Neto Kg)................16 
Tabla 3: Principales proveedores para el Reino Unido: Otros frutos frescos (Valor Fob US\$) .17

Tabla 4: Superficie cultivada de granadas a nivel nacional (ha)...................... 19

Tabla 5: Evolución de las importaciones de frutas (Cap. 08) del Reino Unido...........24

Tabla 6: Volumen de venta de Frutas Reino Unido 2008-2013 (Miles TN).............27

Tabla 7: Proyección de venta de Frutas Reino Unido 2013-2018 (Miles TN)..........27

Tabla 8: Intercambio Comercial Perú-Reino Unido (millones US\$)............................28

Tabla 9: Principales Empresas Exportadoras Peruanas de Granadas....................59

Tabla 10: Crecimiento de las exportaciones de granadas peruanas a los principales

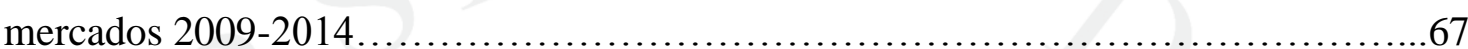

Tabla 11: Data Nutricional Granadas Frescas (Variedad Wonderful)..................70

Tabla 12: Producción de Granadas a nivel Nacional 2012/2013 ......................76

Tabla 13: Rendimiento Kg por Hectárea de granadas a nivel nacional 2012/2013......76

Tabla 14: Exportación de otros Frutos frescos al Reino Unido entre el 2003 y 2012

Tabla 15: Exportación de otros Frutos frescos al Reino Unido entre el 2013 y 2014

Tabla 16: Ventas de frutas por Orgánico / Comercio Justo vs Standard: \% de Volumen

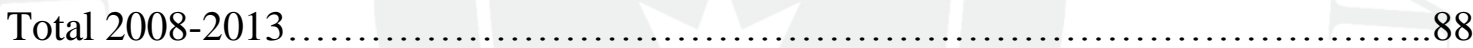

Tabla 17: Proyección de la demanda mensual de la Partida 081090 "Otros frutos

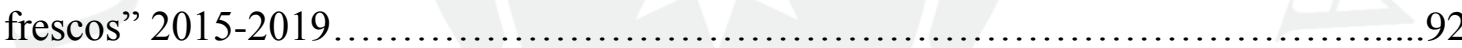

Tabla 18: Proyección de la demanda anual de la Partida081090 "Otros frutos frescos" 2015-2019

Tabla 19: Demanda anual objetivo del Reino Unido de la partida arancelaria 081090:

Otros Frutos Frescos.

Tabla 20: Empresas Peruanas exportadoras de Granada Fresca hacia el Reino Unido .95

Tabla 21: Población de las 10 principales ciudades del Reino Unido. .96

Tabla 22: Principales empresas peruanas exportadoras de Granadas hacia el Reino Unido (FOB US\$)

Tabla 23: Principales empresas peruanas exportadoras de Granadas hacia el Reino Unido (Peso KG).

Tabla 24: Principales proveedores mundiales de Otros Frutos Frescos Año 2012-2013 (US\$). 
Tabla 25: Principales proveedores mundiales de Otros Frutos Frescos 2013

$(\mathrm{TN})$

Tabla 26: Principales mercados proveedores para el Reino Unido de Otros frutos frescos.

Tabla 27: Exportaciones de otros frutos frescos por España en Valor (US\$) y Cantidad (TN). 106

Tabla 28: Principales destinos de exportación de Otros Frutos Frescos por España (US\$) 2003-2014

Tabla 29: Participación de Mercado de los principales destinos de exportación de otros Frutos Frescos para España. 107

Tabla 30: Principales destinos de exportación de Otros Frutos Frescos por España (TN) 2003-2014 108

Tabla 31: Exportaciones de otros frutos frescos por Egipto en Valor (US\$) y Cantidad (TN)

Tabla 32: Principales destinos de exportación de Otros Frutos Frescos por Egipto (US\$) 2003-2014

Tabla 33: Principales destinos de exportación de Otros Frutos Frescos por Egipto (TN) 2003-2014

Tabla 34: Valores unitarios por kilogramos de Otros Frutos frescos exportados por España

Tabla 35: Valores unitarios por kilogramos de Otros Frutos frescos exportados por

Egipto

Tabla 36: Valores unitarios por kilogramos de Otros Frutos frescos exportados por Perú

Tabla 37: Distribución de Frutas en el Reino Unido por formato: \% del volumen total 2008-2013

Tabla 38: Valores unitarios por kilogramos de granadas exportadas por Perú....

Tabla 39: Cronograma de Actividades de Marketing.

Tabla 40: Presupuesto de Actividades de Marketing.

Tabla 41: Producción, Superficie, Rendimiento y Precio en chacra de granadas por región año 2013 136

Tabla 42: Rendimiento por hectárea cultivada de granada fresca en la Región Ica.....136

Tabla 43: Insumos requeridos para la obtención de granadas $\mathrm{kg} / \mathrm{ha}$

Tabla 44: Determinación del tamaño en Has cultivadas 
Tabla 45: Proveedores de Insumos......................................... 138

Tabla 46: Condiciones Óptimas de cultivo de la granada........................... 140

Tabla 47: Características del local.............................................. 145

Tabla 48: Distribución de área por Metro Cuadrado ............................ 145

Tabla 49: Requerimiento de materiales para remodelación........................146

Tabla 50: Requerimiento de Equipos...................................... 147

Tabla 51: Requerimiento de Mobiliario Oficina.................................147

Tabla 52: Requerimiento Anual de Granadas (primer año)........................147

Tabla 53: Requerimiento Anual de Materias Primas relacionadas al empaque.........148

Tabla 54: Requerimiento de MOD para el primer año............................148

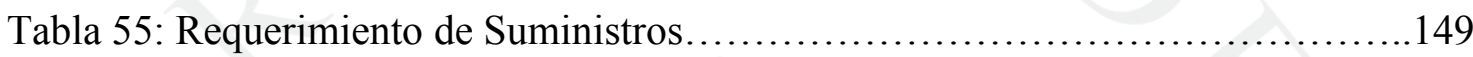

Tabla 56: Datos Generales de la empresa..................................... 150

Tabla 57: Descripción de los puestos de trabajo en Pome Perú......................151

Tabla 58: Beneficios para los trabajadores en pequeñas empresas....................157

Tabla 59: Costos Fijos Mensuales y Anuales......................................158

Tabla 60: Planilla Mensual..................................................... 159

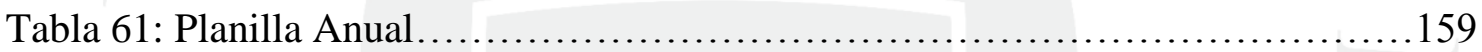

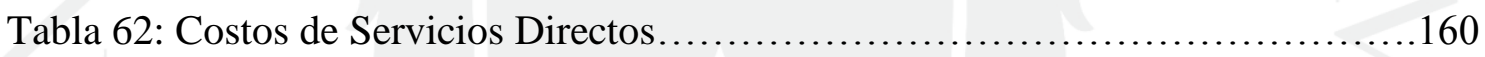

Tabla 63: Gasto de Promoción Proyectado.......................................161

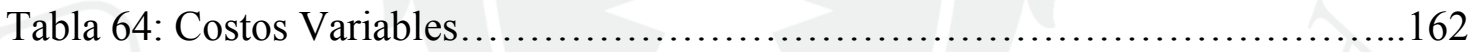

Tabla 65: Costos de Materiales Directos.......................................... 162

Tabla 66: Costos de Mano de Obra Directa (MOD).................................163

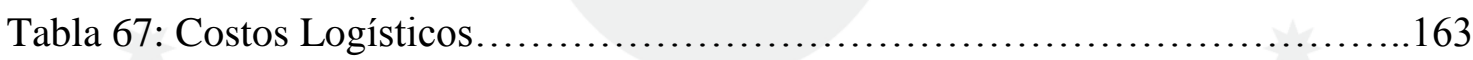

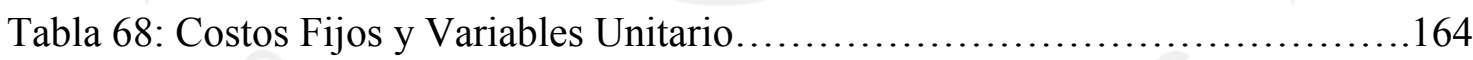

Tabla 69: Precio de Venta FOB............................................... 164

Tabla 70: Proyección de Ventas Anual......................................... 165

Tabla 71: Activos Fijos....................................................... 166

Tabla 72: Activos Intangibles.................................................. 166

Tabla 73: Capital Trabajo........................................................ 167

Tabla 74: Montos en US\$ de la depreciación de Activos..........................167

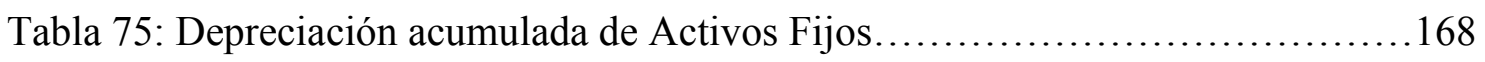

Tabla 76: Monto en US\$ de la amortización....................................168

Tabla 77: Monto en US\$ de la amortización.................................... 168

Tabla 78: Información importante Préstamo Bancario.............................169 


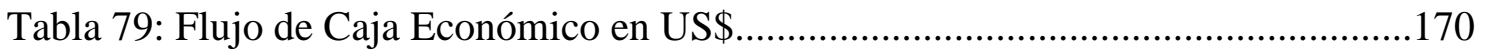

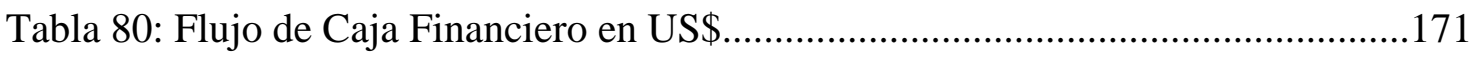

Tabla 81: Indicadores Financieros......................................... 171

Tabla 82:Estado de Ganancias y Pérdidas en US\$.................................................... 173

Tabla 83: Balance General expresado en US\$..............................................................174

\section{ÍNDICE DE FIGURAS}

Figura 1: Participación de la producción de granadas por región $-2013 \ldots \ldots \ldots \ldots \ldots \ldots . . .18$ 
Figura 2: Evolución de la producción de Granadas Región Ica (2008-2013) ............18

Figura 3: Ingesta media de frutas y Vegetales por país..............................26

Figura 4: Tendencia del Reino Unido en la compra de frutas y verduras (excepto

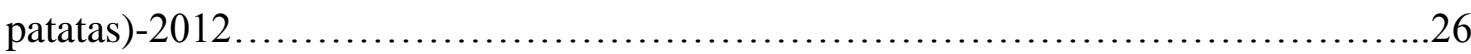

Figura 5: Exportaciones Perú-Reino Unido 2010-2014 (US\$ Millones)...............29

Figura 6: Crecimiento Real del PBI y PBI Per Cápita: 2006-2015 ...................35

Figura 7: Evolución Desempleo en el Reino Unido (sobre los 16 años de edad, 1990 -

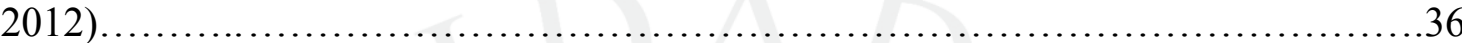

Figura 8: Evolución Comercio Exterior Total Reino Unido: 2006-2013.................37

Figura 9: Pirámide Poblacional Reino Unido 2014 ...............................40

Figura 10: Estructura de la Edad de la Población del Reino Unido...................41

Figura 11: Pirámide Poblacional Perú 2014.....................................43

Figura 12: Gasto en Ciencia, Tecnología e Innovación (CIT) 1999-2011_.............46

Figura 13: El Diamante Competitivo de Porter adaptado a Pome Perú SAC............51

Figura 14: Diversidad de Suelos en el Perú........................................53

Figura 15: Evolución de la exportación de Granada en la Región Ica 2008-2014

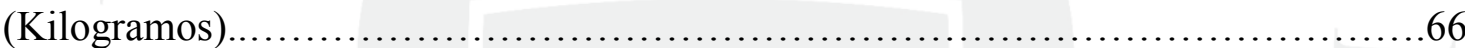

Figura 16: Estacionalidad de los principales países exportadores de granadas

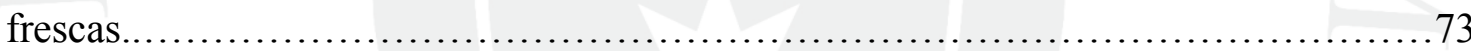

Figura 17: La Granada......................................................... 74

Figura 18: Partes de la Granada.................................................... 74

Figura 19: Principales Mercados Proveedores del Reino Unido para el Producto:

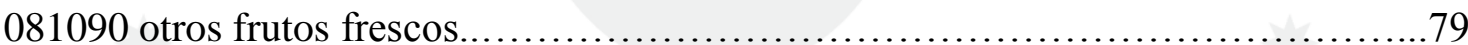

Figura 20: Ingreso por hogar disponible promedio anual por decil: Años 2013 y

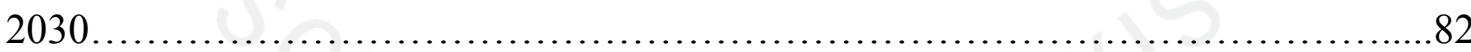

Figura 21: Ingreso Bruto Promedio por Edad: $2013 \ldots \ldots \ldots \ldots \ldots \ldots \ldots \ldots \ldots \ldots \ldots \ldots \ldots$

Figura 22: Tendencia en el consumo de frutas y verduras en hombres, mujeres y niños

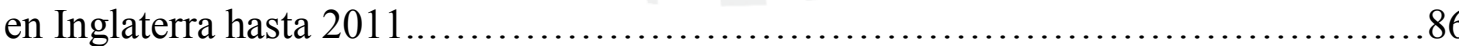

Figura 23: Importaciones mundiales de granada (PA: 081090) del Reino Unido en toneladas (TN) y valores (US\$)

Figura 24: Importaciones de granadas (PA 081090) del Reino Unido desde el Perú en

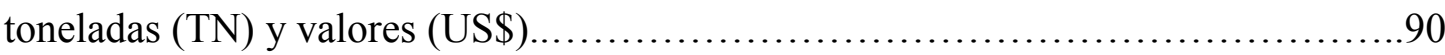

Figura 25: Proyección de la demanda mensual de la PA 081090 (Otros Frutos 
Figura 26: Participación de los principales proveedores en las Exportaciones de Otros frutos Frescos Año 2013 (US\$)

Figura 27: Participación de mercado de los Países proveedores de otras Frutas Frescas a

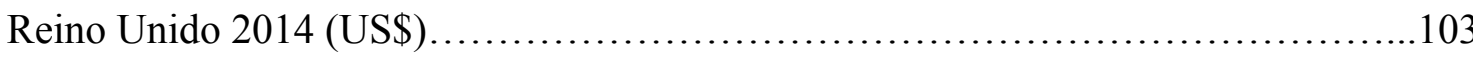

Figura 28: Boceto de caja de exportación.................................. 120

Figura 29: Empaque de las granada......................................... 121

Figura 30: Oficinas de Fruco PLC ............................................ 127

Figura 31: Puerto de Tilbury (London Distribution Park)........................128

Figura 32: Logo de la marca............................................... 129

Figura 33: Mapa de Zonas Potencial...........................................135

Figura 34: Volumen de Exportación de granadas provenientes de la región Ica (2010-

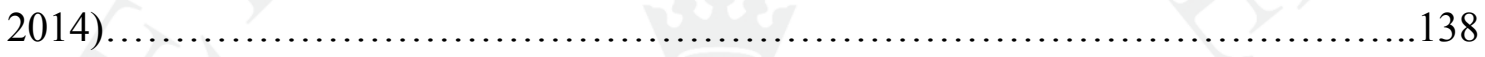

Figura 35: Plantación de la granada........................................... 139

Figura 36: Distribución de Pallets dentro del contenedor de 40 Pies...................142

Figura 37: Plano luego de la remodelación...........................................145

Figura 38: Organigrama de Pome Perú...................................... 150

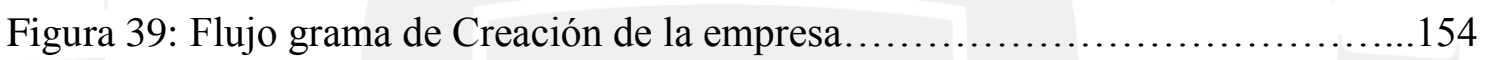




\section{INTRODUCCIÓN}

El Perú cuenta con 84 de los 114 microclimas que existen en el mundo, lo que favorece su biodiversidad. Esto ha permitido el desarrollo de nuevos cultivos y el aprovechamiento de ventanas comerciales para productos demandados a nivel mundial. EL Perú cuenta con estaciones anuales inversas a muchos mercados de Europa y Norteamérica, que son nuestros principales competidores.

La región Ica se considera una zona de muy alto potencial para el cultivo de granado. Actualmente es la principal región productora de Granadas según el MINAG, su producción fue de 5,351 toneladas en el 2013. Los rendimientos y calidad de la fruta mejoran en condiciones de menor humedad relativa, la cual se da en la zona costera sur del país.

Las exportaciones del sector en los últimos 5 años han crecido en promedio alrededor de $18 \%$, siendo uno de los que más ha crecido recientemente.

Es relevante mencionar este hecho debido a que Pome Perú SAC es una empresa que se dedica a la exportación de granadas frescas al Reino Unido.

La granada es un cultivo que cada vez está cobrando más importancia debido a su demanda en los mercados del exterior. Se dice que la granada es una "Superfruta" por las propiedades beneficiosas para la salud que presenta ayudando a prevenir y combatir enfermedades. De acuerdo a Oxford en un año se han publicado más de 194 estudios de esta fruta, más que para cualquier otra fruta.

Los principales destinos a los cuales el Perú exporta la granada pertenecen a Europa, en el caso del Reino Unido ocupó el cuarto lugar en cuanto a valor FOB exportado en el 2014 con un crecimiento del 63\% respecto al 2013. El mercado del Reino Unido se encuentra compuesto por 64.1 millones de personas con un nivel promedio de ingresos medianamente alto, lo que les permite pagar un poco más si es necesario para mantenerse saludables. 
Esto va de la mano con el hecho que el gobierno está cada vez más preocupado en que los niveles de obesidad reduzcan, motivo por el cual está tratando de concientizar el consumo de alimentos saludables entre ellos las frutas y verduras.

No podemos dejar de mencionar la campaña del Servicio Nacional de Salud (NHS) de "5 al día", la cual consiste en resaltar los beneficios de consumir 5 porciones de frutas y verduras de 80 gramos todos los días. Esto es muy importante considerarlo debido a que lo ideal es que la granada tenga más aceptación y las personas la incluyan dentro de su dieta de "5 al Día"

La encuesta "Food and You" realizada en el 2010, en la cual se explican los hábitos alimenticios de la población británica en general mostró que los tipos de alimentos más comúnmente consumidos todos los días eran frutas y hortalizas.

El presente plan de negocios tiene como objetivo desarrollar una estrategia de promoción para la granada para así lograr un mayor posicionamiento para la granada peruana. Asimismo determinar la viabilidad económica y financiera.

El proyecto será ejecutado por la empresa Pome Perú S.A.C. conformada por Carla Rubio y Alejandro Rubio, ambos accionistas de la empresa.

Es importante aprovechar las oportunidades que se presentan actualmente, en primer lugar la disponibilidad de materia prima en la zona sur (Ica) que ha ido creciendo, durante el periodo 2008-2013 el crecimiento promedio de la producción fue de $68 \%$. En segundo lugar el potencial de crecimiento de consumo de la granada peruana del mercado de Reino Unido, debido que ya es una fruta que consume y se conoce la importancia de las propiedades, pero todavía podemos aumentar nuestra participación logrando un mayor posicionamiento como proveedor. (Actualmente nos ubicamos en sexto lugar)

Pome Perú S.A.C. se dedicará a la exportación de granadas frescas hacia al mercado del Reino Unido. La empresa establecerá importantes contactos comerciales con importadores o distribuidores como Fruco PLC Asimismo buscaremos apoyo de la Oficina Comercial del Perú en el Reino Unido para que nos introduzcan a nuevas empresas a las cuales podamos ofrecer nuestro producto. 


\section{CAPÍTUlO I: PLANTEAMIENTO DEL PROBLEMA}

\subsection{Planteamiento del problema}

Dentro de los principales mercados a los cuales el Perú exporta granadas, se encuentra el Reino Unido. En el año 2014 el valor FOB exportado creció en 63\% y durante este año la participación de mercado de ese país alcanzó 9\%, situándose en el cuarto puesto del ranking de mercados de destinos. El mayor crecimiento registrado fue en el año 2011, con un incremento en las exportaciones en valor FOB de $485 \%$.

Tabla 1Principales destinos de exportación: Granada (Valor FOB US\$)

\begin{tabular}{|c|c|c|c|c|c|c|c|c|}
\hline \multirow[b]{2}{*}{ AISES } & \multirow[b]{2}{*}{2009} & \multicolumn{5}{|c|}{ VALOR FOB US\$ } & \multirow{2}{*}{$\begin{array}{c}\text { Var. \% } \\
\text { 2013-2014 } \\
\end{array}$} & \multirow{2}{*}{$\begin{array}{r}\text { Par.\% } \\
2014 \\
\end{array}$} \\
\hline & & 2010 & 2011 & 2012 & 2013 & 2014 & & \\
\hline Total general & $4,117,293.25$ & $4,052,225.35$ & $11,302,532.04$ & $14,193,784.55$ & $17,746,697.55$ & 27,773,123.17 & $56.50 \%$ & $100.00 \%$ \\
\hline 1 PAISES BAJOS & $876,445.87$ & $1,441,808.39$ & $4,051,786.02$ & $3,508,845.15$ & $6,395,734.25$ & $10,772,517.56$ & $68.43 \%$ & $38.79 \%$ \\
\hline 2 RUSIA & $419,109.40$ & $778,021.40$ & $2,742,726.48$ & $3,371,221.65$ & $4,501,738.21$ & $6,539,822.56$ & $45.27 \%$ & $23.55 \%$ \\
\hline 3 ESTADOS UNIDOS & $306,725.60$ & $634,389.02$ & $1,012,915.91$ & $1,456,253.24$ & $2,316,905.79$ & $2,664,003.61$ & $14.98 \%$ & $9.59 \%$ \\
\hline 4 REINO UNIDO & $674,682.36$ & $276,499.14$ & $1,617,544.44$ & $1,805,101.42$ & $1,471,307.86$ & $2,395,817.58$ & $62.84 \%$ & $8.63 \%$ \\
\hline 5 CANADA & $280,812.02$ & $289,302.78$ & $577,308.27$ & $1,073,982.29$ & $1,107,114.46$ & $2,142,161.65$ & $93.49 \%$ & $7.71 \%$ \\
\hline $\begin{array}{l}6 \text { HONG KONG } \\
7 \text { EMIRATOS ARABES }\end{array}$ & & & 525.88 & & $38,604.37$ & $922,617.25$ & $2289.93 \%$ & $3.32 \%$ \\
\hline UNIDOS & & & & $45,600.00$ & $458,644.07$ & $341,314.80$ & $-25.58 \%$ & $1.23 \%$ \\
\hline 8 SINGAPUR & 0.50 & & 27.00 & $50,160.00$ & $248,976.00$ & $328,913.20$ & $32.11 \%$ & $1.18 \%$ \\
\hline 9 FRANCIA & $766,891.98$ & $101,009.95$ & $213,534.74$ & $1,841,516.42$ & $201,641.18$ & $312,378.38$ & $54.92 \%$ & $1.12 \%$ \\
\hline 10 ARABIA SAUDITA & & & & & $36,480.00$ & $292,737.00$ & $702.46 \%$ & $1.05 \%$ \\
\hline OTROS PAÍSES (15) * & $792,625.52$ & $531,194.67$ & $1,086,163.30$ & $1,041,104.38$ & $969,551.36$ & $1,060,839.58$ & $9.42 \%$ & $3.82 \%$ \\
\hline
\end{tabular}

*Exportados en el 2014

Nota. Fuente: Sunat, (2014)

Tabla 2 Principales destinos de exportación: Granada (Peso Neto KG)

\begin{tabular}{|c|c|c|c|c|c|c|c|c|}
\hline \multirow[b]{2}{*}{ PAISES } & \multicolumn{5}{|c|}{ PESO NETO KG } & \multirow{2}{*}{2014} & \multirow{2}{*}{$\begin{array}{c}\text { Var. \% } \\
\text { 2013-2014 }\end{array}$} & \multirow{2}{*}{$\begin{array}{l}\text { Par.\% } \\
2014\end{array}$} \\
\hline & 2009 & 2010 & 2011 & 2012 & 2013 & & & \\
\hline Total general & $1,800,560.52$ & $1,501,815.43$ & $3,981,847.19$ & $5,091,127.99$ & $6,378,666.86$ & $10,401,041.65$ & $63.06 \%$ & $100.00 \%$ \\
\hline 1 PAISES BAJOS & $408,454.20$ & $616,504.17$ & $1,451,883.90$ & $1,308,321.15$ & $2,527,660.15$ & $4,313,735.00$ & $70.66 \%$ & $41.47 \%$ \\
\hline 2 RUSIA & $172,875.80$ & $275,560.80$ & $923,064.40$ & $1,140,347.20$ & $1,702,657.00$ & $2,246,902.60$ & $31.96 \%$ & $21.60 \%$ \\
\hline 3 REINO UNIDO & $321,650.00$ & $103,770.40$ & $694,771.10$ & $766,576.80$ & $564,105.59$ & $1,069,755.75$ & $89.64 \%$ & $10.29 \%$ \\
\hline 4 CANADA & $129,190.20$ & $94,905.20$ & $249,967.72$ & $398,267.40$ & $416,040.60$ & $772,542.20$ & $85.69 \%$ & $7.43 \%$ \\
\hline 5 ESTADOS UNIDOS & $39,622.00$ & $101,609.71$ & $139,139.36$ & $214,629.49$ & $324,389.25$ & $588,823.48$ & $81.52 \%$ & $5.66 \%$ \\
\hline $\begin{array}{l}6 \text { HONG KONG } \\
\text { EMIRATOS ARABES }\end{array}$ & & & 541.49 & & $16,826.40$ & $333,465.60$ & $1881.80 \%$ & $3.21 \%$ \\
\hline 7 UNIDOS & & & & $17,328.00$ & $173,288.00$ & $174,192.00$ & $0.52 \%$ & $1.67 \%$ \\
\hline 8 CHIPRE & & & & $105,968.80$ & $120,979.20$ & $159,552.00$ & $31.88 \%$ & $1.53 \%$ \\
\hline 9 ARABIA SAUDITA & & & & & $17,328.00$ & $117,558.00$ & $578.43 \%$ & $1.13 \%$ \\
\hline 10 FRANCIA & $282,361.80$ & $39,752.40$ & $83,470.80$ & $757,578.80$ & $63,715.79$ & $111,381.95$ & $74.81 \%$ & $1.07 \%$ \\
\hline OTROS PAÍSES (15) * & $446,406.52$ & $269,712.75$ & $439,008.42$ & $382,110.35$ & $451,676.88$ & $513,133.07$ & $13.61 \%$ & $4.93 \%$ \\
\hline
\end{tabular}

*Exportados en el 2014

Nota. Fuente: Sunat, (2014) 
En lo que respecta a las importaciones de Granadas, en la cual consideramos la partida 081090 "0tros frutos frescos" provenientes del Reino Unido durante el 2014 crecieron en $16 \%$. Debido a que las exportaciones de uno de sus principales proveedores incrementaron como Israel, Turquía y Estados Unidos.

Tabla 3 Principales proveedores para el Reino Unido: Otros frutos frescos (Valor FOB US\$)

\begin{tabular}{|c|c|c|c|c|c|c|c|c|}
\hline PAISES & 2009 & 2010 & 2011 & $\begin{array}{c}\text { VALOR FOB US } \\
2012\end{array}$ & 2013 & 2014 & $\begin{array}{c}\text { Var. \% } \\
\text { 2013-2014 }\end{array}$ & $\begin{array}{c}\text { Par.\% } \\
2014\end{array}$ \\
\hline Total General & $47,811,000.00$ & $68,172,000.00$ & $86,051,000.00$ & $53,625,000.00$ & $40,974,000.00$ & $47,719,000.00$ & $16.46 \%$ & $100.00 \%$ \\
\hline 2 Egipto & $2,680,000.00$ & $1,869,000.00$ & $2,161,000.00$ & $3,277,000.00$ & $5,242,000.00$ & $6,470,000.00$ & $23.43 \%$ & $13 \%$ \\
\hline 3 Países Bajos & $13,510,000.00$ & $20,884,000.00$ & $34,478,000.00$ & $14,110,000.00$ & $3,862,000.00$ & $4,260,000.00$ & $10.31 \%$ & $9 \%$ \\
\hline 4 Alemania & $1,695,000.00$ & $2,529,000.00$ & $3,700,000.00$ & $2,543,000.00$ & $3,703,000.00$ & $3,546,000.00$ & $-4.24 \%$ & $9 \%$ \\
\hline 6 Perú & $652,000.00$ & $973,000.00$ & $2,107,000.00$ & $2,092,000.00$ & $2,663,000.00$ & $2,817,000.00$ & $5.78 \%$ & $6 \%$ \\
\hline 7 Israel & $788,000.00$ & $333,000.00$ & $2,022,000.00$ & $2,053,000.00$ & $1,840,000.00$ & $2,456,000.00$ & $33.48 \%$ & $4 \%$ \\
\hline 8 Turquía & $1,944,000.00$ & $1,313,000.00$ & $2,562,000.00$ & $2,675,000.00$ & $1,576,000.00$ & $2,450,000.00$ & $55.46 \%$ & $4 \%$ \\
\hline 9 Estados Unidos & $1,958,000.00$ & $1,428,000.00$ & $980,000.00$ & $1,520,000.00$ & $1,278,000.00$ & $2,354,000.00$ & $84.19 \%$ & $3 \%$ \\
\hline 10 Malasia & $3,095,000.00$ & $3,316,000.00$ & $4,046,000.00$ & $2,183,000.00$ & $1,042,000.00$ & $1,733,000.00$ & $66.31 \%$ & $3 \%$ \\
\hline
\end{tabular}

Cabe resaltar que las importaciones provenientes del Perú han aumentado. En el ranking de proveedores de la partida para el Reino Unido en el 2011 el Perú se encontraba en la posición 11, en el 2012 en el puesto 9, en el 2013 el 7 y finalmente en el 2014 se posicionó como sexto proveedor. Es importante tomar en consideración que la partida abarca frutos de la pasión, carambolas, y demás frutos comestibles, frescos y no se refiere únicamente a la granada.

El principal proveedor del Reino Unido es España, por sus envíos de su principal variedad de Elche. Holanda, antes tenía una participación mucho mayor pero actualmente ha disminuido y ha quedado como tercer proveedor del Reino Unido. Este mercado no es un productor de la fruta sino que este la importa de otros países y luego re-exporta.

Las principales regiones donde se producen las granadas son Ica, Lima y La Libertad. La región Ica, es la que tiene la mayor participación sobre la producción con $79 \%$, razón por la cual nos abasteceremos de este lugar para cubrir la demanda del mercado exterior. 
Otra ventaja es la cercanía, lo cual ayuda a ahorrar costos en transporte, por ende se podrán obtener mayores márgenes de ganancia.

Figura 1 Participación de la producción de granadas por región - 2013

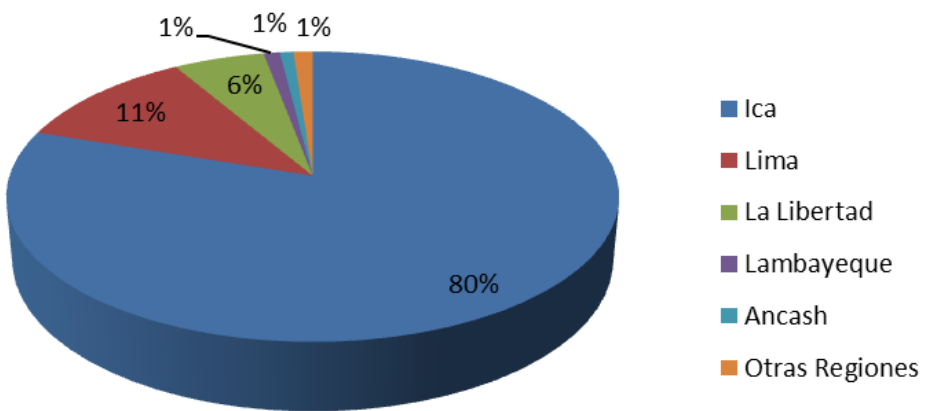

Fuente: Ministerio de Agricultura- Dirección de Estadística Agraria

La producción de la granada ha ido creciendo en los últimos años en la provincia de Ica, observando la data de años anteriores se puede observar una tendencia de crecimiento en la producción por lo que hay potencial para que crezcan las exportaciones, en el 2011 fue el año que más incrementó (174\%) y luego de eso la tendencia ha sido al alza.La información más reciente del Anuario de Producción Hortofrutícola indica que en el 2013 la producción de esta región alcanzó 5,351 toneladas, creciendo 28\%.

Figura 2 Evolución de la producción de Granadas Región Ica (2008-2013)

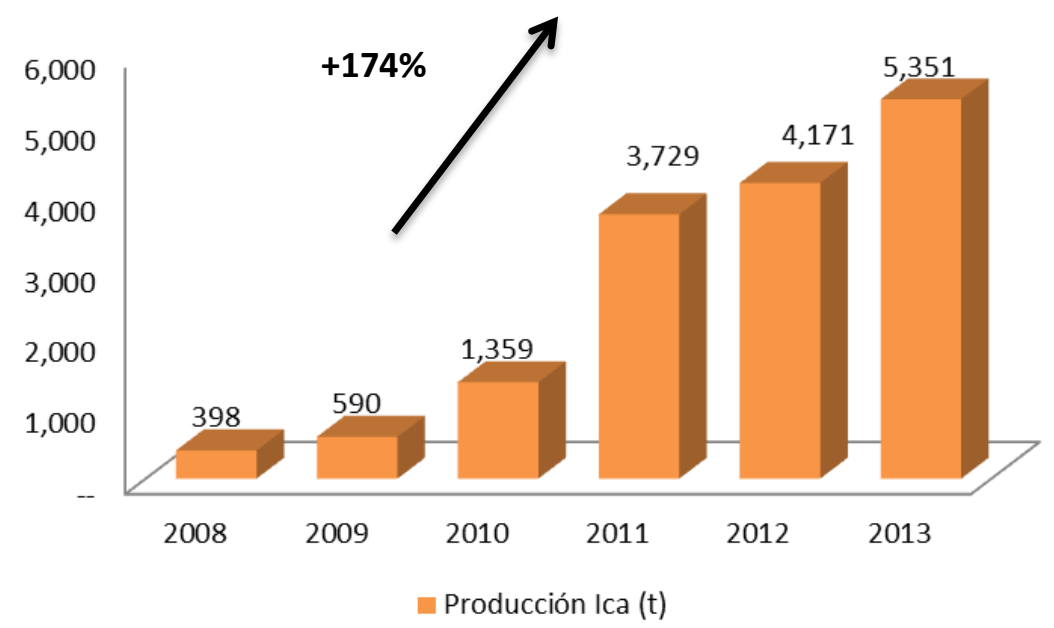

Fuente: Ministerio de Agricultura - Dirección de Estadística Agraria 
Actualmente se debe aprovechar que los principales mercados proveedores han disminuido sus exportaciones hacia el Reino Unido, para posicionarnos y obtener una mayor participación de mercado. Para poder atacar el mercado se debe incrementar la capacidad de producción de la granada para poder abastecer la demanda del mercado, la región Ica aún tiene mucho potencial para crecer.

Al contar con una mayor oferta hacia el Reino Unido podremos ser más competitivos y penetrar el mercado de una forma más agresiva.

Lo expuesto anteriormente daría origen a la pregunta: ¿Es posible hacer un plan de negocios para la exportación de granada fresca hacia el Reino Unido, que logre posicionarnos como uno de los principales proveedores del mercado, genere utilidades y convierta al departamento de Ica como una de las principales regiones de producción de granada?

\subsection{Justificación}

De los 114 microclimas que existen en el mundo el Perú cuenta con 84 , lo que favorece a la biodiversidad de las tres regiones naturales. (Ministerio de Defensa, 2005) Por este motivo contamos el país cuenta con condiciones favorables para dedicarse a diferentes cultivos agrícolas durante todo el año.

En el caso de las granadas de acuerdo al Ministerio de Agricultura y Riego las hectáreas cultivadas, durante el año 2009, fueron 176 y se obtuvo una producción de 1,1 mil TM, siendo Ica (53\%) Lima (22\%) y La Libertad (8\%) las principales regiones donde se cultiva la granada (Agraria.pe, 2010). En el 2013 las hectáreas cultivadas fueron 595, y el mayor crecimiento se dio durante el 2011 cuando se llegó a 482 hectáreas cultivadas.

Tabla 4 Superficie cultivada de granadas a nivel nacional (ha)

\begin{tabular}{ccccccc}
\hline Año & $\mathbf{2 0 0 8}$ & $\mathbf{2 0 0 9}$ & $\mathbf{2 0 1 0}$ & $\mathbf{2 0 1 1}$ & $\mathbf{2 0 1 2}$ & $\mathbf{2 0 1 3}$ \\
\hline Superficie (ha) & 175 & 176 & 287 & 482 & 510 & 595 \\
Crecimiento \% & & $0.57 \%$ & $63.53 \%$ & $67.80 \%$ & $5.81 \%$ & $16.78 \%$ \\
\hline
\end{tabular}

Nota.Fuente: Ministerio de Agricultura - Dirección de Estadística Agraria

Los rendimientos y calidad de la fruta mejoran en condiciones de menor humedad relativa, la cual se da en la zona costera sur del país. La oferta será obtenida de Ica y si 
esta no es suficiente debido a la creciente demanda nos podemos apoyar de las otras regiones para completar los pedidos.

En el Reino Unido se ha difundido a la población los beneficios que brindan las granadas y los consumidores están cada vez más preocupados por consumir alimentos saludables. De acuerdo a Euromonitor el consumo per cápita de fruta en el 2012 fue de $41.9 \mathrm{~kg}$, pero este ha decrecido desde el 2007 cuando se situaba en $46.3 \mathrm{KG}$.

El beneficio más importante de la granada es que es un antioxidante muy poderoso que ayuda a prevenir el cáncer por eso es que cada vez se demanda más de estar fruta. No solo se consume en fresco sino que recientemente se han desarrollado nuevas presentaciones como jugos y cápsulas, por lo que también podríamos dirigirnos a este nicho de mercado. Otras propiedades que contiene:

Vitaminas: C y Provitamina A,

Minerales: Potasio, Calcio y Magnesio

Otros como: Ácido Cítrico, Ácido Málico, Ácido Oxálico, Ántioxidantes. Flavoides. Taninos.

En Europa y Estados Unidos esta fruta es muy reconocida y los consumidores están familiarizados con sus propiedades y beneficios para la salud, a diferencia del Perú donde se consume muy poco, la mayor parte de la producción se destina a la exportación. Aún hay mucho trabajo por realizar para promocionar la granada peruana.

En vez de exportar a mercados como Holanda, los cuales reexportan nuestros productos, es mejor que nosotros directamente nos dirijamos a estos mercados exteriores identificando las oportunidades. Por lo cual debemos ir desarrollando una mayor oferta exportable que nos permita alcanzar niveles más competitivos a comparación de nuestros competidores más fuertes.

\subsection{Objetivos}

\subsubsection{Objetivo General}

Desarrollar un plan de negocios para la exportación de Granadas que cumpla con los requisitos técnicos del mercado de Reino Unido y cubra la demanda insatisfecha del mismo. 


\subsubsection{Objetivos Específicos}

- Identificar canales de distribución para la venta de granada en el Reino Unido.

- Desarrollar una estrategia de promoción para la granada

- Lograr un mayor posicionamiento para la granada peruana

- Escoger la mejor ruta para la exportación de Granadas frescas al Reino Unido

- Determinar la viabilidad económica, financiera y sostenible del plan.

\subsection{Descripción del Entorno}

El Reino Unido el tercer país más poblado de la Unión Europea (UE), las ciudades principales del país son Manchester, Birmingham, Glasgow, Edimburgo y Londres.

El presente estudio se desarrolla en el mercado de las frutas en la ciudad de Londres, esta comparte con Nueva York el título de capital financiera mundial. En el 2013 Londres registró el mayor gasto de consumo, alcanzando los US\$ 253 billones, lo que equivale al $15.7 \%$ del gasto nacional del país. (Euromonitor International , 2014) En los últimos años el sistema financiero del Reino Unido se vio afectado por la crisis que golpeó fuertemente a la Unión Europea a partir del 2009, de la cual durante el 2014 ha ido recuperándose.

Uno de los principales problemas que enfrentó la economía del Reino Unido durante la crisis de la Eurozona fue el impacto de la alza de precio en los ingresos reales, "el shock de confianza" de la zona euro al observar la parálisis política en el continente y un mayor impacto de la crisis financiera sobre la producción del que se pensaba. (Moulds, 2012) De acuerdo a la Organización para la Cooperación Económica y Desarrollo (OECD) la recuperación económica de Gran Bretaña continuará en 2015 y 2016, impulsada por el gasto del consumidor y la inversión empresarial. (Monaghan, UK economic recovery to continue into 2016 , forecasts OECD , 2014)

Es relevante mencionar que el principal exportador de Granadas al reino Unido es España, país que forma parte de la comunidad Europea y uno de los que se vio más 
afectado económicamente. Actualmente se encuentro en un lento proceso de recuperación, la oficina de Estadística de la Unión Europea (Eurostat) informó que el PIB de los Diecinueve países del euro avanzó un 0,3\% en el último trimestre del 2014. (Pérez, 2015) Junto con Alemania España ha contribuido a la recuperación de la Eurozona, pero aún hay países como Italia y Francia que continúan estancados.

Los principales proveedores del Reino Unido son países europeos, por esta razón debemos aprovechar este período para lograr obtener una mayor participación en el mercado de destino.

Hasta el 2014 la población del país llegó a alrededor de 64 millones de habitantes (Eurostat) los cuales tienen un consumo elevado de frutas y verduras, están muy preocupados por mantener una alimentación muy saludable. El mercado al cual nos estamos dirigiendo es Londres, es la ciudad más habitada donde viven 8 millones de personas.

Nuestro nicho de mercado se concentra en los adultos preocupados por cuidar su salud, debido a que la granada se considera una súper fruta, un concepto que ha sido adoptado en los últimos años para clasificar a las frutas que contienen un nivel extremadamente alto de antioxidantes los cuales son importantes porque batallan contra el cáncer. El Bio-médico investigador de la consultora Click Tell Sepe Sehati dijo en su última investigación realizada sobre las granadas: "La sabiduría aceptada es que una súperfruta no es una panacea, pero las frutas puede tener efectos beneficiosos para la salud. Las granadas son una fruta antigua y se ha pensado que tienen propiedades saludables durante milenios." (Maynard, 2015)

\subsubsection{Sector Agroindustrial Perú- Reino Unido}

Las exportaciones peruanas totales sumaron US\$ 38,248 millones en el 2014, disminuyendo10\% respecto al 2013 por los menores envíos registrados de productos tradicionales. Del total de exportaciones, el sector agropecuario y agroindustrias alcanzó la cifra de US\$ 4,217 millones, el más importante dentro de las exportaciones no tradicionales obteniendo un crecimiento de $22 \%$ en relación al año 2013. Las agro exportaciones no tradicionales representaron $11 \%$ del total de las exportaciones peruanas. 
Cabe mencionar que en el sector agrícola son mayores las exportaciones no tradicionales versus las tradicionales, debido que durante los últimos años el Perú ha estado aprovechando sus ventajas competitivas y comparativas. Aún falta desarrollar más la tecnología utilizada para el procesamiento de los productos además de enfocarnos en brindarle mayor valor agregado a los mismos. Las exportaciones tradicionales están compuestas básicamente por el Café, azúcar y en menor grado el algodón. (Ministerio de Agricultura y Riego, 2007)En el 2014 el Reino Unido se situó como quinto mercado de destino para las exportaciones peruanas agrícolas no tradicionales, alcanzando un monto de US\$ 200 millones de acuerdo a información extraída de Adex Data Trade.

Por su parte el Reino Unido no es un país que concentre una gran producción agrícola, al 2013 el sector Agroindustria representaba el 0.7\% de su PBI, produce menos del 60\% de lo que come y utiliza el $75 \%$ del total de las tierras disponibles. La agricultura es de limitada importancia, únicamente el $1.4 \%$ de su fuerza laboral se dedica a esta actividad. La agricultura (1\% del PIB aproximadamente) es altamente mecanizada, sus principales producciones son de papas, remolacha, trigo y cebada. La ganadería es también significativa, sobretodo la ovina y la bovina, siendo un gran productor europeo de leche y sus derivados. (ProChile Oficina Comercial Londres, 2014)

Según el último perfil país publicado por Euromonitor la industria manufacturera concentra el $10.3 \%$ del PBI y emplea al $10.4 \%$ de la fuerza laboral. Por el otro lado el sector servicios es el más importante dentro de la economía del Reino Unido, representa el $79.3 \%$ del PBI, este será el principal motor de crecimiento. Sus exportaciones principalmente se centran en maquinarias y combustibles, debido a que su ventaja competitiva se encuentra en la producción de estos bienes, es el principal productor de petróleo en la Unión Europea. Asimismo es un líder global en exportaciones de servicios financieros.

Las frutas y hortalizas tienen el mayor déficit comercial. En el 2013 las importaciones costaron $£ 9,0$ millones, mientras que las exportaciones fueron de $£ 1,0$ millones, 
resultando en un déficit comercial de 8,0 millones de libras. (Department for Environment, Food \& Rural Affairs , 2013)

Durante el 2014 las importaciones de frutas del Reino Unido de sumaron US\$ $6.1 \mathrm{mil}$ millones, las exportaciones de frutas representan sólo el $4 \%$ de las importaciones, en el 2014 el principal proveedor fue España con 16\% de participación. El Perú se posiciona como proveedor número 14 en todo el universo de frutas. La producción con relación a ciertos productos no es adecuada versus la demanda que tienen los mismos. En la tabla número 5 podemos observar la evolución de las importaciones de frutas del Reino Unido y como a lo largo de los años han ido creciendo y se espera que siga siendo así.

Tabla 5 Evolución de las importaciones de frutas (Cap. 08) del Reino Unido

\begin{tabular}{lllllcc}
\hline Año & 2009 & 2010 & 2011 & 2012 & 2013 & 2014 \\
\hline Total General & $4,738,755,000$ & $4,918,419,000$ & $5,482,609,000$ & $5,365,610,000$ & $5,787,561,000$ & $6,174,108,000$ \\
Crecimiento & & $3.79 \%$ & $11.47 \%$ & $-2.13 \%$ & $7.86 \%$ & $6.68 \%$ \\
\hline
\end{tabular}

Nota. Fuente: Trademap

El intercambio comercial entre Perú y el Reino Unido ha ido en aumento durante los últimos años, nosotros contamos con el Sistema Generalizado de Preferencias y desde el 2005 se adoptó el nuevo esquema del SGP+ el cual estará vigente hasta el 2015. También nos beneficia el hecho que el Acuerdo Comercial Perú-Unión Europea haya entrado en vigencia el $1^{\circ}$ de marzo de 2013. Esto nos brindará mayores oportunidades de negocios y más facilidades al momento de exportar.

El Reino Unido es miembro de Global Gap, una entidad de certificación privada que establece estándares voluntarios para la certificación de los procesos de producción de productos agrícolas alrededor del mundo. Sus miembros se comprometen a brindar seguridad alimentaria, protección de animales, protección del medio ambiente y la protección del trabajador. Para nuestra empresa es un dato muy importante a considerar debido que nosotros exportamos productos agrícolas, los cuales serán más fácilmente aceptados si cumplimos este tipo de estándar el cual cada vez está más difundido a nivel mundial.

\subsubsection{Análisis del Mercado destino como potencia mundial}

a) Potencial del consumo en el Reino Unido 
Al igual que otros países desarrollados los consumidores ingleses fueron fuertemente golpeados por la crisis de los Estados Unidos y la Eurozona. Razón por la cual el desempleo aumentó en el país, sobretodo porque no se encuentran jóvenes capacitados que puedan cumplir con las exigencias del mercado actual. De acuerdo a Euromonitor el Reino Unido se sitúa entre los 10 principales países con mayor ingreso en la Europa occidental, en el 2013 los gastos de consumo per cápita alcanzaron US\$ 25,128 .

Durante el período del 2008 al 2013 el ingreso disponible anual del Reino Unido por hogar se mantuvo y en el 2013 se situó en (US\$ 60,528 mil) reflejando un aumento de sólo $0.3 \%$. (Euromonitor International , 2014)

Al mismo tiempo es importante considerar el contexto que está viviendo actualmente la sociedad, El Reino Unido es uno de los países donde más se ha difundido las propiedades y beneficiosos de la granada. Ya no solo la consumen en forma fresca sino también en otras presentaciones con mayor valor agregado. Lo que se puede percibir es que cada vez más está aumentando la demanda de este bien y la oferta podría llegar a ser insuficiente.

La mayoría de los ciudadanos europeos asocian una dieta saludable con el consumo de frutas y vegetales y creen que su dieta es saludable. En general la Organización mundial de la Salud recomienda ingerir 400 gramos o más de frutas y vegetales al día, pero algunos países de la unión europea recomiendan mayores cantidades. Dentro de esta dieta es donde debemos buscar integrar a la granada, debido a que es una fruta que ayuda a prevenir muchas enfermedades. Según los datos nacionales de consumo de alimentos recopilados por la EFTA (European Food Safety Authority) revelan que la ingesta media de fruta es de $166 \mathrm{~g}$ por día, implicando que el consumo promedio es de 386 gramos por día. Las regiones con el mayor consumo de frutas son las de Europa central y oriental seguido por las del Sur. (European Food Information Council , 2012)

En el Reino Unido el Servicio Nacional de Salud (NHS) apoya fuertemente la campaña de 5 al día, la cual consiste en resaltar los beneficios de consumir 5 porciones de frutas y verduras de 80 gramos todos los días. 
A continuación podemos observar la figura 3 donde se muestra el consumo medio de frutas y vegetales por país.

Figura 3 Ingesta media de frutas y Vegetales por país

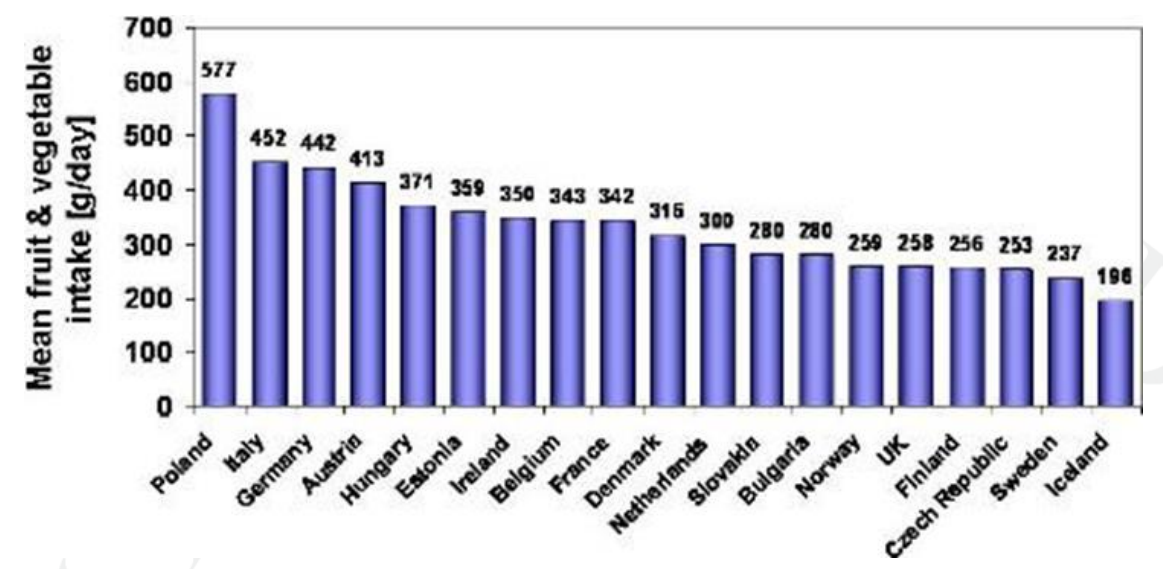

Fuente: European Food Information Council

Asimismo analizaremos el comportamiento de compra de frutas y vegetales de los hogares.

Figura 4 Tendencia del Reino Unido en la compra de frutas y verduras (excepto patatas)- 2012

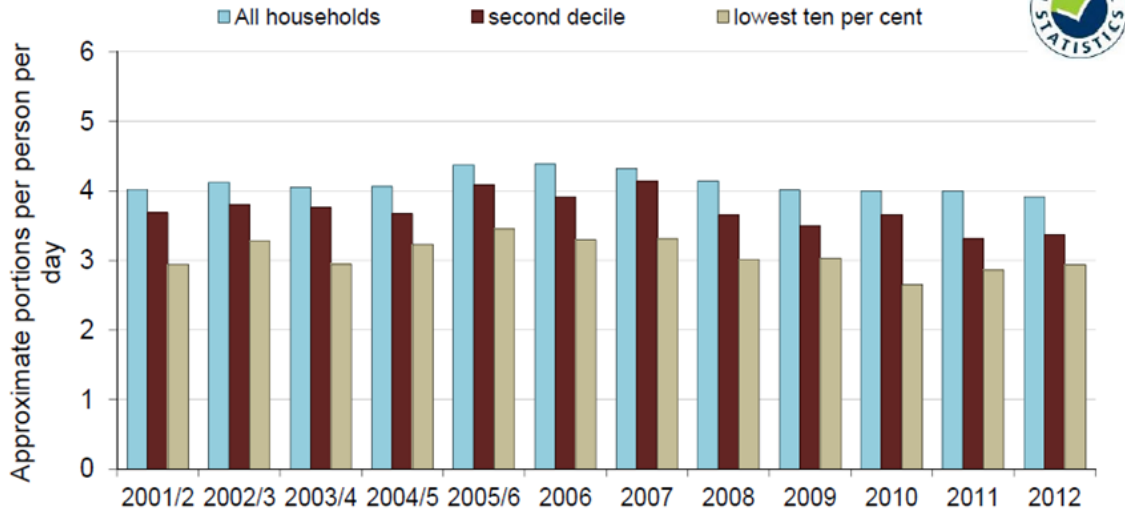

Fuente: Food Statistics Pocket Book

Las compras del hogar de frutas y verduras en el Reino Unido fueron $2,1 \%$ menores en el 2012 a comparación del 2011, una reducción del 11\% desde su máximo en 2006. Respecto a la recomendación de consumir "5 AL DÍA", las compras permanecieron inalteradas del 2009 al 2011 en un promedio de 4 porciones. 
Realizando una segmentación de los hogares, los de menores ingresos compraron las menores cantidades de frutas y verduras en un promedio de 2,9 porciones por persona de las 5 AL DÍA en 2012, mientras que los que se encuentran en el segundo decil han experimentado la mayor reducción en las compras de frutas y verduras desde 2007. (Department for Environment, Food \& Rural Affairs , 2013)

Los datos proporcionados por la Organización mundial de la salud indican que no es suficiente la ingesta actual de frutas, motivo por el cual se debe seguir fomentando su incremento.

En las tablas que se muestran líneas abajo se puede observar la evolución del consumo de frutas específicamente en el Reino Unido además la proyección de ventas para los años futuros.

Tabla 6 Volumen de venta de Frutas Reino Unido 2008-2013 (Miles TN)

\begin{tabular}{|c|c|c|c|c|c|c|}
\hline Año & 2008 & 2009 & 2010 & 2011 & 2012 & 2013 \\
\hline $\begin{array}{c}\text { Volumen Frutas } \\
\text { (Miles TN) }\end{array}$ & $2,903.90$ & $2,810.20$ & $2,773.50$ & $2,744.60$ & $2,724.60$ & $2,711.10$ \\
\hline
\end{tabular}

Nota. Fuente: Euromonitor - Fruits in the United Kingdom

En general el volumen de ventas de frutas en el período (2008-2013) se ha mantenido, a pesar de que a partir del año 2008 comenzaron a decrecer pero no en grandes en proporciones. Una de las causas atribuibles es la crisis económica la cual ha hecho que las personas tengan menos dinero para hacer sus compras. En promedio durante el periodo analizado el volumen de ventas se redujo en $6.6 \%$.

Tabla 7 Proyección de ventas de Frutas Reino Unido 2013-2018 (MILES TN)

\begin{tabular}{ccccccr}
\hline Año & $\mathbf{2 0 1 3}$ & $\mathbf{2 0 1 4}$ & $\mathbf{2 0 1 5}$ & $\mathbf{2 0 1 6}$ & $\mathbf{2 0 1 7}$ & $\mathbf{2 0 1 8}$ \\
\hline $\begin{array}{c}\text { Volumen Frutas } \\
\text { (Miles TN) }\end{array}$ & $2,711.10$ & $2,706.50$ & $2,715.40$ & $2,733.40$ & $2,757.80$ & $2,787.50$ \\
\hline
\end{tabular}

Nota. Fuente: Euromonitor - Fruits in the United Kingdom

La proyección de ventas nos demuestra que los volúmenes ventas no crecerán mucho y permanecerán estables. De todas formas como no van a disminuir nos brinda la oportunidad para venderle al Reino Unido debido a que el consumo de frutas es esencial para mantener un estilo de vida saludable. 


\section{b) Ventajas Comerciales Perú- Reino Unido}

El Reino unido se encuentra en el puesto 8 de 183 países en la última publicación del Índice de facilidad para hacer negocios. (El Banco Mundial , 2014) Al ser considerado mundialmente como un país con el cual es más simple negociar, un entorno regulatorio más favorable nos brinda la posibilidad que en el futuro se pueda establecer una oficina comercial en este país. La categoría de ingresos es alta y el NBI per cápita asciende a US\$39,110.

Durante el 2014 sus principales socios comerciales fueron Estados Unidos (12\%), Alemania (10\%), Países Bajos (7\%) y Suiza (7\%). Son diversos, no solo pertenecen a una zona o continente especifico sino a todo el mundo, pero son grandes potencias con las que es difícil competir debido a que cuentan con una oferta mucho mayor a la nuestra.

Tabla 8 Intercambio Comercial Perú-Reino Unido (millones US\$)

\begin{tabular}{llcccrr}
\hline & Comercio Perú - Mundo & $\mathbf{2 0 1 0}$ & $\mathbf{2 0 1 1}$ & $\mathbf{2 0 1 2}$ & $\mathbf{2 0 1 3}$ & $\mathbf{2 0 1 4}$ \\
\hline (A) & Exportaciones (FOB) & 35,829 & 46,350 & 46,225 & 42,579 & 38,400 \\
(B) & Importaciones (CIF) & 29,976 & 37,911 & 42,177 & 43,332 & 42,201 \\
& Saldo Comercial (X-M) & 5,853 & 8,439 & 4,048 & -752 & $-3,802$ \\
\hline & Comercio Perú - Reino Unido & & & & & \\
\hline (C) & Exportaciones (FOB) & 304 & 425 & 610 & 612 & 533 \\
& (C)/(A) & $0.8 \%$ & $0.9 \%$ & $1.3 \%$ & $1.4 \%$ & $1.4 \%$ \\
(D) & Importaciones (CIF) & 183 & 252 & 304 & 326 & 315 \\
& (D)/(B) & $0.6 \%$ & $0.7 \%$ & $0.7 \%$ & $0.8 \%$ & $0.7 \%$ \\
& Saldo Comercial (X-M) & 121 & 174 & 306 & 286 & 217 \\
\hline
\end{tabular}

Nota. Fuente: Adex Data Trade

Como podemos observar en la tabla número 1 las exportaciones del Perú hacia el Reino Unido se han ido incrementando con el paso de los años, excepto este último año 2014 cuando estas disminuyeron en 13\%. En general luego del brote de la crisis económica europea a partir del 2012 se han ido recuperando las exportaciones. 
Durante el 2014 las exportaciones peruanas totales disminuyeron también en 10\%, por el regular desempeño de la economía peruana en la mayoría de sus sectores, excepto en el agrícola que si creció.

Desde el 2010 hasta el 2014 las exportaciones peruanas al Reino Unido casi se han duplicado alcanzando a los 533 millones de dólares, estas representan el 1.4\% de las exportaciones totales peruanas, motivo por el cual aún hay mucho potencial para que estas continúen creciendo. Para lograr este crecimiento es clave que se desarrollen productos con valor agregado, por los cuales los consumidores en el mercado de destino estén dispuestos a pagar un precio mayor. De igual forma sucede con la participación de nuestras importaciones provenientes de ese mercado que son menos del $1 \%$.

Figura 5 Exportaciones Perú-Reino Unido 2010-2014 (US\$ Millones)

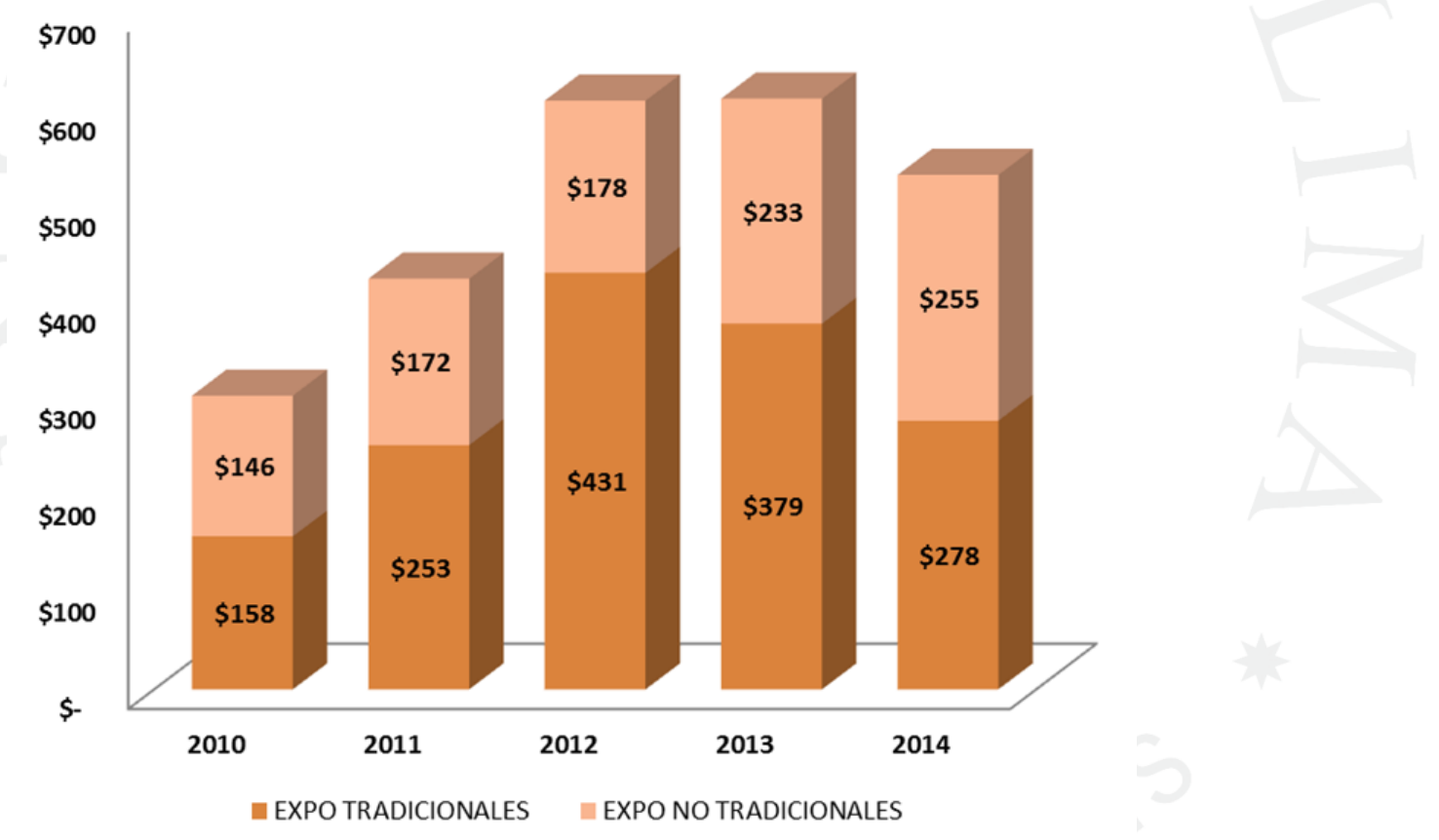

Fuente: Adex Data Trade

La Figura 4 nos muestra la evolución de las exportaciones peruanas hacia el Reino Unido, según su rubro, tradicional y no tradicional. Las exportaciones tradicionales superan a las no tradicionales, demostrándonos que aún hay mucho trabajo por desarrollar los productos que no son tradicionales. Lo importante es que a pesar que el crecimiento de las exportaciones no tradicionales ha sido de menor magnitud que el de las tradicionales, estas sí han crecido. 
Durante el período 2010-2014, el 2013 fue el año en el cual las exportaciones no tradicionales crecieron más, asimismo la participación de los envíos no tradicionales dentro de las exportaciones totales hacia el Reino Unido ha incrementado los últimos años, en el 2014 llegó a 48\%. Las exportaciones de granadas están consideradas dentro de las no tradicionales.

Para fomentar el desarrollo de nuestro país debemos contar con el respaldo de las exportaciones no tradicionales. Estas son de mayor valor agregado, lo que hace que sean más apreciadas, no nos limita a tan solo ser un país productor de materias primas y nos permite obtener mayores márgenes de ganancia.

Observando la evolución de las exportaciones no tradicionales se ve que hay una tendencia de crecimiento, por lo que se debe buscar la constante innovación de productos para apoyar este incremento. En lo que respecta a los tratados de libre comercio y acuerdos comerciales contamos con los siguientes:

- Acuerdo Comercial entre Perú y la Unión Europea (UE): Se terminó de negociar por Perú y la UE en Febrero de 2010. Las aprobaciones por el congreso del Perú y el Parlamento Europeo se debieron haber realizado durante el 2011. El Acuerdo Comercial Perú-Unión Europea entró en vigencia el $1^{\circ}$ de marzo de 2013.

Con este Acuerdo Comercial se ha obtenido un acceso preferencial para el 99.3\% de nuestros productos agrícolas y para el $100 \%$ de nuestros productos industriales. Los productos de interés de Perú como espárragos, paltas, café, frutos del género capsicum, alcachofas, entre otros ingresaran al mercado europeo libre de aranceles a la entrada en vigencia del Acuerdo. (Ministerio de Comercio Exterior y Turismo, 2013 )

- Sistema Generalizado de Preferencias (SGP): Acuerdo unilateral implementado desde 1971 por la UE. en Junio 2005 se adoptó el nuevo esquema del SGP+ (2005 - 2015) de acuerdo a las nuevas directrices generales de la OMC. Gracias a las preferencias arancelarias del SGP+, SGP 
Generaly las de nación más favorecida (NMF) con las que cuenta el Perú, actualmente más del $90 \%$ de las exportaciones peruanas a la UE han ingresado a esta región libre de arancel. Para poder acogernos a esta condición requerimos del Certificado de Origen (Modelo A), el cual debe de tener vigencia por 10 meses, a partir de su fecha de emisión. 


\section{CAPÍTULO II: MARCO TEÓRICO}

\subsection{Análisis PESTEC (Político, Económico, Social, Tecnológico, Económico y Competitivo)}

El análisis PESTEC nos va a permitir identificar los factores del entorno general que afectan al país en estudio. Los aspectos que se toman en consideración son los siguientes: Político, Económico, Social, Tecnológico, Económico y Competitivo. Conocer estas perspectivas sobre el mercado de destino nos ayudará a tomar decisiones más conscientes respecto a la aplicación de nuestro plan de negocios.

\subsubsection{Entorno Político}

El Reino unido es una democracia parlamentaria y al mismo tiempo una monarquía constitucional en la que los ministros de la Corona gobiernan en nombre de la Reina Isabel II, quien es el Jefe de estado. La Jefatura el gobierno está a cargo del Gabinete de ministros, liderado por el Primer ministro David Cameron. Este es un país muy formal por el hecho de existir una realeza las relaciones son un poco más distantes, se debe mostrar mucho respeto y conocimiento sobre el protocolo para saber cómo actuar ante ellos.

El parlamento está constituido por dos Cámaras: la Cámara de los Comunes y la Cámara de los Lores. La primera está integrada por 650 miembros (MP) que son elegidos por sufragio universal mayoritario. Las elecciones a la Cámara de los Comunes se llevaron a cabo en mayo de 2010, el Partido Conservador tomó 306 escaños, el Partido Laborista ganó 258 escaños y el Partido Liberal Demócrata reclamó 57 asientos con partidos menores tomando el resto de asientos. (Euromonitor International , 2015)

Al ver que el partido conservador es el más representativo, predomina el conservadurismo en el cual se defienden los valores familiares y religiosos y se 
encuentra asociado con nacionalismo y el patriotismo. La máxima representante de la política conservadora en el Reino unido es la fallecida Margaret Thatcher. Uno de los grupos y líderes que ejercen presión es la Unión nacional de Agricultores, es importante tomarlo en consideración debido a que nuestro producto a exportar es agrícola y nos podría ayudar a entender cómo funciona el sector de la agricultura en el país. Es una ventaja para nosotros que el Reino Unido no produzca granadas por lo que no tenemos que competir con la producción interna, y no nos veríamos muy afectados por los reclamos o exigencias que podrían presentar. En lo referente al sistema judicial británico, está coronado por un Tribunal Supremo, el cual es el órgano máximo de recursos de la nación.

No se posee una constitución escrita, por lo que las relaciones entre el estado y los ciudadanos se basan en el derecho consuetudinario, normas o prácticas admitidas tácitamente, que responden a la costumbre y las leyes escritas que han sido aprobadas en el Parlamento. Las leyes pueden ser ambiguas en muchos aspectos, ya que se espera que los tribunales las clarifiquen. Esto demuestra la importancia y la capacidad que tienen los tribunales en el Reino Unido, con un sistema transparente porque se le delega la responsabilidad de interpretar el caso de acuerdo a las circunstancias, cada caso es diferente por lo que tiene mucho sentido. Es importante considerar que el Reino Unido es un país diverso étnicamente, en parte como un legado de imperio. En los últimos años el país ha estado luchando con cuestiones relacionadas al multiculturalismo, inmigración e identidad nacional.

Por otro lado la política del Perú es muy diferente a la del Reino Unido, no contamos con una realeza, nuestro representante es el presidente y somos una República Constitucional. Ha sido clasificado como un país "Libre" por lo que los derechos de expresión y asociación están garantizados. Es una democracia, anteriormente los casos de corrupción eran muchos más comunes, pero actualmente han ido disminuyendo aunque siempre cada cierto tiempo se descubre un caso por lo que muchas de los ciudadanos no se encuentran muy conformes con el desempeño de la democracia.

El Presidente Ollanta Humala cumple con ambos roles de jefe de gobierno y jefe de estado. La legislación es dictada por el congreso de la república el cual es elegido por 
voto popular y su período tiene una duración de 5 años. Los principales partidos políticos son los siguientes Gana Perú (43 escaños), Fuerza Popular (36 escaños), PP (10 escaños), Accion Popular-Frente Amplio (10). (Central Intelligence Agency United States of America , 2015)

Los que tienen más escaños son partidos totalmente opuestos, Gana Perú comenzó dictando una ideología izquierdista, pero actualmente han pasado a una izquierda centro mientras que Fuerza Popular tiene un discurso más derechista.

El actual presidente del Perú ha sabido mantener buenas relaciones con nuestros principales socios comerciales contribuyendo al crecimiento de la economía.

Los grupos y líderes que ejercen mayor presión son el CGTP (Confederación General de Trabajadores del Perú) y Sendero Luminoso en mayor grado por el terror y ánimo que generaron en las décadas de los 80 s y 90 s por que el país atravesaba por la terrible época del terrorismo.

Según la Corporación Latinobarómetro el Estado peruano también aparece clasificado por sus propios ciudadanos como uno de los menos eficientes de la región, con un puntaje de 4,9, siendo que el promedio latinoamericano es de 5,3. El Perú es considerado como uno de los países latinoamericanos con mayores brechas entre demanda y oferta de políticas públicas. (PAPEP-PNUD, 2012) Esto demuestra que aún el gobierno tiene mucho trabajo por hacer, debido a que todavía no se alcanza un nivel aceptable de satisfacción de las necesidades delos peruanos, apoyar a los distintos sectores y sobretodo que se siga fomentando el comercio exterior. Al igual que el Reino Unido el Perú también es un país que tiene diversas etnias a lo largo de la costa, sierra y selva donde se encontrarán distintos grupos sociales, lo cual la constitución no puede ignorar.

\subsubsection{Entorno Económico}

La economía británica es la tercera mayor de la UE después de la alemana y francesa y la sexta a nivel mundial. Según "CIA - The World Factbook" durante el 2013 el PBI per cápita del Reino Unido incrementó a $\$ 37,300$, ya que el año anterior (2012) fue de $\$ 37,100$. Podemos ver que el poder adquisitivo de los ingleses no se ha visto tan afectado por la crisis debido a que contaban con una cantidad similar de dinero 
disponible de un año a otro, a pesar de que otros países de la zona euro si fueron muy afectados.

Figura 6 Crecimiento Real del PBI y PBI Per Cápita: 2006-2015

Chart 1 Real GDP Growth and Per Capita GDP: 2006-2015

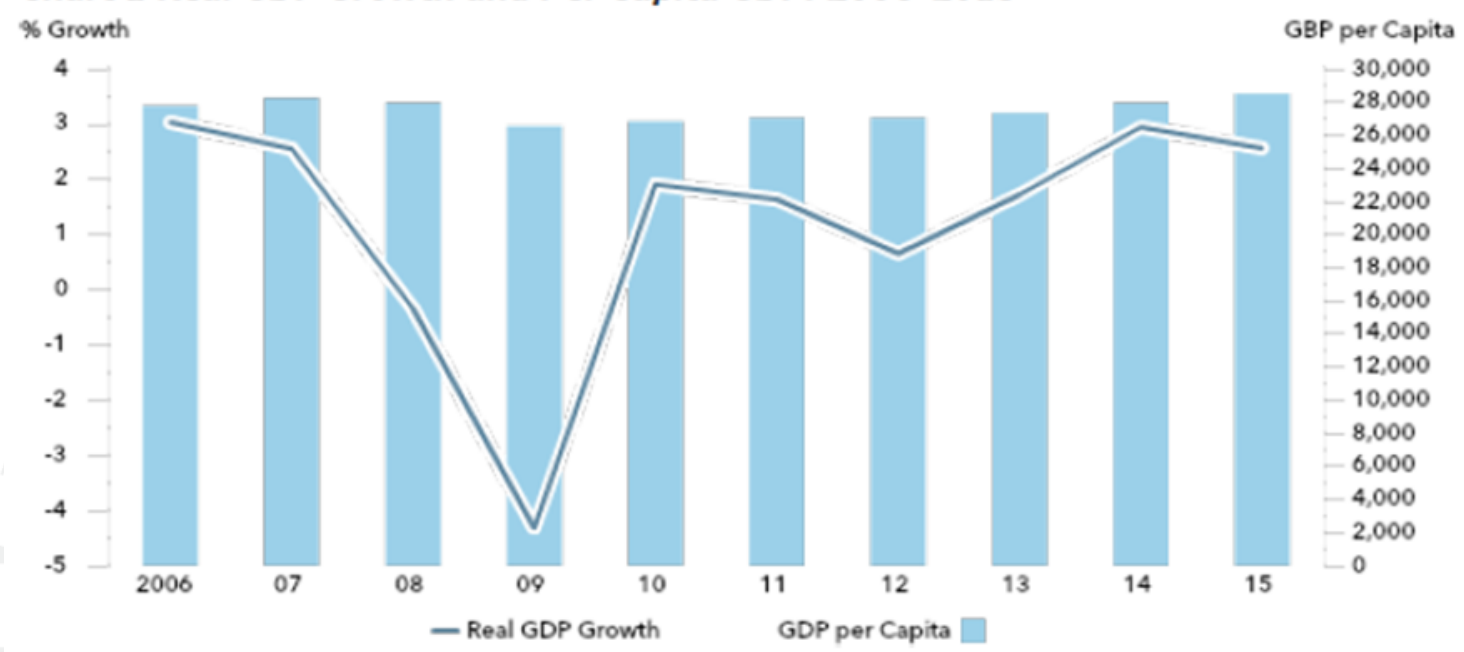

Fuente: Euromonitor International - United Kingdom: Country Profile

Luego de un muy buen desempeño económico durante el 2014, el cual refleja una importante recuperación del Reino Unido, las perspectivas para el 2015 indican una desaceleración económica. En el 2014 el PBI creció 3\% luego de un leve incremento en el 2013 y para el 2015 se pronostica una leve caída a 2.6\%. El Reino Unido fue la última de las grandes economías en salir de la recesión, haciendo de esta su más larga recesión posguerra.

El impacto de la crisis financiera internacional se vio reflejado en términos de PIB, en caídas más pronunciadas en países como Japón, Alemania y el Reino Unido (en el primero, mayor al $10 \%$ y cercano al $7 \%$ en los dos países restantes), debido principalmente al colapso del comercio internacional. En Japón y Alemania, dado que estos son grandes exportadores con una participación activa en las actividades de intercambio comercial y, en el caso del Reino Unido por la exposición de su importante sector financiero a la crisis. (Banco de España , 2012) 
En el 2014 la tasa de desempleo disminuyó a el 6,2\% y continuará esta tendencia alcanzando $5.9 \%$ en el 2015. Los miembros de la clase media británica fueron particularmente afectadas durante el punto más bajo de la crisis financiera mundial de 2008-2009: la pérdida de empleos y el estancamiento salarial tuvieron el impacto más perjudicial en esta cohorte. (Euromonitor International , 2014)

Figura 7 Evolución Desempleo en el Reino Unido (sobre los 16 años de edad, 1990 2012)

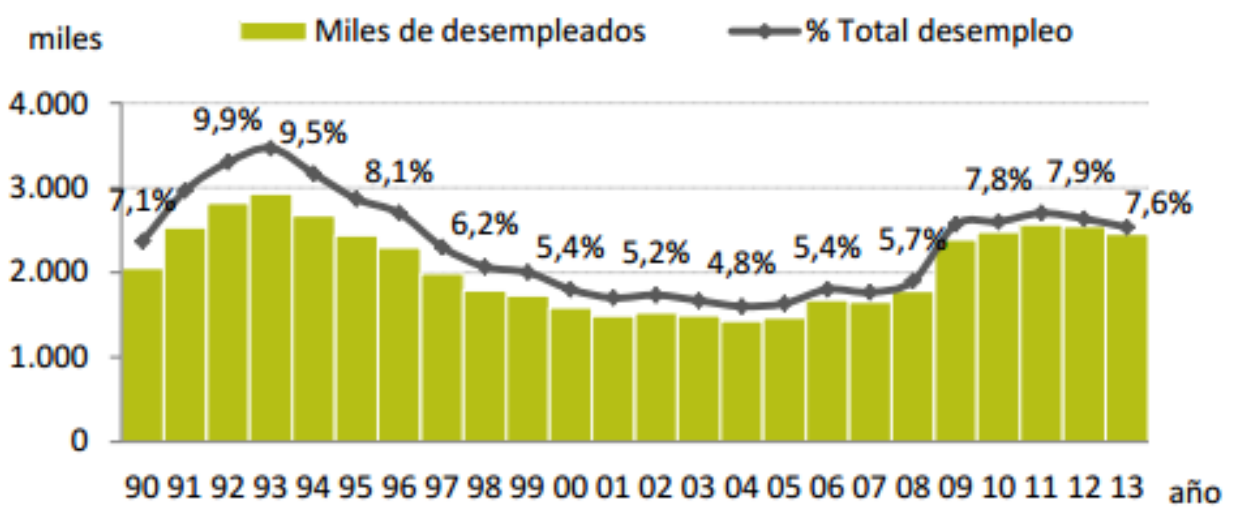

Fuente: ProChile Oficina Comercial Londres - Guía País Reino Unido 2014

Al reducirse el desempleo, más personas cuentan con ingresos disponibles para gastarlo en alimentos, sobre todo en los que son más nutritivos beneficiosos para la salud. A pesar de la caída de la tasa de desempleo de acuerdo con la última Encuesta de Horas y Salarios, la media de ingresos semanales brutos de tiempo completo (en términos reales) se han reducido un 8,8\% entre 2008 y 2014. (Euromonitor International , 2015)

El patrón del mercado laboral inglés se caracteriza por una disminución del trabajo típico (permanente a tiempo completo) y un aumento del trabajo a tiempo parcial temporal y autoempleo (empleo atípico), este empleo atípico está teniendo un efecto dinamizador sobre el desempleo y la población activa de Reino Unido. (ICEX Oficina Económica y Comercial de España en Londres , 2013)

La tasa de desempleo del Reino Unido se ubica actualmente por debajo del promedio de los países miembros de la Comunidad Europea y por debajo de otras grandes economías perteneciente a este grupo, como por ejemplo: Francia (10,3\%), Italia $(10,4 \%)$ y España $(24,9 \%)$. (ProChile Oficina Comercial Londres, 2014) 
Si una gran proporción de personas en el Reino Unido cuentan con empleo, nos dirigiremos a los sectores que cuentan con mayores recursos y por lo tanto han ajustado sus gastos en menor grado. La granada deberá ofertarse como un fruto diferenciado por lo que los consumidores van a sentir la necesidad de hacerlo parte de su dieta diaria.

Alimentarse es una necesidad, motivo por el cual tenemos la ventaja que siempre las personas van a tener que destinar cierta cantidad de su dinero hacia esa actividad, lo que debemos procurar es que las personas tengan a las granadas entre sus principales opciones de consumos por ser una fruta nutritiva con grandes propiedades.

Por otro lado en el 2013 las exportaciones totales sumaron un monto de US\$ 751 mil millones, $0.4 \%$ menos que el año 2012. Las cuales están compuestas $41 \%$ por servicios y el 59\% restante por bienes. Las importaciones totales del país en el 2013 fueron de US\$ 799 mil millones, disminuyendo 1.8\% a comparación del 2012 (US\$ 814 mil millones), $23 \%$ de su valor importado son servicios y el $77 \%$ restante corresponden a bienes.

Figura 8 Evolución Comercio Exterior Total Reino Unido: 2006-2013

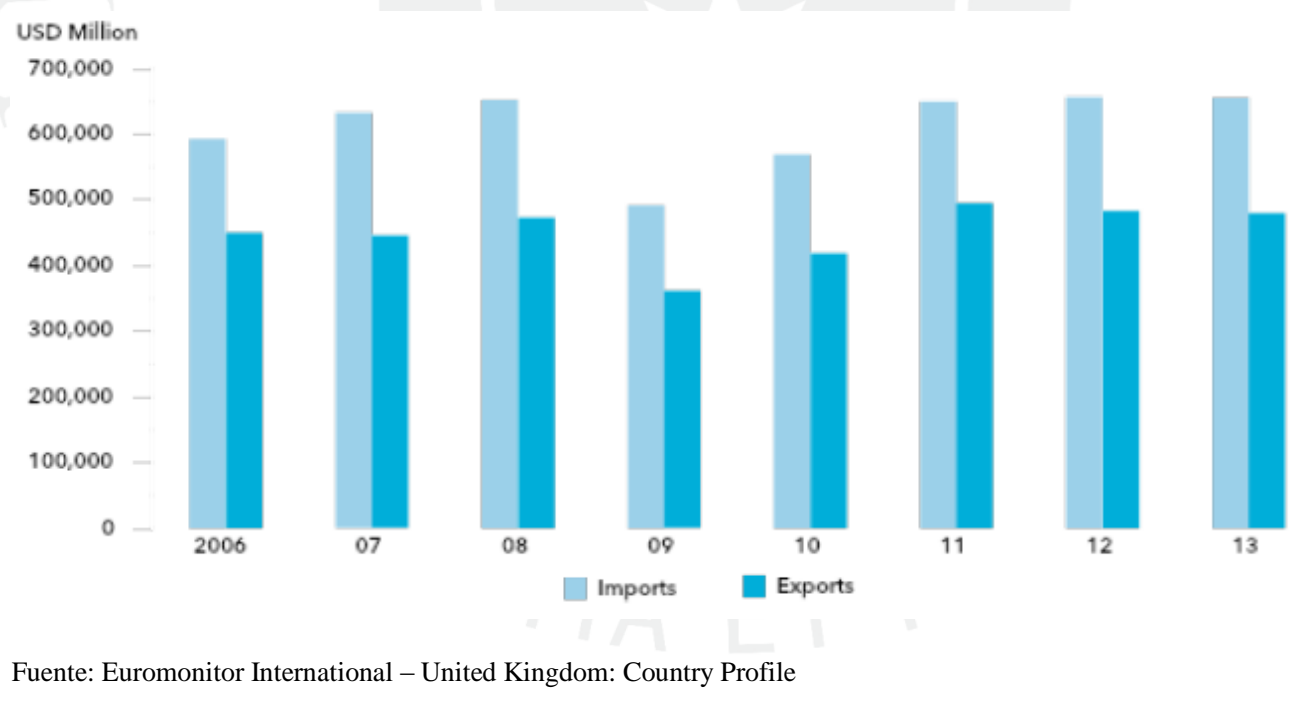

En el caso de Perú desde el 2002 la economía ha ido creciendo a un ritmo de $6.4 \%$ anual en promedio. El crecimiento se ha mantenido en el rango de 6-9\% en los últimos tres años, debido en parte a un salto en la inversión privada, especialmente en el sector extractivo, que representa más del $60 \%$ de las exportaciones totales de Perú. 
Gracias a esto y otros programas la tasa de pobreza nacional se ha reducido en $23 \%$ desde el 2002, a pesar de esto la inequidad sigue persistiendo en el país por lo que se ha propuesto que se impulse el crecimiento económico pero acompañado de la inclusión social para que toda la población se beneficie.

En los últimos años el Perú ha firmado varios acuerdos comerciales con países del Asia como Japón, China, Corea del Sur, Singapur además de Estados Unidos y la Unión Europea, el cual entró en vigencia en marzo del año 2013. El acuerdo más reciente que ha firmado es el de la Alianza del Pacífico con Chile, Colombia y México, este busca posicionarse para competir con el Mercosur en la población combinada, el PIB y el comercio. Esto demuestra que se está manteniendo una política de apertura comercial, lo cual es beneficioso para las condiciones de intercambio comercial.

Según The CIA World factbook el PBI per cápita del Perú en el 2013 fue de US\$ 11,100 dólares mayor al del 2012 que se situó en US\$10,700. Su PBI está compuesto por los sectores de agricultura (6.2\%), industria (37.5\%) y servicios $(56.3 \%)$.

La fuerza laboral está compuesta por 16.2 millones de persona, hay otras personas que son informales o menores de edad que trabajan, pero no están incluidos en esta cifra. La participación del sector servicios en el total de empleos es de $57.4 \%$, la de la agricultura $24.6 \%$ y la industria $18 \%$. La tasa de desempleo en el 2014 se situó en $6 \%$ mayor que en el año 2013, cuando estaba en 4\%. (International Labour Organization, 2014)

Gran parte de la fuerza laboral se dedica a la agricultura, y en muchas ocasiones son familias las que trabajan sus tierras y luego venden sus cultivos a las empresas. En la región Ica la ocupación predominante de la población se sitúa en actividades agropecuarias $(22.3 \%)$, comercio $(15.8 \%)$ y manufactura (11.4\%). (CEPLAN - Centro Nacional de Planeamiento Extratégico , 2012)

Las exportaciones totales en el 2014 alcanzaron los US\$ 38.40 mil millones de dólares, disminuyendo 9.8\% a comparación del 2013 (\$42.58 mil millones). Las importaciones en el 2014 sumaron US\$ 42.20 mil millones disminuyendo 2.61\%. Para este período la balanza comercial del Perú fue negativa. 
Los principales productos que exporta el Perú son los minerales, el café, los espárragos, productos pesqueros, en general con poco valor agregado. Dentro de las principales importaciones se encuentra el petróleo, las maquinarias, vehículos, químicos, bienes que han tenido algún tipo de transformación. La Región Ica, es la cuarta Región en volumen general de exportaciones tradicionales, y tercera en el volumen general de exportaciones no tradicionales. Se debe procurar fomentar el desarrollo de las industrias para poder producir bienes manufacturados de una manera eficiente.

Cabe resaltar que el 2014 no ha sido un buen año en términos de resultados económicos, el Perú creció alrededor de $2.8 \%$ debido al deterioro de la confianza empresarial la cual impactó en los niveles de inversión privada. (Perú21, 2015) Para este año 2015 la agencia clasificadora de riesgo Moody’s estima que el Perú crecerá un $4.4 \%$ este año, desde el $5.1 \%$ que había pronosticado anteriormente. (Semana Económica, 2015)

\subsubsection{Entorno Social}

Inglaterra es uno de los países más densamente poblados del mundo, además de ser el tercer país más poblado de la Unión Europea con 383 habitantes por kilómetro cuadrado, con una concentración particular en Londres y en el sureste del país. (Khan, 2008) En el 2014 la población alcanzó los 64.3 millones de personas, el ritmo de crecimiento se acelerará gradualmente en el futuro llegando a los 66.7 millones en el 2020.

Cabe resaltar que su población es diversa en culturas, razas y costumbres debido al gran número de inmigrantes, principalmente provenientes de las antiguas colonias británicas en el Caribe, el sudeste Asiático y África. (ProChile Oficina Comercial Londres, 2014) Es muy útil conocer esta información para decidir a qué nichos de mercados dirigirnos.

La inmigración ha sido un importante factor en el crecimiento de la población y contribuye con un $48 \%$ al crecimiento de la población. (ICEX Oficina Económica y 
Comercial de España en Londres , 2013) Entonces al ofrecer nuestro producto debemos tomar en cuenta que posiblemente no solo británicos lo irán a consumir sino también personas que viven allí, pero provienen de otros países por lo que podrían tener diferentes hábitos de consumo. La población es predominantemente cristiana (59,5\%), el4,4\% es musulmán, un $1,3 \%$ hindú, otras religiones $2 \%$ y un $25,7 \%$ se declara no perteneciente a ninguna religión por diversos motivos.

En los últimos cuarenta años se han incrementado los núcleos familiares en un 55\%, pero se ha presentado una reducción en su tamaño que era de 3,1 personas, el número de hogares unipersonales se ha multiplicado, pasando de representar el $17 \%$ al $30 \%$ actual. (ICEX Oficina Económica y Comercial de España en Londres , 2013) Este es un dato importante al momento de realizar la promoción, debido a que se tiene que saber a quién se está dirigiendo el producto porque dependiendo de eso es que se va cambiando la estrategia de venta.

Asimismo es útil para más adelante cuando se desarrolle un producto con mayor valor agregado, debe ser una bebida o snack que esté listo rápidamente porque normalmente las personas quieren optimizar su tiempo al máximo. Actualmente los hogares con una o dos personas representan más del $65 \%$ del total de los hogares del Reino Unido. (ProChile Oficina Comercial Londres, 2014) El porcentaje de población urbana es de $80 \%$, nosotros vamos a enfocar nuestras exportaciones en Londres y las ciudades aledañas.

A continuación podemos observar la pirámide poblacional del Reino Unido:

Figura 9 Pirámide Poblacional Reino Unido 2014

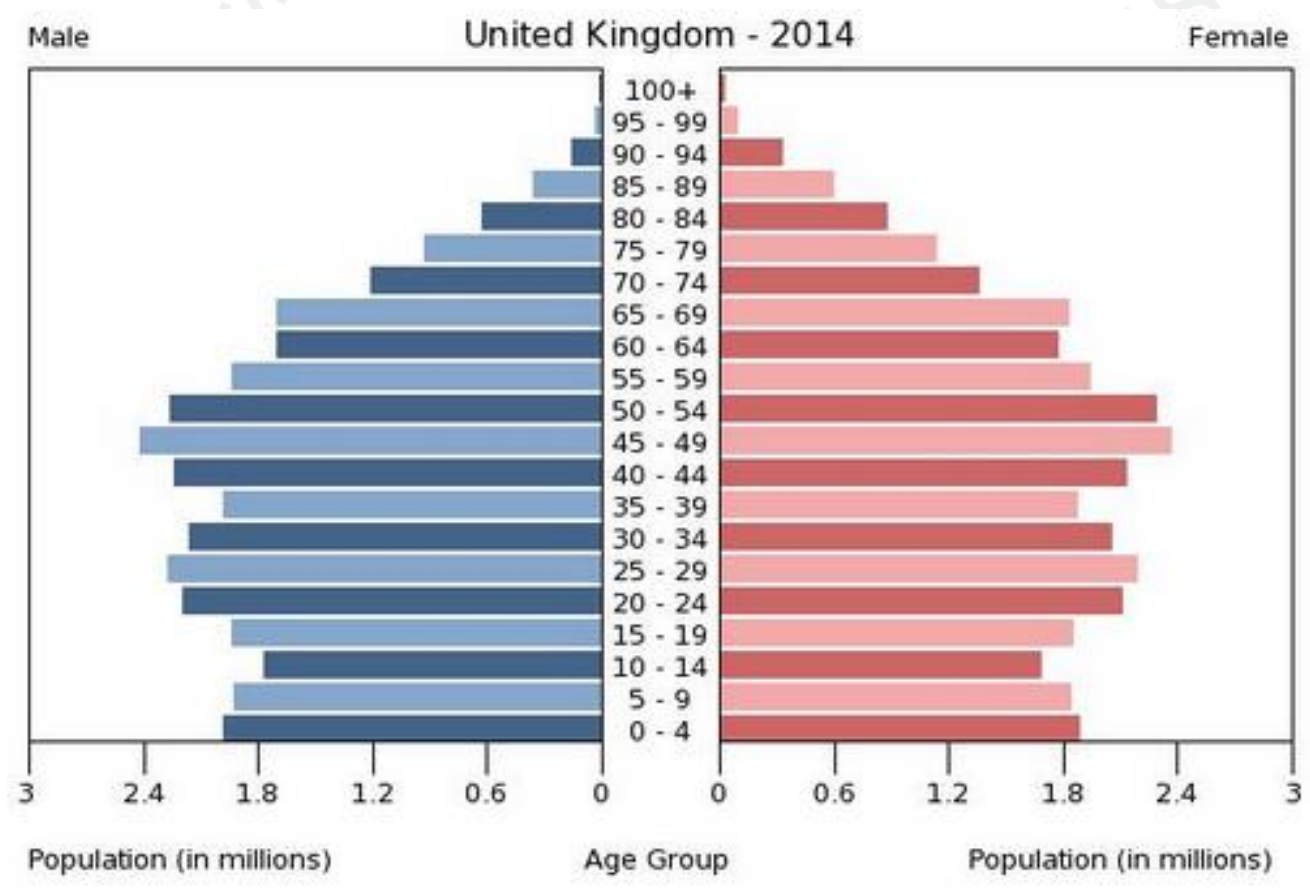


Fuente: CIA - The World Factbook

Figura 10 Estructura de la Edad de la Población del Reino Unido

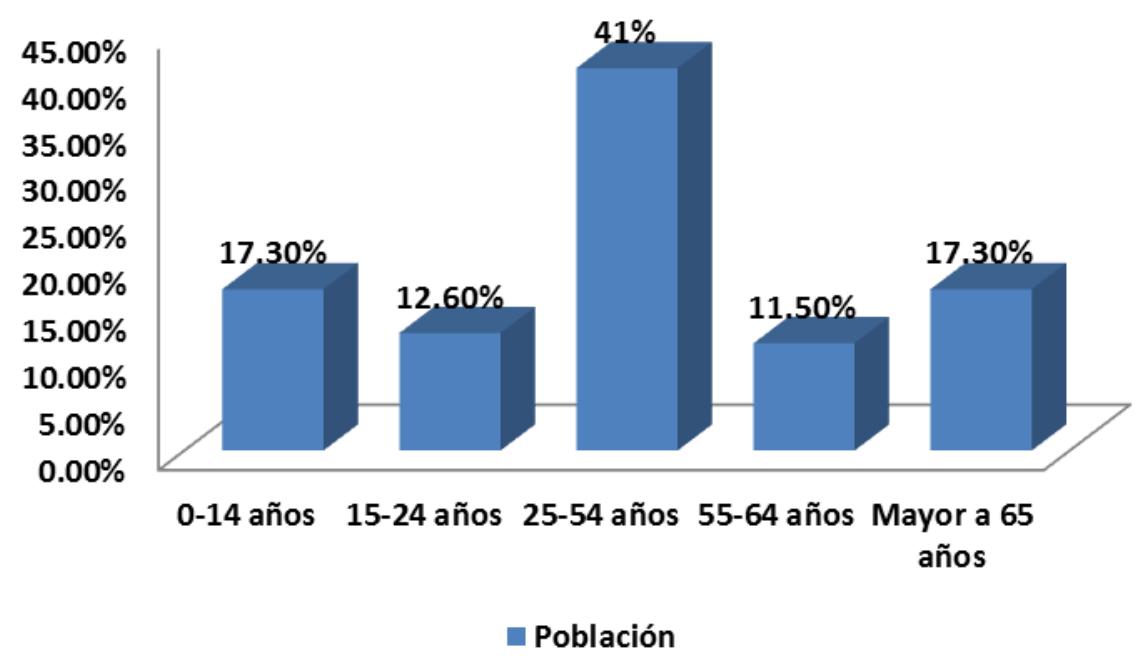

Fuente: CIA - The World Factbook

En el 2014 la edad media en el Reino Unido fue 39.9 años, desde 1980 ha significado un incremento de 5.7 años. (Euromonitor International ,2015) El análisis de la pirámide de población indica que la población continúa envejeciendo gradualmente. Asimismo nos muestra que la mayor concentración tanto de hombres como de mujeres se encuentra en el grupo de edad entre 45 y 54 años.

En lo que se refiere a la distribución por edades el grupo de población en edad activa representa el $62 \%$ de la población. Las personas en edad de jubilación (65 para los hombres y 60 para las mujeres) con 12,2 millones de personas suponen el $20 \%$ de la población y es ligeramente superior al número de personas en edad inferior a los 16 años (18\%). (ICEX Oficina Económica y Comercial de España en Londres , 2013)

De acuerdo al sexo, hasta los 70 años existe bastante igualdad entre hombres y mujeres, la esperanza de vida al nacer de los hombres es 78,1 y el de las mujeres 82,1. Esto se puede deber a que las personas del sexo femenino se preocupan más por cuidar de su salud por lo que nuestro principal nicho de mercado deben ser las mujeres. La mayor 
proporción se concentra en el grupo de personas que se encuentran entre los 25 y 54 años $(41 \%)$ lo que también nos da una indicación sobre a cual grupo de edades debemos dirigirnos, las personas deben empezar a cuidar su salud desde jóvenes y no esperar a ser muy mayores.

Respecto a las clases sociales, el sector social D, fue la clase social más grande en el Reino Unido durante el 2013, compuesta por 37.6\% de la población de más de 15 años con el rango de edad más predominante dentro del cohorte de 65 a más, delante de la clase social E con 34.3\%. (Euromonitor International , 2014) Ellos son consumidores sensibles a los cambios en los precios abiertos a ir a tiendas de descuento, marca blanca, minoristas online y en la búsqueda de oportunidades para economizar.

Por otro lado el Perú cuenta con una población de 30`814,175 habitantes, 8.751 millones de personas viven en Lima (la capital) le sigue Arequipa con 1'273,200. (INEI - Instituto Nacional de Estadística e Informática, 2014) En el año 2013 se estimó que existieron 8 millones de hogares de los cuales el $76 \%$ corresponde al área urbana y el restante $24 \%$ al área rural. El principal motivo ha sido porque muchas personas de provincia han inmigrado a las ciudades en busca de mejores oportunidades. El Perú se ha convertido en un país de emigración en las últimas décadas por la crisis económica y social causada por el terrorismo que se vivió en los años 80. Gracias a las mejoras de la economía esta situación ha disminuido, pero aun así en la última década emigraron 2 millones personas a países como Argentina y España.

La etnia es muy variada, podemos encontrar amerindios (45\%), mestizos (37\%), blancos (15\%) chinos, japoneses por la inmigración que se dio en los siglos 19 y 20 . Al ser un país diverso debe existir un mayor sentido de tolerancia hacia los demás y los niveles de discriminación aun menores. Lamentablemente aún existe mucha discriminación en el país y hasta se puede dejar de contratar a personas en alguna organización por su color de piel.

En el 2014 la edad mediana de la población peruana se situó en 26,9 años, lo que indica que hay más población en edades mayores, por una expectativa de vida más alta. (INEI - Instituto Nacional de Estadística e Informática, 2014) Como se puede observar en la pirámide poblacional la mayor parte de la población es joven. Por lo que se debe 
aprovechar para invertir en educación y tener una mano de obra más capacitada que pueda apoyar a los sectores de la economía. A diferencia del Reino Unido, Perú concentra grandes cantidades de población en el rango de edad entre 10 a 24 años. El segmento más grande de la población se encuentra en el rango de edad de 25-54 años (39.4\%), seguido por un 19.2\% en el cual se encuentra la población entre 15 y 24 años. (Central Intelligence Agency - United States of America , 2015) Al contar con una gran porción de población joven hay más actividad en el país.

Figura 11 Pirámide Poblacional Perú 2014

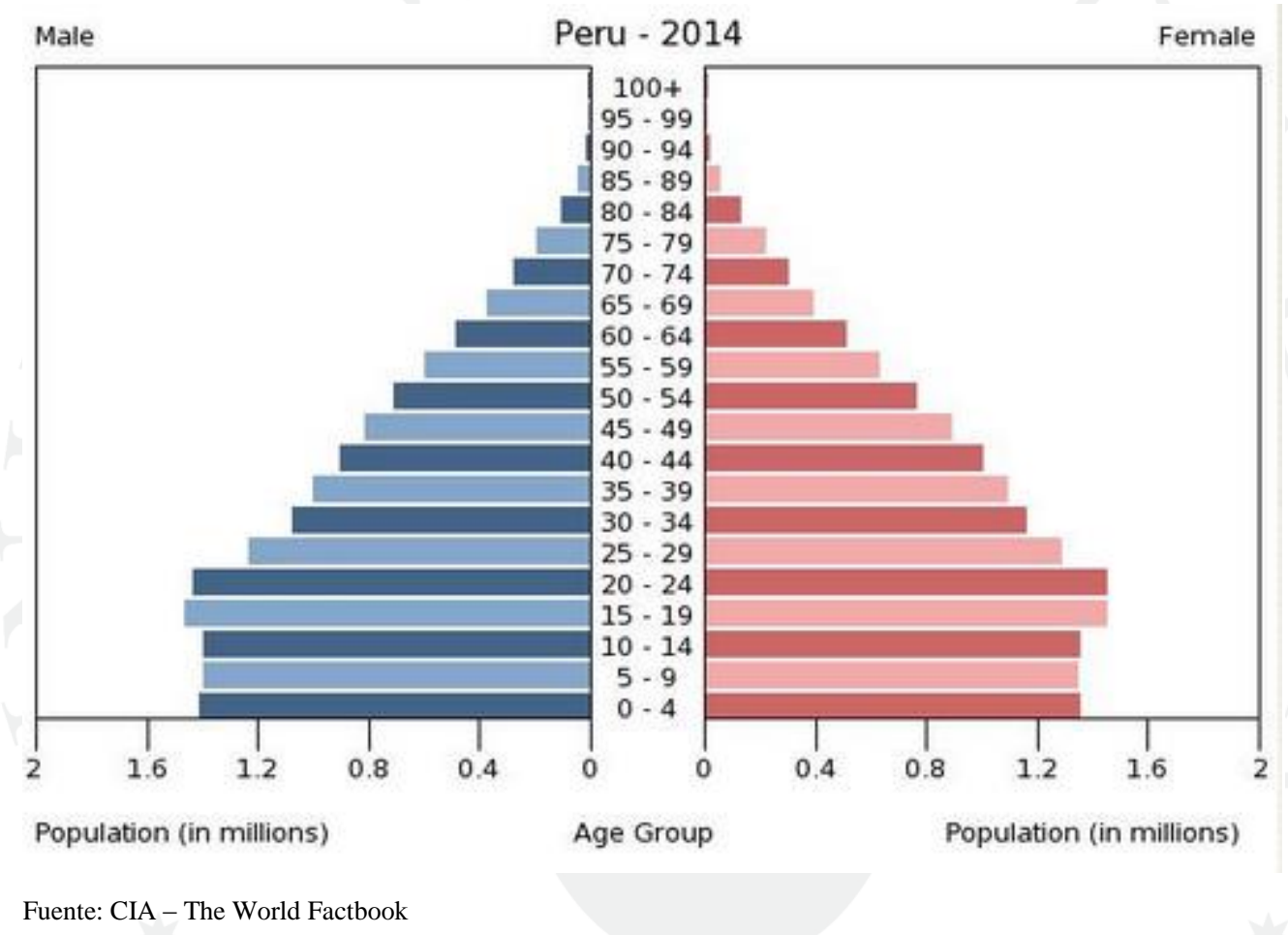

Es importante que se invierta en educación sobretodo observando cómo se está comportando la población en los últimos años, la escolarización ha mejorado, pero las puntuaciones obtenidas reflejan los problemas que siguen existiendo con la calidad educativa.

La población en Ica, región de la cual nos proveeremos de granadas, alcanza los 711,932 habitantes (358,546 mujeres y 353,386 Hombres:). Cuenta con 5 provincias y 43 distritos (INEI-Censo 2007). La población en edad laboral (15-64 años) asciende en total a 208,673 habitantes $(64.9 \%$ del total) y presenta un Índice de desarrollo humano alto. 


\subsubsection{Entorno Tecnológico}

El Reino unido fue el país líder de la Revolución Industrial, por lo que ellos brindaron al mundo varias innovaciones, desde hace muchos años atrás es un referente a seguir cuando se trata de temas de desarrollo. Con el transcurso de los años ha experimentado un progresivo abandono de sus industrias menos competitivas y ha enfocado su especialización en sectores intensivos en tecnología.

En términos generales, las manufacturas son responsables del $75 \%$ del gasto total en I+D del país y de éste más del $60 \%$ de se efectúa en industrias de alta tecnología por lo que se encuentra en los primeros puestos de la OCDE. (ICEX Oficina Económica y Comercial de España en Londres , 2013) Nuestra empresa exportará un producto que implica un nivel muy básico de tecnología, por lo que debemos aspirar en el futuro a exportar un producto que contenga mayor valor agregado, como un snack o bebida hecho de granada. En lo que respecta a las actividades de montaje en los sectores de alta tecnología, no han sido inmunes a la competencia proveniente de países emergentes. Cada vez más en los países en vías de desarrollo se está buscando innovar y desarrollar tecnologías que los ayuden a ser más eficientes.

Algunos sectores de manufactura avanzada en los que el Reino Unido se encuentra a la vanguardia son: nanotecnología, cerámica, plásticos, instrumentos y sistemas de tecnología avanzada, manipulación de materiales sólidos, software para la industria manufacturera. En este segmento destaca la industria aeroespacial, en el que Reino Unido es líder en Europa y segundo tras EEUU. Tiene como meta reducir en un 80\% las emisiones de CO2 para el 2050 a través de la innovación tecnológica.

Reino Unido gastó menos como proporción del ingreso nacional en investigación y desarrollo que el resto de la UE en 2012 a pesar del aparente impulso de innovación del gobierno para impulsar el crecimiento. (Monaghan, British R\&D spending down despite government's innovation strategy, 2014) En Diciembre de 2012 el gobierno publicó una Política de Inversión en Investigación, Desarrollo e Innovación.

Esto es muy importante porque las empresas innovadoras contribuyen al crecimiento económico. Algunas acciones importantes son la protección, £ 4,6 billones al año para 
la financiación de programas científicos y de investigación, asimismo conseguir que las empresas trabajen más estrechamente con las universidades e instituciones de investigación para que se comercialicen sus investigaciones. (GOV.UK, 2015) Lo cual también debe ser un ejemplo a seguir para el Perú, debido que todavía no existe una debida articulación entre el sector empresarial y educativo para juntos crear sinergias y desarrollar en conjunto un proyecto interesante.

Los servicios informáticos y tecnologías de la información han adquirido una gran importancia, suponen cerca del 4\% del PIB y emplean en torno a un millón de personas. $\mathrm{Su}$ impacto en la economía británica es incluso mayor como fuente de innovación y nuevas formas de organización del trabajo. (ICEX Oficina Económica y Comercial de España en Londres , 2013) Al ver que es un país que se concentra mucho en la tecnología, podemos dirigir las granadas frescas, a empresas que desarrollen productos secundarios como jugos, cápsulas, concentrados que son más elaborados y permiten obtener mayores ganancias.

Como se sabe en materia de Ciencia, Tecnología e innovación (CTI), existen tres tareas básicas que se deben alcanzar:

a) Lograr mayor eficiencia en generación de nuevos conocimientos y tecnologías

b) Lograr mayor eficiencia en transferencia de conocimientos y tecnologías

c) Lograr mayor eficiencia en absorción y uso de conocimientos y tecnologías

(Ministerio de Economía y Finanzas, 2012)

Para el Perú actualmente el aspecto más relevante es la tarea de adquisición de nuevos conocimientos y tecnologías.

En lo referente a la tecnología, el Perú aún no se encuentra muy posicionado en este ámbito debido a las pocas inversiones que se destinan a la investigación y desarrollo, tampoco se fomenta la innovación. El Presidente de la Comisión TIC de La CCL mencionó que: "Mientras el Perú destina el $0.11 \%$ de su PBI a este rubro, en Chile se invierte seis veces más y en Argentina, casi cinco.” (Gestión, 2012) Las cifras del Ranking de Competitividad Global 2014-2015, elaborado por el Foro Económico mundial, confirmaron que de 144 países evaluados, el Perú ocupó el puesto 65 en el 
Índice de Competitividad, en cuanto a preparación tecnológica el lugar 92 y en innovación solo llegamos al puesto 99. (World Economic Forum, 2014)

Figura 12 Gasto en Ciencia, Tecnología e Innovación (CIT) 1999-2011

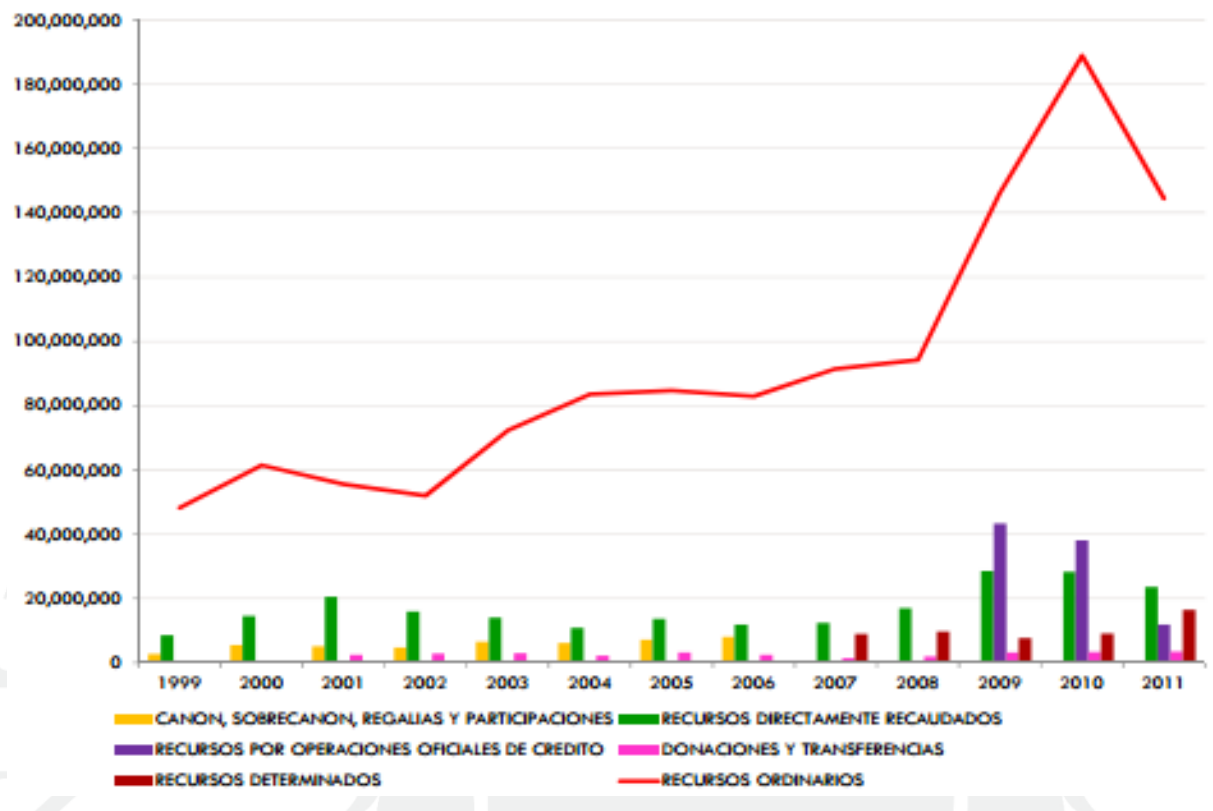

Fuente: Ministerio de Economía y Finanzas - Sistema Integrado de Administración Financiera

En la figura $\mathrm{n}^{\circ} 12$ podemos ver la evolución del gasto en Ciencia, Tecnología e Innovación (CIT) de la última década en el Perú, la cual nos muestra que el volumen de inversión en CTI que realiza el país es extremadamente pobre, comparado no solamente con los países de altos ingresos sino también comparado con los países latinoamericanos. (Ministerio de Economía y Finanzas, 2012)

En términos generales estas cifras no son nada atractivas y cuando comparamos con nuestros pares en Latinoamérica nos damos cuenta que la situación aún está muy crítica, pero se debe empezar poco a poco destinando un mayor presupuesto a la investigación y desarrollo. En Perú contamos con el Fondo para la Innovación, la Ciencia y la Tecnología (FINCyT) a partir del año 2006, el cual apoya la innovación en empresas a través de financiamiento para proyectos de desarrollo tecnológico e innovación, financia la investigación científica y tecnológica. 
Estos últimos años se ha difundido más entre las empresas, pero aún no se aprovecha como se debería este tipo de incentivos por parte del gobierno.

América Latina es un mercado emergente para las tecnologías de la comunicación y la información (TIC), por lo que el Perú debe aprovechar para posicionarse allí debido a que su creatividad le permitirá lograr cosas muy interesantes.

Es por este motivo que el SNIP en estrecha colaboración con el Consejo Nacional de Ciencia Tecnología e Innovación (CONCYTEC y los demás actores del sistema nacional han formulado la "POLÍTICA DE INVERSIÓN PÚBLICA EN CIENCIA, TECNOLOGÍA E INNOVACIÓN (CTI), 2013-2020".

El objetivo de la misma es mejorar el desempeño del sistema nacional ciencia, tecnología e innovación en términos de mayor eficiencia en la generación, transferencia y adopción de conocimientos, los cuales permitan lograr incrementar la productividad y competitividad del país a mediano y largo plazo. (Ministerio de Economía y Finanzas, 2012)

Se debe usar la tecnología y la investigación y desarrollo para contribuir a la inclusión social, en temas como la salud y educación. En la región Ica tampoco hay mucho desarrollo de tecnología, para la agricultura, por ejemplo, se necesita hacer más eficientes las técnicas de riego.

\subsubsection{Entorno Económico y Competitivo}

El Reino Unido es miembro del Grupo de los 8 (G-8), Organización para la Cooperación y el Desarrollo Económicos (OCDE), OMC y miembro fundador del FMI, ONU y Banco Mundial, aunque no es perceptor de fondos, lo que demuestra su gran influencia en el comercio internacional en el mundo. Cuenta con un organismo encargado de la promoción de comercio e inversiones en el exterior (UKTI - UK Trade and Investment).

El Gobierno británico ha promovido diversas medidas en los últimos años para fomentar la actividad emprendedora, sobre todo en lo relativo a la creación de pequeñas y medianas empresas. Ha alcanzado muy buenos niveles de competitividad gracias al desarrollo de sus industrias y con el apoyo de la tecnología ha sacado adelante proyectos muy interesantes. A pesar que el Reino Unido durante la revolución industrial 
se posicionó como uno de los países más industrializados del mundo, durante las últimas décadas y producto de una baja en la competitividad del Reino Unido en sus industrias (naval, automotriz y aérea, producción de acero, industria textil) la composición de la economía ha cambiado desde las manufacturas e industrias hacia la industria de servicios (77\% del PIB). (ProChile Oficina Comercial Londres, 2014)

Los sectores en los cuales resalta su competitividad la son los siguientes:

- Tecnología: Tech City es el mayor conglomerado de Europa de empresas dedicadas al sector tecnológico, situado en el este de Londres, que nació en 2010 con la intención de convertirse en un centro tecnológico a la altura de Sillicon Valley.

- Energías Renovables: Es el líder mundial en energía eólica marina con 1,3 GW de capacidad operativa a través de 15 parques eólicos, contribuyen a la conservación de la ecología del país. El gobierno británico también tiene ambiciosos planes para ampliar el papel de la energía renovable. El objetivo es que la energía renovable represente el $15 \%$ del consumo total de energía en 2020, frente a sólo el 3\% en la actualidad. (Euromonitor International , 2015)

Un punto débil es la infraestructura, a pesar que los productos de mercado se consideran relativamente competitivos, la infraestructura del país es inferior y mala con necesidad de mejoras. Este defecto frena el crecimiento de la productividad. (Euromonitor International , 2015)

Por otro lado es importante mencionar la facilidad para hacer negocios en este país, en el último ranking del Banco anivel mundial, "Doing Business 2014”, el Reino Unido se situó en el $8^{\circ}$ lugar de 185 países. (El Banco Mundial , 2014) Por ejemplo No se requiere permiso para establecer una empresa, aunque sí existen ciertas limitaciones respecto al nombre y en algunos sectores se requiere de licencia o autorización. Asimismo ocupa el puesto número 9 de 144 países en Índice de Competitividad Global del Foro Económico y cabe resaltar que en el noveno pilar: Disposición Tecnológica se sitúan en segundo lugar. (World Economic Forum, 2014) En caso más adelante queramos establecer un punto de distribución el mercado de 
destino para estar más cerca del consumidor, sabemos que hay más facilidades a comparación de otros países.

En el entorno competitivo peruano vamos a analizar algunas de las ventajas por las cuales el Perú se ha hecho más reconocido:

- Es un "hub regional" en la zona del Pacífico Sudamericano. Nos encontramos ubicados al medio de América del Sur, frente al Océano Pacífico, pero para sacar ventaja al máximo de esta ubicación la infraestructura logística como lo son los puertos debe ser mejorada.

De 160 países el Perú ocupa el puesto 71 y cuenta con un puntaje de 2.84 de 5 en el último informe publicado por el Banco Mundial sobre el Índice de Desempeño logístico. (El Banco Mundial , 2014)

- Ocupa el tercer puesto como país más extenso en Sudamérica y 2do con bosques naturales. Cuenta con tres regiones geográficas muy marcadas: Costa, Sierra y Selva y por cierto disfrutamos de las cuatro estaciones del año y de los 84 microclimas de los 108 que existen en el mundo.

- Por el Océano Pacífico, el Perú se conecta con los países de la APEC -de la cual el Perú es miembro- el mercado más importante, rico y de mayor crecimiento en el mundo

- El crecimiento en medio de la crisis mundial sobre el 6\% promedio, con reservas internacionales de más de 50 mil millones de dólares, y 1,577 peruanos con depósitos por encima del millón de soles. (Gestiopolis, 2012)

Es por estas razones que la mayoría de países eligen al Perú como su socio estratégico comercial, porque en la actualidad está ofreciendo una mejor perspectiva económica.

Respecto a la región Ica, es muy competitiva en las actividades que realiza. El Índice de Competitividad Regional 2014 realizado por el Instituto Peruano de Economía sitúa a Ica en el cuarto puesto. Esto se ve reflejado en los pilares de infraestructura y salud en los cuales de 24 departamentos se posicionan como el tercero. Un ámbito en el cual aún debe mejorar es en el de las instituciones, ubicándose número 18 de 24, pero aun así tiene una puntuación bastante buena 
en el aspecto de acceso al crédito, 8.69 de 10 y ocupa el tercer puesto del total. (Instituto Peruano de Economía , 2014 )

Ica, es la cuarta región en exportaciones y potencialidades, para el desarrollo de los sectores: agropecuario, pesquería, turismo, industria y minería. También es importante el desarrollo del turismo dado que este permite que se vuelva más conocida la ciudad y en ese caso sus productos típicos. De la mano con todas estas ventajas debe ir la evolución ascendente del rol protagónico que compete a los gobiernos regional y locales en la promoción y generación de condiciones propicias para el desarrollo económico y social. (CEPLAN - Centro Nacional de Planeamiento Extratégico , 2012)

\subsection{Diamante Competitivo de Porter}

Para que una nación alcanze el éxito en un sector debe basarse en cuatro atributos que se presentan en el entorno en el cual compiten las empresas locales. Son los siguientes: Condiciones de los factores, condiciones de la demanda, Sectores Afines y de Apoyo, Estrategia, estructura y rivalidad de la empresa.

Las premisas que se deben tomar en consideración antes de realizar el análisis son:

1. La naturaleza de la competencia y las fuentes de ventaja competitiva difieren mucho de unos a otros sectores e incluso entre los segmentos de un sector.

2. Los competidores mundiales frecuentemente llevan a cabo algunas actividades de la cadena de valor fuera de su país de origen

3. Las empresas consiguen y mantienen ventaja competitiva en la competencia internacional mediante la mejora, innovación, y perfeccionamiento. Exigen unas inversiones continuadas para el cambio.

4. Las empresas que consiguen ventaja competitiva en un sector suelen ser con mucha frecuencia aquellas que no sólo detectan una nueva necesidad en el mercado o el potencial en nueva tecnología sino que son las primeras y las más agresivas en explotarlo. 
Vamos a realizar el análisis en el contexto de la situación que se está viviendo en el Perú respecto a las exportaciones de granadas.

Figura 13 El Diamante Competitivo de Porter adaptado a Pome Perú SAC

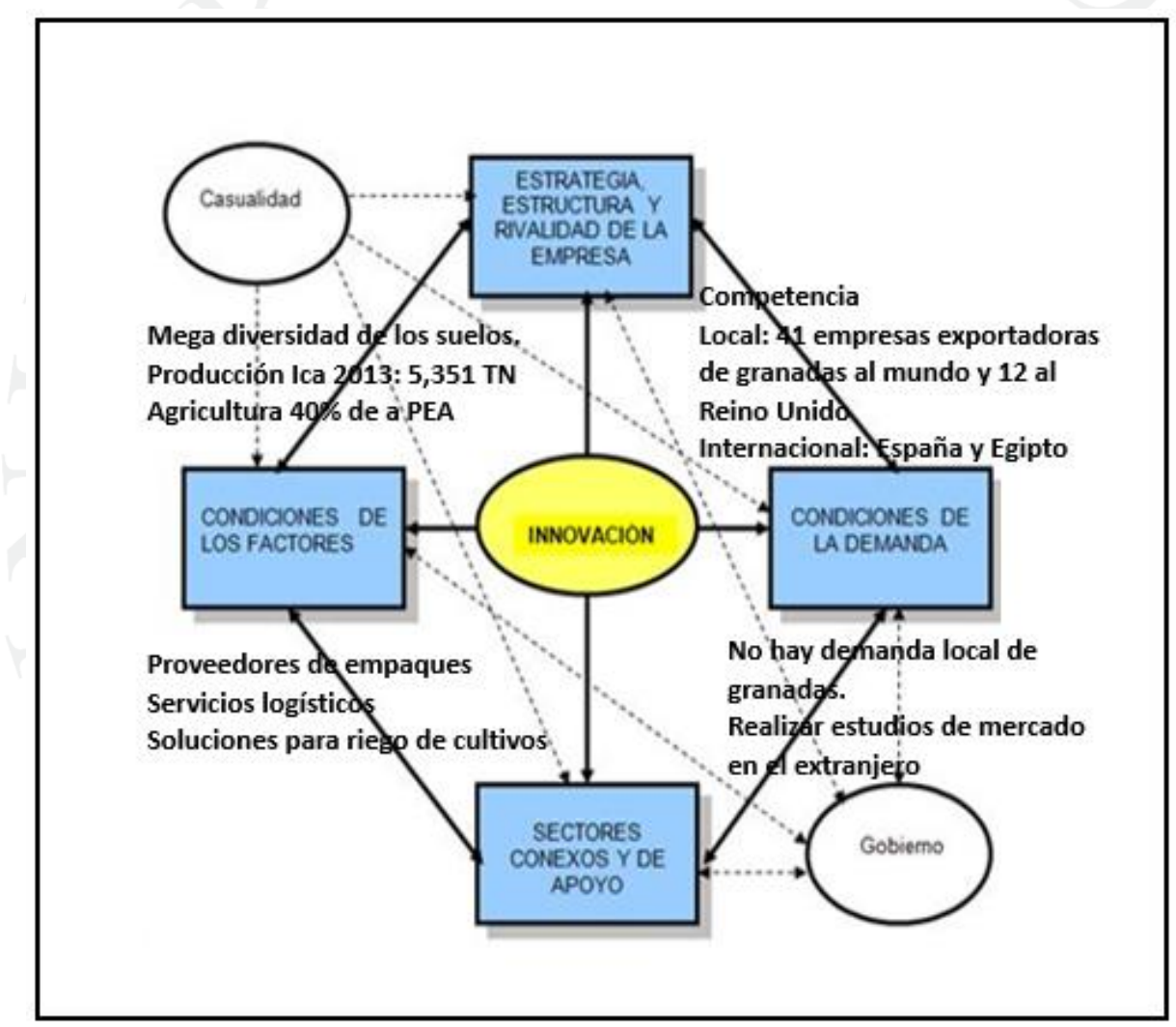

Fuente: 12Manage - Modelo del Diamante de Porter y Clústeres

\subsubsection{Condiciones de los Factores}

Este aspecto concierne a la mano de obra especializada o infraestructura necesaria para competir en un sector dado. Los factores de producción son los insumos necesarios para competir en cualquier sector, tales como la mano de obra, tierra cultivable, recursos naturales, capital e infraestructura. (Porter, 1991) 
Con el transcurrir del tiempo el nivel de dependencia alimentaria de productos importados se ha ido reduciendo, manteniéndose en aquellos productos donde no poseemos ventajas competitivas ni comparativas como es el caso del trigo y de la soya. (Libélula, 2011) Nos dedicamos a exportar los productos en los que somos más competitivos como el espárrago, que es nuestra exportación no tradicional número $1, \mathrm{y}$ por la que somos más conocidos.

La dotación de factores en la agricultura peruana es favorable debido a que somos un país muy biodiverso y extenso en tierras. Según los datos del Banco Mundial publicados en el 2012 sobre tierras agrícolas (porción del área de tierra cultivable), el Perú posee $19 \%$ de tierras agrícolas mientras que en el 2011 este número era 16.8\%. (El Banco Mundial, 2012)

Es uno de los doce países considerados como mega-diversos y se estima que posee entre 60 y $70 \%$ de la diversidad biológica. En este sector la dotación de factores se basa en los siguientes recursos:

- Recursos físicos: La superficie total del Perú es de 1.280.000,0 kilómetros cuadrados, sin incluir la superficie cubierta por masas de agua interiores. (El Banco Mundial, 2012) En el 2000 la superficie agrícola total del Perú alcanzó 11’285,334 hectáreas, de las cuales Ica tenía 137,925 hectáreas. (Ministerio de Agricultura y Riego, 2000)

El país también se ve favorecido por sus condiciones climáticas debido a que cuenta con una variada biodiversidad o mega diversidad. Esto se ve reflejado en la existencia de 28 climas y 84 zonas de vida sobre un total de 104 que existen en el planeta, además de contar con una gran variedad de suelos como podemos observar en la figura 11.

En el caso de la granada, sus rendimientos y calidad mejoran en condiciones de menor humedad relativa, por ello sus cultivos se vienen adaptando a las zonas del Sur de Costa central. En el 2013 la superficie total disponible para el cultivo de granadas fue de 595 hectáreas de las 426 pertenecen a la región Ica. Nuestra empresa se proveerá de este lugar, al 2013 la producción fue de 5,351 toneladas, representando $80 \%$ del total liderando la producción nacional. 
- Recursos Humanos: En el año 2006 el 31.6\% (8.1 millones de habitantes) de la población nacional vivía de la actividad agropecuaria. (Ministerio de Agricultura y Riego , 2007)

Los hogares cuya principal actividad es la agricultura representan al 34\% de los hogares peruanos y generan aproximadamente el 7.6\%del PBI Nacional. Excluyendo a Lima, la agricultura ocupa aproximadamente el $40 \%$ de la PEA (en la sierra alcanza el 55\%) y representa entre el 20\% y el 50\% de los PBIs regionales. (Libélula, 2011) Al 2011 en el Perú el $26 \%$ de los empleos totales eran en agricultura, a nivel mundial en promedio el $30.5 \%$ son empleos agrícolas. (El Banco Mundial, 2012)

Se puede deducir que sí hay una gran proporción de mano de obra calificada para trabajar las tierras, normalmente las familias trabajan en unidades agrícolas. Muchas veces esto representa un problema dado que no existe un mercado de tierras y la transferencia de ellas se presenta a través de la herencia familiar. Gracias a los recursos físicos y la mano de obra se puede llevar a cabo niveles de producción bastante considerables. MINAGRI indicó que el valor bruto de la producción agropecuaria alcanzó en el 2014 S/. 30,240.4 millones, 1.4\% más que en el 2013. La región Ica fue responsable de S/ 2,342.9 millones con un crecimiento de $6.5 \%$ respecto al 2013.

Figura 14 Diversidad de Suelos en el Perú 


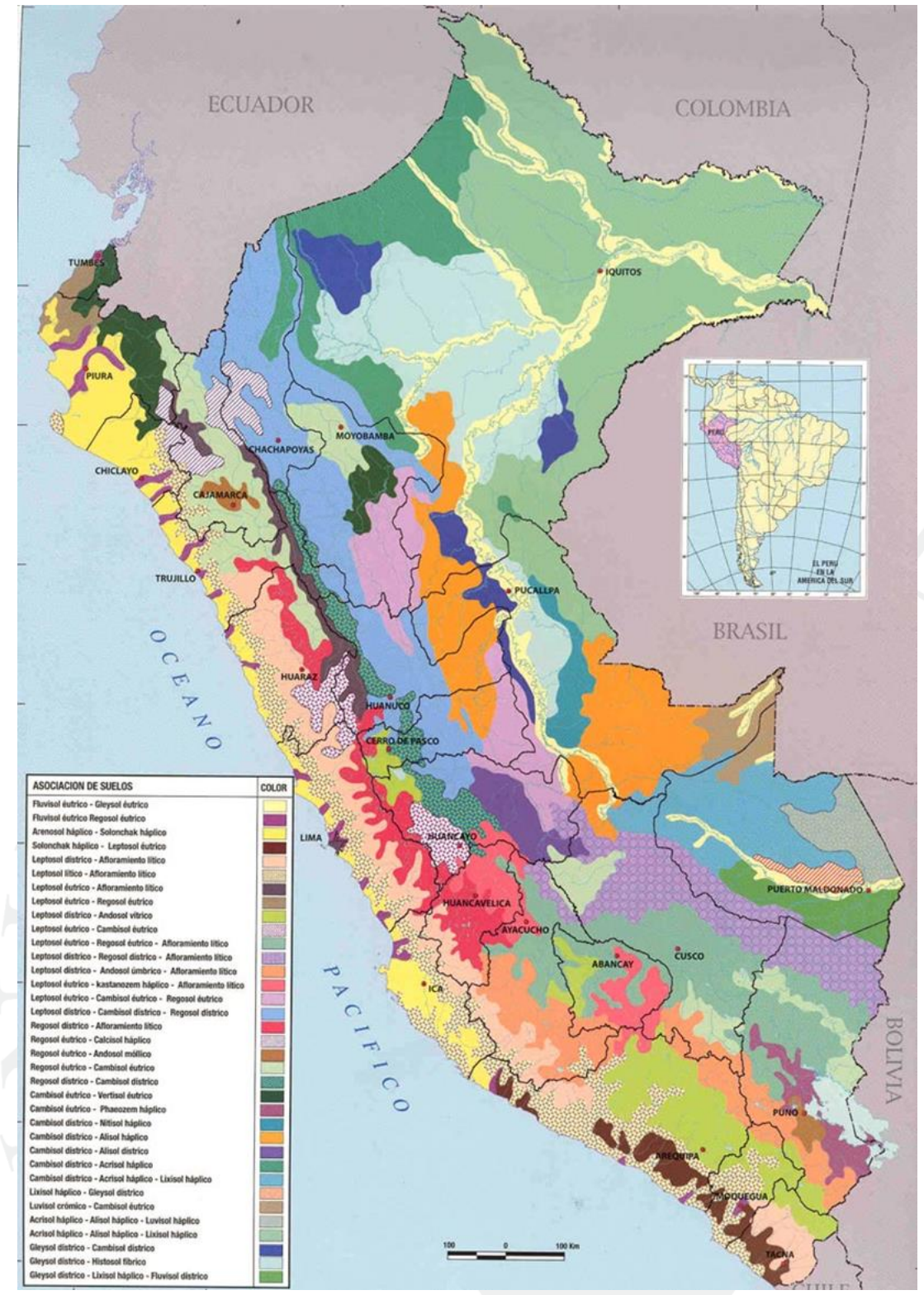

Fuente: Servicio Nacional de Áreas Naturales Protegidas por el Estado

El conocimiento en la agricultura se encuentra principalmente en un nivel técnico, dado que al ser una actividad familiar es la experiencia la que dicta cuanto se sabe y por eso se van traspasando los conocimientos de generación en generación. Lo que se quiere fomentar en la actualidad es que cada vez más existan cursos y capacitaciones respecto al tema. De esta manera impulsar un mayor desarrollo y el uso de tecnologías como técnicas más modernas de riego para hacer esta actividad más eficiente.

Por otro lado también es importante tomar en consideración la infraestructura que nos apoya para la exportación del producto. Aún falta aumentar la capacidad de nuestros puertos, debido que la mayor parte del comercio exterior se da en el puerto del Callao 
cuando hay otros puertos con mucho potencial para crecer, por ejemplo el Puerto de Pisco o el de Ilo. Tampoco contamos con un ferrocarril que interconecte las regiones y que facilite el transporte de las cargas pesadas.

Para nuestra operación en realidad no nos vemos muy afectados por estos factores, debido a que Ica esta solo a 4 horas del Callao. La carga se transporta a través de la carretera Panamericana Sur la cual se encuentra en buenas condiciones y facilita la comunicación. En el puerto del Callao se encuentran la mayoría de las líneas navieras que ofrecen disponibilidad de destinos y frecuencias para exportar el producto.

A pesar de las ventajas presentadas en lo que respecta a la disponibilidad de recursos físicos y humanos, estos se deben de administrar mejor. Ha habido un inadecuado manejo de recursos existentes llevando a niveles críticos de deterioro a ciertas zonas del país generando problemas de desertificación, deforestación, pérdida de tierras agrícolas, agotamiento de las fuentes de agua, degradación de ecosistemas y más. A esto se suma la situación de extrema pobreza que la mayoría de campesinos y pequeños productores agropecuarios atraviesan, además que muchas veces carecen de las nuevas técnicas que pueden convertir sus tierras más productivas.

Esto nos demuestra que aún hay mucha inversión que realizar en el tema, debido que la agricultura es una de las actividades más representativas dentro del PBI y el comercio exterior. El Perú participa en el comercio internacional como un pequeño abastecedor de la mayoría de productos que exporta, representando alrededor del $0.5 \%$ del comercio agrícola mundial, se trata de una participación pequeña si la comparamos con países como Chile. (Ministerio de Agricultura y Riego, 2007) Tenemos mucha variedad pero nos falta aumentar la oferta por lo que debemos encontrar la forma de hacer nuestras tierras más productivas sin comprometer los recursos del futuro.

\subsubsection{Condiciones de la Demanda}

Es la naturaleza de la demanda interior de los productos o servicios del sector. Hay tres atributos genéricos de la demanda interior (o naturaleza de las necesidades del comprador), la magnitud y pautas del crecimiento de la demanda interior y los 
mecanismos mediante los cuales se transmiten a los mercados extranjeros las preferencias domésticas de una nación.

Por sus cualidades antioxidantes y su uso para cosméticos la granada cuenta con un gran potencial agro exportador. Pero uno de los problemas es que internamente, en el mercado peruano no cuenta con una demanda, son muy pocas las personas que han oído hablar de sus propiedades y que son capaces apreciar el valor de esta fruta.

- En primer lugar, no es tan común encontrar la fruta, no se encuentra disponible todo el año y no está en la mayoría de supermercados.

- Segundo, no se ha realizado una adecuada promoción de la fruta, se debe hacer que se conozcan más sus propiedades y su poder para prevenir enfermedades.

- Tercero, la fruta en fresco no es tan fácil de consumir, toma tiempo pelarla y no es tan simple de comer como lo sería con una manzana o pera.

- Por último, la línea de productos desarrollada partir de la granada es muy limitada, cuando en realidad hay muchas opciones como jugos, concentrados, cápsulas que son más fáciles de consumir.

Probablemente no se hayan realizado más desarrollos a partir de la granada debido que la población peruana no encuentra atractivo el producto, porque aún no ha habido una gran difusión de sus propiedades y por la disponibilidad del cultivo en el país.

Normalmente son "los compradores locales los que presionan a las empresas locales para que innoven más de prisa y alcancen ventajas competitivas más refinadas en comparación con sus rivales extranjeros". (Porter, 1991) En este caso no hay muchos compradores locales y casi toda la producción se destina a la exportación por lo que no hay presión por innovar con productos, las empresas locales buscan las oportunidades en los mercados exteriores.

Para el caso de la exportación de granadas no se aplican los conceptos referentes a la internacionalización de la demanda interior, debido a que la demanda local es casi nula. No existen compradores locales o móviles que viajen a los mercados extranjeros y que vayan a demandar granadas, ni tampoco se ha logrado inculcar a los compradores foráneos métodos y valores locales que los lleven a demandar granadas peruanas en los 
mercados exteriores. (Porter, 1991) Esto se podría dar con productos un poco más diferenciados que no se encuentren en todas partes, por ejemplo la Inca Kola sí cuenta con demanda en los Estados Unidos.

Pome Perú SAC busca la oportunidad en el mercado del Reino Unido, quien importó \$ 47719000 de la partida otros frutos frescos (081090) en el 2014, las granadas se encuentran englobadas en esta partida. En realidad este producto se basa más en la demanda exterior, que la interior. Las necesidades del comprador se perciben a través de estudios de mercado, la granada se exporta en primer lugar en estado fresco, en el 2014 el 95\% de las exportaciones eran en fresco y el 5\% restante en congelado como los arilos de la granada. En el mercado de destino se procesa la materia prima para transformarlo en los productos que demanda el consumidor. De acuerdo a las exportaciones registradas durante los últimos años no se han exportado productos con valor agregado salvo en el 2014 jugos de granada, pero en volúmenes muy pequeños.

Como se mencionó anteriormente la Unión Europea cuenta con un gran consumo de frutas, porque se preocupan mucho por tener una alimentación saludable. En el 2013 el volumen de ventas de frutas para el Reino Unido alcanzó las 2,711 toneladas, $0.5 \%$ menos que en el 2012 pero desde el 2008 hasta el 2013 las ventas se han mantenido estables a pesar que en total decrecieron 6.6\%. (Euromonitor International, 2014) Se espera que la demanda del sector frutas incremente hacia el 2018 por el crecimiento del poder adquisitivo del consumidor, pero aún estas son consideradas un producto de lujo por los altos precios.

\subsubsection{Sectores afines y de apoyo}

Se refiere a la presencia o ausencia en la nación de sectores proveedores y sectores afines que sean internacionalmente competitivos. La ventaja competitiva en algunos sectores proveedores confiere ventajas potenciales a las empresas de muchos sectores de la nación, porque producen insumos que se emplean mucho y que tienen una gran importancia para la innovación o internacionalización. (Porter, 1991) 
Para la exportación de granadas frescas la importancia de contar con sectores proveedores no es tan importante como en las grandes industrias de manufactura, debido a que es una materia prima que no está siendo transformada y tampoco requiere de componentes sofisticados para su producción. Nuestra empresa se dedicará al acopio de la fruta, por lo que por el momento no tenemos que preocuparnos por el cultivo sino identificar proveedores adecuados.

Uno de los implementos necesarios para el cultivo son los fertilizantes que son nutrientes para mantener o incrementar el contenido de estos elementos en el suelo. En 10 años las importaciones de este producto se han casi duplicado alcanzando 1 millón de toneladas y la región que más los consume es la costa con una participación de $75 \%$. Recientemente se ha beneficiado este sector gracias a las últimas modificaciones arancelarias, realizadas a fines del 2006, que redujeron a $0 \%$ el pago de aranceles para los fertilizantes. (Misti Fertilizantes , 2010)

Otro proveedor importante para las empresas agrícolas son los que ofrecen las soluciones o herramientas para el riego de los cultivos. Las granadas requieren el sistema de riego por goteo, se estima que en el Perú 90,000 ha hacen uso de esta técnica. En la costa, el $87 \%$ de tierras cuenta con riego; mientras que en sierra solamente el $30 \%$. De la superficie agrícola bajo riego y con cultivos, predomina el riego por gravedad (el menos tecnificado) con 88\%. (Ministerio de Agricultura y Riego , 2013) Una de las principales limitaciones para la adopción de riego tecnificado es su alto costo relativo a los costos de producción agropecuarios promedio nacionales y el limitado acceso a servicios financieros de los agricultores. (Libélula, 2011) Motivo por el cual entre las principales prioridades del MINAGRI destaca la inversión en riego.

Los sectores conexos y auxiliares importantes para nosotros en el proceso de la exportación son los proveedores de empaques y los servicios logísticos disponibles. El empaque que se utiliza para vender la granada son cajas de cartón o materiales similares que soporten aproximadamente 3.8 kilos. Al no ser un producto tan difícil de realizar, existe una gran gama proveedores locales de cartones. Debemos escoger al más eficiente y el que tenga la mejor calidad, debido que esta es la forma en que llegará el producto a los clientes. Por ejemplo conocemos a empresas como CARVIMSA que es la principal proveedora de cajas de agro exportación, por lo que sería más fácil trabajar 
con ellos porque ya conocen el sector. Asimismo es importante considerar los pallets para el adecuado transporte del producto porque deberá soportar la larga travesía hacia el Reino Unido.

En lo que respecta a los servicios logísticos cada vez hay más líneas navieras que ofrecen transporte a diferentes mercados de destino, al Reino Unido va CSAV, Maersk entre otras, se busca la que ofrezca los mejores precios y tenga el menor tiempo de tránsito, debido a que muchas veces el cliente solicita la mercancía con urgencia. Al ser una empresa nueva también se podría optar por contratar a un operador logístico, el cual se encarga de toda la cadena: almacenaje, distribución, manipulación, carga completa y carga fraccionada, uno de los principales en el Perú es Kuehne + Nagel que se encuentra a nivel mundial.

En el caso de la granada se puede exportar por vía marítima o vía aérea, se debe hacer un análisis costo beneficio porque depende de varios factores como los costos y si se requiere de su disponibilidad inmediata. Para el transporte interno que debemos cubrir, Ica-Callao si se cuenta con varias opciones de transportistas, pero se debe elegir al más confiable y que sea cumplido, porque en este sector hay muchos informales. También se debe de tratar de negociar, para conseguir mejores precios, pero siempre a mayor volumen se pueden conseguir reducir los costos. La nueva empresa al comienzo no tendrá mucho poder de negociación por los menores volúmenes que manejará, pero a medida que vaya creciendo se podrá obtener mejores tarifas.

\subsubsection{Estrategia, estructura y rivalidad de la empresa}

Se refiere a las condiciones vigentes en la nación respecto a cómo se crean, organizan, y gestionan las compañías, así como la naturaleza de la rivalidad doméstica. Las pautas de la rivalidad interior también desempeñan un profundo papel en el proceso de innovación y en las perspectivas de éxito internacional que se ofrezcan. (Porter, 1991) Las principales empresas productoras de granadas exportan casi toda su oferta al mercado exterior, porque como ya mencionamos anteriormente, la demanda local del 
producto es muy reducida. En la tabla $n^{\circ} 9$ podemos ver las principales empresas exportadoras.

Tabla 9 Principales Empresas Exportadoras Peruanas de Granadas

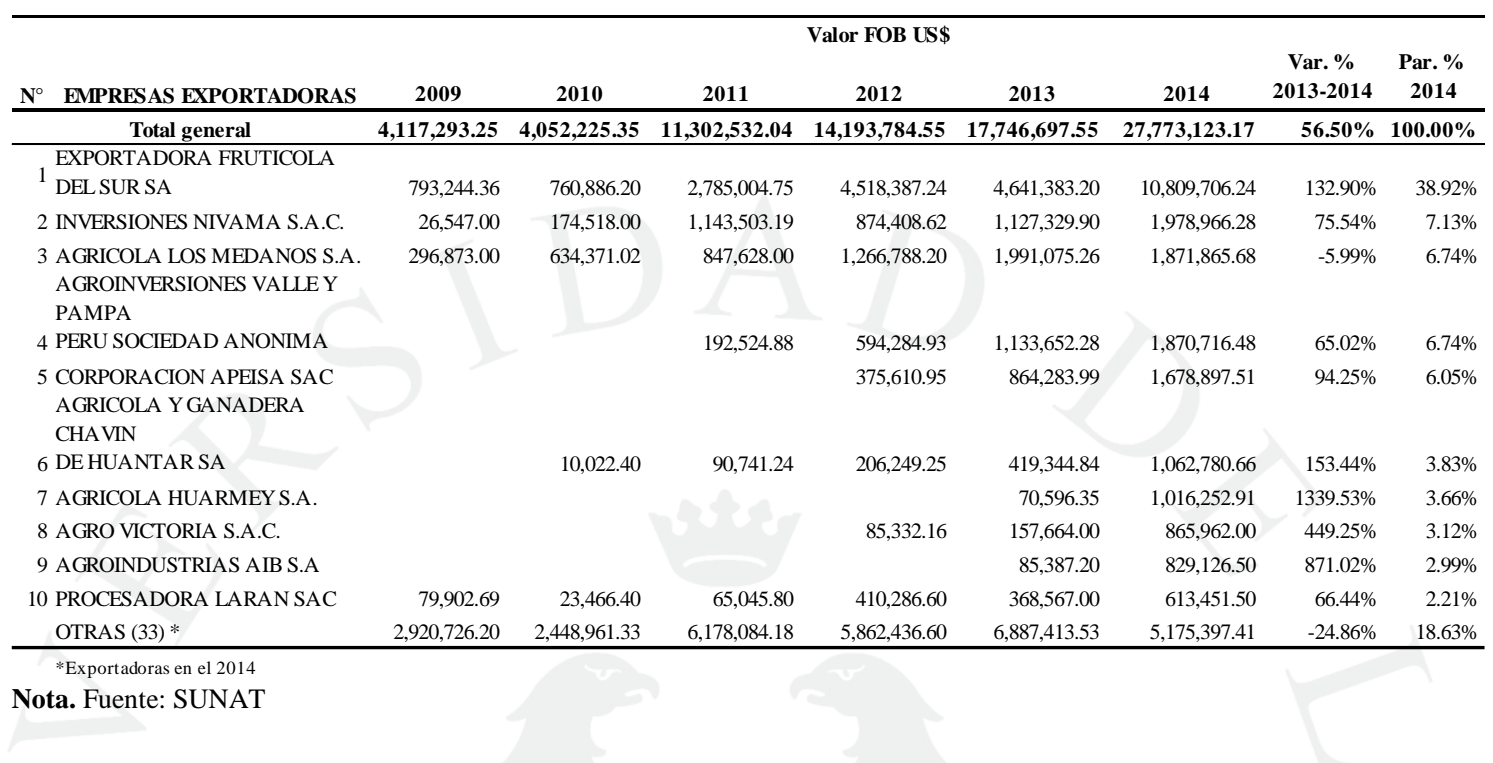

De acuerdo a información extraída de SUNAT en el 2014 el número de empresas exportadoras fue 39, considerando las empresas que sumaban envíos hasta más de 1,000 dólares, una gran diferencia al 2009 cuando existían únicamente 7 empresas exportadoras. Con el transcurso de los años podemos ver como el cultivo de granadas ha ido tomado importancia.

La principal empresa exportadora, es Exportadora Frutícola del Sur perteneciente al Grupo Athos y tiene sus cultivos en Nazca e Ica. Cuenta con certificaciones internacionales de buenas prácticas agrícolas y de manufactura, como las siguientes: BRC Global Standard for Food Safety, SA 8000:2001, BASC, LEAF, Global GAP, Tesco Natural Choice, SMETA y Fundo Verde (SENASA - Perú). (Corporación Interamericana de Inversiones , 2013) Tanto para sus campos como para sus plantas de empaque esta última es la región que concentra la mayor parte de producción nacional de granadas con $80 \%$ de participación.

Por otro lado si analizamos el año 2013 lidera el ranking de empresas, Agrícola Athos con una trayectoria de 25 años y actualmente está canalizando sus exportaciones del fruto a través de Exportadora Frutícola del Sur. La variedad que cultiva es una californiana de características más resistentes para largos viajes lo que le permite 
exportar a diferentes países del mundo. (AMPEX, 2006) La empresa exporta sus productos a Estados Unidos, Europa y Asia. Para mejorar su competitividad solicitó a la Corporación interamericana de Inversiones un préstamo de US\$2 millones y así incentivar el crecimiento de su actividad agrícola.

En el segundo puesto ya con bastante diferencia de valor de exportación se encuentra la empresa Inversiones Nivama, con US\$ 1.978 millones. Actualmente La disponibilidad y capacidad de las empresas para competir a escala mundial es parcialmente función de otros determinantes en este caso no es por la presión derivada de la saturación del mercado local o de la rivalidad local sino por la generación de demanda internacional. (Porter, 1991)

Bajo este contexto debemos de tomar en consideración también la competencia internacional, debido a que en el mercado de destino no solamente se estará compitiendo con empresas peruanas sino también extranjeras. Hemos identificado como principal competidor en el Reino Unido a España por encontrarse en primer lugar como proveedor de este mercado en los años 2013 y 2014.

El segundo proveedor es Egipto, sus exportaciones hacia el Reino Unido crecieron 23\% en el 2014. En los meses de Febrero a Junio meses en que España, principal abastecedor del mercado Europeo, deja de exportar es justamente cuando países como Perú y Egipto compiten directamente por el mercado europeo. (AMPEX, 2006) Por otro lado otro mercado importante, pero que ha disminuido sus exportaciones en volumen considerablemente es Holanda. Este último no es un país productor, sino que este importa de los principales productores y luego re-exporta a los diferentes mercados extranjeros que demandan esta fruta.

La principal variedad exportada por España es la de Mollar delche, ha aumentado, con respecto al 2013, un 13,64 \% una vez concluida recientemente la campaña 2013-2014. De las 44.000 toneladas del año 2013, donde ya había crecido un 10 por ciento, en el 2014 logró una producción de 50,000 toneladas. Alrededor del 40 por ciento de la producción, unas 20.000 toneladas, se están destinando al mercado nacional y el 60 por ciento restante de la producción se encara a la exportación, entre los principales mercados destaca Rusia que en los últimos años ha sido uno de los principales países 
compradores de granada junto a Alemania, Reino Unido, Francia y los Países Bajos. (GranaVida, 2014)

En este sentido España tiene una ventaja sobre nosotros debido que si cuenta con una demanda doméstica del producto, por lo que los consumidores locales pueden ejercer presión para que se dé más innovación, inclusive de las 20,000 toneladas, 5,000 se dirigen a la industria del zumo. En lo que respecta a sus exportaciones, la mayor parte va dirigida a la Unión Europea y se benefician por la cercanía de los mercados por lo cual incurre en menores costos logísticos. Está diversificándose hacia mercados emergentes, el Perú también está haciendo lo mismo poco a poco por ejemplo ingresando a mercados como Emiratos Árabes y Arabia Saudita.

\subsubsection{El papel del gobierno}

El auténtico papel del gobierno en la ventaja competitiva nacional es el de influir en los cuatro determinantes, puede hacerlo positiva o negativamente.

"Las condiciones de los factores se ven afectadas por las subvenciones, la política respecto a los mercados de capital, la política educativa y otras intervenciones por el estilo." (Porter, 1991) También puede afectar a los sectores conexos imponiendo regulaciones a esas empresas respecto a su producción o condiciones de venta.

Para este estudio es relevante analizar la intervención gubernamental en la política comercial del país. El Perú tiene una política de libre mercado por lo que busca fomentar el comercio exterior. No cobra impuestos a las exportaciones, y las fomenta a través del drawback, el cual permite obtener la restitución total o parcial de los derechos arancelarios, que hayan gravado la importación para el consumo de las mercancías contenidas en los bienes exportados o consumidos durante su producción. (SIICEX, 2012)

Hasta el 2013 la tasa del drawback se situaba en 5\% del valor FOB del bien exportado, pero por Decreto Supremo 314-2014 rebajó la misma 4\% a partir del 1 de Enero de 2015 y a 3\% desde el 1 de Enero de 2016. El Ministerio de Economía y Finanzas tomó esta decisión porque considera que se trata de un subsidio a los exportadores, debido a 
que los montos que se restituyen son mayores a los aranceles que se pagaron al momento de la importación de los insumos. (El Comercio, 2014) En el contexto actual es importante considerar este factor y probablemente sea mejor no considerar el drawback como un ingreso adicional porque con los últimos hechos se demuestra que el objetivo a mediano plazo es desaparecer este mecanismo.

Por otro lado uno de los lanzamientos más importantes del gobierno en el 2014 fue el Plan Nacional de diversificación Productiva el cual busca generar nuevos motores de crecimiento económico que lleven a la diversificación y la sofisticación económica, la reducción de la dependencia a los precios de materias primas, la mejora de la productividad, el aumento del empleo formal y de calidad, y un crecimiento económico sostenible de largo plazo. El gobierno ha intervenido porque es importante que el país se fortalezca y sea menos vulnerable a cambios en el contexto externo.

Tiene los siguientes objetivos específicos:

- Lograr tasas de alto crecimiento económico que sean sostenibles en el largo plazo

- Acentuar la transformación productiva necesaria para transitar hacia el nivel de ingresos medios-altos y reducir la dependencia de la economía peruana por los recursos naturales

- Reducir las brechas regionales de productividad

- Aumentar el empleo formal y de calidad, al reducir la informalidad (Ministerio de Producción, 2014)

Los tres ejes estratégicos son: a) promoción de la diversificación productiva; b) adecuación de regulaciones y simplificación administrativa, y c) expansión de la productividad. El primer eje es muy importante porque a través del mismo se promoverá la innovación y emprendimiento, esencial para una empresa como la nuestra que busca desarrollar más adelante productos con valor agregado. Asimismo el segundo eje busca incrementar la rentabilidad de las empresas y disminuir la carga de trámites, lo cual ayudará a que más empresas permanezcan y no se desanimen por la excesiva burocracia del estado peruano. En esta línea de trabajo el Ministerio de Producción ha instaurado mesas de trabajo conformadas por los sectores público y privado. 
Sumado a esto, otra iniciativa notable del gobierno ha sido la creación del Plan Estratégico Nacional Exportador el cual ha sido actualizado hacia el 2025, este busca el desarrollo de una oferta exportable diversificada y el posicionamiento de las exportaciones peruanas en mercado internacional, sobre todo para crecer en las exportaciones no tradicionales. Este plan es específico hacia nuestro ámbito por lo que se debe estar al tanto de sus líneas de acción y programas.

Durante los últimos años el Perú ha realizado una buena labor en identificar los mercados más importantes para así firmar acuerdos comerciales con los mismos, que entre muchos beneficios el más importante es la desgravación arancelaria. Actualmente el país tiene 14 acuerdos comerciales en vigencia, dos por entrar en vigencia y 6 en negociación.

El Perú no cuenta con un tratado de libre comercio con el Reino Unido, pero si con la Unión Europea el cual ha entrado en vigencia a partir del 2013. Este es un ejemplo positivo del papel que el gobierno puede adoptar en un país, por lo que debe seguir fomentando el comercio y apoyando a las industrias sin imponer trabas. Se debe realizar un trabajo conjunto entre las empresas privadas y el gobierno, siempre realizando acciones transparentes que no creen suspicacias.

\subsection{Hipótesis General}

A manera de responder la pregunta “¿Es posible hacer un plan de negocios para la exportación de granada fresca hacia el Reino Unido, que logre posicionarnos como uno de los principales proveedores del mercado, genere utilidades y convierta al departamento de Ica como una de las principales regiones de producción de granada?"

Se ha planteado la siguiente hipótesis: Un plan de negocios es viable para facilitar la exportación de granadas frescas al Reino Unido, debido a que este mercado aún tiene una gran demanda potencial por estas y se preocupa constantemente por el consumo de alimentos saludables. 
La variable independiente a considerar es la viabilidad de la implementación del plan de negocios en el Reino Unido.

La variable dependiente es la exportación de las granadas frescas. Debido a que si no se determina la viabilidad del plan, este no se implementará y no se exportarán las granadas frescas.

\subsubsection{Hipótesis especificas}

1. La disminución de cantidades importadas de granadas frescas por el Reino Unido provenientes de la Unión Europea, aumentará las cantidades exportadas por Perú a ese mercado.

2. La creación de una estrategia de promoción más agresiva en el mercado de destino aumentará las ventas de granadas frescas.

3. La investigación de mercado del Reino Unido nos ayudará a identificar nuevos canales de distribución, preferencias del consumidor y los productos a base de granada demandados por el mercado.

4. Los mayores volúmenes de exportación y los precios atractivos en el mercado de destino generará utilidades.

\section{CAPÍTULO III: PLAN DE NEGOCIOS}

\subsection{Información General del proyecto}




\subsubsection{Datos generales de la empresa}

\section{Nombre}

El producto a exportar es la granada fresca también conocida en inglés como pomegranate al mercado del Reino Unido. Su nombre científico es púnicagranatum y el comercial, granada. Esta es una fruta que se caracteriza por su gran poder antioxidante y sus variados usos.

Partida Arancelaria: 0810909000

Descripción Arancelaria: LOS DEMAS FRUTAS U OTROS FRUTOS FRESCOS

Descripción Comercial: Granadas Frescas

\section{Ubicación del proyecto}

Las actividades relacionadas al negocio, como lo son el acopio, producción y comercialización se realizarán en los siguientes lugares:

- Acopio: Se realizará en la ciudad de Ica, ubicada en el sur de país y se encuentra a 306 kilómetros de la ciudad de lima. En la figura podemos apreciar la evolución de la exportación de la Granada proveniente de la región Ica la cual ha alcanzado en el 2014 sus volúmenes de exportación más altos desde el 2008. En general la tendencia ha sido de crecimiento en el período evaluado en la figura $n^{\circ} 15$.

- Producción: Se realizará en la ciudad de Ica, donde se hará toda la preparación previa a la exportación. La limpieza, calibraje y pulido de la fruta para que luego sea empacada y embalada adecuadamente.

- Comercialización: Las oficinas de la empresa estarán ubicadas en Ica, así como las instalaciones donde se almacenará y preparará la fruta acopiada para su exportación. Debido a que los costos de alquiler son menores en esta ciudad, y se generarán también menores costos de desplazamiento de la materia prima.

Figura 15 Evolución de la exportación de Granada en la Región Ica 2008-2014 (kg) 


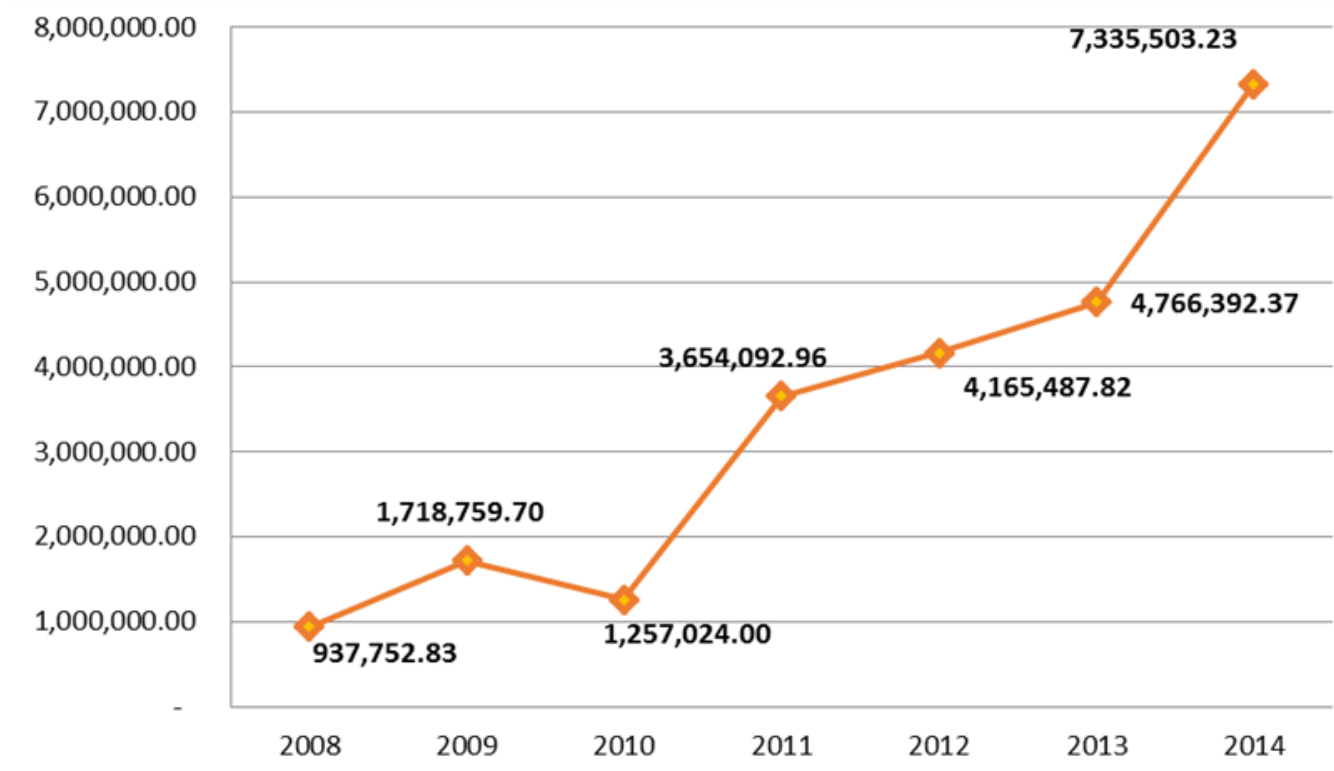

Fuente: Adex Data Trade

\section{Unidad Ejecutora del Proyecto}

La ejecución del proyecto será realizada por la empresa "Pome Perú" la cual cuenta con un accionista principal, Carla Rubio y su socio Alejandro Rubio.

\section{Unidad Formuladora del Proyecto}

Carla Rubio, alumna de la Universidad de Lima - actualmente cursando el 10mo ciclo de la carrera negocios internacionales será la persona responsable de la Unidad formuladora del Proyecto.

\subsubsection{Identificación de la oportunidad de negocio.}

La granada es considerada una de las nuevas estrellas dentro de las exportaciones peruanas debido a que cada vez está teniendo más aceptación en los distintos mercados en donde se comercializa. El sub director de inteligencia y prospectiva comercial de Prom-Perú, Mario Ocharán, informó que las ventas de este producto pasaron de US\$ 1,1 millones en el 2007 a US\$ 11,6 millones en el 2011, crecieron en aproximadamente $900 \%$ en tan solo 4 años.

Las personas cada vez demandan más la fruta por sus características y grandes poderes antioxidantes que ayudan a prevenir enfermedades.

La consultora Maximixe indicó que la producción nacional de granada alcanzaría las 9,418.1 toneladas métricas TM al cierre del 2014, lo que implica un crecimiento 
interanual de $41 \%$. Esto se debería al incremento en el rendimiento de cultivos y el aumento de la superficie sembrada con fines de exportación, principalmente en la región Ica, Lima y Arequipa. (Gestión, 2014)

Ica se ha convertido en la principal región productora de este cultivo, por producción y superficie cosechada, cerrando el 2013 con una producción de 5,351 toneladas y 595 hectáreas de acuerdo a la información proporcionada por el Ministerio de Agricultura y Riego. Desde el 2008 hasta el 2013 la producción ha crecido en 1245\% y el crecimiento de las exportaciones ha generado que se amplíen las áreas de cultivo. La aceptación del producto en mercados del exterior ya ha sido identificada y para no saturar el mercado también es importante ir planeando para diversificar la exportación del fruto mediante distintas presentaciones.

Además Maximixe informó que las expectativas de crecimiento de las exportaciones de granada se basan en la creciente demanda por las "súper frutas" (denominación para aquellas frutas que poseen características más allá de los nutrientes básicos) y la tendencia hacia el consumo de productos elaborados a base de ingredientes naturales.

Tabla 10 Crecimiento de las exportaciones de granadas peruanas a los principales mercados 2009-2014

\begin{tabular}{|c|c|c|c|c|c|c|c|}
\hline \multirow[b]{2}{*}{$\mathbf{N}^{\circ}$} & \multirow{2}{*}{$\begin{array}{c}\text { Mercados de } \\
\text { Exportación }\end{array}$} & \multicolumn{6}{|c|}{ Valor FOB US\$ } \\
\hline & & 2009 & 2010 & 2011 & 2012 & 2013 & 2014 \\
\hline & Total General & $4,117,293.25$ & $4,052,225.35$ & $11,302,532.04$ & $14,193,784.55$ & $17,746,697.55$ & $27,773,123.17$ \\
\hline \multirow{3}{*}{1} & Crecim. \% & & $-2 \%$ & $179 \%$ & $26 \%$ & $25 \%$ & $56 \%$ \\
\hline & PAISES BAJOS & $876,445.87$ & $1,441,808.39$ & $4,051,786.02$ & $3,508,845.15$ & $6,395,734.25$ & $10,772,517.56$ \\
\hline & Crecim. \% & & $65 \%$ & $181 \%$ & $-13 \%$ & $82 \%$ & $68 \%$ \\
\hline \multirow{2}{*}{2} & RUSIA & $419,109.40$ & $778,021.40$ & $2,742,726.48$ & $3,371,221.65$ & $4,501,738.21$ & $6,539,822.56$ \\
\hline & Crecim. \% & & $86 \%$ & $253 \%$ & $23 \%$ & $34 \%$ & $45 \%$ \\
\hline \multirow{2}{*}{3} & ESTADOS UNIDOS & $306,725.60$ & $634,389.02$ & $1,012,915.91$ & $1,456,253.24$ & $2,316,905.79$ & $2,664,003.61$ \\
\hline & Crecim. \% & & $107 \%$ & $60 \%$ & $44 \%$ & $59 \%$ & $15 \%$ \\
\hline \multirow{2}{*}{4} & REINO UNIDO & $674,682.36$ & $276,499.14$ & $1,617,544.44$ & $1,805,101.42$ & $1,471,307.86$ & $2,395,817.58$ \\
\hline & Crecim. \% & & $-59 \%$ & $485 \%$ & $12 \%$ & $-18 \%$ & $63 \%$ \\
\hline \multirow{2}{*}{5} & CANADA & $280,812.02$ & $289,302.78$ & $577,308.27$ & $1,073,982.29$ & $1,107,114.46$ & $2,142,161.65$ \\
\hline & Crecim. \% & & $3 \%$ & $100 \%$ & $86 \%$ & $3 \%$ & $93 \%$ \\
\hline
\end{tabular}

Nota. Fuente: SUNAT

Durante el 2014 las exportaciones de granadas crecieron 56\% respecto al 2013, alcanzando casi los US\$ 28 millones. Desde el 2009 hasta el 2014 las exportaciones totales han incrementado 575\%. El mercado elegido es el Reino Unido porque se encuentra entre los principales 5 destinos de exportación y en los últimos 5 años ha 
crecido en promedio 29\%, la principal presentación exportada a este mercado es fresca. Pome Perú SAC exportará las granadas en presentación fresca. Asimismo como se había mencionado anteriormente de acuerdo a información de Euromonitor se espera que el consumo de frutas en el Reino Unido se recupere por el crecimiento del poder adquisitivo del consumidor y su disposición a pagar más sobretodo por las súper frutas. Se prevé que al cierre del 2016 las exportaciones de Granada lleguen a US\$ 45 millones anuales.

\subsubsection{Propiedades Beneficiosas de la Granada}

La granada, fruta proveniente de los países del Este y de Oriente, con el transcurso de los años está siendo cada vez más reconocida por las cualidades que posee y los efectos positivos que tiene sobre la salud.

Ésta es una característica muy importante debido que al mercado al cual nos dirigimos, está apoyado en las nuevas tendencias de alimentación saludable y productos naturales que permitan mejorar la calidad de vida de las personas.

Dentro de sus propiedades nutricionales, las granadas contienen:

- Vitaminas: C y Provitamina A,

- Minerales: Potasio, Calcio y Magnesio

- Otros como: Ácido Cítrico, Ácido Málico, Ácido Oxálico, Antioxidantes. Flavoides. Taninos.

Cabe destacar que la granada es una fruta con un gran poder antioxidante que retarda el envejecimiento, lo cual es muy importante, porque cada vez más las personas están preocupadas por su apariencia. Se deben dar a conocer las propiedades de la fruta, porque eso permite que sea más reconocida por sus beneficios.

Algunas de las enfermedades que previene y ayuda a curar son:

- Problemas cardiovasculares y degenerativos

- Colesterol.

- Problemas de tránsito intestinal, estreñimiento (gran poder laxante)

- Hipertensión 
- Ácido Úrico: lo expulsa.

- Anemia

- Diarreas y Flatulencias

Investigadores en Oxford han analizado los ensayos clínicos por más de un año y los resultados han reavivado el interés por el efecto de súper frutas - especialmente las granadas. Los últimos estudios muestran un impacto prometedor en el manejo del índice glucémico del cuerpo - un tema clave en la diabetes tipo 2. La diabetes tipo 2 afecta a más de tres millones de británicos y se prevé un aumento de cinco millones en 2025. También hay un vínculo entre la granada y una ralentización en la propagación de los cánceres de próstata y el intestino. (Maynard, 2015)

Otros beneficios que nos provee son: Antiinflamatorio y antiséptico, refuerza el sistema inmunológico, frena los procesos de envejecimiento, previene ciertos tipos de cáncer, aumenta las defensas del organismo y defiende de los virus etc. Las Granadas Wonderful ofrecen una serie de importantes nutrientes como la vitamina $\mathrm{K}$, potasio $\mathrm{y}$ una variedad de polifenoles de la granada, por lo que forman parte importante de una dieta sana y equilibrada. (POM Wonderful, 2015)

Podríamos seguir nombrando más cosas positivas respecto a ella, pero estas son las principales y por las cuales en los últimos años ha salido a relucir como una fruta con gran potencial de crecimiento y es una de las protagonistas de las exportaciones agroindustriales. Una súper fruta no promete ser la cura de todo, pero sí provee propiedades beneficiosas para la salud.

En la siguiente tabla podemos observar los valores nutricionales correspondientes a la granada:

Tabla 11 Data Nutricional Granadas Frescas (Variedad Wonderful) 


\begin{tabular}{|c|c|c|}
\hline Nutrientes & Unidad: 1 & Valor por $100 \mathrm{~g}$ \\
\hline \multicolumn{3}{|l|}{ Aproximados } \\
\hline Agua & $\mathrm{g}$ & 77.93 \\
\hline Energía & kcal & 83 \\
\hline Proteína & $\mathrm{g}$ & 1.67 \\
\hline Lípidos totales (grasa) & $\mathrm{g}$ & 1.17 \\
\hline Carbohidratos, por diferencia & $\mathrm{g}$ & 18.7 \\
\hline Fibra, dietética total & $\mathrm{g}$ & 4 \\
\hline Azúcares, total & $\mathrm{g}$ & 13.67 \\
\hline \multicolumn{3}{|l|}{ Minerales } \\
\hline Calcio, $\mathrm{Ca}$ & $\mathrm{mg}$ & 10 \\
\hline Fierro, $\mathrm{Fe}$ & $\mathrm{mg}$ & 0.3 \\
\hline Magnesio, Mg & $\mathrm{mg}$ & 12 \\
\hline Fosforo, $\mathrm{P}$ & $\mathrm{mg}$ & 36 \\
\hline Potasio, $\mathrm{K}$ & $\mathrm{mg}$ & 236 \\
\hline Sodio, $\mathrm{Na}$ & $\mathrm{mg}$ & 3 \\
\hline Zinc, Zn & $\mathrm{mg}$ & 0.35 \\
\hline \multicolumn{3}{|l|}{ Vitaminas } \\
\hline Vitamina C, ácido ascórbico total & $\mathrm{mg}$ & 10.2 \\
\hline Tiamina & $\mathrm{mg}$ & 0.067 \\
\hline Riboflavina & $\mathrm{mg}$ & 0.053 \\
\hline Niacina & $\mathrm{mg}$ & 0.293 \\
\hline Vitamina B-6 & $\mathrm{mg}$ & 0.075 \\
\hline Folato, DFE & $\mu g$ & 38 \\
\hline Vitamina B-12 & $\mu \mathrm{g}$ & 0 \\
\hline Vitamina A, RAE & $\mu g$ & 0 \\
\hline Vitamina A, IU & IU & 0 \\
\hline Vitamina E (alpha-tocoferol) & $\mathrm{mg}$ & 0.6 \\
\hline Vitamina D (D2+D3) & $\mu g$ & 0 \\
\hline Vitamina D & IU & 0 \\
\hline Vitamina K (filoquinona) & $\mu g$ & 16.4 \\
\hline \multicolumn{3}{|l|}{ Lípidos } \\
\hline Ácidos grasos, saturados totales & $\mathrm{g}$ & 0.12 \\
\hline Ácidos grasos, monoinsaturados & $\epsilon \mathrm{g}$ & 0.093 \\
\hline Ácidos grasos, poliinsaturados t & $\mathrm{g}$ & 0.079 \\
\hline Colesterol & $\mathrm{mg}$ & 0 \\
\hline Otro & & \\
\hline Cafeína & $\mathrm{mg}$ & 0 \\
\hline
\end{tabular}

*Basado en muestras de variedad Wonderful/California

Nota. Fuente: USDA National Nutrient Database for Standard Reference 27 Software v.2.2.6

\subsubsection{Objetivos del plan de negocios}




\section{a) Objetivos de Marketing}

- Obtener una participación del mercado de Reino Unido de $0.28 \%$ para el primer año, en el segundo $0.55 \%$, tercero $0.96 \%$, cuarto $1.35 \%$ y en el quinto año 1.61\%. A partir del tercer año se apunta a una participación del 1\%, cuando ya seamos más conocidos.

- La política de precios que se planea adoptar estará basada en los precios de la competencia internacional.

- Comenzar exportando a grandes distribuidores que nos ayuden a ingresar a cadenas de supermercados más adelante, vendiéndoles directamente, para así aumentar el margen de ganancia.

- Posicionarnos como proveedores que cumplen con sus tiempos y con las condiciones estipuladas en el contrato.

- Aliarnos con otros productores de Granadas para crear campañas de educación sobre las bondades y valores nutricionales de la fruta.

\section{b) Objetivos de Operaciones}

- Contar con al menos 2 proveedores en la zona de Ica

- En el futuro buscar diversificar nuestra zona de acopio a Lima, donde también se cultiva el fruto.

- Identificar a los proveedores de las principales empresas exportadoras de granada.

- Exportar 2 contenedores durante el primer año, 4 en el segundo, 7 en el tercer, 10 en el cuarto y finalmente 12 en el quinto año.

- Asegurar ausencia de grietas de crecimiento, cortes, magulladuras y pudrición.

- Garantizar un empaque adecuado a las características del producto.

\section{c) Objetivos Económicos y Financieros}

- Lograr un período de recuperación de la inversión no mayor a dos años.

- Obtener una tasa interna de retorno (TIR) mayor a $25 \%$ durante los 5 años operaciones. 
- Obtener un margen de ganancia no menor a $25 \%$ durante el primer año de operaciones.

- Financiamiento de inversiones a través de una deuda de 4 años.

\subsubsection{Estrategia del Proyecto}

Para nuestro proyecto adoptaremos una estrategia de enfoque, debido a que nos focalizaremos en obtener mayores márgenes de ganancia durante los meses que el mercado se encuentra desabastecido.

Lo que se va a buscar es posicionar a la granada frente otras frutas que actualmente se exportan del Perú en grandes cantidades como lo son: los mangos, uvas, paltas.

Se debe explotar y ampliar la oferta para abastecer mejor al segmento de personas que buscan consumir alimentos saludables.

La súper fruta GRANADA está clasificada entre los súper alimentos de los últimos tiempos debido a sus propiedades, lo que se busca desarrollar es la moda de consumo de esta fruta por sus altos valores nutritivos y antioxidantes. En Estados Unidos periódicos y revistas como “Time y Vogue” y el "American Journal of Clinical Nutrition" han dado a conocer los excelentes beneficios de la granada en la salud y su gran poder antioxidante. Por eso es que se le llama una "Súper fruta". No solo se cuenta con la granada en fresco, sino que se está desarrollando muchos productos nuevos a partir de ella, como jugos y vinos de acuerdo a información obtenida del portal Vida nutrida. En el mercado de bebidas, la granada que está justo en la parte superior de la categoría súper frutas, es realmente muy estable y se ha establecido muy bien casi convertido en un sabor convencional. (ProQuest, 2012)

Es importante considerar también la estacionalidad de la fruta. Hay cinco meses al año de disponibilidad de este fruto desde Febrero hasta Junio (ver figura $\mathrm{n}^{\circ} 16$ ). Se debe de aprovechar sobre todo los meses de marzo y abril cuando otros proveedores de la fruta no cuentan con ella. En estos meses el objetivo debe ser obtener mayores márgenes de ganancia. Se aprovecha una ventana comercial, porque España el mayor exportador para Europa deja de exportar en el periodo en que se inician las exportaciones peruanas. (AMPEX, 2006) España también es el mayor exportador de la partida Otros frutos frescos al Reino Unido, nuestro mercado de destino. Asimismo las granadas peruanas 
tienen una ventaja comparativa en las exportaciones marítimas con respecto a los exportadores de la India, pues la variedad actual que se exporta desde Ica es más resistente permitiéndoles llegar en mejores condiciones con el producto por vía marítima. (AMPEX, 2006)

Figura 16 Estacionalidad de los principales países exportadores de granadas frescas

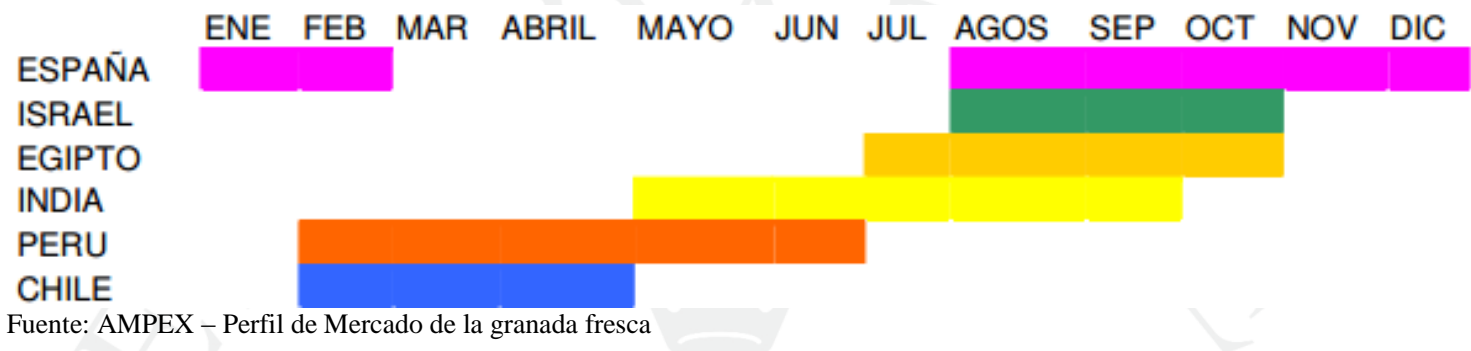

\subsection{Estudio de Mercado}

\subsubsection{Análisis de la demanda}

\subsubsection{Definición del producto}

El bien a ser exportado es la granada, una fruta que en el Perú aún no forma parte de la dieta diaria, pero que en el mundo desde hace muchos años viene tomando más importancia.

La Granada consta de un árbol de $(6$ o $10 \mathrm{~m})$ de alto, sus ramas son algo espinosas, y extremadamente duraderas. Las flores son muy llamativas, la fruta, $21 / 2$ a 5 adentro (6.25-12.5centímetros) de par en par, tiene una piel resistente, coriácea o la corteza, amarillea básicamente más o menos ovalada con rojo ligero o de color rosa oscuro o rico.

El interior se encuentra separado por las paredes membranosas y el tejido fino esponjoso blanco, tienen compartimientos embalados con sacos transparentes llenos de pulpa agria, sabrosa, carnuda, jugosa, roja, rosada o blanquecina, técnicamente se le conoce a este relleno como el aril, que es la semilla de la fruta y el cual podemos observar en la figura 17. En cada saco hay una semilla, las cuales representan cerca de $52 \%$ del peso de la fruta entera. (Fundación Chile, 2009) 
Figura 17 La Granada

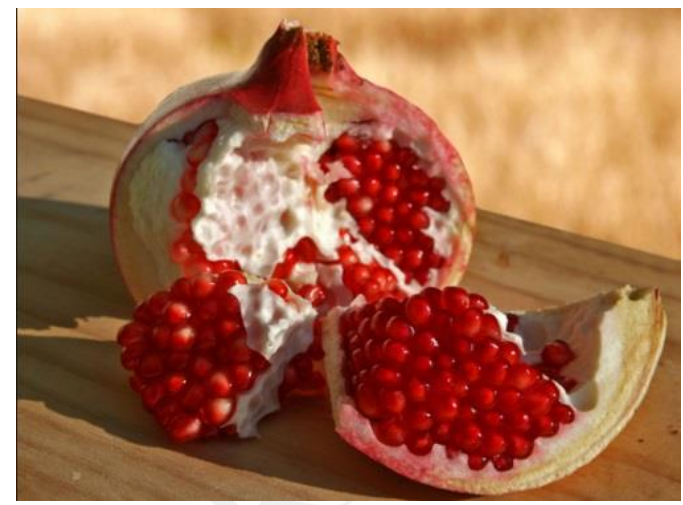

Fuente: PomWonderful

La variedad que exportaremos es la wonderful, que es una de las más explotadas comercialmente, la presentación será en fresco.

- Wonderful: Es la variedad norteamericana de uso universal que se explota comercialmente, va color rosado a rojo intenso en la cáscara y los arilos.Las semillas son pequeñas y medianamente duras, relativamente ácidas. La planta es vigorosa y productiva y los frutos maduran tarde en la temporada (entre marzo y abril). Es la más cultivada en California e Israel. Se cosecha durante un mes y medio

\section{Figura 18 Partes de la Granada}

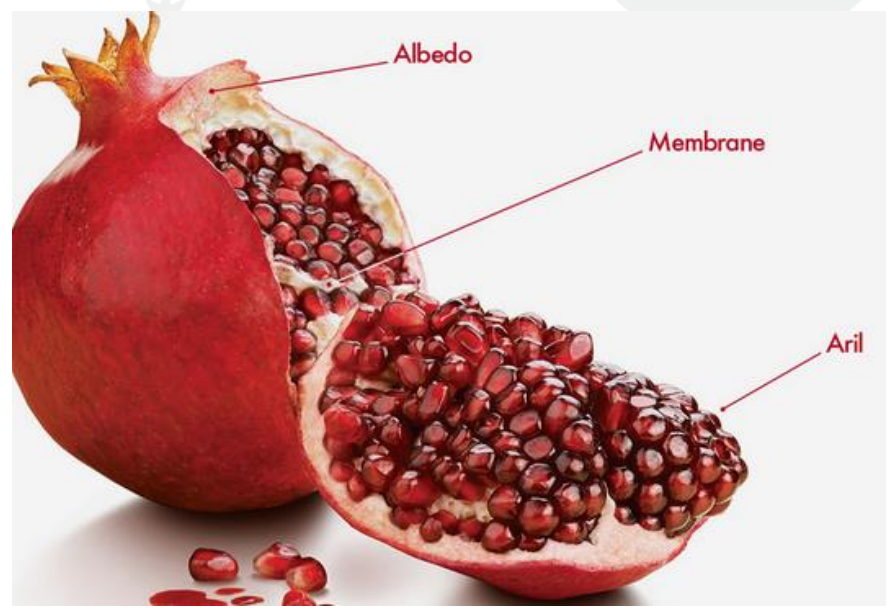

Fuente: PomWonderful

A continuación se detallan las partes de la granada: 
- Arilo (aril): Es el término botánico para una semilla rodeada por un saco de jugo. A diferencia de otras variedades, los arilos de la variedad Wonderful son de un brillante color rojo rubí, con indicación del dulce, jugo saludable que contiene.

- Albedo: Es la sustancia blanca y carnosa que se encuentra directamente bajo la piel de una granada.

- Membrana (membrane): El material amarillo translúcido que rodea los arilos de granada. La membrana es amarga y no se recomienda para el consumo.

- Cáscara (rind): La cáscara exterior o cáscara de una granada. Gran parte del contenido antioxidante del jugo viene de aplastar la fruta entera, la cáscara es donde se encontrará una mezcla única de fitonutrientes.

(POM Wonderful, 2015)

La granada tiene muchos usos, pero su verdadera esencia se encuentra en los arilos (semillas) en los cuales resaltan los valores nutricionales de la fruta. Gracias a sus altas concentraciones de antioxidantes es que se ha hecho muy conocida y demandada no solo en fresco sino también en jugos, tés, concentrados, cápsulas y muchos productos innovadores.

\subsubsection{Subpartida nacional}

\begin{tabular}{|l|l|l|}
\hline $\begin{array}{l}\text { Partida } \\
\text { Arancelaria }\end{array}$ & Descripción arancelaria & $\begin{array}{l}\text { Descripción } \\
\text { Comercial }\end{array}$ \\
\hline & $\begin{array}{l}\text { LOS DEMAS FRUTAS U } \\
\text { OTROS rRUTOS }\end{array}$ & \\
0810909000 & FRESCOS & Granadas Frescas \\
\hline
\end{tabular}

Las granadas pueden encontrarse dentro de dos partidas, la 0810901000 (Granadilla, maracuyá (parchita) y demás frutas de la pasión (Passifloraspp) y la 0810909000 (Los demás frutas u otros frutos frescos), la cual estaremos considerando para efectos de nuestra exportación. La razón por la cual se toma esta partida es porque según las 
estadísticas de exportación la mayor parte de granadas frescas se envían bajo esta denominación.

\subsubsection{Producción del producto en el Perú}

Tabla 12 Producción de Granadas a nivel Nacional 2012/2013

\begin{tabular}{lrrrrrrrr}
\hline \multirow{2}{*}{ Región/subregión } & \multicolumn{2}{c}{ Producción(t) } & \multicolumn{2}{c}{ Var.\% } & \multicolumn{2}{c}{ Par. \% } & Superficie (ha) & \multicolumn{2}{c}{ Var.\% } & \multicolumn{2}{c}{ Par. \% } \\
& $\mathbf{2 0 1 2}$ & $\mathbf{2 0 1 3}$ & $\mathbf{1 2 - 1 3}$ & $\mathbf{2 0 1 3}$ & $\mathbf{2 0 1 2}$ & $\mathbf{2 0 1 3}$ & $\mathbf{1 2 - 1 3}$ & $\mathbf{2 0 1 3}$ \\
\hline Nacional & $\mathbf{5 , 2 4 8}$ & $\mathbf{6 , 6 7 7}$ & $\mathbf{2 7 \%}$ & $\mathbf{1 0 0 \%}$ & $\mathbf{5 1 1}$ & $\mathbf{5 9 5}$ & $\mathbf{1 7 \%}$ & $\mathbf{1 0 0 \%}$ \\
\hline Ica & 4,171 & 5,351 & $28 \%$ & $80 \%$ & 372 & 426 & $14 \%$ & $72 \%$ \\
Lima & 523 & 759 & $45 \%$ & $11 \%$ & 42 & 72 & $71 \%$ & $12 \%$ \\
La Libertad & 366 & 369 & $1 \%$ & $6 \%$ & 59 & 64 & $9 \%$ & $11 \%$ \\
Lambayeque & 30 & 65 & $117 \%$ & $1 \%$ & 15 & 15 & $0 \%$ & $3 \%$ \\
Ancash & 53 & 55 & $4 \%$ & $1 \%$ & 6 & 6 & $0 \%$ & $1 \%$ \\
Tacna & 39 & 40 & $3 \%$ & $1 \%$ & 5 & 5 & $0 \%$ & $1 \%$ \\
Arequipa & 33 & 33 & $0 \%$ & $0 \%$ & 7 & 7 & $0 \%$ & $1 \%$ \\
Moquegua & 18 & 5 & $-70 \%$ & $0 \%$ & 3 & 1 & $-67 \%$ & $0 \%$ \\
Abancay & 8 & - & - & - & 1 & - & - & - \\
Apurímac & 8 & - & - & - & 1 & - & - & - \\
\hline
\end{tabular}

Nota. Fuente: Ministerio de Agricultura y Riego- Dirección de Estadística Agraria

Como se puede observar en la tabla superior, la producción de granadas se concentra en la región Ica, predomina con el $80 \%$ de participación de mercado, seguido por Lima que representa el $11 \%$ de la producción total. Asimismo Ica cuenta con la superficie más grande en hectáreas ( $72 \%$ del total de hectáreas de granadas) de igual forma Lima se encuentra segundo en los que respecta a hectáreas con $12 \%$ de participación. Como se mencionó anteriormente Pome Perú se abastecerá de la región Ica y en el futuro buscaremos también proveedores en la zona de Lima.

Tabla 13 Rendimiento Kg por Hectárea de granadas a nivel nacional 2012/2013

\begin{tabular}{lrrr}
\hline \multirow{2}{*}{ Región/subregión } & \multicolumn{2}{c}{ Rendimiento(kg/ha) } & \multicolumn{2}{c}{ Var.\% } \\
& $\mathbf{2 0 1 2}$ & $\mathbf{2 0 1 3}$ & $\mathbf{1 2 - 1 3}$ \\
\hline Nacional & $\mathbf{1 0 , 2 8 3}$ & $\mathbf{1 1 , 2 2 0}$ & $\mathbf{9 \%}$ \\
\hline Ica & 11,208 & 12,572 & $12 \%$ \\
Lima & 12,452 & 10,542 & $-15 \%$ \\
Ancash & 8,833 & 9,167 & $4 \%$ \\
Tacna & 7,800 & 8,000 & $3 \%$ \\
La Libertad & 6,256 & 5,816 & $-7 \%$ \\
Moquegua & 6,150 & 5,490 & $-11 \%$ \\
Arequipa & 4,657 & 4,657 & $0 \%$ \\
Lambayeque & 2,000 & 4,333 & $117 \%$ \\
Abancay & 7,500 & - & - \\
Apurímac & 7,500 & - & - \\
\hline
\end{tabular}


La principal región en términos de rendimiento kilogramos por hectárea es la región Ica, con un crecimiento de $12 \%$ en el 2013 respecto al 2012, motivo por el cual es probable que durante el 2014 también haya crecido y continúe incrementando durante el 2015 porque varias empresas están invirtiendo en cultivos en ese lugar. Cabe resaltar el rendimiento de Lambayeque, que a pesar que no sea una de las regiones con la mayor producción ha crecido y también ha incrementado en más de $100 \%$ su rendimiento. A futuro también se podría considerar este lugar como potencial proveedor en caso se saturen las otras regiones.

\subsubsection{Demanda histórica y presente}

A continuación en la tabla número 14 podemos observar los principales países exportadores al Reino Unido de la partida armonizada 081090 correspondiente a "Otros Frutos Frescos" y en la cual se encuentran las granadas.

Tabla 14 Exportación de otros Frutos frescos al Reino Unido entre el 2003 y 2012 (TN)

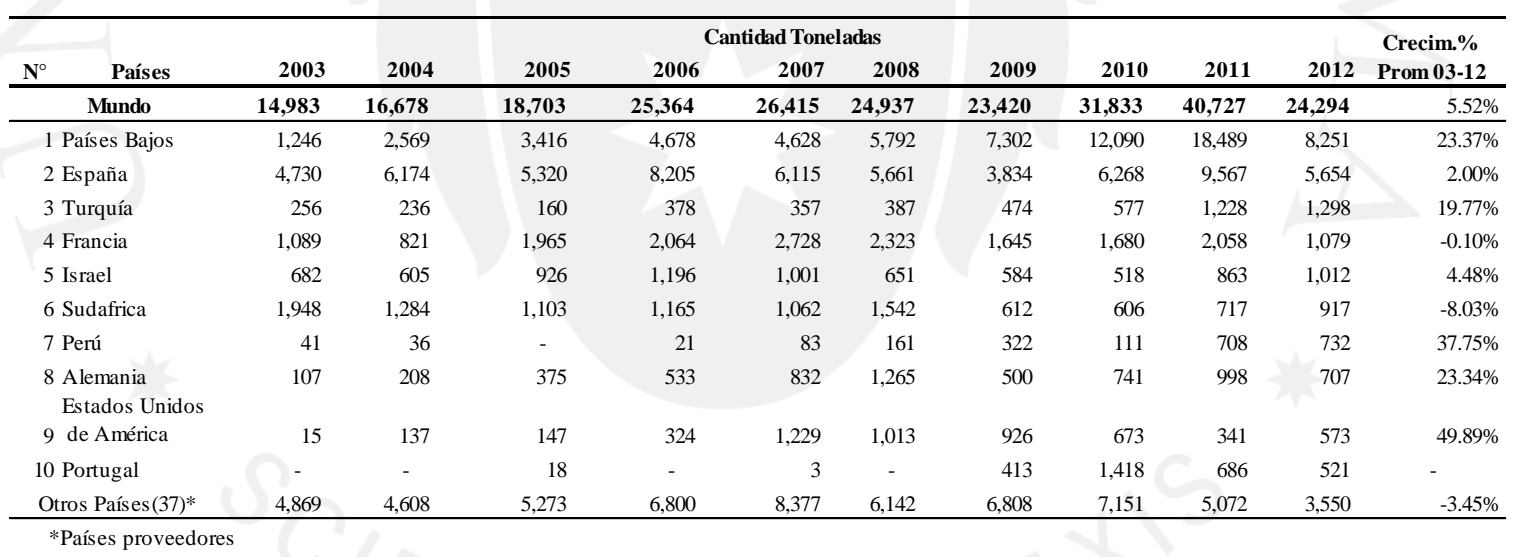

Nota. Fuente: Trademap

Como podemos apreciar en la tabla la demanda mundial de la partida se ha ido incrementando de forma sostenida a lo largo de los años excepto en los años 2008 y 2009 donde tuvo una leve caída, del 2007 al 2009 las importaciones cayeron en 11\%, recuperándose en el 2010 año en el cual aumentaron 35\% siguiendo una tendencia al alza para el 2011, en el 2012 se presentó una fuerte caída del 40\%. El país que más le exportó al Reino Unido hasta el 2012 fue Holanda, el cual importa de diferentes 
mercados para abastecer la demanda, seguido por España el cual cuenta con 5 variedades muy bien posicionadas en el mercado y es un fuerte competidor. Se observa en la tabla que la caída en el 2012 se dio principalmente por los menores envíos de Holanda y España, probablemente este haya sido uno de los estragos de la crisis económica que en ese año aún afectaba a Europa.

Nuestro país se encuentra en el puesto número 7 como proveedor (cantidad) del Reino Unido y en 10 años (período 2003-2012) sus exportaciones hacia este mercado incrementaron 1685\%, a partir del año 2007 se empezaron a exportar cantidades más significativas.

Tabla 15 Exportación de otros Frutos frescos al Reino Unido entre el 2013 y 2014 (TN)

\begin{tabular}{|c|c|c|c|c|}
\hline & \multicolumn{4}{|c|}{ Cantidad Toneladas } \\
\hline Países & 2013 & 2014 & $\% \quad 13-14$ & Par. \% 2014 \\
\hline Mundo & 15,534 & 16,800 & $8.15 \%$ & $100.00 \%$ \\
\hline 1 España & 4,840 & 4,753 & $-1.80 \%$ & $28.29 \%$ \\
\hline $\begin{array}{l}2 \text { Estados Unidos } \\
\text { de América }\end{array}$ & 721 & 1,628 & $125.80 \%$ & $9.69 \%$ \\
\hline 3 Turquía & 1,893 & 1,609 & $-15.00 \%$ & $9.58 \%$ \\
\hline 4 Países Bajos & 1,294 & 1,370 & $5.87 \%$ & $8.15 \%$ \\
\hline 5 Alemania & 1,177 & 1,242 & $5.52 \%$ & $7.39 \%$ \\
\hline 6 Israel & 808 & 1,113 & $37.75 \%$ & $6.63 \%$ \\
\hline 7 Perú & 543 & 977 & $79.93 \%$ & $5.82 \%$ \\
\hline 8 Sudafrica & 1,088 & 833 & $-23.44 \%$ & $4.96 \%$ \\
\hline 9 Egipto & 513 & 641 & $24.95 \%$ & $3.82 \%$ \\
\hline 10 Tailandia & 323 & 328 & $1.55 \%$ & $1.95 \%$ \\
\hline Otros Países (36)* & 2,334 & 2,306 & $-1.20 \%$ & $13.73 \%$ \\
\hline
\end{tabular}

Nota. Fuente: Trademap

Analizando el período 2013/2014 la demanda del Reino Unido por la partida Otros Frutos Frescos (081090) en la cual están clasificadas las granadas, creció 8\% a nivel global. Asimismo los mercados proveedores que más aumentaron sus envíos en toneladas fueron Estados Unidos $(+126 \%)$ y en segundo lugar Perú $(80 \%)$, motivo por el cual se espera que para los próximos años el Perú se vaya posicionando aún más. El mismo se ha mantenido en la posición número 7 dentro de los principales 10 países exportadores de la fruta al Reino Unido. 
Figura 19 Principales Mercados Proveedores del Reino Unido: 081090 otros frutos frescos

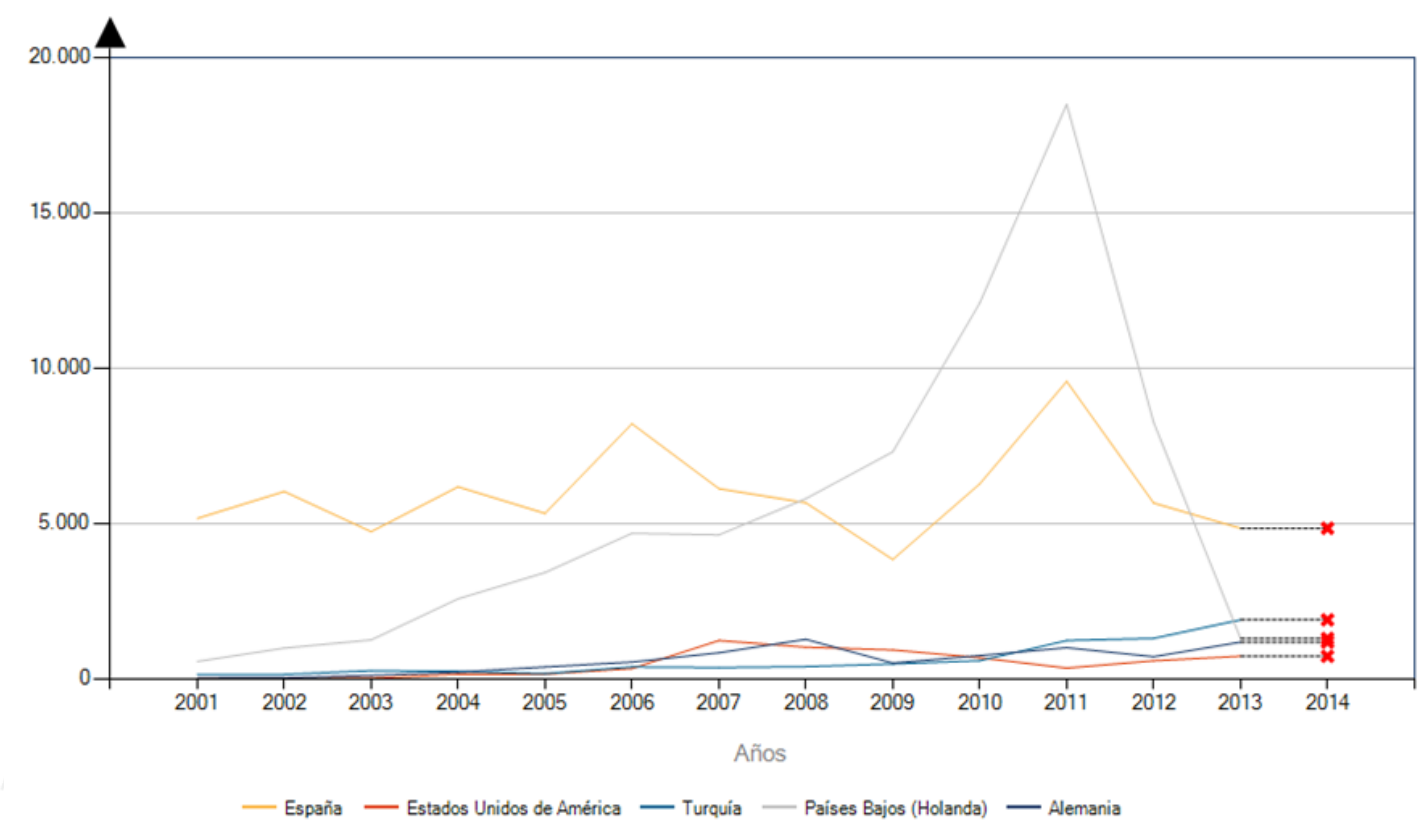

Fuente: Trademap

Las importaciones de la partida Otros Frutos Frescos no han crecido a una tasa constante, al comienzo el aumento de los envíos fue moderado en general para los países exportadores (desde el 2001 hasta el 2006). Durante el periodo de los años 2008 y 2009 disminuyeron los envíos de los principales países exportadores.

A partir del 2010 comenzaron a crecer más a tasas más elevadas, sobre todo países como España y Holanda, en el gráfico se puede observar la línea gris que presenta un pico en sus envíos hacia el Reino Unido alcanzando aproximadamente 18,000 toneladas, la cantidad más grande exportada en el tiempo analizado (desde el 2001 hasta el 2014).Asimismo España presentó un crecimiento más significativo en el 2011, llegando a las 9,000 toneladas, lo cual se puede ver en la línea naranja del gráfico superior.

En el 2012 las exportaciones de los principales países proveedores (Holanda y España) comenzaron a desacelerarse y ésta tendencia continuó hasta el 2013 motivo por el cual las importaciones totales del Reino Unido disminuyeron. El 2014 mostró una recuperación de la demanda de Otros frutos Frescos por parte del reino Unido, 
posicionando a España como principal proveedor en términos de cantidades y en segundo lugar a Estados Unidos, que aunque no exporte aún volúmenes tan grandes desplazó a Holanda hasta el cuarto lugar, asimismo las cantidades exportadas no son proporcionales a los valores en dólares, debido a que en el ranking de proveedores en términos de valor FOB se encuentran en la posición número 8.

\subsubsection{Variables que afectan la demanda}

\subsubsection{Precio del bien}

El precio del bien sí afecta la demanda debido a que dependiendo de este la demanda disminuirá o incrementará al contar con un precio más bajo. En el Reino Unido el gasto en frutas para algunos grupos de personas aún se considera un lujo, por lo que a medida que el precio disminuya el consumidor estará más dispuesto a gastar en este tipo de producto.

- Competencia: Si la competencia es intensa en nuestro mercado de destino, puede hacer que el precio disminuya por la gran oferta existente. Sobre todo si son países que cuentan con grandes volúmenes de producción, que sería el caso de España, nuestro principal competidor. El cual alcanzó en la campaña 2013-2014 las 50,000 toneladas de granada mollar, su principal especie.

Nuestro mayor competidor es España debido a que exportó en el 2014 grandes cantidades, de acuerdo a Trademap 4,753 toneladas, a comparación del Perú que únicamente exportó977 toneladas. Es importante mencionar también a Estados Unidos, país que está obteniendo una participación de mercado mayor y en el año 2014 envió 1,628 toneladas al Reino Unido. EEUU está quinto en el ranking de producción de granadas frescas, detrás de los líderes que son Irán, India, China y Turquía. (Oficina Comercial ProChile Los Ángeles, 2012) Asimismo California cuenta con la mayor cantidad de hectáreas en producción de granadas, siendo la principal variedad que se cultiva la wonderful. (Oficina Comercial ProChile Los Ángeles, 2012) 
- Demanda interna: En lo que respecta a las granadas, en el Reino Unido se ha difundido a la población los beneficios que estas brindan. Asimismo ellos están cada vez más preocupados por consumir alimentos saludables y son conscientes del alto contenido de antioxidantes y de las propiedades que ayudan a prevenir ciertas enfermedades. El consumo per cápita de fruta en el 2010 fue de $43.1 \mathrm{~kg}$ (Euromonitor) mayor al de sus pares franceses que se encontró en 36.5 $\mathrm{kg}$.

Durante el 2013 las ventas de frutas en el Reino Unido registraron 2’711,000 toneladas y para el 2018 se espera que crezcan hasta 2’787,500 toneladas. Los hogares en el Reino Unido compraron una media de 4,0 porciones de frutas y verduras por persona por día en 2011 y el consumo per cápita de frutas en el Reino Unido se redujo de $46.3 \mathrm{~kg}$ a $41.9 \mathrm{~kg}$ entre 2007 y 2012. (Euromonitor International , 2013)

\subsubsection{Los Ingresos}

De acuerdo a Euromonitor el ingreso bruto anual per cápita del Reino Unido se situó en $£ 24.168$ (US \$ 37.776) en 2013, después de haberse contraído un 1,9\% en términos reales durante el período 2008-2013. (Euromonitor International , 2014) Los gastos de consumo per cápita fueron de $£ 17.183$ (US \$28.291) en 2014 y se espera que crezcan un $2,2 \%$ en términos reales durante 2015. El ingreso disponible per cápita ascendió a $£ 17.498$ (US \$28.810) en 2014. En 2015, el ingreso disponible per cápita (en términos reales) se incrementará en un 2,2\%. (Euromonitor International , 2015)

Durante el periodo del 2008-2013 el ingreso disponible anual del Reino Unido por hogar se mantuvo casi inalterado, en el 2013 se situó en $£ 38.724$ (US \$ 60.528 mil). En el año 2013, el 27,1\% de la renta disponible anual total se destinó al 10,0\% de los hogares británicos más ricos (decil 10), mientras que el 10,0\% más pobre (decil 1) estuvo en posesión del 2,5\% de ingresos. (Euromonitor International , 2014)

Las amas de casa son las que normalmente toman las decisiones al momento de hacer las compras de los alimentos como la frutas y vegetales, mientras cuenten con los 
ingresos necesarios seguirán comprando. Como se puede observar en la figura 20, la proyección hacia el año 2030 es que el 10\% (decil 10) más rico de los hogares cuente con más de US\$200,000 de ingreso anual disponible, por lo que es un segmento con un gran poder adquisitivo al cual es conveniente dirigirnos para ofrecer un producto como la granada considerado una súper fruta y por la cual pueden estar dispuestos a pagar un precio mayor.

El estudio "FamilyFood 2011" concluyó que los hogares de bajos ingresos se asocian con niveles de consumo más bajos de frutas, verduras y de fibra, así como niveles más altos de consumo de azúcar." (Euromonitor International , 2013)

Figura 20 Ingreso por hogar disponible promedio anual por decil: Años 2013 y 2030

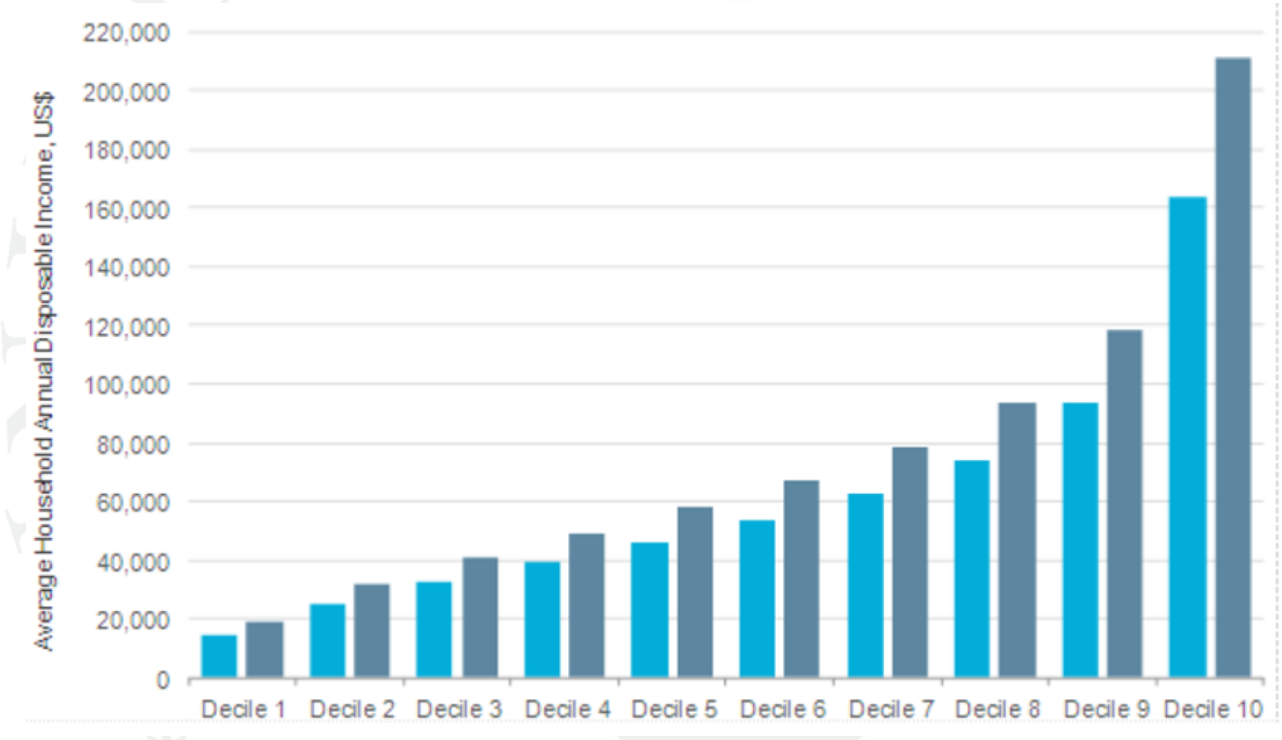

Fuente: Euromonitor International - Income and Expenditure: United Kingdom

La Granada es una fruta que por sus propiedades debería de ser consumida en grandes cantidades y que debe ser parte de la dieta diaria de las personas, sobre todo las que están muy preocupadas por su salud. Debido a que sabemos que los adultos y adultos mayores son los que más se preocupan por cuidar de su salud y cuentan con mayores ingresos es el segmento elegido para dirigir nuestro producto. En la figura 21 se puede observar que a partir de los 35 años hasta los 60 años el ingreso bruto promedio se situó en más de US\$ 50,000 que es el mayor para todas las categorías de edades. 
En el caso de las frutas en algunos sectores de la población del Reino Unido son consideradas un bien de lujo, por lo que si solo si incrementa el poder adquisitivo va a incrementar el consumo de las mismas. Se ha demostrado que las compras de frutas y vegetales aumentan fuertemente con el ingreso, han incrementado $51 \%$ las compras del quintil de mayores ingresos en comparación con los del más bajo quintil en el 2012. (Department for Environment, Food \& Rural Affairs , 2013)

Figura 21 Ingreso Bruto Promedio por Edad: 2013
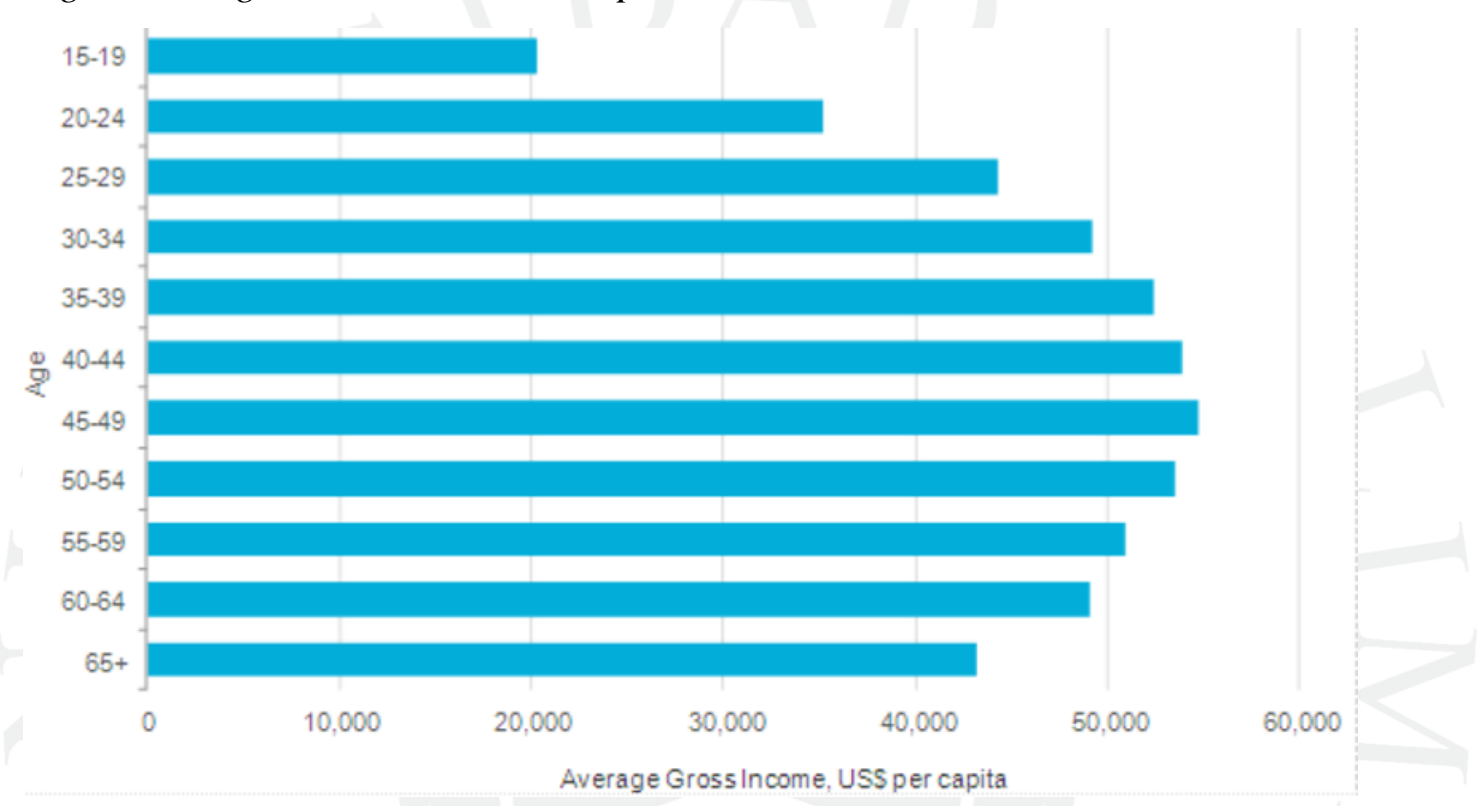

Fuente: Euromonitor International - Income and Expenditure: United Kingdom

\subsubsection{Gustos y preferencias}

Las frutas, particularmente los plátanos y las manzanas, son snacks muy populares sobre todo entre las mujeres, las cuales están más preocupadas de su salud que los hombres. El nuevo concepto de las súper frutas, la granada es considerada una súper fruta por que previene el cáncer y otras enfermedades como las del corazón gracias a su alta concentración de antioxidantes. El Profesor Gary Stoner del Departamento de medicina interna de la Universidad de Ohio dijo: "La gente debe considerar consumir más granadas para protegerse contra el desarrollo del cáncer de mama y de otros tejidos y órganos. (Znews, 2010)

En una encuesta realizada por la aseguradora de salud privada BUPA en el 2011 encontró que el $12 \%$ de los consumidores británicos piensan que los súper alimentos 
podrían prevenir el cáncer. El $51 \%$ de los encuestados estaban familiarizados con el término"súper", un $38 \%$ cree que los beneficios de salud pueden derivarse de comer este tipo de alimentos. El $61 \%$ dijo que el concepto influyó en sus decisiones de consumo, por lo que si se sigue haciendo conocida a la granada como un superalimento su demanda seguirá aumentando.

En lo que respecta a la segmentación y el consumo de frutas en el país de destino de acuerdo a la organización "Children's Food Trust" más del 90\% de los alumnos (niños) que toman un almuerzo escolar comieron alimentos y bebidas que contienen verduras, ensaladas, legumbres o frutas (incluyendo el jugo de la fruta), en comparación con sólo el 58\% de los alumnos que toman comida para llevar. (Euromonitor International, 2013)

En el caso de los adolescentes durante el 2012, la encuesta del Departamento de Salud Nacional de Dieta y Nutrición encontró que los niños de edades comprendidas entre 11 y 18 años consumieron un promedio de alrededor de tres porciones de frutas y verduras al día, mientras que las niñas consumen un promedio de 2,8 porciones, no mostrando un incremento significativo respecto al año 2011. (Euromonitor International , 2013)

La encuesta "Food and You" realizada en el 2010, en la cual se explican los hábitos alimenticios de la población británica en general mostró que los tipos de alimentos más comúnmente consumidos todos los días eran frutas y hortalizas $(72 \%$ de los encuestados); pan, arroz, pasta, patatas y otros alimentos con almidón (71\%); y productos lácteos (70\%). (Euromonitor International , 2013) Es importante tomar en consideración este hecho debido que nosotros buscamos posicionar la granada dentro de la dieta diaria de los consumidores y que no lo perciban como un bien no accesible. Si buscamos un nicho más específico las mujeres más que los hombres prefieren comer frutas y verduras para cuidar su salud y apariencia física. La encuesta anual de Euromonitor Internacional indica que el 96.2\% de mujeres de mediana edad (45 a 64 años) considera que consumir frutas y verduras es beneficioso para su salud. (Euromonitor International , 2013) 
Por otro lado dentro de los hábitos de consumo de bebidas los consumidores en el Reino Unido suelen acompañar su desayuno con jugo de naranja, pero una alternativa muy interesante sería poder reemplazar o complementar con jugo de granada, sobre todo porque allí sí existe una industria de bebidas de esta fruta incluso combinada con otras frutas.

\subsubsection{Tendencias en el mercado de destino}

Como se mencionó anteriormente las tendencias de consumo en el Reino Unido al igual que en todo en Europa se dirigen hacia lo saludable, cada vez se consumen más frutas y verduras dentro de la dieta diaria. Las campañas de alimentación saludable también son fomentadas por el gobierno, en este caso a través del NHS (Servicio Nacional de Salud del Reino Unido). A través de su página web lanzó una iniciativa de consumo llamada "5 a day" la cual consiste en consumir 5 porciones de 80 gramos de frutas o verduras. Se mencionan 5 razones por las cuales se debe consumir "5 al día":

- Las frutas y vegetales saben muy bien y hay una gran variedad para escoger.

- Son una buena fuente de vitaminas y minerales incluidos vitamina C y Potasio.

- Son una excelente fuente de fibra dietaría que ayuda a mantener saludable el sistema digestivo y prevenir el estreñimiento y otros problemas digestivos.

- Pueden ayudar a reducir el riesgo de enfermedades del corazón, infartos y algunos tipos de cáncer.

- Las frutas y los vegetales contribuyen a una dieta saludable y balanceada.

Las compras de "5 al día" en todos los hogares se mantuvo sin cambios entre 2009 y 2011 a 4,0 porciones; la reducción en el 2012 a un promedio de 3,9 porciones retrocede a los niveles de la década de 1990. (Department for Environment, Food \& Rural Affairs , 2013)

En 2011 el 24\% de los hombres, el 29\% de las mujeres y el $18 \%$ de los niños (de 
edades comprendidas entre 5 y 15 años), consumieron la dosis recomendada de frutas y verduras 5 AL DÍA. Asimismo es importante considerar que las personas en el rango de edad entre 55 y 75 años comen mayores cantidades de frutas y vegetales. En el 2011 el consumo de frutas y verduras de los adultos mayores de 55 a 65 aumentó a un promedio de 3,9 porciones por día para los hombres y 4,3 porciones por día para las mujeres. (Department for Environment, Food \& Rural Affairs , 2013) Como se puede observar en la figura 22 la tendencia es que las mujeres concentren el mayor porcentaje de logro en el consumo de 5 Frutas y Verduras al día.

Esta información es muy relevante para una empresa que debe tomar decisiones sobre segmentación y a que nicho de mercado dirigirse, porque claramente se ve que los adultos mayores son los más conscientes en cuidar su salud y serán más receptivos a incluir dentro de su dieta una fruta que contenga propiedades beneficiosas.

Figura 22 Tendencia en el consumo de frutas y verduras en hombres, mujeres y niños en Inglaterra hasta 2011

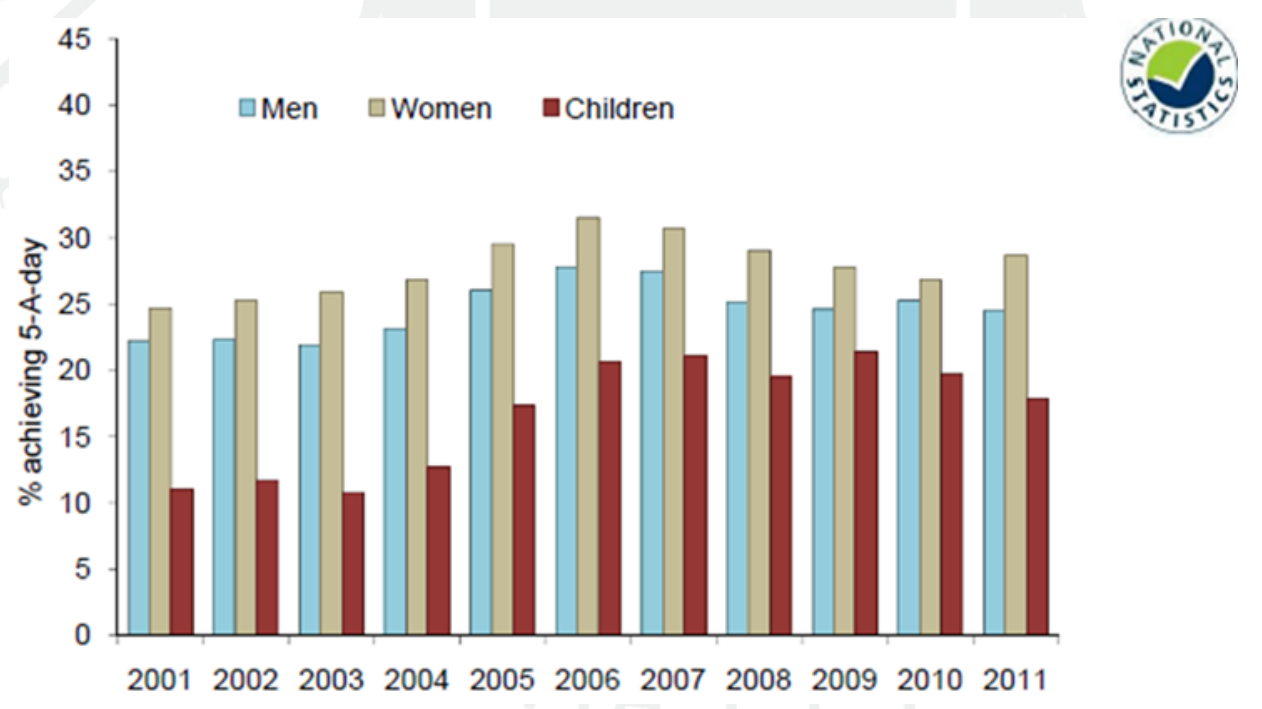

Fuente: Food Statistics Pocket Book - Encuesta de Salud para el Reino Unido 2011

Por otro lado el estudio de Euromonitor: Estilos de Vida del Consumidor nos muestra que los gastos de consumo per cápita en libras a precios constantes en la categoría de frutas desde el 2010 hasta el 2015 incrementaran 22\% alcanzando las $£ 110$ per cápita. Un factor importante a considerar para fomentar el consumo de frutas son los niveles de obesidad en el país, por lo que se debe de reemplazar el consumo de alimentos con altos 
contenidos de grasa y azúcar por diferentes tipos de comidas más saludables y una de las opciones pueden ser las frutas.

El gobierno del Reino Unido tiene el programa "Change 4 Life" con el cual busca motivar a las personas obesas a adoptar una dieta más sana, tomar menos alcohol y ejercitarse más, pero no interviene directamente en los mercados aplicando impuestos adicionales a comidas más grasosas. Algunas otras acciones que el gobierno plantea es que los restaurantes coloquen las calorías de los menús y también mejorar la calidad de la comida en las escuelas por ejemplo actualmente deben incluir en cada comida por lo menos dos porciones de frutas y verduras. (Euromonitor International, 2013)

Las frutas más populares producidas en el Reino Unido son las manzanas y las bananas, en el 2013 ambas decrecieron sus volúmenes de venta. En el caso de manzanas si cuentan con producción local la cual resultó en $10 \%$ menos del nivel esperado. Las bananas son importadas, 25\% de Colombia y en el 2013 por una huelga en la zona de producción disminuyeron los envíos por lo que son más dependientes de otros países y vulnerables a los problemas que puedan presentar sus proveedores. Este es el mismo caso para las granadas debido que ellos no cuentan con producción local por lo que dependen de los países productores, es importante que diversifiquen sus proveedores para no depender únicamente de uno y así también tener mayor poder de negociación. Otras frutas que cada vez toman más importancia en el mercado británico son los cranberries y blueberries, en el 2013 mostraron un fuerte crecimiento.

Se espera que la categoría de frutas retorne a niveles de crecimiento en el transcurso del periodo de previsión (2013-2018), con una constante mejora en el rendimiento. En el contexto de crecimiento del poder adquisitivo se beneficiaran algunas categorías de frutas; especialmente frutas como arándanos valorados por muchos consumidores como súper bayas porque están llenas de poderosos antioxidantes. Las granadas también son consideradas súper frutas por lo que hay continuar realizando campañas para dar a conocer esta información y sean cada vez más valoradas.

Por otro lado una variedad de declaraciones sobre las propiedades saludables de las frutas se continuarán realizando entre 2013 y 2018. Por ejemplo una investigación 
encontró que los adultos de mediana edad conscientes del consumo de frutas eran menos propensos a sufrir ataques cardíacos o derrames cerebrales, pero el efecto en los adultos jóvenes fue menos claro. (Euromonitor International, 2014)

Es importante también identificar cuanto valoran los consumidores que las frutas sean orgánicas o estándares. En la siguiente tabla se pueden ver los volúmenes de cada tipo.

Tabla 16 Ventas de frutas por Orgánico / Comercio Justo vs Standard: \% de Volumen Total 2008-2013

\begin{tabular}{lrrrrrr}
\hline Certificación & $\mathbf{2 0 0 8}$ & $\mathbf{2 0 0 9}$ & $\mathbf{2 0 1 0}$ & $\mathbf{2 0 1 1}$ & $\mathbf{2 0 1 2}$ & $\mathbf{2 0 1 3}$ \\
\hline Standard & $87 \%$ & $92 \%$ & $95 \%$ & $96 \%$ & $92 \%$ & $89 \%$ \\
Organic/Fair Trade & $13 \%$ & $8 \%$ & $5 \%$ & $4 \%$ & $8 \%$ & $11 \%$ \\
Total & $100 \%$ & $100 \%$ & $100 \%$ & $100 \%$ & $100 \%$ & $100 \%$ \\
\hline
\end{tabular}

Fuente: Euromonitor International - Fruits in the United Kingdom

El 2008 fue el año en el cual se realizaron más ventas de frutas orgánicas $(13 \%$ del total) pero en los siguientes años 2009, 2010 y 2011 esta tendencia decreció, coincide con la crisis de la Eurozona por lo que la gente tenía menos dinero para comprar este tipo de frutas y optaba las estándares, en el 2013 año en que se empezó a recuperar la economía incremento nuevamente la cantidad hasta $11 \%$. Aunque aún no sea de suma importancia el consumo de frutas orgánicas en el mercado de destino es una tendencia que se debe considerar porque podría ayudar a la empresa a incrementar su participación de mercado, debido que hay consumidores que si consideran este factor decisivo al momento de realizar sus compras.

Podemos concluir que el consumo de frutas es importante en el Reino Unido y continuará creciendo en próximos años, por lo que debemos aprovechar para introducir a las granadas dentro de las principales frutas consumidas sobretodo en este momento en el cual cada vez las personas se han vuelto más conscientes de las propiedades de las súper frutas y los efectos positivos que pueden tener sobre su salud. Asimismo que nuestra empresa sea parte del crecimiento de las exportaciones de granadas al Reino Unido para escalar posiciones dentro de la lista de proveedores y no sean tan dependientes de uno o dos mercados.

\subsubsection{Demanda futura}




\subsubsection{Demanda potencial}

Las importaciones mundiales de granadas del Reino Unido desde el 2003 hasta el 2007 mantuvieron una tendencia hacia el alza, pero en los años 2008 y 2009 disminuyeron sobre todo por los menores envíos desde Francia e India. En los años 2010 y 2011 se recuperaron llegando al pico de valor total importado de aproximadamente US\$ 86 millones el cual podemos observar en la figura $\mathrm{N}^{\circ} 23$. Esto se debió a las mayores exportaciones de Holanda y España, este último en el 2011 triplicó el valor exportado en el 2009. Para los años siguientes (2012 y 2013) las importaciones de granadas del Reino Unido se vieron afectadas por los menores envíos de parte de Holanda y España, países europeos que atravesaban por una crisis económica.

Durante el 2014 las importaciones comenzaron a recuperarse brindando mayor protagonismo a nuevos países proveedores como Egipto, Israel y Estados Unidos que han incrementado sus exportaciones de granadas hacia el Reino Unido. En general se puede ver que las importaciones no han presentado un crecimiento continuo sino más bien han sido fluctuantes a lo largo del tiempo.

Figura 23 Importaciones mundiales de granada (PA: 081090) del Reino Unido en volumen (TN) y valor (US\$)

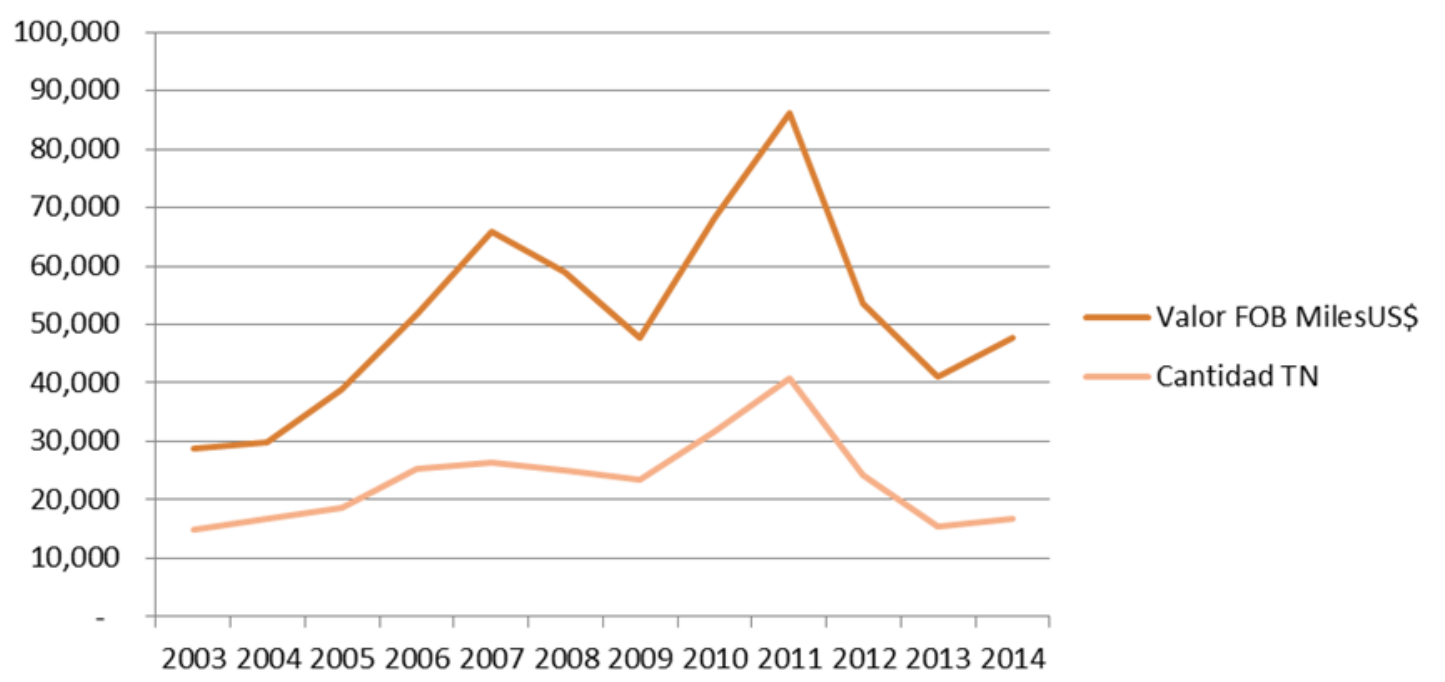

Fuente: Trademap

Por otro lado las cantidades importadas por el Reino Unido desde el Perú no han sido tan fluctuantes sino más bien en general se han mantenido estables y con cierta tendencia al alza, en el año 2012 se mantuvo. Solo presentó una caída estrepitosa en el 
2010, uno de los años más críticos de la crisis mundial, pero luego en general continuó creciendo hasta el 2014 alcanzando los US\$ 2.8 millones.

Figura 24 Importaciones de granadas (PA 081090) del Reino Unido desde el Perú en USD y TN

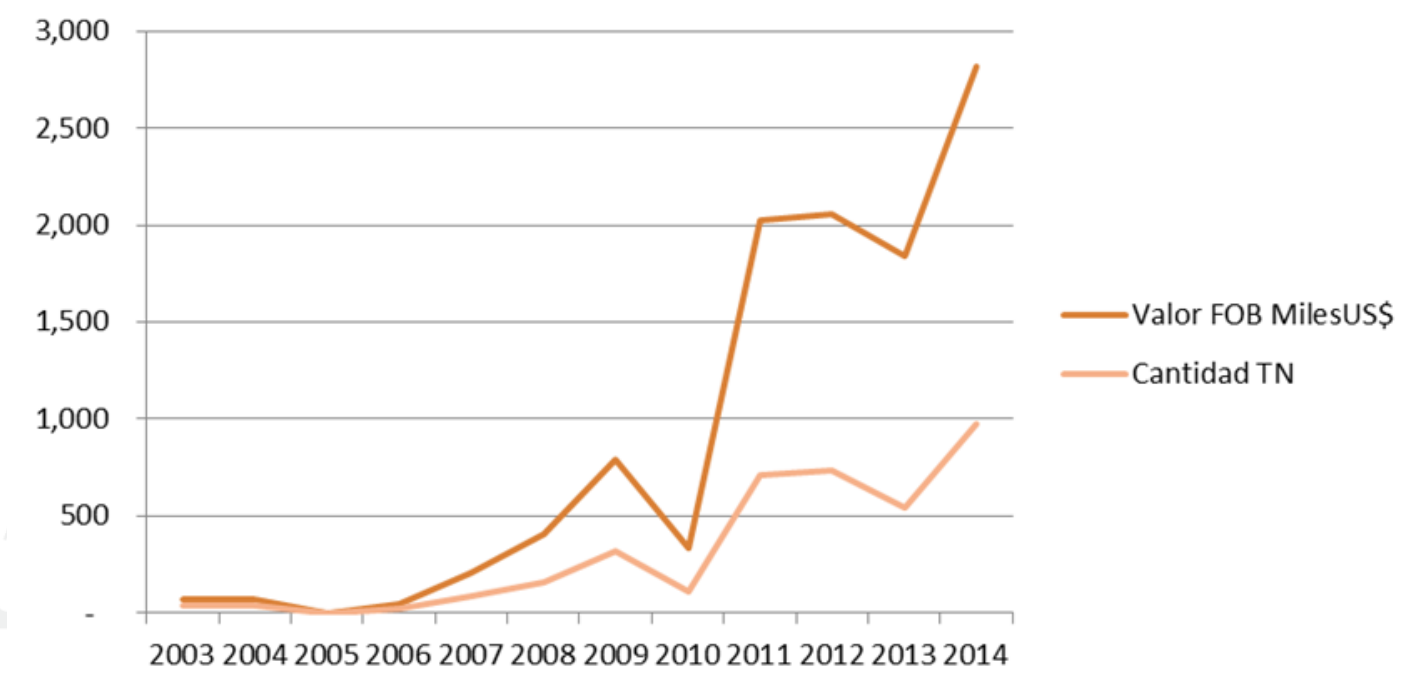

Fuente: Trademap

De acuerdo a la demanda histórica que se vio en la tabla 14, se realizó el método de descomposición de series de tiempo, el cual se ajusta a un modelo que pondera de igual forma todas las observaciones para determinar el mejor ajuste de regresión de los datos ajustados según las estaciones. Con los datos históricos mensuales de importaciones del Reino Unido de la partida 081090 Otros Frutos Frescos de los últimos 11 años se realizó el pronóstico de importaciones mensuales para los próximos 5 años.

Cabe resaltar que se utilizó el modelo aditivo por brindar resultados más exactos, en este caso el MAPE fue menor, en cuanto a las medidas de exactitud se detallan a continuación:

- MAPE: Porcentaje promedio absoluto de error, mide la exactitud de los valores estimados de la serie de tiempo.

- MAD: Desviación media absoluta, mide la exactitud de los valores estimados de la serie de tiempo. 
- MSD: Desviación cuadrática media, es más sensible a errores anormales de pronóstico que el MAD.

Estos indicadores sirven para comparar la efectividad de diferentes modelos utilizados. Siempre se busca el valor menor en los indicadores MAPE, MAD y MSD ya que representa un mejor ajuste del modelo. En el caso del pronóstico de la demanda mediante la descomposición se obtuvo un menor MAPE que el método de análisis de la tendencia. (Reyes, 2007) Mediante el método de descomposición de series de tiempo se obtuvo la siguiente ecuación de tendencia ajustada:

\section{$Y t=1897138+1556 \times t$}

Donde:

- Y: Cantidad

- $\quad$ t: Tiempo

A continuación en la figura $\mathrm{N}^{\circ} 25$ se podrá observar la gráfica de descomposición de series de tiempo de los Kilogramos importados por el Reino Unido, en la cual se muestra la tendencia y pronósticos mensuales calculados con la herramienta informática Minitab.

Figura 25: Proyección de la demanda mensual de la PA 081090 (Otros Frutos

Frescos)

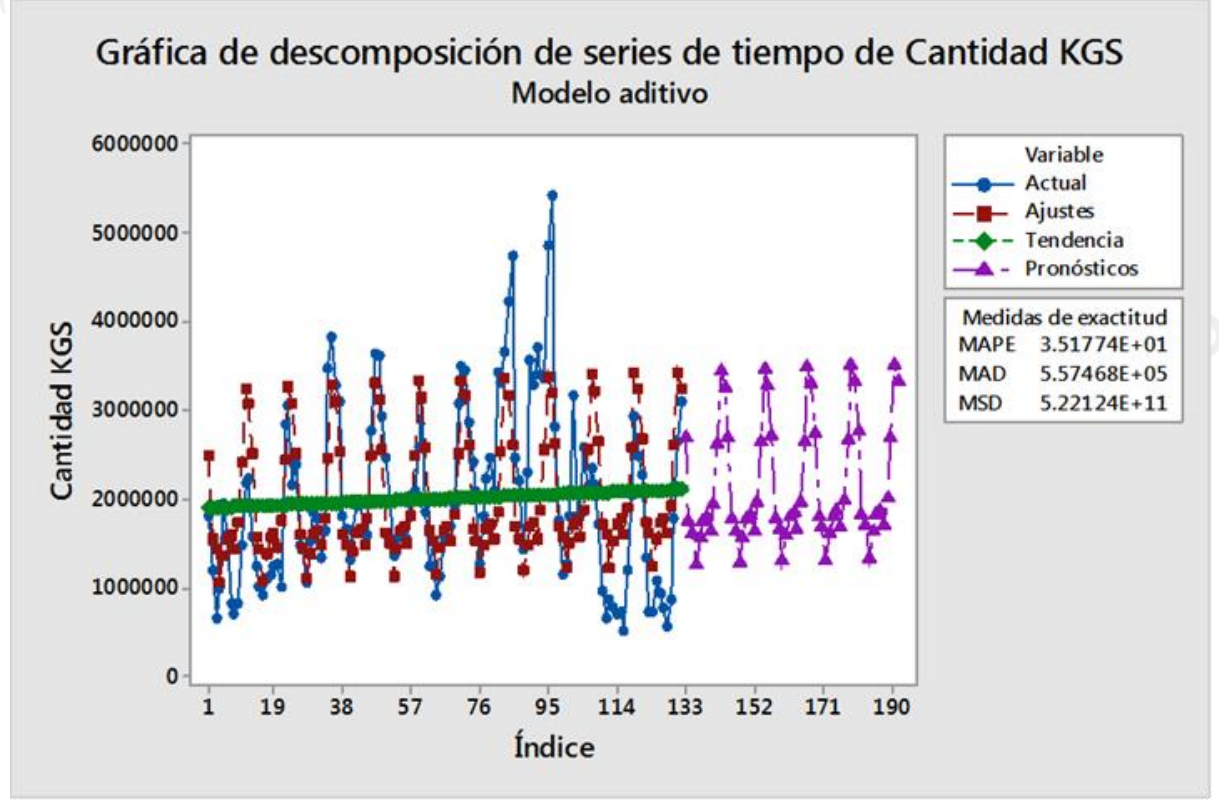

Fuente: Minitab17 
A través de la descomposición se llegó a estimar las proyecciones para cinco años, contándose desde el horizonte de valuación. El 2015 será nuestro periodo de inversión y el 2019 el de operación (para cálculos de ingresos).

El método de descomposición calcula el pronóstico como la línea de regresión multiplicada por (método multiplicativo) o agregado a (método aditivo) los índices de estacionalidad, este complementa al modelo de tendencias para realizar los pronósticos. (Reyes, 2007)

Se presenta a continuación la tabla mensual del 2015 al 2019 con las cantidades proyectadas a importarse de la partida 081090 “Otros Frutos Frescos”.

Tabla 17 Proyección de la demanda mensual de la Partida 081090 "Otros frutos frescos" 2015-2019

\begin{tabular}{|c|c|c|c|c|c|}
\hline \multirow[b]{2}{*}{ Mes/Año } & \multicolumn{5}{|c|}{ Cantidad (KG) } \\
\hline & 2015 & 2016 & 2017 & 2018 & 2019 \\
\hline Enero & $2,686,569$ & $2,705,240$ & $2,723,911$ & $2,742,582$ & $2,761,253$ \\
\hline Febrero & $1,751,729$ & $1,770,400$ & $1,789,071$ & $1,807,742$ & $1,826,413$ \\
\hline Marzo & $1,622,868$ & $1,641,539$ & $1,660,210$ & $1,678,881$ & $1,697,552$ \\
\hline Abril & $1,263,049$ & $1,281,720$ & $1,300,391$ & $1,319,062$ & $1,337,733$ \\
\hline Mayo & $1,557,230$ & $1,575,901$ & $1,594,572$ & $1,613,243$ & $1,631,914$ \\
\hline Junio & $1,758,078$ & $1,776,749$ & $1,795,420$ & $1,814,091$ & $1,832,761$ \\
\hline Julio & $1,805,925$ & $1,824,596$ & $1,843,267$ & $1,861,938$ & $1,880,609$ \\
\hline Agosto & $1,631,044$ & $1,649,715$ & $1,668,386$ & $1,687,057$ & $1,705,727$ \\
\hline Septiembre & $1,938,662$ & $1,957,333$ & $1,976,004$ & $1,994,675$ & $2,013,346$ \\
\hline Octubre & $2,621,635$ & $2,640,306$ & $2,658,977$ & $2,677,648$ & $2,696,318$ \\
\hline Noviembre & $3,450,045$ & $3,468,716$ & $3,487,387$ & $3,506,058$ & $3,524,729$ \\
\hline Diciembre & $3,264,747$ & $3,283,417$ & $3,302,088$ & $3,320,759$ & $3,339,430$ \\
\hline
\end{tabular}

Nota. Fuente: Minitab 17

La información sobre la demanda histórica del Reino Unido del producto solo se basó en la partida 081090 "Otros Frutos frescos" debido a que se obtuvo de Trademap y en esa herramienta se presentan la partidas armonizadas a seis dígitos. Se tomó esta partida porque dentro de ella se encuentran las granadas, si se observan los principales mercados proveedores de la partida (tabla 6) se podrá encontrar a mercados como España, Egipto y Turquía que son principalmente productores y exportadores del fruto de la granada. 
A continuación se detalla la demanda proyectada anual del Reino Unido de "Otros frutos frescos" proveniente del Perú del para los años 2015 a 2019.

Tabla 18 Proyección de la demanda anual de la Partida081090 "Otros frutos frescos" 2015-2019

\begin{tabular}{cr}
\hline Año & $\begin{array}{c}\text { Demanda } \\
\text { Proyectada KG }\end{array}$ \\
\hline 2015 & $25,351,580$ \\
2016 & $25,575,632$ \\
2017 & $25,799,683$ \\
2018 & $26,023,734$ \\
2019 & $26,247,786$ \\
\hline
\end{tabular}

Nota. Fuente: Minitab 17

\subsubsection{Demanda objetivo}

A fin de poder determinar la demanda objetivo de Pome Perú, se deben analizar ciertas variables del país y su población.

El Reino Unido está compuesto por una población de 64'105,700 habitantes al 2013, según información proporcionada por la Oficina para Estadísticas Nacionales del Reino Unido. Nuestro producto está dirigido al segmento de la población entre 35 y 75 años, tanto hombres como mujeres y representa el 48\% del total, 31’225,608 personas. En primer lugar se eligió el rango de edad desde los 35 porque a partir de este segmento los ingresos de las personas son mayores y hasta los 75 porque entre los $55 \mathrm{y}$ 75 años es el grupo de personas que más consume frutas. Esta información se detalla y justifica líneas abajo.

La proyección de la demanda objetivo, depende de la participación que la empresa se ha trazado en los objetivos económicos. Pome Perú, buscará obtener la siguiente participación de mercado para el período 2015-2019: 
- 2015: 0.28\%

- 2016: $0.55 \%$

- 2017: 0.96\%

- 2018: $1.35 \%$

- 2019: $1.61 \%$

Sin embargo debemos tener en cuenta que las circunstancias políticas y socio económicas que se pueden ir presentando en el mercado de destino también afectarán nuestras decisiones sobre la cuota que se establecerá. En el anexo $n^{\circ} 6$ se detalla el cálculo realizado para obtener la demanda objetivo del mercado.

A continuación se detalla la demanda objetivo proyectada para el período 2015-2019:

Tabla 19 Demanda anual objetivo del Reino Unido de la PA 081090 Otros Frutos Frescos

\begin{tabular}{|c|c|c|c|}
\hline Año & & Cantidad (KG) & Cantidad (TN) \\
\hline & 2015 & $33,926.40$ & 33.93 \\
\hline & 2016 & $67,852.80$ & 67.85 \\
\hline & 2017 & $118,742.40$ & 118.74 \\
\hline & 2018 & $169,632.00$ & 169.63 \\
\hline & 2019 & $203,558.40$ & 203.56 \\
\hline
\end{tabular}

En el 2013 las exportaciones de la partida 0810909000 del Perú hacia el Reino Unido sumaron 564 toneladas lo cual representó el 3.6\% de lo que importa el mercado de destino. Mientras que en el 2014 según información extraída del sistema Adex Data Trade los envíos alcanzaron 1,069TN incrementando en $89 \%$ la cantidad exportada, lo cual posiciona al Perú como proveedor número 7 del Reino Unido en términos de cantidad (en toneladas).

En lo que respecta a la participación de mercado que tendremos sobre las exportaciones peruanas de granadas al Reino Unido, se situaría alrededor de 3\% (de acuerdo al volumen exportado en el 2014), debido que se estarían enviando dos contenedores $(33,926.40 \mathrm{Kg})$ en el primer año. 
En la siguiente tabla podemos observar las empresas exportadoras de Granada Fresca, de la cual nos guiamos para calcular la participación estimada entre las empresas peruanas que exportan granadas al Reino Unido, esta información se verá a mayor detalle en el punto 3.2.5.1 Análisis de la competencia local.

Tabla 20 Empresas Peruanas exportadoras de Granada Fresca hacia el Reino Unido

\begin{tabular}{|c|c|c|c|}
\hline EMPRESAS & $\begin{array}{r}\text { Valor FOB US\$ } \\
2014\end{array}$ & $\begin{array}{r}\text { Peso Neto KG } \\
2014\end{array}$ & $\begin{array}{c}\text { Par. \% } 2014 \\
\text { Peso }\end{array}$ \\
\hline Total general & $2,395,817.58$ & $1,069,755.75$ & $100.00 \%$ \\
\hline 1 EXPORTADORA FRUTICOLA DEL SUR SA & $1,209,405.00$ & $466,889.60$ & $43.64 \%$ \\
\hline $\begin{array}{l}\text { AGROINVERSIONES VALLE Y PAMPA } \\
2 \text { PERU SOCIEDAD ANONIMA }\end{array}$ & $378,198.16$ & $213,415.60$ & $19.95 \%$ \\
\hline 3 AGRO VICTORIA S.A.C. & $328,320.00$ & $138,624.00$ & $12.96 \%$ \\
\hline 4 PROCESADORA LARAN SAC & $116,910.00$ & $46,764.00$ & $4.37 \%$ \\
\hline 5 INVERSIONES NIVAMA S.A.C. & $92,704.60$ & $35,385.60$ & $3.31 \%$ \\
\hline 6 FUNDO DOñA PANCHA S.A.C & $86,400.00$ & $34,416.00$ & $3.22 \%$ \\
\hline $\begin{array}{l}7 \text { AGRICOLA W AMBRA S.A.C } \\
\text { AGRICOLA Y GANADERA CHA VIN DE }\end{array}$ & $56,449.75$ & $31,475.40$ & $2.94 \%$ \\
\hline 8 HUANTAR SA & $56,160.00$ & $32,832.00$ & $3.07 \%$ \\
\hline 9 I.T.N. S.A. & $38,442.90$ & $44,212.75$ & $4.13 \%$ \\
\hline 10 CAMPOSOL S.A. & $14,070.82$ & $7,296.00$ & $0.68 \%$ \\
\hline 11 AGRICOLA LOS MEDANOS S.A. & $11,628.00$ & $1,520.00$ & $0.14 \%$ \\
\hline 12 CONSORCIO DE PRODUCTORES DE FRUTA & $7,128.35$ & $16,924.80$ & $1.58 \%$ \\
\hline
\end{tabular}

Nota. Fuente: SUNAT

\subsubsection{Segmentación de mercado}

Nuestro producto irá dirigido a Mujeres y Hombres que se encuentren en ese rango de edad entre 35 y 75 años residentes en el Reino Unido. Es importante mencionar que la principal ciudad es Londres, la cual representa un área total de 1,572 kilómetros cuadrados con una densidad de población de 5,197 londinenses por kilómetro cuadrado, haciéndola la ciudad más grande de Europa. En Febrero de 2015 la 
Gran Autoridad de Londres reveló que su población ha alcanzado un máximo de 8.6 millones. (BBC News, 2015) Otras ciudades importantes en términos de población son Birmingham y Glasgow, a continuación se detalla la población de las 10 principales ciudades del Reino Unido del último censo realizado en el 2011.

Tabla 21 Población de las 10 principales ciudades del Reino Unido

\begin{tabular}{cllr}
\hline $\mathbf{N}^{\circ}$ & \multicolumn{1}{c}{ Ciudad } & Adm. & $\begin{array}{r}\text { Población } \\
\text { Census (C) } \\
27 / 03 / 2011\end{array}$ \\
\hline $\mathbf{1}$ & London & ENG & $8,250,205$ \\
$\mathbf{2}$ & Birmingham & ENG & $1,085,810$ \\
$\mathbf{3}$ & Glasgow & SCO & 590,507 \\
$\mathbf{4}$ & Liverpool & ENG & 552,267 \\
$\mathbf{5}$ & Bristol & ENG & 535,907 \\
$\mathbf{6}$ & Sheffield & ENG & 518,090 \\
$\mathbf{7}$ & Manchester & ENG & 510,746 \\
$\mathbf{8}$ & Leeds & ENG & 474,632 \\
$\mathbf{9}$ & Edinburgh & SCO & 459,366 \\
$\mathbf{1 0}$ & Leicester & ENG & 443,760 \\
\hline Nota. Fuente: Citypopulation - ONS - Office for National Statistics UK
\end{tabular}

Las principales diez ciudades del Reino Unido representan el 21\% de la población total, el objetivo es que las granadas que exportamos vía el Puerto de Tilbury, que es el mayor puerto de Londres se distribuyan a través del Reino Unido. Se ha identificado de la data extraída de SUNAT que en el 2014 el principal puerto de ingreso para las exportaciones de granada peruana fue Tilbury, con 39\% de participación.

En primer lugar se ha elegido el rango de edades (35-75 años) debido que entre los 35 hasta los 60 años el ingreso bruto promedio se situó en más de US\$ 50,000 (Ver Figura $\mathrm{N}^{\circ} 21$ ). Es importante mencionar que según el informe realizado por Euromonitor sobre 
“Frutas en El Reino Unido" en el 2014, se mencionó que se espera que la categoría de frutas vuelva a crecer durante el período pronosticado (2014 al 2018)

Asimismo de acuerdo a la Encuesta de Salud para Inglaterra del año 2011 el grupo de personas entre 55 a 75 años es el que más consume frutas. El estudio también menciona que únicamente el $6.6 \%$ de los adultos no incluyeron ninguna fruta o vegetal en su dieta. (Department for Environment, Food \& Rural Affairs , 2013) Los adultos mayores buscan alimentos que sean beneficiosos para la salud pero cada vez más se ve gente joven que se preocupa por comer alimentos más saludables y la granada es una fruta con muchas propiedades beneficiosas para la salud. Según la encuesta "Food and You" del año 2010 el 72\% de los encuestados respondieron que los tipos de alimentos más consumidos normalmente eran las frutas y vegetales. (Euromonitor International , 2013) Para las personas más jóvenes el objetivo de su consumo será que ayude a prevenir enfermedades y para las personas mayores que se mantengan saludables o no contraigan más enfermedades de las que ya padecen.

\subsubsection{Análisis de la competencia}

\subsubsection{Análisis de la competencia local}

En el Perú durante el 2014 fueron 12 las empresas que exportaron granadas al Reino Unido, cifra que se duplicó respecto al 2013 cuando únicamente fueron 5 empresas como podemos observar en la tabla 22. La empresa con mayor participación de mercado es Exportadora Frutícola del Sur, con una participación de 50.48\% en términos de valor FOB y $43.64 \%$ en volumen. En segundo lugar encontramos a Agroinversiones Valle y Pampa Perú representando $15.79 \%$ del total de exportaciones de granadas en valor FOB y $19.95 \%$ en volumen hacia el Reino Unido.

Cabe mencionar que de acuerdo a información extraída de SUNAT en el año 2014 el $95 \%$ de las exportaciones peruanas de granadas se exportaron frescas, el $5 \%$ en congelado (que principalmente son los arilos) y en el caso de los envíos hacia el Reino Unido en el 2014 el 100\% fueron granadas frescas. Nuestra demanda objetivo proyectada de 33,926.4kg para el primer año de operaciones, equivale al $3 \%$ de lo que el Perú exportó al Reino Unido durante el 2014, (1’069,755.75 kg) aproximadamente 
dos contenedores. Las exportaciones de granadas de las empresas peruanas hacia el Reino Unido crecieron en promedio 27.17\% en los últimos 6 años (2009-2014).

\subsubsection{Principales empresas exportadoras peruanas}

La composición de participación de mercado de las empresas peruanas se encuentra bastante concentrada predominantemente por Exportadora Frutícola del Sur desplazando a Agrícola Athos que en el año 2011 se encontraba en el primer lugar. Exportadora Frutícola del Sur pertenece al Grupo Athos y cuenta con 50\% de participación en valor FOB incrementando $15 \%$ sus exportaciones en valor FOB a comparación del 2013, la cantidad exportada en el 2014 fue alrededor de 467 mil kilos. Ellos cuentan con campos de granada en Ica y son una empresa diversificada que además de las granadas se ocupa de otros cultivos como espárragos, arándanos y dátiles. Cuentan con importantes certificaciones como desde BASC, BRC, Global Gap hasta la certificación Tesco Nurture, la cual es un requisito para los productores que suministran a Tesco con frutas y hortalizas frescas. Asegura las mejores prácticas agrícolas en la producción de productos frescos. (NSF Spain, 2015)

En términos de representatividad le sigue Agroinversiones Valle y Pampa Perú con $16 \%$ de participación, pero un crecimiento de 56\% en valor FOB. Desde el 2011 ha ido incrementando sus envíos de granadas hacia el Reino Unido sosteniblemente, hasta alcanzar en el 2014213 mil kilos (tabla 22). El centro de operaciones de la empresa está ubicado en Pisco y también cuenta con cultivos de espárragos y arándanos los cuales se encuentran certificados bajo la norma Global Gap y Tesco Nurture.

Como se puede observar en la tabla 22, durante el año 2014 la participación de empresas exportadoras hacia el Reino Unido se ha diversificado, en ese año ingresaron 7 nuevas empresas y desde el 2009 se han cuadriplicado el número de empresas. Esto demuestra que la granada es una fruta que cada vez gana más popularidad, motivo por el cual más empresas están invirtiendo en sus cultivos y aún tiene potencial para crecer debido que la costa peruana presenta condiciones muy buenas para su cultivo. 
La cantidad exportada Granadas hacia el Reino Unido en el 2014 fue 1'069,755 Kg con un crecimiento de casi 90\% respecto al 2013, desde el 2009 la cantidad se ha triplicado. A lo largo de los años ha tenido un crecimiento sostenible, lo que quiere decir que gradualmente el Perú se está posicionando como un sólido proveedor para el Reino Unido, aunque aún nos falta mucho más por desarrollar.

Tabla 22 Principales empresas peruanas exportadoras de Granadas hacia el Reino Unido (FOB US\$)

\begin{tabular}{|c|c|c|c|c|c|c|c|c|}
\hline \multirow[b]{2}{*}{ Empresas } & \multicolumn{8}{|c|}{ Valor FOB US\$ } \\
\hline & 2009 & 2010 & 2011 & 2012 & 2013 & 2014 & Var.\% 13-14 & Par.\% 2014 \\
\hline Total general & $674,682.36$ & $276,499.14$ & $1,617,544.44$ & $1,805,101.42$ & $1,471,307.86$ & $2,395,817.58$ & $62.84 \%$ & $100.00 \%$ \\
\hline $\begin{array}{l}1 \text { EXPORTADORA FRUTICOLA DEL SUR SA } \\
\text { AGROINVERSIONES VALLE Y PAMPA }\end{array}$ & $400,681.96$ & & $683,718.75$ & $1,099,883.64$ & $1,052,616.00$ & $1,209,405.00$ & $14.90 \%$ & $50.48 \%$ \\
\hline 2 PERU SOCIEDAD ANONIMA & & & $2,886.00$ & $272,887.12$ & $243,100.26$ & $378,198.16$ & $55.57 \%$ & $15.79 \%$ \\
\hline 3 AGRO VICTORIA S.A.C. & & & & & & $328,320.00$ & - & $13.70 \%$ \\
\hline 4 PROCESADORA LARAN SAC & $56,530.29$ & $4,182.00$ & $35,928.00$ & $260,595.00$ & $45,252.00$ & $116,910.00$ & $158.35 \%$ & $4.88 \%$ \\
\hline 5 INVERSIONES NIVAMA S.A.C. & & & & $39,780.00$ & & $92,704.60$ & - & $3.87 \%$ \\
\hline 6 FUNDO DOñA PANCHA S.A.C & & & & & & $86,400.00$ & - & $3.61 \%$ \\
\hline $\begin{array}{l}7 \text { AGRICOLA WAMBRA S.A.C } \\
\text { AGRICOLA Y GANADERA CHA VIN DE }\end{array}$ & & & & & & $56,449.75$ & - & $2.36 \%$ \\
\hline 8 HUANTAR SA & & & & & & $56,160.00$ & - & $2.34 \%$ \\
\hline 9 I.T.N. S.A. & & & 49.50 & & 90.00 & $38,442.90$ & $42614.33 \%$ & $1.60 \%$ \\
\hline 10 CAMPOSOL S.A. & & & & & & $14,070.82$ & - & $0.59 \%$ \\
\hline $\begin{array}{l}11 \text { AGRICOLA LOS MEDANOS S.A. } \\
\text { CONSORCIO DE PRODUCTORES DE }\end{array}$ & & & & & & $11,628.00$ & - & $0.49 \%$ \\
\hline 12 FRUTA S.A. & & & & & & $7,128.35$ & - & $0.30 \%$ \\
\hline 13 TALS A & & & & $97,743.36$ & & & - & $0.00 \%$ \\
\hline 14 AGRICOLA ATHOS SA & $217,470.11$ & $272,317.14$ & $894,962.19$ & $34,212.30$ & $130,249.60$ & & - & $0.00 \%$ \\
\hline
\end{tabular}

Nota. Fuente: SUNAT

Tabla 23 Principales empresas peruanas exportadoras de Granadas hacia el Reino Unido (Peso KG) 


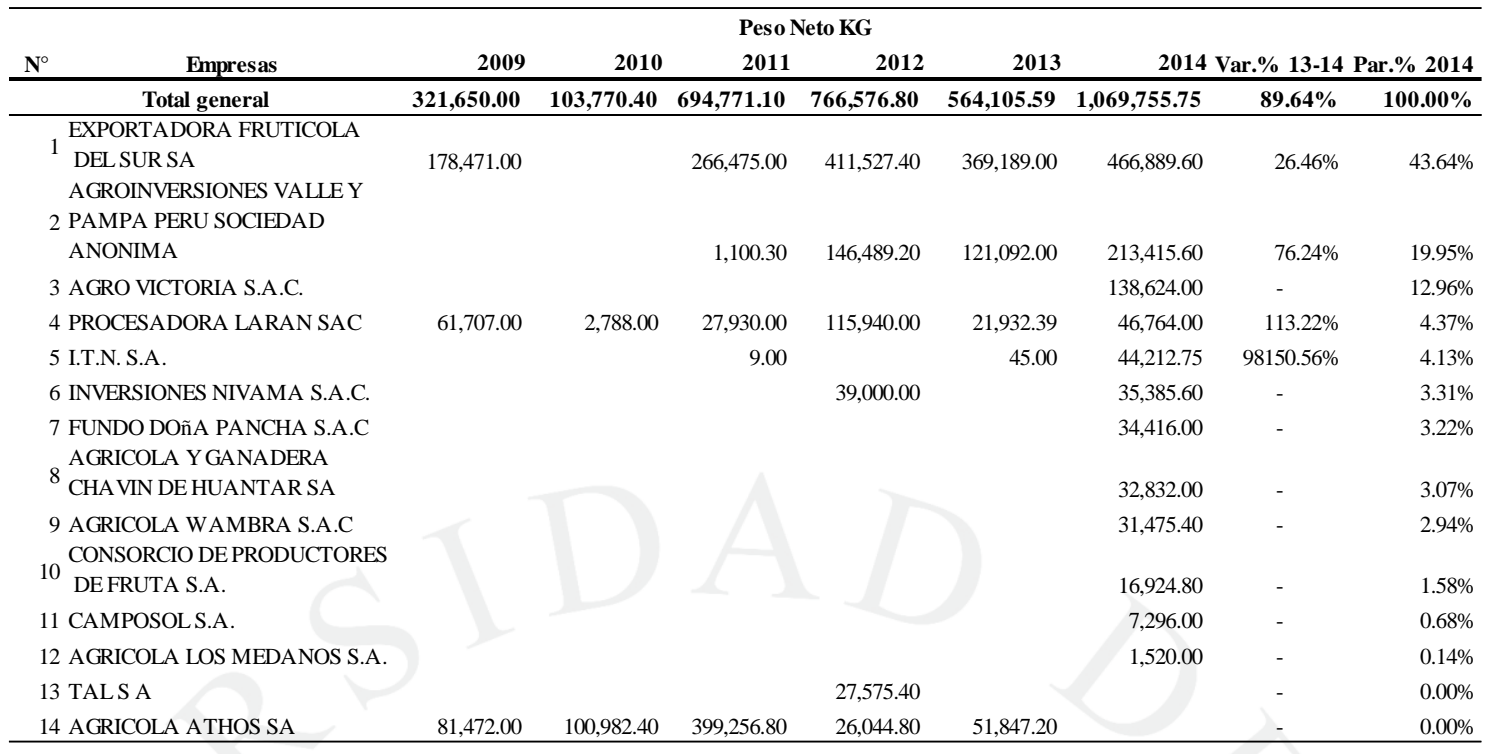

Nota. Fuente: SUNAT

\subsubsection{Análisis de la competencia internacional}

El país que más exporta hacia el Reino Unido la partida de otros frutos frescos actualmente es España. Cabe resaltar que la cantidad exportada por Holanda en el 2011 fue de 18’830,000 kilos, ubicándose como principal proveedor del Reino Unido. Según el CBI, los países bajos son el tercer exportador de frutas de la Unión Europea, por lo que es considerado el más grande re exportador de la UE, 75\% de la importación es reexportada, 70\% de lo reexportado son frutas frescas. (Silva-Santisteban, 2010) Esto es lo que explica el porqué de su ubicación como el primer exportador de la partida hacia el Reino Unido. No quiere decir que cuenta con toda la producción que exporta sino que la mayoría es importada de otros países productores. España anteriormente se posicionaba como proveedor número dos del Reino Unido, pero ha pasado al puesto número 1 con 4’753,000 kilos, este país sí cuenta con un gran nivel de producción y con muchas variedades de calidad que se cosechan en distintos períodos. Esto le permite tener una mayor disponibilidad de la fruta por lo que lo consideraremos como nuestra mayor competencia.

\subsubsection{Principales proveedores mundiales del producto}


Dentro los principales exportadores de la partida 081090 a nivel mundial, se puede identificar en la lista a varios países productores, de los mediterráneos Turquía, Egipto e Israel, del Asia China e India (uno de los mayores del mundo), de Europa España que es prácticamente el único productor relevante en esta zona. Estados Unidos durante los últimos años también se ha convertido en un importante productor que ha evolucionado en términos de cantidades exportadas y también en el desarrollo de su mercado local. Podemos observar que Perú se encuentra en la lista de los 20 principales proveedores de Otros Frutos Frescos, la mayor parte de sus exportaciones dentro de esa partida bolsa son de granadas. Asimismo encontramos a Chile, otro país que aunque no tenga una producción tan grande es uno de nuestros principales competidores dentro de la región.

Tabla 24 Principales proveedores mundiales de Otros Frutos Frescos Año 2012-2013 (US\$)

\begin{tabular}{|c|c|c|c|c|}
\hline Paises & $\begin{array}{c}\text { Valor Fob Mi } \\
2012 \\
\end{array}$ & es US\$ & $\begin{array}{c}\text { Var.\% } \\
\text { 2012-2013 } \\
\end{array}$ & Par. \% 2013 \\
\hline Mundo & $2,032,122$ & $2,189,916$ & $7.76 \%$ & $100 \%$ \\
\hline 1 Viet Nam & 391,392 & 560,402 & $43.18 \%$ & $26 \%$ \\
\hline 2 Tailandia & 349,538 & 344,901 & $-1.33 \%$ & $16 \%$ \\
\hline 3 China & 162,663 & 183,824 & $13.01 \%$ & $8 \%$ \\
\hline 4 Países Bajos (Holanda) & 123,467 & 149,148 & $20.80 \%$ & $7 \%$ \\
\hline 5 Turquía & 74,027 & 112,021 & $51.32 \%$ & $5 \%$ \\
\hline 6 Egipto & 83,982 & 91,499 & $8.95 \%$ & $4 \%$ \\
\hline 7 España & 93,072 & 89,045 & $-4.33 \%$ & $4 \%$ \\
\hline 8 Estados Unidos de América & 88,282 & 77,653 & $-12.04 \%$ & $4 \%$ \\
\hline 9 India & 59,534 & 66,080 & $11.00 \%$ & $3 \%$ \\
\hline 10 Colombia & 48,462 & 51,321 & $5.90 \%$ & $2 \%$ \\
\hline 11 Bélgica & 29,633 & 45,492 & $53.52 \%$ & $2 \%$ \\
\hline 12 Israel & 40,567 & 44,977 & $10.87 \%$ & $2 \%$ \\
\hline 13 Sudafrica & 23,834 & 28,342 & $18.91 \%$ & $1 \%$ \\
\hline 14 Taipei Chino & 17,287 & 26,113 & $51.06 \%$ & $1 \%$ \\
\hline 15 Francia & 14,014 & 23,785 & $69.72 \%$ & $1 \%$ \\
\hline 16 Arabia Saudita & 18,857 & 18,899 & $0.22 \%$ & $1 \%$ \\
\hline 17 Perú & 14,535 & 18,009 & $23.90 \%$ & $1 \%$ \\
\hline 18 Malasia & 15,864 & 17,485 & $10.22 \%$ & $1 \%$ \\
\hline 19 Chile & 19,329 & 17,281 & $-10.60 \%$ & $1 \%$ \\
\hline 20 Alemania & 14,127 & 16,435 & $16.34 \%$ & $1 \%$ \\
\hline Otros $(116)^{*}$ & 349,656 & 207,204 & $-40.74 \%$ & $9 \%$ \\
\hline
\end{tabular}

*Exportadores en el 2013 
Nota. Fuente: Trademap

\begin{tabular}{|c|c|c|}
\hline \multirow[t]{2}{*}{ Países } & \multicolumn{2}{|c|}{$\begin{array}{l}\text { Peso TN } \\
2013 \text { Par.\% 2013 }\end{array}$} \\
\hline & $2,072,880$ & $100.00 \%$ \\
\hline 1 Viet Nam & 748,073 & $36.09 \%$ \\
\hline 2 Tailandia & 482,847 & $23.29 \%$ \\
\hline 3 Turquía & 135,804 & $6.55 \%$ \\
\hline 4 China & 92,096 & $4.44 \%$ \\
\hline 5 India & 62,389 & $3.01 \%$ \\
\hline 6 Egipto & 58,516 & $2.82 \%$ \\
\hline 7 España & 55,972 & $2.70 \%$ \\
\hline 8 Estados Unidos de América & 40,256 & $1.94 \%$ \\
\hline 9 Países Bajos (Holanda) & 30,462 & $1.47 \%$ \\
\hline 10 México & 26,635 & $1.28 \%$ \\
\hline 11 Israel & 21,807 & $1.05 \%$ \\
\hline 12 Yemen & 21,497 & $1.04 \%$ \\
\hline 13 Arabia Saudita & 21,294 & $1.03 \%$ \\
\hline 14 Madagascar & 18,020 & $0.87 \%$ \\
\hline 15 Senegal & 17,564 & $0.85 \%$ \\
\hline 16 Bélgica & 17,432 & $0.84 \%$ \\
\hline 17 Sudafrica & 16,196 & $0.78 \%$ \\
\hline 18 Taipei Chino & 13,353 & $0.64 \%$ \\
\hline 19 República Árabe Siria & 12,887 & $0.62 \%$ \\
\hline 20 Nicaragua & 11,064 & $0.53 \%$ \\
\hline Otros $(111)^{*}$ & 168,716 & $8.14 \%$ \\
\hline
\end{tabular}

Tabla 25 Principales proveedores mundiales de Otros Frutos Frescos 2013 (TN)

*Exportadores en el 2013 
Figura 26 Participación \% de los principales proveedores de Otros frutos Frescos Año 2013 (US\$)

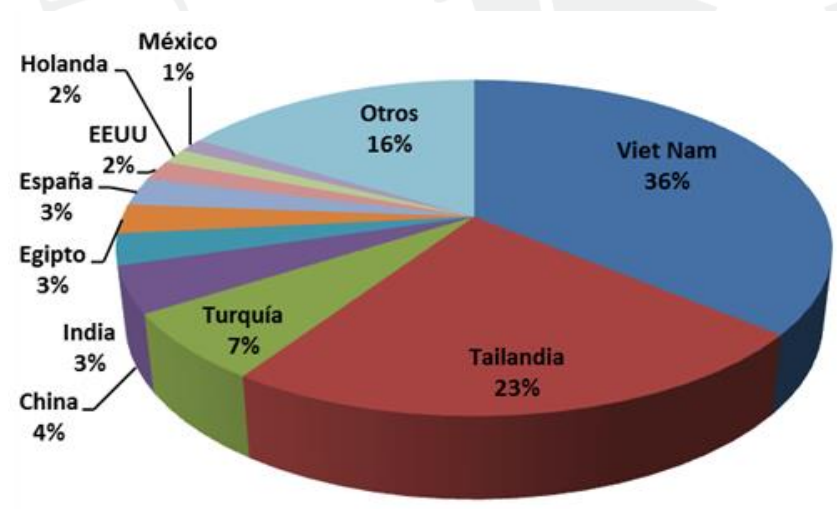

Fuente: Trademap

\subsubsection{Principales proveedores del producto al mercado de destino}

A continuación podemos observar la composición de las importaciones del mercado de destino es: 
Figura 27 Participación \% de los Países proveedores de otras Frutas Frescas a Reino Unido 2014 (US\$)

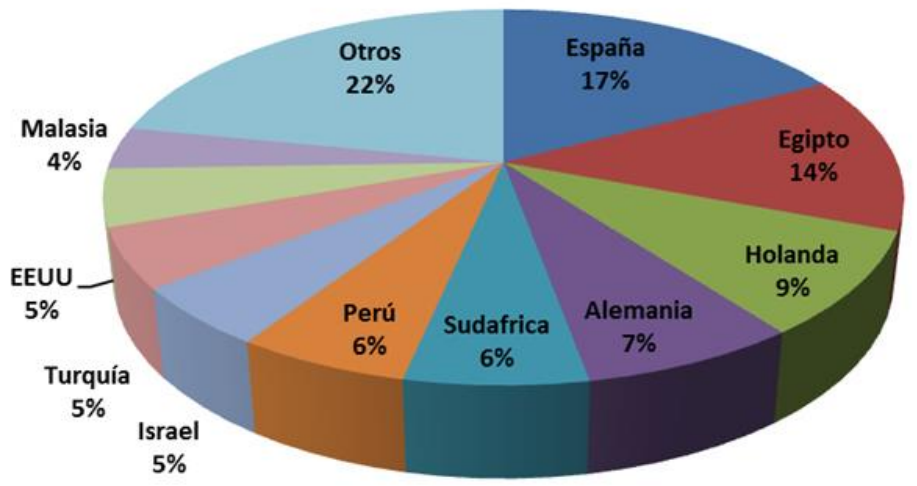

Fuente: Trademap

De acuerdo a la información obtenida durante el 2014 España fue el principal de Otros frutos frescos al Reino Unido, partida bajo la cual se exportan las granadas. Como se mencionó anteriormente, en el 2014 España logró una producción de 50,000 toneladas de la variedad mollar delche. Alrededor del 40 por ciento de la producción, unas 20.000 toneladas, se están destinando al mercado nacional y el 60 por ciento restante de la producción se encara a la exportación.

En el campo de Elche, se cultiva el $50 \%$ de la producción europea de la variedad "Granadas de Elche", considerada la mejor del mundo. (GranaVida, 2014) Son estos factores los que nos hacen considerar a España como nuestra principal competencia. En segundo lugar se encuentra Egipto, desplazando a Holanda, país que actualmente se ubica como tercer proveedor del Reino Unido. Egipto es un importante productor que tradicionalmente implantaba este cultivo para el consumo propio. Los egipcios descubrieron que pueden proveer al mercado europeo de frutas y hortalizas gracias a sus costos competitivos. (Quiles, 2008)

Tabla 26 Principales mercados proveedores para el Reino Unido de Otros frutos frescos 


\begin{tabular}{|c|c|c|c|c|c|c|c|c|c|}
\hline \multirow[b]{2}{*}{ PAISES } & \multirow[b]{2}{*}{2009} & \multicolumn{5}{|c|}{ VALOR FOB US\$ } & \multirow{2}{*}{$\begin{array}{c}\text { Var. \% } \\
2013-2014\end{array}$} & \multirow{2}{*}{$\begin{array}{c}\text { Par.\% } \\
2014\end{array}$} & \multirow{2}{*}{$\begin{array}{l}\text { Crecim. } \\
\text { Prom. \% }\end{array}$} \\
\hline & & 2010 & 2011 & 2012 & 2013 & 2014 & & & \\
\hline Total General & $47,811,000.00$ & $68,172,000.00$ & $86,051,000.00$ & $53,625,000.00$ & $40,974,000.00$ & $47,719,000.00$ & $16.46 \%$ & $1250.35 \%$ & $-0.04 \%$ \\
\hline 1 España & $5,426,000.00$ & $12,165,000.00$ & $15,763,000.00$ & $9,117,000.00$ & $8,576,000.00$ & $8,216,000.00$ & $-4.20 \%$ & $262 \%$ & $8.65 \%$ \\
\hline 2 Egipto & $2,680,000.00$ & $1,869,000.00$ & $2,161,000.00$ & $3,277,000.00$ & $5,242,000.00$ & $6,470,000.00$ & $23.43 \%$ & $160 \%$ & $19.28 \%$ \\
\hline 6 Perú & $652,000.00$ & $973,000.00$ & $2,107,000.00$ & $2,092,000.00$ & $2,663,000.00$ & $2,817,000.00$ & $5.78 \%$ & $81 \%$ & $29.02 \%$ \\
\hline
\end{tabular}

Nota. Fuente: Trademap

Egipto ha incrementado sus envíos de granadas hacia el Reino Unido en 19\% desde el 2009 hasta el 2014 mientras que España ha crecido casi 9\%, en el 2011 fue el año que más exportó el fruto (US\$ 15.763 millones) en el 2014 exportó solo cerca de la mitad de ese valor. A comparación de estos dos países, Perú creció en promedio durante el periodo analizado 29\%, siendo el 2014 el año que más exportó con US\$2.817 millones posicionándose como sexto proveedor del Reino Unido.

España también se encuentra en primer lugar como proveedor para el Reino Unido en términos de cantidad, en el 2014 exportó a ese mercado 4’753,000 kilos disminuyendo 1.80\%. Esta cantidad representó el 28\% de las importaciones versus los 977,000 kilos que exportó el Perú, con una participación de 6\% sobre la cantidad total importada de otros frutos frescos por el Reino Unido. España gradualmente ha ido disminuyendo sus exportaciones de granadas y a partir del 2013 ha mantenido estables las cantidades exportadas. En general el Reino Unido también ha disminuido sus cantidades totales importadas de Otros frutos frescos disminuyendo en promedio desde el 2009 al 2014 $0.04 \%$.

Por otro lado Egipto a diferencia de España ha ido incrementando sus exportaciones año a año con potencial para continuar creciendo. En términos de cantidades exportadas Egipto se encuentra en la posición número 9 con 641,000 kilos enviados en el año 2014 al Reino Unido, cantidad inclusive menor que la exportada por el Perú. Lo que se puede concluir a partir de esto es que la granada proveniente de Egipto obtiene mayores precios, eso también puede depender de las categorías enviadas de la fruta.

Cabe mencionar que Holanda, país que hasta el 2012 fue el segundo proveedor del Reino Unido disminuyó en promedio el valor exportado 21\% entre el 2009 y 2014 y este último año envió 1’370,000 kilos a este mercado. El 2012 fue el año que cayeron más las exportaciones, tiempo también en el que la crisis golpeaba fuertemente a la Eurozona, actualmente sus exportaciones al Reino Unido representan el 9\% de las 
importaciones.

En el 2014 el Perú incrementó sus exportaciones en valor FOB de Otros frutos frescos al Reino Unido en $53.10 \%$, crecimiento mayor al de sus principales competidores.

Cabe mencionar que en términos de cantidades exportadas Estados Unidos ocupa el segundo lugar como proveedor del Reino Unido con casi $10 \%$ de participación de mercado (ver tabla 15), pero en términos de valor ocupa el noveno lugar. EEUU está quinto en el ranking de producción de granadas frescas, detrás de los líderes que son Irán, India, China y Turquía. (Oficina Comercial ProChile Los Ángeles, 2012) Asimismo su principal variedad es la wonderful que es la que Perú también cultiva y exporta en mayor proporción.

\subsubsection{Tendencia de la competencia}

\section{- España}

Tabla 27 Exportaciones de otros frutos frescos por España en Valor (US\$) y Cantidad $(T N)$

\begin{tabular}{crr}
\hline & \multicolumn{2}{c}{ Valor FOB } \\
Años & Miles US\$ & Peso TN \\
\hline 2003 & 73,817 & 61,239 \\
2004 & 89,882 & 69,630 \\
2005 & 94,830 & 81,236 \\
2006 & 115,421 & 98,882 \\
2007 & 145,327 & 102,410 \\
2008 & 159,144 & 97,681 \\
2009 & 135,105 & 93,333 \\
2010 & 178,191 & 121,614 \\
2011 & 229,501 & 156,199 \\
2012 & 140,067 & 89,614 \\
2013 & 144,041 & 84,757 \\
2014 & 112,433 & 72,485 \\
\hline
\end{tabular}

Nota. Fuente: Trademap 
Según los datos extraídos de Trademap, desde el 2003 hasta el 2011 el valor exportado de la partida otros frutos frescos por España se triplicó alcanzando US\$229’501,000, de los cuales US\$15'763,000 fueron destinados hacia el Reino Unido como se puede apreciar en la tabla 26, significando el $7 \%$ de sus exportaciones totales. En general en el año 2012 las exportaciones totales de la partida cayeron en 39\% lo cual también se vio reflejado en sus menores envíos hacia el Reino Unido, disminuyendo 42\%. Durante ese mismo año también disminuyó sus exportaciones a sus 3 principales destinos dentro de la Unión Europea como lo son Italia, Alemania y Francia, España es uno de los principales proveedores de fruta fresca de esta zona.

Por este motivo, uno de los principales objetivos del cultivo de la granada es la exportación en fresco, a la cual destina entre el 50-60\% de la producción. (Quiles, 2008) En el 2012 el Perú exportó hacia el mundo US\$ 14’535,000 de otros frutos frescos lo cual equivale tan solo al $10 \%$ de las exportaciones españolas de la partida hacia el mundo.

En lo que respecta a las cantidades exportadas, del 2003 al 2011, se duplicaron llegando a las 156,199 toneladas de las cuales 9,567 se destinaron al Reino Unido representando $6 \%$ de las exportaciones totales de España. Asimismo como sucedió con los valores exportados, las cantidades totales exportadas disminuyeron en $43 \%$, también a sus principales destinos: Italia, Francia y Alemania.

Tabla 28 Principales destinos de exportación de Otros Frutos Frescos por España (US\$) 2003-2014

\begin{tabular}{|c|c|c|c|c|c|c|c|c|c|c|c|c|}
\hline \multirow[b]{2}{*}{ Paises } & \multicolumn{12}{|c|}{ Valor FOB Miles US\$ } \\
\hline & 2003 & 2004 & 2005 & 2006 & 2007 & 2008 & 2009 & 2010 & 2011 & 2012 & 2013 & 2014 \\
\hline Total General & 73,817 & $\mathbf{8 9 , 8 8 2}$ & 94,830 & 115,421 & 145,327 & 159,144 & 135,105 & 178,191 & 229,501 & 140,067 & 144,041 & 112,433 \\
\hline 1 Italia & 21,651 & 22,404 & 17,561 & 19,997 & 25,371 & 26,628 & 22,543 & 23,938 & 29,019 & 21,940 & 26,654 & 24,585 \\
\hline 2 Alemania & 12,175 & 21,220 & 27,242 & 33,025 & 41,984 & 43,801 & 24,117 & 31,200 & 44,629 & 23,727 & 18,770 & 16,676 \\
\hline 3 Francia & 10,355 & 12,671 & 11,965 & 14,661 & 16,605 & 19,152 & 18,739 & 20,015 & 26,797 & 14,243 & 15,760 & 15,965 \\
\hline 4 Holanda & 2,817 & 3,835 & 4,168 & 5,047 & 6,294 & 5,389 & 9,040 & 12,071 & 13,032 & 11,972 & 11,681 & 8,570 \\
\hline 5 Reino Unido & 4,684 & 5,505 & 5,753 & 7,931 & 9,679 & 9,109 & 5,426 & 12,165 & 15,763 & 9,117 & 8,576 & 8,216 \\
\hline 6 Portugal & 7,417 & 7,630 & 7,526 & 7,743 & 7,677 & 15,225 & 13,113 & 15,854 & 14,194 & 4,531 & 7,103 & 7,692 \\
\hline $\begin{array}{l}7 \text { Irlanda } \\
\text { Federación }\end{array}$ & 242 & 242 & 269 & 503 & 3,523 & 3,029 & 3,502 & 2,483 & 1,728 & 2,663 & 2,751 & 4,237 \\
\hline 8 de Rusia & 340 & 843 & 2,119 & 3,857 & 6,748 & 7,458 & 9,529 & 19,522 & 27,683 & 8,832 & 8,775 & 3,635 \\
\hline 9 Bélgica & 1,686 & 2,205 & 2,389 & 1,918 & 2,032 & 2,742 & 2,796 & 2,939 & 3,387 & 2,548 & 3,006 & 2,951 \\
\hline 10 República Checa & 602 & 882 & 1,156 & 1,047 & 1,706 & 1,153 & 860 & 1,407 & 2,100 & 2,134 & 2,205 & 2,340 \\
\hline Otros $(35) *$ & 11,848 & 12,445 & 14,682 & 19,692 & 23,708 & 25,458 & 25,440 & 36,597 & 51,169 & 38,360 & 38,760 & 17,566 \\
\hline
\end{tabular}

Nota. Fuente: Trademap 
Tabla 29 Participación principales destinos de otros Frutos Frescos exportados por España

\begin{tabular}{|c|c|c|}
\hline Paises & $\begin{array}{c}\text { Var.\% } \\
\text { 2013-2014 } \\
\end{array}$ & Par.\% 2014 \\
\hline Total & $-22 \%$ & $100 \%$ \\
\hline 1 Italia & $-8 \%$ & $22 \%$ \\
\hline 2 Francia & $-11 \%$ & $15 \%$ \\
\hline 3 Alemania & $1 \%$ & $14 \%$ \\
\hline 4 Portugal & $-27 \%$ & $8 \%$ \\
\hline 5 Reino Unido & $-4 \%$ & $7 \%$ \\
\hline 6 Holanda & $8 \%$ & $7 \%$ \\
\hline 7 Irlanda & $54 \%$ & $4 \%$ \\
\hline 8 Bélgica & $-59 \%$ & $3 \%$ \\
\hline 9 Estados Unidos d & $-2 \%$ & $3 \%$ \\
\hline 10 República Checa & $6 \%$ & $2 \%$ \\
\hline Otros $(35)^{*}$ & $-55 \%$ & $16 \%$ \\
\hline
\end{tabular}

Nota. Fuente: Trademap

El principal importador de otros frutos frescos provenientes de España en el 2014 fue Italia con $22 \%$ de participación, seguido por Francia (15\%) y Alemania (14\%). Italia y Francia disminuyeron sus valores importados en $8 \%$ y 11 , respectivamente. Durante el 2014 el Reino Unido se posicionó como quinto destino de exportación de Otros Frutos Frescos para España con 7\% de participación y en este mismo año disminuyó en 4\%, continuando la tendencia a la baja que se ha dado desde el 2012. Durante el 2014 España exportó 72,485 toneladas de Otros Frutos Frescos, disminuyendo la cantidad enviada en $14 \%$, lo cual significa que para este año se obtuvieron menores precios promedios. 
Tabla 30 Principales destinos de exportación de Otros Frutos Frescos por España (TN) 2003-2014

\begin{tabular}{|c|c|c|c|c|c|c|c|c|c|c|c|c|}
\hline \multirow[b]{2}{*}{ Paises } & \multicolumn{12}{|c|}{ Peso TN } \\
\hline & 2003 & 2004 & 2005 & 2006 & 2007 & 2008 & 2009 & 2010 & 2011 & 2012 & 2013 & 2014 \\
\hline Total & 61,239 & 69,630 & 81,236 & 98,882 & 102,410 & 97,681 & 93,333 & 121,614 & 156,199 & 89,614 & 84,757 & 72,485 \\
\hline 1 Italia & 12,738 & 14,853 & 11,563 & 14,718 & 12,794 & 12,984 & 13,746 & 15,177 & 18,559 & 14,800 & 16,779 & 17,560 \\
\hline 2 Francia & 9,151 & 10,203 & 10,686 & 12,707 & 12,760 & 10,673 & 13,483 & 14,986 & 19,928 & 11,608 & 11,650 & 12,311 \\
\hline 3 Alemania & 10,031 & 13,786 & 21,251 & 24,032 & 27,828 & 22,446 & 14,717 & 19,618 & 24,812 & 12,971 & 9,462 & 8,628 \\
\hline 4 Portugal & 6,914 & 6,866 & 6,392 & 7,063 & 5,972 & 12,768 & 12,363 & 10,888 & 11,307 & 3,252 & 5,172 & 5,491 \\
\hline 5 Reino Unido & 4,730 & 6,174 & 5,320 & 8,205 & 6,115 & 5,661 & 3,834 & 6,268 & 9,567 & 5,654 & 4,840 & 4,753 \\
\hline 6 Países Bajos & 2,721 & 3,365 & 3,907 & 4,515 & 5,695 & 4,282 & 3,640 & 9,343 & 9,520 & 8,495 & 5,461 & 4,519 \\
\hline 7 Irlanda & 101 & 82 & 98 & 210 & 2,133 & 1,220 & 1,978 & 973 & 513 & 1,465 & 1,465 & 2,772 \\
\hline 8 Bélgica & 1,549 & 1,679 & 1,960 & 1,259 & 1,219 & 1,317 & 1,936 & 2,177 & 2,318 & 1,943 & 2,171 & 2,242 \\
\hline 9 Estados Unidos d & 52 & 71 & & 18 & & 34 & 108 & 327 & 1,170 & 1,740 & 1,275 & 1,978 \\
\hline 10 República Checa & 660 & 807 & 1,352 & 1,366 & 1,230 & 754 & 562 & 924 & 1,277 & 1,293 & 1,155 & 1,821 \\
\hline Otros $(35)^{*}$ & 12,592 & 11,744 & 18,707 & 24,789 & 26,664 & 25,542 & 26,966 & 40,933 & 57,228 & 26,393 & 25,327 & 10,410 \\
\hline
\end{tabular}

*Paises exportados en el 2014

Nota. Fuente: Trademap

\section{- Egipto}

Tabla 31 Exportaciones de otros frutos frescos por Egipto en Valor (US\$) y Cantidad (TN)

\begin{tabular}{crr}
\hline \multicolumn{3}{c}{ Valor FOB } \\
Años & Miles US\$ & Cantidad (TN) \\
\hline 2003 & 1,745 & 3,965 \\
2004 & 4,066 & 7,122 \\
2005 & 7,113 & 12,255 \\
2006 & 13,553 & 17,822 \\
2007 & 26,430 & 30,437 \\
2008 & 20,760 & 21,876 \\
2009 & 27,284 & 29,891 \\
2010 & 31,402 & 26,996 \\
2011 & 26,038 & 21,631 \\
2012 & 32,966 & 22,017 \\
2013 & 33,710 & 21,509 \\
2014 & 22,012 & 10,472 \\
\hline
\end{tabular}

Nota. Fuente: Trademap 
De acuerdo a los datos obtenidos de Trademap se puede observar que desde el 2003 hasta el 2014 las exportaciones de Egipto de Otros Frutos Frescos aumentaron en más de 12 veces en términos de valor. El valor total exportado en el 2014 fue US\$ 22’012,000 del cual US\$ 6’470,000 se destinaron al Reino Unido (ver Tabla 32), representando 29\%. Del período analizado (2003-2014) el 2014 fue el año en el cual disminuyeron más las exportaciones mundiales de Otros Frutos Frescos por parte de Egipto, 35\%, pero esa tendencia no se dio para Reino Unido ni Jordania, principales destinos de exportación que crecieron. La caída en las exportaciones se dio porque según los datos publicados por Trademap no se registraron envíos a Arabia Saudita, que en el 2013 contaba con $28 \%$ de participación de mercado.

El principal destino de exportación es la Federación de Rusia, país que ya hemos identificado como un gran comprador de granadas, se provee también de España en buenas cantidades y fue el segundo mercado de destino de exportación de las granadas peruanas en el 2014 (ver tabla 1). A pesar que en el 2014 los envíos hacia Rusia disminuyeron, la tendencia ha sido al alza, varios países lo están viendo como un destino atractivo. Egipto ha diversificado sus envíos hacia la Unión Europea sobre todo Europa del Este, pero también provee a los países árabes.

En el 2014 el Perú exportó hacia el mundo US\$ 27’072,000 de otros frutos frescos US\$ 5 millones más que Egipto, pero debemos considerar que en el 2013 sus exportaciones alcanzaron los US\$ 33 millones cifra que el Perú no ha logrado sobrepasar.

Tabla 32 Principales destinos de exportación de Otros Frutos Frescos por Egipto (US\$) 2003-2014

\begin{tabular}{|c|c|c|c|c|c|c|c|c|c|c|c|c|}
\hline \multirow[b]{2}{*}{ Paises } & \multicolumn{12}{|c|}{ Valor FOB Miles US\$ } \\
\hline & 2003 & 2004 & 2005 & 2006 & 2007 & 2008 & 2009 & 2010 & 2011 & 2012 & 2013 & 2014 \\
\hline Total & 1,745 & 4,066 & 7,113 & 13,553 & 26,430 & 20,760 & 27,284 & 31,402 & 26,038 & 32,966 & 33,710 & 22,012 \\
\hline 1 Federación de Rusia & 18 & 344 & 1,717 & 5,641 & 11,588 & 6,119 & 12,050 & 16,755 & 7,857 & 11,574 & 10,928 & 9,975 \\
\hline 2 Reino Unido & 41 & 7 & 91 & 754 & 3,055 & 2,873 & 2,680 & 1,869 & 2,161 & 3,277 & 5,242 & 6,470 \\
\hline 3 Jordania & 1 & - & & 20 & 55 & 2 & 128 & 490 & 458 & 1,306 & 2,149 & 2,163 \\
\hline 4 Holanda & 152 & 404 & 1,060 & 1,094 & 2,767 & 2,521 & 3,077 & 1,250 & 1,175 & 1,167 & 903 & 695 \\
\hline 5 Suiza & 97 & 130 & 109 & 92 & 110 & 132 & 58 & 48 & 74 & 180 & 328 & 445 \\
\hline 6 Belarús & - & 3 & 59 & 648 & 845 & 783 & 971 & 635 & 399 & 1,281 & 666 & 430 \\
\hline 7 Ucrania & - & 3 & 165 & 618 & 955 & 1,683 & 1,929 & 1,224 & 1,021 & 1,624 & 642 & 397 \\
\hline 8 Lituania & - & 160 & 407 & 515 & 615 & 811 & 964 & 215 & 19 & 187 & - & 293 \\
\hline 9 Francia & 36 & 90 & 46 & 95 & 150 & 180 & 68 & 48 & 56 & 17 & 60 & 233 \\
\hline 10 Líbano & 4 & 16 & 3 & 2 & - & - & 10 & 38 & 77 & 52 & 75 & 194 \\
\hline Otros $(17)^{*}$ & 1,396 & 2,909 & 3,456 & 4,074 & 6,290 & 5,656 & 5,349 & 8,830 & 12,741 & 12,301 & 12,717 & 717 \\
\hline
\end{tabular}

Nota. Fuente: Trademap 
Tabla 33 Principales destinos de exportación de Otros Frutos Frescos por Egipto (TN) 2003-2014

\begin{tabular}{|c|c|c|c|c|c|c|c|c|c|c|c|c|}
\hline \multirow[b]{2}{*}{ Paises } & \multicolumn{12}{|c|}{ Peso TN } \\
\hline & 2003 & 2004 & 2005 & 2006 & 2007 & 2008 & 2009 & 2010 & 2011 & 2012 & 2013 & 2014 \\
\hline Total & 3,965 & 7,122 & 12,255 & 17,822 & $\mathbf{3 0 , 4 3 7}$ & 21,876 & 29,891 & 26,996 & 21,631 & 22,017 & 21,509 & 10,472 \\
\hline 1 Federación de Rusia & 49 & 643 & 2,909 & 6,963 & 14,371 & 7,466 & 14,485 & 14,939 & 7,480 & 7,037 & 6,366 & 5,954 \\
\hline 2 Jordania & 1 & & & 15 & 63 & 1 & 52 & 347 & 382 & 906 & 1,538 & 1,560 \\
\hline 3 Reino Unido & 60 & 13 & 87 & 261 & 603 & 581 & 648 & 239 & 245 & 279 & 513 & 641 \\
\hline 4 Países Bajos & 158 & 219 & 533 & 919 & 1,929 & 1,779 & 1,239 & 699 & 726 & 814 & 572 & 422 \\
\hline 5 Belarús & & 3 & 72 & 764 & 799 & 617 & 820 & 466 & 337 & 1,082 & 602 & 417 \\
\hline 6 Lituania & & 194 & 421 & 470 & 558 & 699 & 807 & 147 & 17 & 154 & & 264 \\
\hline 7 Ucrania & & 10 & 447 & 1,623 & 2,656 & 3,415 & 1,583 & 1,263 & 1,183 & 928 & 367 & 228 \\
\hline 8 Líbano & 6 & 15 & 4 & 2 & & & 5 & 30 & 65 & 37 & 82 & 188 \\
\hline 9 Rumania & 9 & 17 & 38 & 123 & 54 & & 39 & & & 20 & & 135 \\
\hline 10 Italia & 93 & 119 & 62 & 188 & 173 & 117 & 75 & & 5 & 92 & 293 & 133 \\
\hline Otros $(17)^{*}$ & 3,589 & 5,889 & 7,682 & 6,494 & 9,231 & 7,201 & 10,138 & 8,866 & 11,191 & 10,668 & 11,176 & 530 \\
\hline
\end{tabular}

Nota. Fuente: Trademap

Respecto a las cantidades exportadas, al igual que los valores disminuyeron en el 2014 a la mitad respecto al 2013 llegando a las 10,472 toneladas. Las cantidades enviadas a Jordania y el Reino Unido aumentaron levemente. Jordania es un destino atractivo para Egipto, debido a la cercanía entre ambos, son países fronterizos por lo que las exportaciones tienen potencial para seguir creciendo.

En el 2014 se exportaron 1,560 de toneladas hacia Jordania y es un destino que gradualmente ha ido creciendo posicionándose en segundo destino de exportación. En tercer lugar le sigue el Reino Unido con envíos de 641 toneladas por parte de Egipto. Por otro lado la Federación de Rusia, que es el principal destino de exportación con 5,954 toneladas (57\% de participación en términos de cantidades) no ha mantenido estables sus cantidades importadas, a partir del 2011 han ido disminuyendo. Las cantidades exportadas han disminuido más respecto a los valores, motivo por el cual se puede deducir que en el 2014 se obtuvieron mejores precios promedios.

\subsubsection{Marco legal de la competencia}

El Reino Unido al igual que España forma parte de la Unión Europea, uno de los principios en los cuales se sustenta esta es el libre comercio. No se requiere más documentación que la ordinaria, sin poder establecer restricciones a la importación, cuotas, tarifas, etc. para aquellos productos que procedan de cualquiera de los países 
miembros de la comunidad europea. (Agencia Andaluza de Promoción Exterior, 2014) Esto brinda una ventaja a España debido a que sus costos se reducen al no tener que pagar a aranceles y evitar los trámites adicionales que muchas veces se imponen a terceros países para exportar. Aun así se tienen que cumplir con las medidas sanitarias y fitosanitarias para que el producto ingrese al mercado, y que se cumpla el principio de inocuidad sobre los alimentos. Además existen una serie de estándares y normativas de calidad y seguridad e higiene que sin modificar la legislación comunitaria, la especifican, de modo que los productos afectados, deben cumplir ambas regulaciones para poder ser comercializados.

En el caso de Egipto la información obtenida de Export Help Desk indica que las granadas provenientes de este país (PA: 0810907530) ingresan al Reino Unido con 0\% de arancel y el IVA es $0 \%$. No se aplican controles de cuotas ni se requieren licencias. Los documentos requeridos para la importación son aproximadamente 10 y casi la mitad son solicitados a nivel de acuerdo comercial. De acuerdo a la plataforma Santander Trade algunos de ellos son:

- Declaración de Factura (puede reemplazar al Certificado de movimiento EUR1 para los exportadores autorizados)*

- Declaración del productor (Verificar reglas de origen)*

- Certificado de Movimiento EUR 1 (Detalles necesarios para identificar el producto)*

- Declaración de entrada por lo menos 24 horas del comienzo del carguío de la mercancía en el puerto

- Declaración Resumen

- Documento Único Administrativo

- Documento de tránsito acompañante

- Manifiesto de Carga

* A nivel de acuerdo comercial negociado entre Egipto y la Comunidad Europea.

De los documentos mencionados para la importación, a España se le exige únicamente 4, que son la Declaración de Entrada, Documento Único Administrativo, Declaración Resumen, Manifiesto de Carga. (Santander Trade Portal , 2014)

\subsubsection{Mix comercial de la competencia}




\section{Producto}

- España:

Descripción Arancelaria: Granadas

Nombre comercial: Granadas Frescas

Partida Arancelaria (código TARIC): 0810907530

El TARIC es el código del Arancel Integrado de las Comunidades Europeas (TARIC). Está integrado por la nomenclatura arancelaria (compuesto por capítulos, partidas y subpartidas) y los derechos arancelarios.

- Egipto:

Descripción Arancelaria: Otras frutas, frescas, distintas de las especificadas.

Código del producto: 0810900090

\section{Precio}

España es el tercer exportador en el mundo de la partida otros frutos frescos, y uno de los mayores productores de granadas en el mundo. Este país cultiva el 95\% de la Unión Europea de granadas, siendo las regiones productoras principales Murcia y Alicante, la variedad de mayor calidad es la Mollar de Elche.

Según las investigaciones de la universidad Miguel Hernández en España La superficie de cultivo en España alcanza las 2.325 ha con una producción de 27.389 t, siendo la provincia de Alicante la principal productora con 2.047 ha y 25.104 t (MAPA, 2007); es decir, el cultivo se concentra en esta provincia con el $88 \%$ de la superficie nacional y el 92\% de la producción, y en la vecina provincia de Murcia se cultiva prácticamente el resto. En términos de la superficie cultivada a partir de 1980 se produce un gran crecimiento, alcanzándose el máximo histórico de 3.300 ha en el año 2000 y en 2008 la superficie plantada ascendía a 2.885 ha (MAPA (1999); MMARM (2009), Esto se debe a la progresiva evolución del precio obtenido por el agricultor. (Poscosecha, 2010)

Tabla 34 Valores unitarios por kg de Otros Frutos frescos exportados por España

\begin{tabular}{lrrrrrrrrrrrr}
\hline Año & $\mathbf{2 0 0 3}$ & $\mathbf{2 0 0 4}$ & $\mathbf{2 0 0 5}$ & $\mathbf{2 0 0 6}$ & $\mathbf{2 0 0 7}$ & $\mathbf{2 0 0 8}$ & $\mathbf{2 0 0 9}$ & $\mathbf{2 0 1 0}$ & $\mathbf{2 0 1 1}$ & $\mathbf{2 0 1 2}$ & $\mathbf{2 0 1 3}$ & $\mathbf{2 0 1 4}$ \\
\hline Precio US\$/KG & 1.21 & 1.29 & 1.17 & 1.17 & 1.42 & 1.63 & 1.45 & 1.47 & 1.47 & 1.56 & 1.70 & 1.55 \\
\hline
\end{tabular}

Nota. Fuente: Trademap

Desde el año 2002 hasta el 2008 el precio promedio creció en 35\%, pero en el año 2009 disminuyó y para los siguientes años (2010 y 2011) se mantuvo estable aumentando 
nuevamente en el 2013. En el 2014 se pudo observar una leve caída alcanzando US\$ 1.55/kg de Otros Frutos Frescos. En el 2009 las cantidades exportadas disminuyeron pero en menor grado que el valor total exportado, lo que se puede deducir es que los países compradores estaban dispuestos a pagar menos por el producto, sobre todo los principales destinos de exportación que son países de la Unión Europea afectados por la crisis financiera. El precio obtenido equivale al promedio de toda la variedad de otras frutas frescas incluidas en la partida, pero nos ayuda a tener una referencia de los precios ofertados de granadas por España, el principal exportador de granadas en la Unión Europea.

Tabla 35 Valores unitarios por $\mathrm{kg}$ de Otros Frutos frescos exportados por Egipto

\begin{tabular}{lrrrrrrrrrrrr}
\hline Año & $\mathbf{2 0 0 3}$ & $\mathbf{2 0 0 4}$ & $\mathbf{2 0 0 5}$ & $\mathbf{2 0 0 6}$ & $\mathbf{2 0 0 7}$ & $\mathbf{2 0 0 8}$ & $\mathbf{2 0 0 9}$ & $\mathbf{2 0 1 0}$ & $\mathbf{2 0 1 1}$ & $\mathbf{2 0 1 2}$ & $\mathbf{2 0 1 3}$ & $\mathbf{2 0 1 4}$ \\
\hline Precio US\$/kg & 0.44 & 0.57 & 0.58 & 0.76 & 0.87 & 0.95 & 0.91 & 1.16 & 1.20 & 1.50 & 1.57 & 2.10 \\
\hline
\end{tabular}

Durante el período del 2003 hasta el 2014 el precio promedio de Otros Frutos Frescos exportados por Egipto incrementó 378\% alcanzando en el 2014 US\$ 2.10 por KG. Comenzó con precios bastante bajos, US\$ 0.44 por $\mathrm{KG}$, pero año a año ha ido incrementándose. Cabe mencionar que Egipto es uno de los más grandes productores de granadas en África, en el 2003 aún exportaba volúmenes pequeños, 3,965 toneladas a comparación de España que exportó 61,239. Este último destina la mayor parte de su producción hacia la exportación y una menor cantidad se destina para el consumo interno. A continuación podemos observar los precios promedio por kg de Otros Frutos Frescos exportados por Perú, que es la partida con la cual se exportan las granadas.

Tabla 36 Valores unitarios por kg de Otros Frutos frescos exportados por Perú

\begin{tabular}{|c|c|c|c|c|c|c|c|c|c|c|c|c|}
\hline Año & 2003 & 2004 & 2005 & 2006 & 2007 & 2008 & 2009 & 2010 & 2011 & 2012 & 2013 & 2014 \\
\hline Precio US\$/KG & 1.64 & 1.70 & 1.76 & 1.69 & 1.73 & 2.05 & 2.28 & 2.70 & 2.84 & 2.81 & 2.83 & 2.69 \\
\hline
\end{tabular}

En el período correspondiente a los años 2003-2014 el precio de las granadas aumentó en $65 \%$ con una marcada tendencia de crecimiento durante este tiempo. La ventana comercial se da durante los meses de marzo a junio, que son los meses en los cuales nuestro principal competidor, España no exporta granadas y el precio incrementa. A comparación de los precios españoles, los precios obtenidos por Perú son mayores, el 
más alto se dio en el año 2011, y el principal destino de exportación fue Holanda. En el 2014 el precio se ubicó en US\$ 2.69 por kilo. Egipto cuenta con mejores precios que España, pero de todas formas los precios de Perú son más altos. Es importante mencionar que los precios son promedio debido que la partida Otros Frutos Frescos engloba más productos que las granadas.

\section{Plaza}

España tiene la ventaja de encontrarse geográficamente cercana al Reino Unido, por lo que sus costos logísticos son menores a comparación de los nuestros. El principal objetivo del cultivo de granadas en España es la exportación, pero en los últimos años están realizando acciones para incrementar el consumo interno. Respecto a los mercados nacionales de granada destacan los correspondientes a las dos grandes ciudades españolas, Mercamadrid en Madrid y Mercabarna en Barcelona. (Poscosecha, 2010)

Prácticamente todas las fruterías de la Unión Europea cuentan con granadas, las exportaciones de granadas provenientes de España son en fresco, los productos derivados de las granadas como son los zumos, néctares, extractos, mermeladas aumentan significativamente su comercialización y cuota de mercado fuera de sus fronteras. (Poscosecha, 2010) Por este motivo las granadas se distribuyen a grandes cadenas de supermercados donde se venden frescas, pero también son utilizadas para producir diferentes productos derivados en los cuales se concentren todas las propiedades de la fruta.

En el caso de otro de nuestros competidores, Egipto, no hay mucha información disponible al respecto. Se conoce que es un importante productor a nivel mundial y el consumo local es bastante significativo, pero en los últimos años ha desarrollado el negocio de la exportación sobretodo proveyendo de frutas y hortalizas a la Unión Europea, la granada se exporta en fresco.

De acuerdo a la información publicada por Euromonitor en el documento "Fruits in the United Kingdom" el formato de distribución predominante para el mercado de frutas es el retail, seguido de los autoservicios e institucional. 
Los países proveedores de este mercado tienen la opción de exportar a las cadenas retail directo hacia el consumidor final o hacerlo a través de un distribuidor/mayorista.

Tabla 37 Distribución de Frutas en el Reino Unido por formato: \% del volumen total 2008-2013

\begin{tabular}{lrrrrrr}
\hline Distribution Format & $\mathbf{2 0 0 8}$ & $\mathbf{2 0 0 9}$ & $\mathbf{2 0 1 0}$ & $\mathbf{2 0 1 1}$ & $\mathbf{2 0 1 2}$ & $\mathbf{2 0 1 3}$ \\
\hline Retail & 83.2 & 83.4 & 83.4 & 83.5 & 83.6 & 83.1 \\
Foodservice & 14.1 & 14 & 14 & 13.9 & 13.8 & 13.4 \\
Institutional & 2.7 & 2.6 & 2.6 & 2.6 & 2.6 & 3.5 \\
Total & 100 & 100 & 100 & 100 & 100 & 100 \\
\hline
\end{tabular}

Nota. Fuente: Euromonitor - Fruits in the United Kingdom

\section{Promoción}

Gracias a la difusión de las propiedades y beneficios para la salud que tienen las granadas estas se han hecho cada vez más conocidas, en el mercado del Reino Unido son muy apreciadas debido a la concientización que ha ocurrido durante los últimos años por consumir alimentos más saludables. Diversos estudios científicos demuestran el poder del zumo de granada como antioxidante natural en concentraciones muy superiores a las encontradas en otros alimentos.

Nuestro principal competidor, España, concentra la mayor parte de sus esfuerzos en realizar campañas de promoción de consumo de granadas en el mercado local a través de la Asociación de Productores y Comercializadores de Granadas de Elche. Por ejemplo durante el 2014 puso en marcha una campaña de promoción en los mercados de Madrid, en la se ofrecieron degustaciones gratuitas de granadas de Elche así como demostraciones sobre cómo pelar la granada. Una de sus estrategias es no solo promocionar la fruta sino también la variedad (mollar delche) y su calidad, también se diferencia por su dulzor y carencia de pepitas. El presidente de la Asociación precisó que el objetivo de esta campaña es dar a conocer esta fruta entre los consumidores para fomentar su consumo a nivel nacional. (Granadas de Elche, 2014)

Asimismo asisten a ferias locales como la "Fruit Attraction" que se realiza en Madrid. Otras de las acciones bastante ingeniosas que ha realizado la Asociación de Productores y Comercializadores de Granadas de Elche en el 2014 fue firmar un convenio de 
colaboración para promocionar, difundir y divulgar los valores y propiedades de la granada mollar de Elche con Elche Club de Fútbol.

Por otro lado ha desarrollado el Proyecto Granatum Plus el cual cuenta con su propia página (www.zumodegranadas.com) en donde se publican artículos relacionados a las propiedades y beneficios de las granadas. Combina investigación y desarrollo, colaboran laboratorios y empresas agroalimentarias de toda España que cuentan con más de 14 años de experiencia en la extracción de zumos, concentrados y extractos de la granada cultivada en España

Respecto a la promoción en mercados internacionales una de las ferias a las que asisten los exportadores de granadas provenientes de España es la "Fruit Logística" que se realiza en Berlín, Alemania todos los años. Es el principal lugar de encuentro internacional del comercio de productos frescos donde se presentan más de 2,700 empresas. FRUIT LOGISTICA ofrece excelentes oportunidades para establecer contacto con los principales grupos objetivos a nivel de toma de decisiones en el mercado de los productos frescos. (Messe Berlin, 2015) La próxima edición se realizará del 3 al 5 de Febrero del año 2016. España tiene la ventaja de estar cerca, por lo que incurre en menores costos, lo que le puede permitir invertir ese dinero en obtener un mejor stand y contar con una mejor promoción para su producto.

\subsubsection{Análisis FODA de la competencia}

\subsubsection{Análisis de la comercialización}

\section{- FODA España}

Se analizarán las fortalezas, oportunidades, debilidades y amenazas respecto a las exportaciones de granadas provenientes de España hacia el Reino Unido. 


\section{FORTALEZAS}

DEBILIDADES

- Prácticamente el único productor de importancia de granadas de la Unión Europea y el único proveedor europeo de granadas.

- Problemas en la calidad surgidas por: material genético heterogéneo, frutas con insuficiente color o tamaño.

- En el mercado local los españoles no temen la competencia de • Variedades plantadas en España normalmente presentan un otros países, ya que están muy acostumbrados a la granada tipo dulce como es la española.

- Alicante es la provincia en la cual se concentra el $90 \%$ de la producción de granadas de Europa menor color exterior que las que provienen de otros países - No hay mucha producción con valor agregado, la mayor parte de su exportación es en fresco.

- Los mayores costos y el euro revalorizado ponen en - Compromiso rural con los agricultores de la zona, fomentando desventaja al producto español frente al hindú, turco, iraní. la sostenibilidad y el desarrollo agrario - Factores climáticos los cuales puedan afectar la producción, - La mayor parte de su producción (96\%) se basa en la variedad calentamiento global.

Mollar de elche, una de las más aceptadas y demandadas en la • No hay mucho consumo de granadas en el mercado interno a UE por su dulzor y carencia de pepitas. comparación de otros países de Europa.

\section{OPORTUNIDADES}

- Proyecto para el aprovechamiento integral de la granada:

desarrollo de máquina des granadora.

- Gran potencial para desarrollar nuevos productos derivados

de los arilos.

- Cercanía con el mercado de destino, disminuyen los costos

logísticos.

- España y Reino Unido ambos pertenecen a la Unión Europea.

Preferencias arancelarias y menos documentos solicitados para

la importación

- Se han incrementado notablemente las exportaciones,

producción de granada crece todos los años.

- En los últimos años han adquirido importancia los destinos Alemania, Francia e Italia.

- La granada mollar se encuentra en pleno trámite para obtener la denominación de origen protegida para proteger la calidad de los alimentos

\section{- FODA Egipto}

Se analizarán las fortalezas, oportunidades, debilidades y amenazas respecto a las exportaciones de granadas provenientes de Egipto hacia el Reino Unido. 


\begin{tabular}{|c|c|}
\hline FORTALEZAS & DEBILIDADES \\
\hline $\begin{array}{l}\text { - Granadas eran altamente valoradas en el antiguo Egipto } \\
\text { (símbolo de prosperidad y ambición) } \\
\text { - Importante productor que tradicionalmente implantaba este } \\
\text { cultivo para el } \\
\text { consumo propio. } \\
\text { - El uso de antitranspirantes para reducir el agrietado de los } \\
\text { frutos fue descrito hace ya } 30 \text { años en Egipto. } \\
\text { - Cuentan con mano de obra barata y, por tanto, un producto } \\
\text { más asequible } \\
\text { - En Assiut se encuentra el área con la concentración de } \\
\text { granada más alta del mundo es un cultivo estratégico para el } \\
\text { país. } \\
\text { - Execelente clima y tierra fértil } \\
\text { - Cuenta con aproximadamente más de } 9 \text { variedades de } \\
\text { granadas }\end{array}$ & $\begin{array}{l}\text { - Uso intensivo de pesticidas y técnicas de poda obsoletas. } \\
\text { - Incapacidad de los agricultores para comercializar sus } \\
\text { cosechas como un cuerpo colectivo lo que resulta en } \\
\text { intermediarios que consiguen sus productos a precios más } \\
\text { bajos } \\
\text { - No se exporta producción con valor agregado } \\
\text { - Calidad inferior a la de sus competidores cercanos como Irán } \\
\text { y Turquía }\end{array}$ \\
\hline OPORTUNIDADES & AMENAZAS \\
\hline $\begin{array}{l}\text { - PNUD se asoció con otras tres agencias de la ONU para } \\
\text { implantar las "cadenas de valor de Horticultura a favor de los } \\
\text { pobres" en el Alto Egipto } \\
\text { - Mayor cercanía que Perú hacia el mercado de destino } \\
\text { - Las exportaciones egipcias de granada cuentan con una } \\
\text { ventana comercial, debido a que se dan cuando España deja de } \\
\text { exportar } \\
\text { - Egipto es uno de los países que más ha crecido como } \\
\text { proveedor de frutas y verduras a la Unión Europea }\end{array}$ & $\begin{array}{l}\text { - Creciente competencia de otros proveedores } \\
\text { - Compite directamente con Perú por el mercado Europeo } \\
\text { - Se encuentra geográficamente cerca de Irán (el mayor } \\
\text { productor de granadas) } \\
\text { - Produce variedades como la "Black" y "Yellow" que también } \\
\text { la produce Irán, pero es de mayor de calidad que la egipcia }\end{array}$ \\
\hline
\end{tabular}

\subsubsection{Decisiones sobre el producto}

\subsubsection{Ficha técnica del producto}

- Nombre: Granada Fresca

- Segmento: Alimentos, Bebidas y Tabaco/ Frutas, verduras y Frutos secos/ verduras

- Código ONU: 50305900

- Unidad de Medida: Kilogramo $(\mathrm{kg})$

- Descripción general: Es una baya grande con piel brillante y gruesa contiene numerosas semillas, con arilo muy gustoso de color rojo vivo violáceo.

- Características: Técnicas del Bien: Su interior está dividido por medio de una membrana blanquecina donde cada receptáculo alberga numerosas semillas de color rosa o rojo de sabor agridulce.

- Variedad Wonderful: una fruta más grande que lo normal con un sabor más agradable. Su carne es roja, jugosa con un sabor agudo. Crece bien en el suelo alcalino 
que mataría a la mayoría de las plantas. Crecimiento de hasta cerca de 20 pies (aprox. 6metros) de alto o acortados a la forma. (AMPEX, 2006)

- Cultivo tardío: Color Rosado

- Cáscara: Color Rosado - Rojo Oscuro

- Sabor: Agridulce

- Época de Cosecha: Febrero a Junio

- Color de arilos: Rojos

- Suavidad de las semillas: mediana

- Grosor de cáscara: Mediano

- Peso: Aprox. $650 \mathrm{~g}$ (de acuerdo al calibre)

- Calibre: 5', 6', 7', 8', 9', 10',12', 15'

- Piel: $10-15 \mathrm{~cm}$ de diámetro

\subsubsection{Empaque y Embalaje}

El empaque de exportación para las granadas consistirá en cajas de cartón corrugado de $3.8 \mathrm{~kg}$ a $4 \mathrm{~kg}$, dentro de las cuales irán las granadas dentro de bolsas de atmósfera y humedad modificada con el objetivo de prolongar la vida útil del producto. Cabe mencionar que el sobrepeso de las cajas varía entre 3\% a 5\% dependiendo de la presentación. Estas cajas se colocarán en los pallets que irán dentro del contenedor refrigerado, a continuación se detalla las especificaciones técnicas. El peso de la caja más la bolsa es de 298 gramos, por lo que el peso total de las cajas será de $4.298 \mathrm{~kg}$ aproximadamente.

CAJAS: Caja genérica para $3.8 \mathrm{Kg}$. color blanca litografiada marca (Ver Anexo 01) Medidas: 30 × 33 × 12 cms.

Figura 28: Boceto de caja de exportación

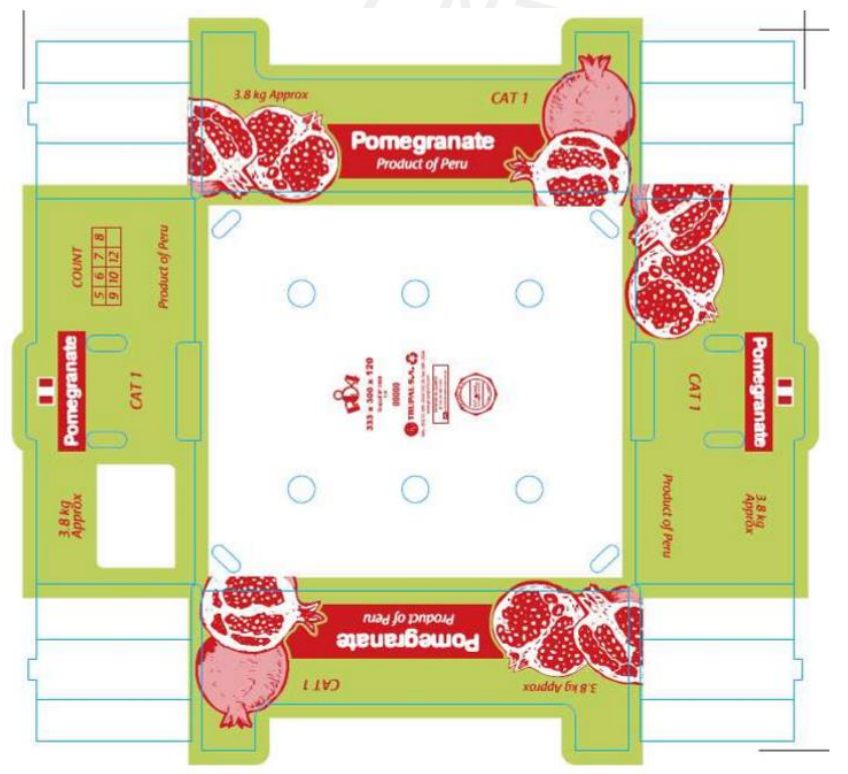


Bolsas Xtend: Acomodar las bolsas adentro de la caja, sobre todo para el lado que da para el interior del túnel de frio.

STICKERS: Pegar un sticker color naranja en un lado largo y corto de la caja Medidas: 4.1 x $4.7 \mathrm{~cm}$, el cual variará de acuerdo al peso final de producto entre $3 \% \mathrm{y}$ $5 \%$.

Figura 29 Empaque de las granadas

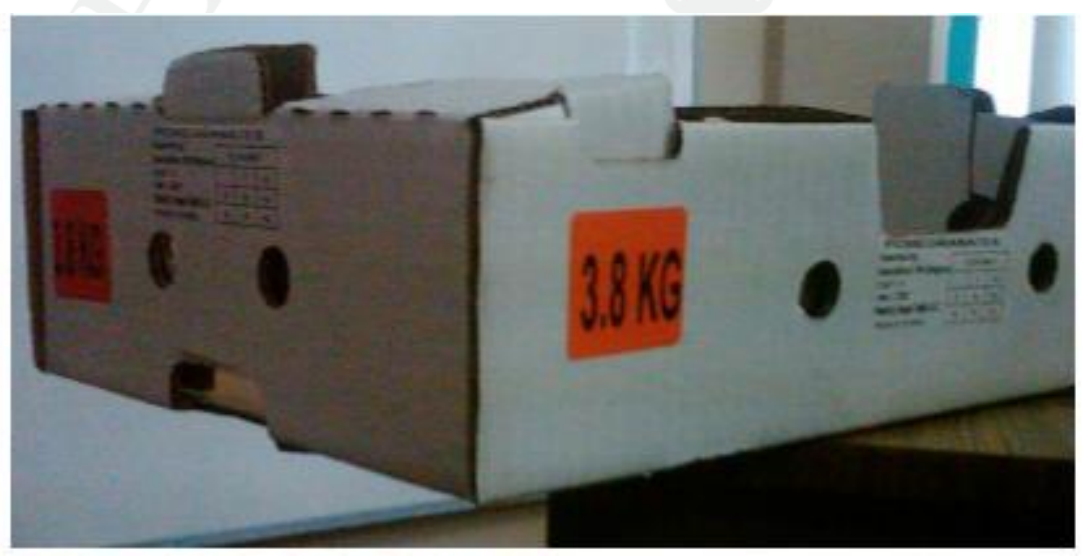

\subsubsection{Etiquetado}

Las granadas serán comercializadas a un consumidor final, al cual se le debe transmitir la información pertinente relacionada al producto ya que es muy importante que se cumpla con la normativa y reglas de etiquetado que permiten mantener la inocuidad del producto.

La empresa deberá de brindar esta información al proveedor final para que este la transmita. La información obligatoria debe ser fácilmente comprensible y visible, claramente legible $y$, en su caso, indeleble. La altura de los caracteres ' $x$ ' debe ser al menos 1,2mm (excepto para los envases o recipientes de pequeño tamaño).

Lista de menciones obligatorias:

- El nombre 
- Clase o calibre

- Lista de ingredientes

- Sustancias que causan alergias o intolerancias

- La cantidad de determinados ingredientes o categorías de ingredientes

- La cantidad neta del alimento

- La fecha de duración mínima o fecha de caducidad

- Las condiciones especiales de almacenamiento y /o utilización

- El nombre o razón social y domicilio del productor o importador

- Instrucciones de uso, cuando su ausencia haría difícil el uso adecuado del producto alimenticio

- Una declaración nutricional.

La información obligatoria debe aparecer en una lengua fácilmente comprensible para el consumidor y, en su caso, en varios idiomas. Específicamente para el mercado del Reino Unido la etiqueta al menos debe estar en inglés. (European Comission Trade, 2015)

\subsubsection{Información Adicional}

Es importante tomar en consideración otros requisitos de entrada impuestos por la Unión Europea como:

\section{- Control de los contaminantes alimenticios en los alimentos}

Los alimentos (inclusive frutas y verduras, carne, pescado, cereales, especias, productos lácteos) que contengan contaminantes a una cantidad inaceptable desde el punto de vista de la salud pública y, en particular, a un nivel toxicológico, no podrán ingresar en el mercado de la UE y serán rechazados. El Reglamento (CE) no 1881/2006 de 19 de diciembre de 2006 que fija el contenido máximo de determinados contaminantes en los productos alimenticios (DO L-364 20/12/2006) (CELEX 32006R1881) fija el contenido máximo de determinados contaminantes en los productos alimenticios que ingresen al mercado de la UE. 
- Control de los residuos de plaguicidas en productos alimenticios de origen vegetal y animal

Las importaciones de productos vegetales y animales deben cumplir con los límites máximos de residuos de plaguicidas (LMR) establecidos por la Comisión Europea para proteger a los consumidores de la exposición a niveles inaceptables de residuos de plaguicidas.

El Reglamento (CE) nº 396/2005 del Parlamento Europeo y del Consejo (DO L70 16/03/2005) (CELEX 32005R0396) define un conjunto totalmente armonizado de normas sobre residuos de plaguicidas. Las granadas sí son un producto al cual se debe aplicar el criterio de los límites máximos de residuos de plaguicidas, en la base de datos de pesticidas de la Unión Europea (EU Pesticides database) se pueden encontrar los LMRs por producto, el código de las granadas es 0163050 .

\section{- Control sanitario de los productos alimenticios de origen no animal}

Cuando un problema de higiene que pueda representar un riesgo grave para la salud humana higiene surge o se extiende en el territorio de un tercer país, las autoridades europeas podrán suspender las importaciones procedentes de la totalidad o parte del tercer país en cuestión o adoptar medidas cautelares con respecto a los productos alimenticios en cuestión, en función de la gravedad de la situación.

Las normas de higiene relevantes de los alimentos que deben ser respetados por los operadores de empresas alimentarias de terceros países figuran en el Reglamento (CE) n ${ }^{\circ}$ 852/2004 del Parlamento Europeo y del Consejo.

\section{- Control fitosanitario}

Las importaciones en la Unión Europea (UE) de plantas, productos vegetales y cualquier otro material capaz de albergar plagas de las plantas (por ejemplo, productos de madera y contenedores, el suelo, etc.) pueden estar sujetos a las siguientes medidas de protección, según lo establecido por la Directiva 2000 / 29 / CE (DO L-169 10/07/2000) (CELEX 32000L0029):

1. Prohibiciones de importación 
2. Certificado fitosanitario y / o certificado fitosanitario para la reexportación

3. Inspección de Aduanas y fitosanitarias cheques

4. Importadores Registro

5. Avanzar notificación de las importaciones

- Trazabilidad, cumplimiento y responsabilidad en los alimentos y los piensos Los alimentos y operadores de empresas de piensos deberán cumplir las obligaciones específicas establecidas por el Reglamento (CE) no 178/2002 del Parlamento Europeo y del Consejo (DO L 31 de 01/02/2002) (CELEX 32002R0178), que abarca todas las etapas de alimento / producción de piensos y distribución:

1. El cumplimiento de la legislación alimentaria: requisitos pertinentes de la legislación alimentaria o condiciones reconocidas por la UE por lo menos equivalente a éstas.

2. Trazabilidad: capacidad de rastrear y seguir cualquier alimento, pienso, animal o sustancia que se utilizará para el consumo, a través de todas las etapas de producción, transformación y distribución. (Incluido para las frutas y vegetales)

3. Responsabilidades: Los operadores en todo momento deben poder asegurar que los alimentos satisfacen los requerimientos de la legislación alimentaria. (European Comission Trade, 2015)

Las granadas frescas serán comercializadas por los distribuidores a los cuales exportaremos y debemos brindar toda la información pertinente para no incurrir en una falta. El producto se exportará en fresco hacia los consumidores finales, para que compren la fruta y la adopten en su dieta diaria. Otro uso que también se le estará dando es para ser utilizada en la producción de derivados de la granada, algunos productos son los zumos de granada, los arilos congelados, cápsulas.

\subsubsection{Decisiones sobre el precio}

\subsubsection{Método para determinación de precios}


El precio de la granada es mayor al de su competencia, España. Se estará utilizando el método de la competencia, para que así podamos identificar nuestra posición con relación a los otros países, y aprovechar la ventana comercial, cuando nuestros principales competidores no están exportando para incrementar el precio. Como vimos en la figura $\mathrm{N}^{\circ} 16$ la estacionalidad de la granada peruana se da entre los meses de Enero a Marzo, debemos aprovechar los meses de Marzo y Abril para descremar el mercado y tomar la oportunidad para dictar los precios.

Debido que muchos de nuestros competidores como España, Egipto, Israel no cuentan con granadas en esa época, podemos salir al mercado y obtener mayores márgenes de ganancia.

\subsubsection{Fijación de precios}

Para poder fijar el precio nos basaremos en los precios referenciales obtenidos a lo largo de los último años para poder encontrarnos en similar posición que nuestra competencia local.

Tabla 38 Valores unitarios por kilogramos de granadas exportadas por Perú

\begin{tabular}{|c|c|c|c|c|c|c|c|c|c|c|c|c|}
\hline Año & 2003 & 2004 & 2005 & 2006 & 2007 & 2008 & 2009 & 2010 & 2011 & 2012 & 2013 & 2014 \\
\hline Precio I & 1.54 & 1.53 & 1.72 & 1.61 & 1.64 & 2.01 & 2.29 & 2.70 & 2.84 & 2.79 & 2.78 & 2.67 \\
\hline
\end{tabular}

Nota. Fuente: SUNAT

En la tabla superior podemos ver los precios en dólares por kilo correspondientes solo a las exportaciones de los frutos de la granada. La presentación que nuestra empresa estará exportando, son cajas de $3.8 \mathrm{~kg}$, por lo que tomando el precio del 2014 fijaremos nuestro precio FOB en aproximadamente 7 dólares.

Vamos a tomar como referencia para el precio a un país que se está posicionando cada vez más en el mercado de las granadas, a pesar de que no se encuentre entre los principales competidores, es un país muy cercano de nosotros del que tenemos mucho que aprender ya que ellos han sabido sacarle provecho a las herramientas de marketing para promocionar sus granadas. El precio de una caja de 4kg de Granadas provenientes de Chile ofrecida al mercado europeo se sitúa en 10 euros, lo que equivale a aproximadamente USD\$12. Es allí donde podemos sacar ventaja en costos, debido a que nosotros también ofreceremos un producto de calidad, pero a un menor precio. 


\subsubsection{Política de pago}

El entorno de negocio actual cada vez ofrece mejores condiciones para sus participantes, entre ellas se encuentran variadas opciones de pago que permiten facilitar el intercambio entre importadores y exportadores. Lo ideal para nuestra empresa sería comenzar con una política de pago adelantado, pero debido a que no es tan simple que un comprador confíe en una empresa que recién inicia, tendremos que ser más flexibles. El medio de pago más apropiado dada nuestra situación sería la carta de crédito. El único problema es que se incurren en costos muy altos, pero estos permiten asegurarnos el pago y le da la confianza al importador de que recibirá su mercancía una vez que reciba toda la documentación estipulada. Les brindaremos la alternativa a nuestros clientes de optar por la forma de pago $30 \%$ prepago/70\% contra documentos y carta de crédito a la vista. Con relación a los INCOTERMS 2010 se estará utilizando el FOB para así poder delimitar de una mejor manera las responsabilidades y deberes de cada uno.

\subsubsection{Política de descuento}

En el primer año no estaremos aplicando una política de descuento, debido a que primero queremos posicionarnos en el mercado y también a partir del segundo año exportar mayores cantidades. Nuestro precio como hemos visto a comparación del chileno se encuentra en una posición competitiva y accesible para nuestros compradores. Luego en el segundo año dependiendo del cliente que sea, la cantidad que vaya importar y el medio de pago a utilizar se podría aplicar una política de descuento que oscile entre el $2 \%$ y $5 \%$.

\subsubsection{Decisiones sobre plaza}

\subsubsection{Cobertura de Mercado}

Nos estaremos enfocando en el mercado de Londres y ciudades aledañas, por ser la capital y contar con una población de casi 9 millones de personas lo que la ubica como la ciudad más poblada del Reino Unido. Asimismo se encuentra entre las ciudades europeas más pobladas y es la ciudad más grande de Europa. De acuerdo al 
profesor Michael Batty de "University College of London" gran parte del crecimiento de la población en los últimos 10 años se debió a la migración internacional, lo cual podría hacer difícil predecir su tamaño en el futuro. La esperanza de vida de los londinenses ha incrementado de 62 años en 1939 a 82 en la actualidad. (BBC News, 2015)

Asimismo también debemos tomar en consideración otras ciudades importantes como Birmingham, Glasgow, Liverpool y otras, a las cuales el producto también puede llegar debido a que la exportación se realizará a un distribuidor.

Nuestro comprador principal será Fruco PLC, es un importador líder que y distribuidor de productos frescos a lo largo del Reino Unido. En el anexo $\mathrm{n}^{\circ} 2$ se muestra un directorio de otros posibles clientes a los cuales podemos ofertar nuestro producto en el Reino Unido, la mayoría son distribuidores. Hay un mercado más grande que atacar y el cual debemos aprovechar porque está siguiendo las tendencias de consumo de alimentos saludables. Sumado a que Inglaterra es uno de los países donde más se ha difundido los beneficios de la granada. Son consideradas una súper fruta por proteger y prevenir las enfermedades del corazón gracias a sus altos contenidos de antioxidantes.

Fruco PLC es un importador líder y distribuidor de productos frescos en todo el Reino Unido e Irlanda. La ubicación geográfica de la sede principal de la compañía es ideal debido a que se encuentra a poca distancia de los principales puertos donde llegan las frutas, Tilbury, Sheerness, Dover y Portsmouth. (Fruco PLC , 2015)

\section{Figura 30: Oficinas de Fruco PLC}

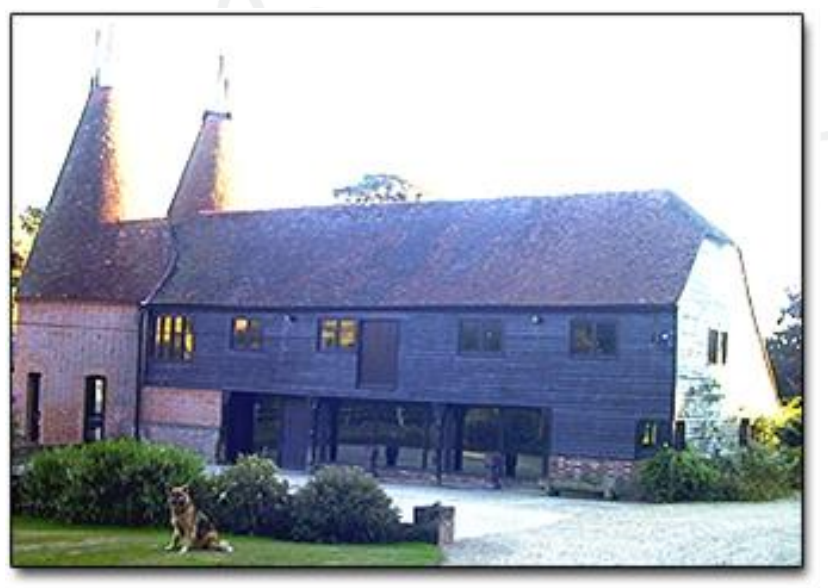




\subsubsection{Logística}

El transporte a utilizar será el marítimo, debido a la gran distancia que existe entre el Reino Unido y Perú, además que se busca exportar volúmenes significativos que nos permitan obtener buenos ingresos. La mercancía saldría del puerto del Callao hacia el Puerto de Tilbury. El puerto se encuentra ubicado en el Río Támesis en Tilbury, Essex y es el principal puerto de Londres.

Figura 31 Puerto de Tilbury (London Distribution Park)

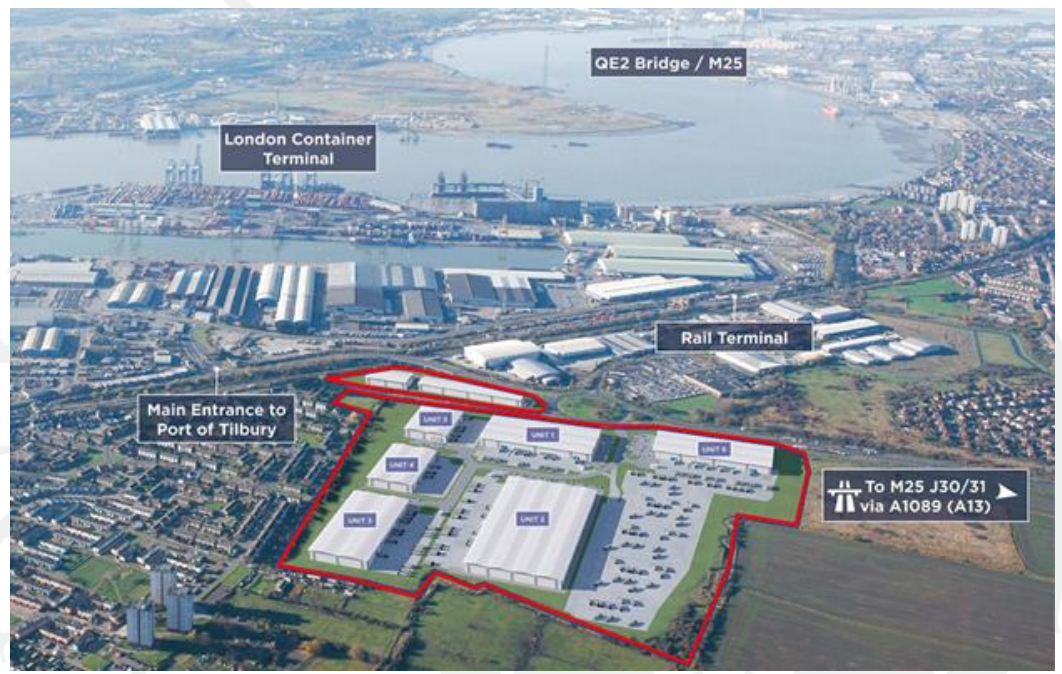

Fuente: Roxhill

La venta se realizará bajo el Incoterm FOB porque aún no tenemos mucha experiencia en el comercio de los bienes, y este implicará una mayor responsabilidad para el comprador, el cual deberá hacerse cargo de los bienes una vez que estos hayan pasado la borda del buque.

\section{- Flete marítimo}

El flete marítimo que se tomará es aquel brindado por el operador logístico Kuehne Nagel, quien nos ofrece todos los servicios integrados para trasladar la carga desde el puerto del Callao, Perú hacia el Puerto de Tillbury, Reino Unido. La carga se transportará en un contenedor reefer de cuarenta pies. El costo de este servicio se sitúa alrededor de US\$2,800, según la cotización enviada por la línea. En el anexo n³ se 
adjunta la cotización. Al comenzar el negocio el Incoterm a utilizar será FOB, al ser nuestros clientes grandes empresas, ellos podrán conseguir tarifas de flete más competitivas que Pome Perú SAC.

\subsubsection{Decisiones sobre promoción}

\subsubsection{Mensaje}

Se transmitirá junto con el logo y la marca Pome Perú. El mensaje que se dará a los clientes finales será: "Prevén tu salud y vive mejor!”. Es muy fácil lograr esto, solo se tiene que incorporar las granadas en la dieta diaria. También se aprovechará el logo de la marca Perú para identificar a nuestro producto como uno de gran calidad. Aprovechando la importancia que cada vez más están adquiriendo las redes sociales, para comenzar se creará un perfil en Facebook donde se publique todo lo que los consumidores deben de conocer sobre la fruta, desde beneficios a los distintos usos que se le puede dar.

Figura 32 Logo de la marca

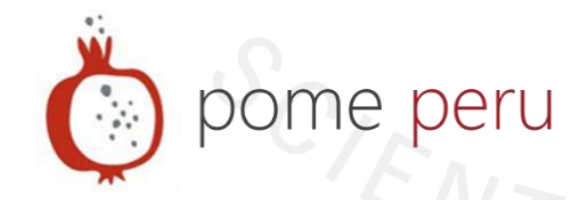

\subsubsection{Posicionamiento}

Para un mejor posicionamiento nos uniremos con otros productores de granadas locales, para concertar esfuerzos y realizar una campaña de consumo de granadas peruanas. Actualmente ya existe una asociación de productores de granadas llamada ProGranada la cual reúne a las 14 empresas productoras y exportadoras de granada más importantes del Perú. Lo ideal sería crear una página web con información 
relevante sobre las granadas y esta sea un punto de contacto para que compradores de fuera puedan identificar la oferta de granadas peruanas.

Tenemos la ventaja que la granada ya es conocida en el mercado, pero lo importante es poder diferenciar las granadas del Perú del resto, vendiendo una idea de gran calidad.

Nos apoyaremos en la campaña actual que existe en el Reino Unido de "5 a Day" la cual consiste en resaltar los beneficios de consumir 5 porciones de 80 gramos de frutas o vegetales, son 5 en total no de cada una. Esta iniciativa se promueve a través de la página web del NHS (Servicio Nacional de Salud) del Reino Unido, por lo que es una fuente confiable como sustento a los potenciales consumidores de granadas. El objetivo es aprovechar este concepto y explotarlo para que dentro de las dietas se incorpore, o se vuelva más conocida la fruta granada. Se mencionan 5 razones por las cuales se debe consumir "5 al día":

- Las frutas y vegetales saben muy bien y hay una gran variedad para escoger.

- Son una buena fuente de vitaminas y minerales incluidos vitamina $\mathrm{C}$ y Potasio.

- Son una excelente fuente de fibra dietaría que ayuda a mantener saludable el sistema digestivo y prevenir el estreñimiento y otros problemas digestivos.

- Pueden ayudar a reducir el riesgo de enfermedades del corazón, infartos y algunos tipos de cáncer.

- Las frutas y los vegetales contribuyen a una dieta saludable y balanceada. (National Health Service , 2013)

La página cuenta con herramientas de promoción, entre las cuales se podrían utilizar las siguientes:

- Planificador de comidas de "5 al día": Ayuda a crear un planificador semanal de 5 al día, te brinda ideas para comida, ricas recetas y consejos. Sugerir que se incorpore recetas que contengan granadas, como postres y jugos.

- Recetas de "5 al día": Las frutas y verduras que se cocinan en cualquier tipo de plato cuentan para el "5 AL DÍA". La granada también puede introducirse en algunos platos, jugos o smoothies que hagan más atractivo consumir la fruta.

Se contactará a el NHS con la ayuda de la Oficina Comercial de Perú en el Reino Unido. Acompañada de esta acción se utilizará la estrategia Below the line para llegar 
al segmento de mercado definido, a través de afiches y volantes que se pueden enviar a las cadenas de supermercados para que sean distribuidos allí. No realizaremos esto por nuestra cuenta porque evidentemente requiere de una fuerte de inversión de dinero, se lo propondremos a la asociación ProGranadas y a la oficina Comercial de Perú en el Reino Unido. En las semillas se encuentra toda la concentración de antioxidantes.

Se colocarán afiches en los supermercados que hablen de los beneficios para salud de la granada, pero especificando que proviene del Perú allí nos será de mucha el logo de la marca Perú. La fruta ya es conocida en el mercado de destino por sus beneficios para la salud, pero lo que se tiene dar a conocer es que el Perú también es un importante proveedor de ella. Como Pome Perú recién está comenzando y los primeros años venderemos a distribuidores se enviará mailing a nuestros potenciales clientes con la disponibilidad de oferta que se cuenta en el momento, detallando categoría, calibre y variedades.

\subsubsection{Mix Promocional Etapa de Lanzamiento}

Para la etapa de lanzamiento se estarán utilizando las siguientes dos estrategias:

- Misiones comerciales: Primero se estará tomando contacto con la Oficina Comercial de Perú en Londres para poder identificar a los posibles compradores interesados en granadas para luego poder concertar reuniones con ellos

- Ferias: Se estarán enfocando en 2 ferias una de ellas realizada en el Perú, que es la feria de alimentos más importante de la región, Expoalimentaria, y otra que se realiza en Reino Unido especializada en el comercio de fruta fresca. En los dos primeros años solo se asistirá a la feria London Produce como visitantes debido a que aún no se cuenta con mucho presupuesto para participar con stand y para tener la oportunidad de prospectarla. En los siguientes años se puede evaluar la participación con stand. 
En el anexo $n^{\circ} 4$ podemos ver que en comunicación por correo electrónico con la Oficina Comercial del Perú en el Reino Unido (OCEX Londres) nos recomiendan asistir a esta feria dado el tipo de producto que estamos ofreciendo. La feria Expoalimentaria es importante también porque nos permitirá ver lo que está haciendo nuestra competencia local y ver la posibilidad de contactarnos con potenciales compradores internacionales que asisten y en el futuro poder diversificar mercados.

- Expoalimentaria del 26 al 28 de Agosto de 2015 - Lima, Perú (http://www.expoalimentariaperu.com/)

\begin{tabular}{ll}
\hline \multicolumn{3}{l}{ Feria Expoalimentaria 2016} \\
\hline Superficie & $23,000 \mathrm{mt} 2$ \\
Expositores & Más de 650 \\
Visitantes internacionales & 2,556 \\
Visitantes nacionales & 32,594 \\
\hline
\end{tabular}

- Feria London Produce Junio 2016 en Londres, Reino Unido (http://londonproduceshow.co.uk/)

\begin{tabular}{ll}
\hline Feria London Produce & \\
\hline Expositores & 128 \\
Visitantes Totales & 1,650 \\
& $\begin{array}{l}\text { compradores mayoristas, productores, } \\
\text { exportadores, importadores y proveedores de } \\
\text { servicios, los medios de comunicación } \\
\text { comerciales y de consumo, la horticultura, }\end{array}$ \\
\hline Perfil de los asistentes
\end{tabular}

- Página web: No solo va a servir para ofrecer el producto, sino que también va a funcionar como un portal donde se cuelguen noticias interesantes sobre la granada como nuevas investigaciones, recetas para realizar ensaladas jugos, y consejos importantes.

- Afiches que serán colocados en los puntos de venta, donde se promocionen las granadas y se haga alusión a los beneficios que tiene para la salud. Serán avisos 
compartidos con otras empresas exportadoras, colocar el logo de la marca Perú para que se identifique la procedencia de la granada.

- Degustaciones de la granada en los supermercados en donde se venda nuestra marca.

\subsubsection{Mix Promocional Etapa de Mantenimiento}

Se colocarán anuncios en revistas especializadas del sector hortofrutícola y también algunas que se enfoquen en temas de salud.

Las acciones promocionales que se llevarán a cabo son:

- A través de la página web de Pome Perú, las personas podrán inscribirse y recibir boletines trimestrales sobre nuevos descubrimientos y noticias sobre la granada y otras súper frutas.

- Se asistirá a ferias, y se evaluará la participación en las mismas con stand, buscaremos unirnos a otros comercializadores de granadas para poder realizar acciones de marketing más impactantes.

- Envío de catálogos a las cadenas más importantes de supermercados y distribuidores, explicando la estacionalidad del fruto y su disponibilidad en el Perú. Enviar recordatorios en los meses en que no se exporta la granada para que la marca siempre esté en mente, regalos o recuerdos

\subsubsection{Presupuesto y Cronograma de Actividades de Marketing}

Tabla 39 Cronograma de Actividades de Marketing

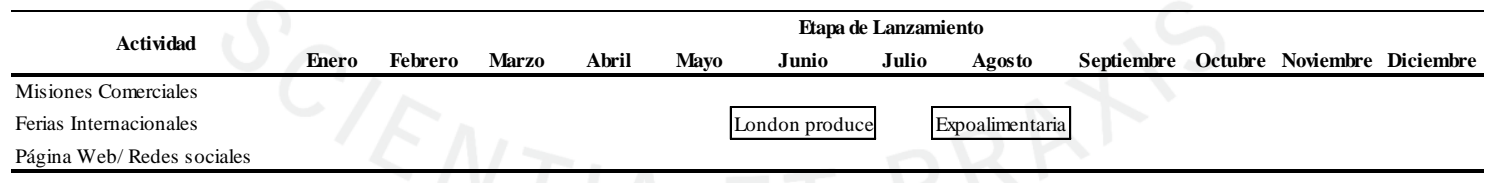

Tabla 40 Presupuesto de Actividades de Marketing

\begin{tabular}{|c|c|c|c|c|c|c|c|c|c|c|c|c|c|c|c|c|}
\hline \multirow{2}{*}{ Actividad } & \multicolumn{16}{|c|}{ Etapa de Lanzamiento (Año 1) } \\
\hline & Enero & & ebrero & Marzo & & Abril & Mayo & & Junio & Julio & & Agosto & Septiembre & Octubre & Noviembre & Diciembre \\
\hline \multicolumn{17}{|l|}{ Misiones Comerciales } \\
\hline Ferias Internacionales & & & & & & & & $\$$ & $1,800.00$ & & $\$$ & 100.00 & & & & \\
\hline Página Web & & $\$$ & 20.00 & & $\$$ & 30.00 & & $\$$ & 20.00 & & $\$$ & 30.00 & & $\$ 20.00$ & & \\
\hline Gasto total & & $\$$ & 20.00 & & $\$$ & 30.00 & & $\$$ & $1,820.00$ & & $\$$ & 130.00 & & $\$ 20.00$ & & \\
\hline
\end{tabular}

\subsection{ESTUDIO TÉCNICO}




\subsubsection{Tamaño del Proyecto}

Pome Perú es una pequeña empresa (MYPE) según la Ley $\mathrm{N}^{\circ} 28015$; DS $\mathrm{N}^{\circ}$ 009-2003 en donde las ventas deben ser desde 150 UIT hasta 1,700 UIT, siendo 1 UIT equivalente a S/ 3,850 al tipo de cambio actual aproximadamente US\$ 1,222.

\subsubsection{Factores determinantes de tamaño}

\subsubsection{Demanda objetivo proyectada:}

El factor que será determinante para definir el tamaño del proyecto es la demanda objetivo la cual para el 2015 será una participación de mercado del $0.28 \%$ de la demanda potencial del Reino Unido con lo cual se obtiene para este año una demanda objetivo de $33,926.4 \mathrm{~kg}$ del producto.

A continuación se hace referencia al Tabla 19 de Proyección de la demanda objetivo.

\begin{tabular}{|c|c|c|c|}
\hline Año & & Cantidad (KG) & Cantidad (TN) \\
\hline & 2015 & $33,926.40$ & 33.93 \\
\hline & 2016 & $67,852.80$ & 67.85 \\
\hline & 2017 & $118,742.40$ & 118.74 \\
\hline & 2018 & $169,632.00$ & 169.63 \\
\hline & 2019 & $203,558.40$ & 203.56 \\
\hline
\end{tabular}

Año 1: 2 contenedores (33.93 TN)

Año 2: 4 contenedores $(67.85 \mathrm{TN})$

Año 3: 6 contenedores $(118.74 \mathrm{TN})$

Año 4: 8 contenedores (169.63 TN)

Año 5: 10 contenedores (203.56 TN)

Como podemos ver la demanda objetivo del proyecto aumentará al 2019 en 500\% respecto al 2015.

\subsubsection{Disponibilidad de insumos}


Como se había mencionado anteriormente las principales regiones productoras de granada son Ica, La Libertad y Lima, a continuación podemos observar el siguiente mapa con las zonas potenciales de granado.

Figura 33: Mapa de Zonas Potencial 


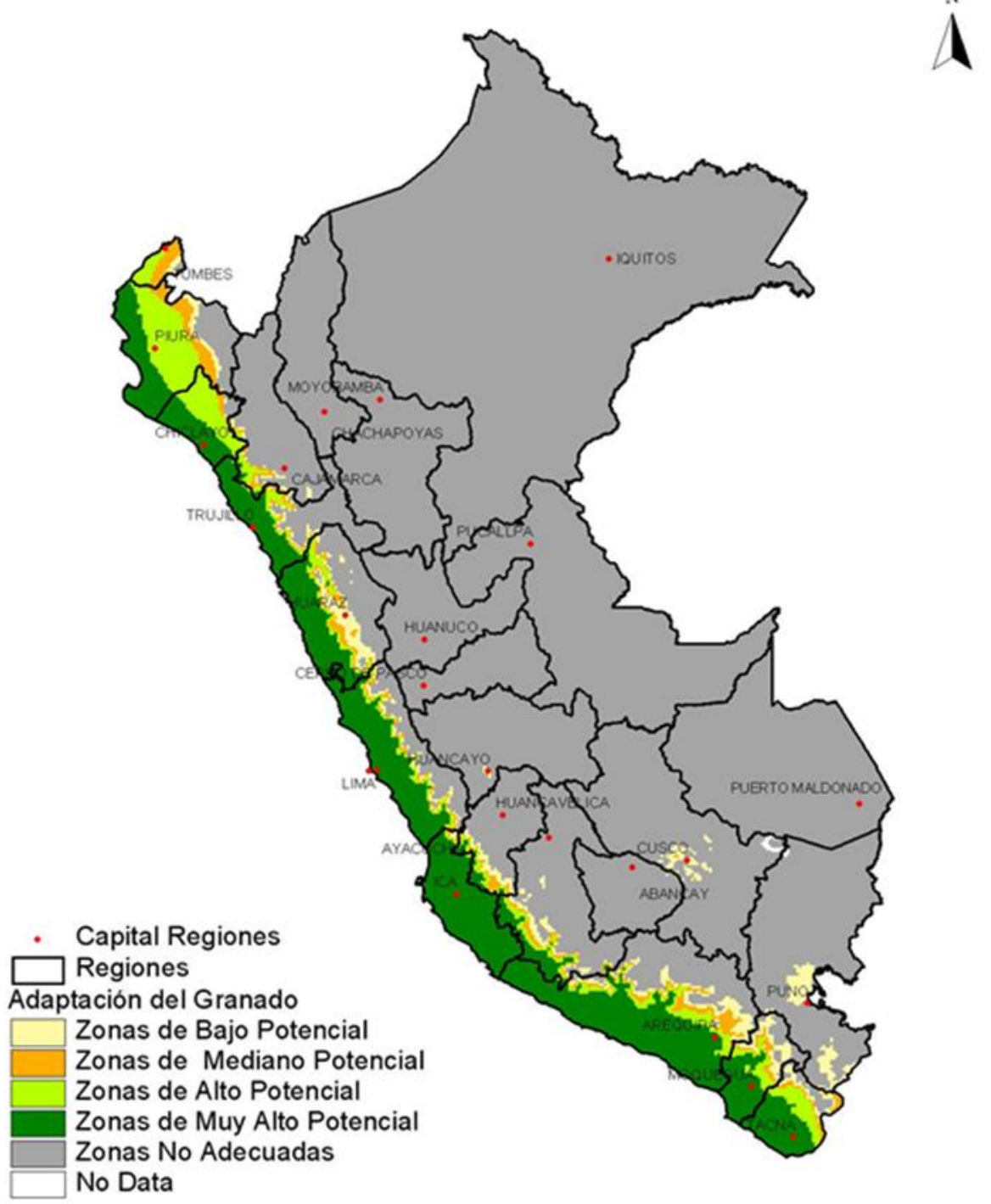

Fuente: Ministerio de Agricultura y Riego

Pome Perú se proveerá de granadas del Departamento de Ica. Este lugar fue elegido para el acopio debido a las siguientes razones:

- Es la principal región productora de Granadas según el MINAGRI, su producción fue de 5,351 toneladas en el 2013 y ha crecido en promedio $68 \%$ en el periodo de 2008 a 2013.

- Mejores rendimientos se dan en climas cuyas temperaturas fluctúan entre los 15 y $25^{\circ} \mathrm{C}$

- Clima semi-cálido. 
- Rendimientos y calidad de la fruta mejoran en condiciones de menor humedad relativa, la cual se da en la zona costera sur del país.

A continuación presentamos una tabla con la producción, rendimiento y precios de las granadas en Ica.

Tabla 41 Producción, Superficie, Rendimiento y Precio en chacra de granadas por región año 2013

\begin{tabular}{lrrrrr}
\hline Región/subregión & $\begin{array}{c}\text { Producción } \\
\text { (t) }\end{array}$ & $\begin{array}{c}\text { Superficie } \\
\text { (ha) }\end{array}$ & $\begin{array}{c}\text { Rendimiento } \\
\text { (kg/ha) }\end{array}$ & $\begin{array}{c}\text { Precio en chacra } \\
\text { (S/./ kg) }\end{array}$ & $\begin{array}{c}\text { Par. \% } \\
\text { Producción } \\
\mathbf{2 0 1 3}\end{array}$ \\
\hline \multicolumn{1}{c}{ Nacional } & $\mathbf{6 , 6 7 7}$ & $\mathbf{5 9 5}$ & $\mathbf{1 1 , 2 2 0}$ & $\mathbf{1 . 5 6}$ & $100.00 \%$ \\
\hline Ica & 5,351 & 426 & 12,572 & 1.55 & $80.14 \%$ \\
Lima & 759 & 72 & 10,542 & 0.98 & $11.37 \%$ \\
La Libertad & 369 & 64 & 5,816 & 2.64 & $5.53 \%$ \\
Lambayeque & 65 & 15 & 4,333 & 3.20 & $0.97 \%$ \\
Ancash & 55 & 6 & 9,167 & 1.52 & $0.82 \%$ \\
Tacna & 40 & 5 & 8,000 & 0.96 & $0.60 \%$ \\
Arequipa & 33 & 7 & 4,657 & 1.64 & $0.49 \%$ \\
Moquegua & 5 & 1 & 5,490 & 1.50 & $0.08 \%$ \\
\hline
\end{tabular}

Nota. Fuente: Ministerio de Agricultura y Riego - Dirección de Estadística Agraria

Durante el primer año de operaciones de Pome Perú se exportarán 2 contenedores de 40 pies. Considerando la oferta local del departamento de Ica representado en la tabla anterior, se requiere $0.63 \%$ del total de producción de esta localidad.

También tenemos la opción de abastecernos de granadas desde el departamento de Lima. Sin embargo, la producción total de esta fruta en este departamento es menor 759 toneladas en el año 2013 - comparada con la de Ica.

Tabla 42 Rendimiento por hectárea cultivada de granada fresca en la Región Ica

\begin{tabular}{cccc}
\hline & Producción & Superficie & Rendimiento \\
& Ica ( TM) & (Ha) & Kg./ha \\
\hline GRANADA & 5,351 & 426 & 12,572 \\
\hline
\end{tabular}

Nota. Fuente: Ministerio de Agricultura y Riego - Dirección de Estadística Agraria

Debemos mencionar que se estará tomando 15\% de merma para la producción requerida para cubrir la demanda objetivo, para así poder tener un mejor control sobre posibles factores que puedan causar problemas o inconvenientes a la 
exportación (como poca producción, parte de la producción exportada se malogró, clima, entre otros).

Tabla 43 Insumos requeridos para la obtención de granadas $\mathrm{kg} / \mathrm{ha}$

\begin{tabular}{lc}
\hline \multicolumn{1}{c}{ Insumo } & Superficie \\
\hline Granada & $\mathrm{Ha}$ \\
$33,926.40 \mathrm{KG}$ & 2.7 \\
$39,015.36 \mathrm{KG}($ merma $15 \%)$ & 3.1 \\
\hline
\end{tabular}

Considerando la información presentada, se necesitarían 3.1 hectáreas para obtener la demanda objetivo proyectada del primer año, 33, $926.40 \mathrm{kgs}$, para esto se ha tomado en cuenta el nivel promedio de rendimiento por hectárea cultivada. La principal región productora es Ica, (80\%) de la cual nosotros hemos decidido abastecernos, le sigue Lima (11\%) y La Libertad (6\%). En otras ocasiones para diversificar el riesgo también buscaremos proveedores en Lima, pero en Ica se encuentran las mejores condiciones para el cultivo de la fruta.

Tabla 44 Determinación del tamaño en Has cultivada

\begin{tabular}{rrrrrr}
\hline Año & $\mathbf{2 0 1 5}$ & $\mathbf{2 0 1 6}$ & $\mathbf{2 0 1 7}$ & $\mathbf{2 0 1 8}$ & $\mathbf{2 0 1 9}$ \\
\hline Demanda objetivo Proyectada (KG) & $33,926.40$ & $67,852.80$ & $118,742.40$ & $169,632.00$ & $203,558.40$ \\
Requerimiento de Granada & $39,015.36$ & $78,030.72$ & $136,553.76$ & $195,076.80$ & $234,092.16$ \\
Nro de Has & 3.10 & 6.21 & 10.86 & 15.52 & 18.62 \\
\hline
\end{tabular}

Es importante mencionar que durante el año 2014 fueron 23 empresas las que exportaron granadas de la región Ica, lo que sumó un total de 7’335,503.23 kg (7,335.5 toneladas). En la siguiente figura podemos observar el crecimiento de las exportaciones de granadas de la región Ica, y como las exportaciones han ido creciendo proporcionalmente a la producción disponible en esta región. (Ver Figura $\mathrm{N}^{\circ}$ 2). Aún no tenemos información disponible sobre la producción de granadas en Ica para el 2014 pero se puede estimar que la misma crezca aproximadamente en $50 \%$, debido a que las exportaciones para este año se incrementaron en 54\%. Pome Perú exportará 33.93 toneladas en el 2015 lo que equivale al $0.46 \%$ de las exportaciones totales de granadas de la región Ica. 
Figura 34 Volumen de Exportación de granadas provenientes de la región Ica (20102014

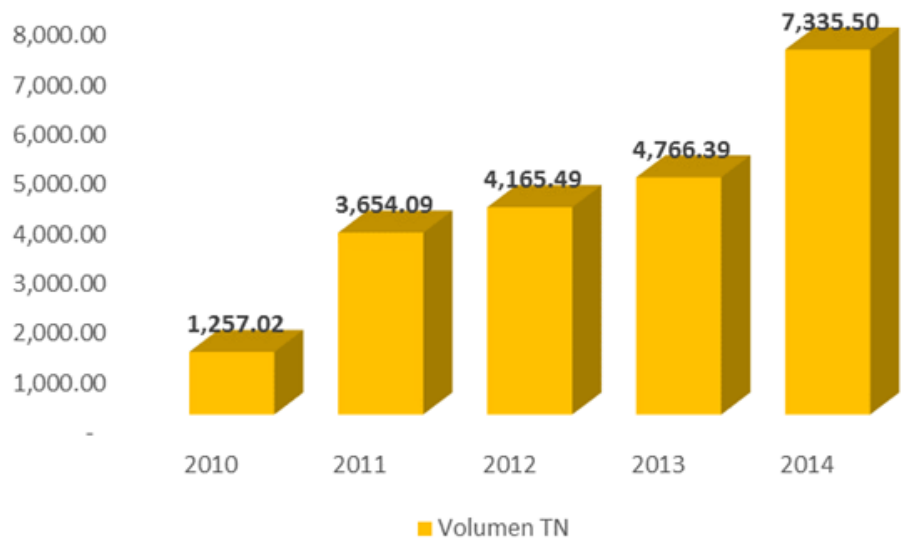

Fuente: SUNAT

A continuación se detalla el proveedor de los insumos:

Tabla 45 Proveedores de Insumos

\begin{tabular}{lll}
\hline Insumo & Proveedor & Ubicación \\
\hline \multirow{2}{*}{ Granadas Frescas } & Ica Pacific SA & Valle de Ica \\
& & Sector: Bajo \\
& Sub Sector: Santiago \\
\hline
\end{tabular}

Nota. Fuente: SENASA

Ica Pacific es una empresa agroindustrial que cultiva espárragos verdes y granadas, la cual inició sus actividades en 1995, en Ica le pertenecen varios predios como el Proyecto Parcela y Santa Filomena.

\subsubsection{Proceso productivo}

\section{Plantación}

La apertura de los hoyos puede efectuarse entre 1-2 meses antes de la plantación. Ésta puede realizarse a nivel del suelo o sobre mesetas.

Los marcos de plantación deben ser suficientes para garantizar una buena iluminación, que permita a los frutos desarrollar plenamente su coloración, también deben permitir la realización de las labores de cultivo. 
La plantación suele realizarse durante los meses de enero y febrero y hasta principios de primavera (depende también si el trasplante es a raíz desnuda o con cepellón), aunque en climas benignos puede efectuarse también durante el mes de diciembre. En la actualidad lo usual es la propagación en maceta o en bolsas con fibra de coco, con lo que la plantación puede realizarse prácticamente en cualquier momento, desde febrero a octubre habitualmente. Se planta aproximadamente a la misma profundidad que se encontraba en vivero. Una vez realizada la plantación se efectúa el denominado riego de plantación.

Figura 35 Plantación de la granada

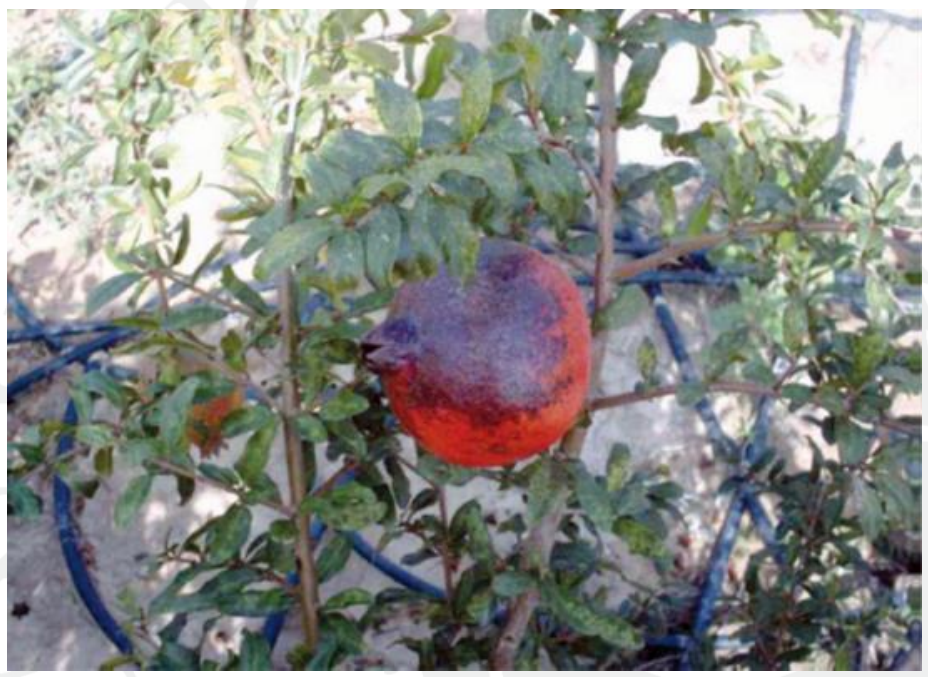


Tabla 46 Condiciones Óptimas de cultivo de la granada

\begin{tabular}{lcl}
\hline GMIN (días) & 180 & Periodo de crecimiento mínimo (días) \\
GMAX (días) & 365 & Periodo de crecimiento máximo (días) \\
KTMP $\left({ }^{\circ} \mathbf{C}\right)$ & -10 & Temperatura absoluta que acabará con la vida de la planta $\left({ }^{\circ} \mathrm{C}\right)$ \\
TMIN $\left({ }^{\circ} \mathbf{C}\right)$ & 8 & Temperatura mínima promedio con la que la planta crecerá $\left({ }^{\circ} \mathrm{C}\right)$ \\
TMAX $\left({ }^{\circ} \mathbf{C}\right)$ & 40 & Temperatura máxima promedio con la que la planta dejara de crecer $\left({ }^{\circ} \mathrm{C}\right)$ \\
TOPMN $\left({ }^{\circ} \mathbf{C}\right)$ & 23 & Temperatura mínima promedio con la que la planta crecerá óptimamente $\left({ }^{\circ} \mathrm{C}\right)$ \\
TOPMX $\left({ }^{\circ} \mathbf{C}\right)$ & 32 & Temperatura máxima promedio con la que la planta crecerá óptimamente $\left({ }^{\circ} \mathrm{C}\right)$ \\
Rmin $(\mathbf{m m})$ & 400 & Lluvia mínima durante la estación de crecimiento $(\mathrm{mm})$ \\
Rmax $(\mathbf{m m})$ & 4200 & Lluvia máxima durante la estación de crecimiento $(\mathrm{mm})$ \\
Ropmin $(\mathbf{m m})$ & 900 & Lluvia mínima optima durante la estación de crecimiento $(\mathrm{mm})$ \\
$\operatorname{Ropmax~}(\mathbf{m m})$ & 1200 & Lluvia máxima optima durante la estación de crecimiento $(\mathrm{mm})$ \\
\hline
\end{tabular}

Nota. Fuente: ASISTENCIA TÉCNICA PARA LOS PLANES OPERATIVOS (POS)

\section{Riego}

Para poder desarrollar una recomendación de riego adecuada, es necesario disponer de datos fiables sobre el clima de la zona, el sistema de riego utilizado, las características edafológicas de la parcela y la calidad del agua de riego.

A nivel práctico, los métodos más utilizados actualmente para determinar cuándo se debe regar son los que miden a tensión matricial del suelo mediante tensiómetros o bloques de yeso (water mark).

La técnica del riego deficitario controlado no se aplica en el cultivo del granado, debido fundamentalmente a la falta de estudios que hay a este respecto, en esta especie.

Riego por goteo bajo requerimiento de agua de aproximadamente 6 a $8000 \mathrm{~m} 3$ por año.

\section{Fertilización}

El granado no es muy exigente en cuanto a la fertilización; el momento óptimo para aportar abonos fosfatados y potásicos es durante la caída de la hoja. Cuando entra en vegetación son útiles los nitrogenados en fórmulas equilibradas.

La fertilización, va en función del análisis del suelo, normalmente se recomienda aplicaciones de:

- Nitrato de potasio en dosis de $300 \mathrm{~kg} / \mathrm{ha}$

-Nitrato de calcio en dosis de $250 \mathrm{~kg} / \mathrm{ha}$

-Nitrato de Magnesio en dosis de $200 \mathrm{~kg} / \mathrm{ha}$ 
-Fosfato Mono amónico en dosis de $250 \mathrm{~kg} / \mathrm{ha}$

-Ácido Fosfórico en dosis de $50 \mathrm{~kg} / \mathrm{ha}$

-Control de Hierba Mala

-El suelo se mantiene limpio de malas hierbas a través del uso de herbicidas

\section{Recolección}

Esta comienza a principios de marzo, se dan dos o tres pases debido a la maduración no uniforme de la granada, ya que la floración es escalonada. La recolección se realiza manualmente, utilizando tijeras de podar de hoja más pequeña y se tiene mucho cuidado, ya que los frutos son muy sensibles a los golpes.

\subsubsection{Proceso y tecnología}

\subsubsection{Descripción de los principales procesos del proyecto}

1. Acopio de Granada: Se recopila la cantidad deseada, incluyendo la merma, a exportar. La fruta debe ser amortiguada con papel o paja en jabas cosecheras para luego llevar estas frutas a la planta o almacén de procesamiento donde se realizara el proceso de empaque.

2. Supervisión y verificación de las características de la granada: Se contará con 1 supervisor de campo para que revise el producto, debe verificar que no se encuentren grietas de crecimiento, cortes, magulladuras y pudrición.

3. Transporte a planta de procesamiento: Se estará trasladando la mercancía a exportar al centro de acopio en Ica.

4. Calibración, Selección y Embalaje: Todo lo que no cumple con los requisitos de CAT 1, separarlo en una jaba de CAT 2.Dispondrán de fruta que serán clasificadas según el calibre que le toque a cada clasificador.

5. Pesado: Tener en cuenta que la presentación exportada por Pome Perú será la de cajas de $3.8 \mathrm{kgs}$.

6. Etiquetado: Se colocará una etiqueta en cada fruta, también se colocarán las etiquetas en la caja terminada. 


\section{Armado de Pallet:}

- Se arman los pallets con la finalidad de introducirlos a frio lo más pronto posible.

- Los operarios enzuncharán los pallets colocando un cartón en la parte superior, se realizará 7 lazadas horizontalmente y 2 verticalmente.

- Los pallets entran a los túneles de frio por número de par y tienen que tener una altura mínima de $1.69 \mathrm{mts}$.

PomePerú exportará cajas de $3.8 \mathrm{kgs}$ con las cuales se armará un pallet con base de 12 cajas y 18 pisos de altura, con lo que tendremos 216 cajas por pallet. Para un contenedor de 40' tendremos 20 pallets lo que equivale a 4,320 cajas, más un pallet "candado" que tiene capacidad para 144 cajas, motivo por el cual se exportarán 4,464 cajas en total. Ver anexo $n^{\circ} 5$, el cual contiene extracto del Protocolo de Paletizado para cajas agroindustriales elaborado por Trupal.

A continuación podemos ver la distribución de pallets del contenedor:

Figura 36 Distribución de Pallets dentro del contenedor de 40 Pies

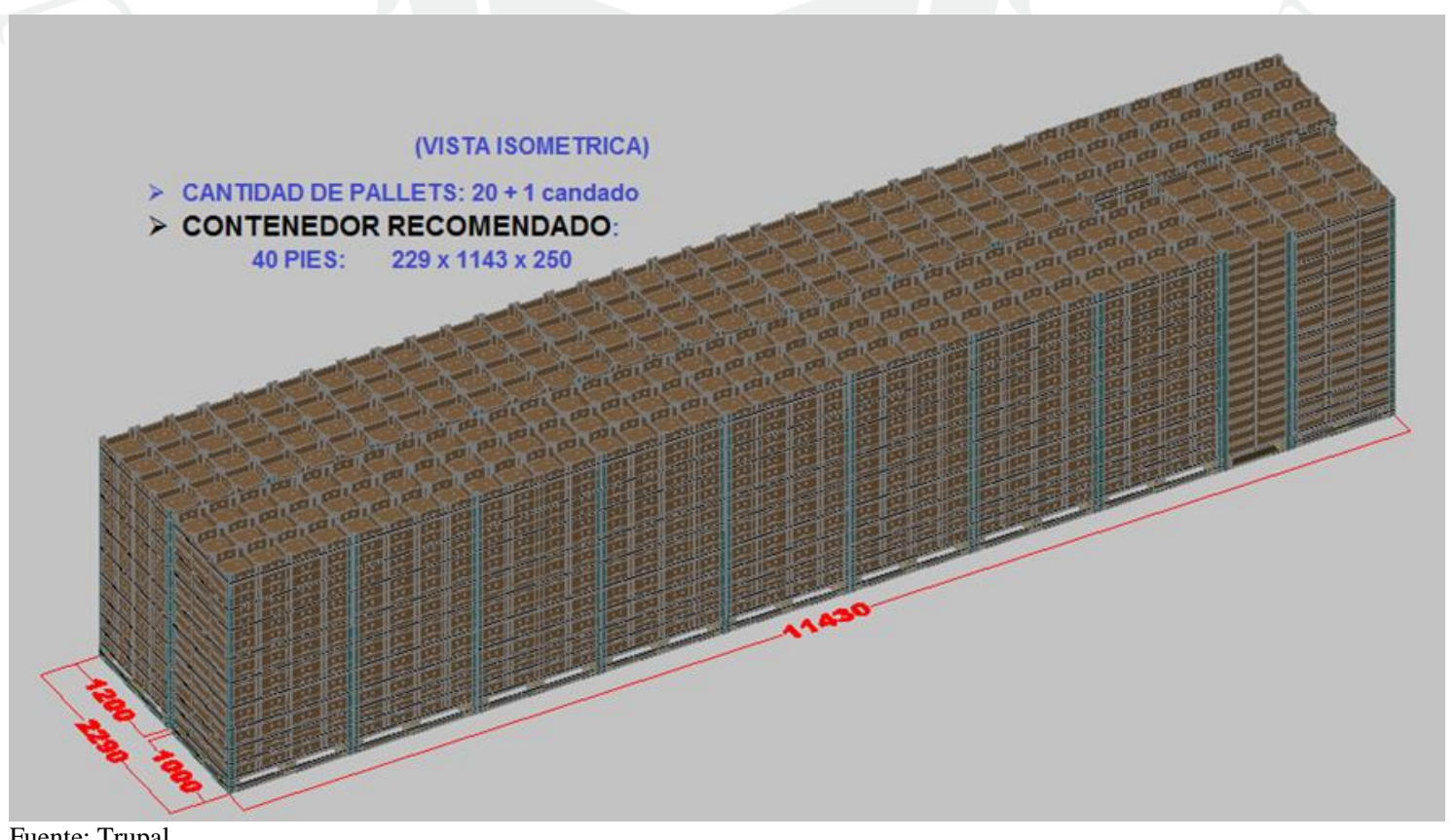

Fuente: Trupal

\section{Enfriamiento con aire forzado - túnel}


- No pondrán ingresar pallet con distinta altura. (Altura mínima $1.69 \mathrm{mts}$ )

- Colocar los pallets en la posición que el lado más pequeño de la parihuela vaya de manera transversal al panel del túnel.

- Acomodar las bolsasXtend adentro de la caja, sobre todo para el lado que da para el interior del túnel de frio.

- Colocar la lona sobre los pallets de manera que tape los espacios vacíos que pueden permitir la entrada de aire.

- Colocar pedazos de cartón en la base de las parihuelas de manera que solo se direccione la entrada de aire por las cajas de fruta.

- El túnel tiene que estar con una $\mathrm{T}^{\circ}$ de $5.0^{\circ} \mathrm{C}$ y un diferencial de $1^{\circ} \mathrm{C}$.

- Se anotará la $\mathrm{T}^{\circ}$ de la fruta inicial y la $\mathrm{T}^{\circ}$ de los evaporadores. Asi mismo se tomará la $\mathrm{T}^{\circ}$ cada hora.

- Se apagarán los túneles cuando ambas temperaturas de la pulpa se encuentren entre $7.5^{\circ} \mathrm{C}$ y $7.9^{\circ} \mathrm{C}$. Tiempo de enfriamiento aproximado es entre 4-5 horas.

- Terminado los pallets se llevarán a las cámaras de almacenamiento que se encuentran configurados a $6^{\circ} \mathrm{C}$ y $7^{\circ} \mathrm{C}$.

- Mantener la humedad de la cámara entre un 90\% - 95\%.

9. Cerrado de la Bolsa: Mantener la humedad de la cámara entre un 90\% - 95\%.

10. Paletizado: Un operario colocará las cajas con las bolsas ya cerradas en una parihuela de exportación donde apilará por calibre.

11. Contenedorizado: El contenedor debe tener una temperatura de $5.5^{\circ} \mathrm{C}$, humedad relativa de $95 \%$ y ventilación $15 \%$.

(Montoya, 2015) 


\subsubsection{Diagrama de flujo del proceso de producción}

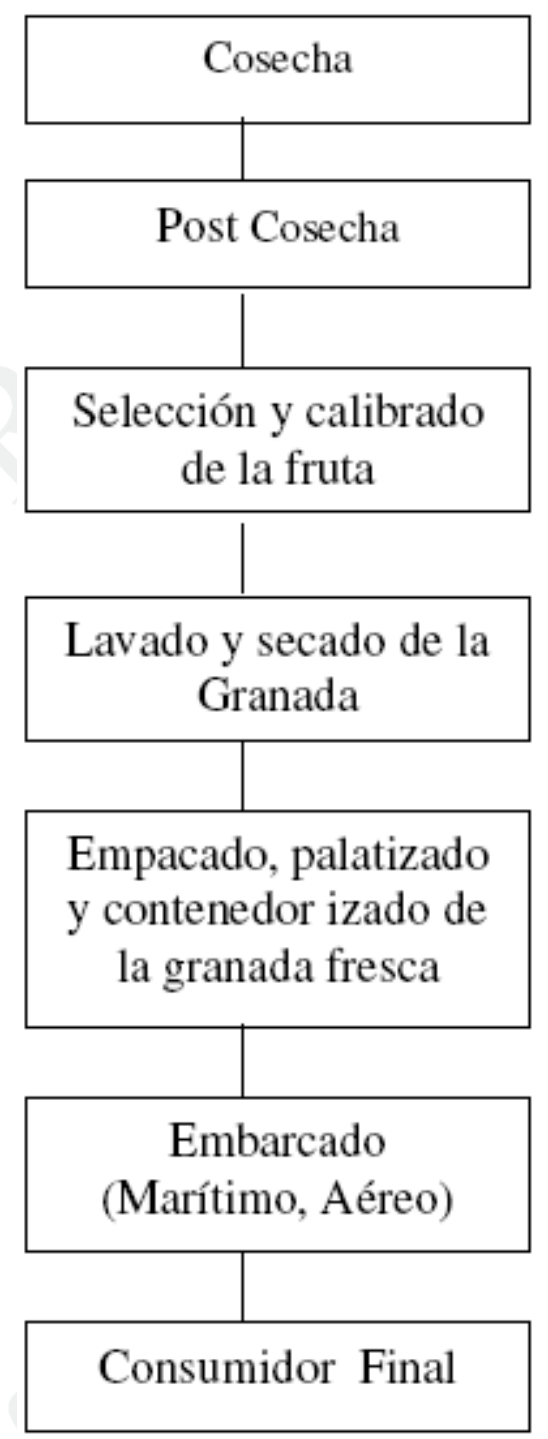

\subsubsection{Localización}

\subsubsection{Especificación del local en la situación actual}

La empresa Pome Perú tendrá su oficina comercial en Ica, donde principalmente permanecerá el analista de exportación. Asimismo el local servirá como almacén de insumos como, jabas, cajas y bolsas que se necesitan para el empaque de las 
granadas. En base a la localización se alquilará un local que servirá como oficina y almacén de insumos de las siguientes características.

Tabla 47 Características del local

\begin{tabular}{ccc}
\hline & Items & Características \\
\hline & Área & $120 \mathrm{~m}^{2}$ \\
& Servicios Públicos & Agua potable, luz, teléfono, internet \\
& Seguridad & Cámaras de Vigilancia y Seguridad local \\
& Accesos & URB. SAN JOSE CALLE LOS PACAES K 16 ICA \\
& Oficinas & 1 \\
& Sala de Reuniones & 1 \\
& Servicios Higiénicos & 1 \\
& Estacionamiento & Pisos piso: Mayólicas en buen estado \\
\hline
\end{tabular}

\subsubsection{Especificación del local en la situación con proyecto}

Según los requerimientos de la empresa establece como necesarias las siguientes áreas:

Tabla 48 Distribución de área por Metro Cuadrado

\begin{tabular}{lc}
\hline \multicolumn{1}{c}{ Items } & M2 \\
\hline Oficina Administrativa & 20 \\
Almacén & 80 \\
Servicios higiénicos & 10 \\
Pasillos (15\% a 20\%) & 10 \\
Total en (M2) & $\mathbf{1 2 0}$ \\
\hline
\end{tabular}

De acuerdo a las especificaciones dadas, se requiere remodelar el local para que este se adapte a las necesidades de la empresa. Se tendrá un almacén que servirá de espacio para poder revisar la fruta y guardar las herramientas e insumos como los pallets y el empaque.

Figura 37: Plano luego de la remodelación 


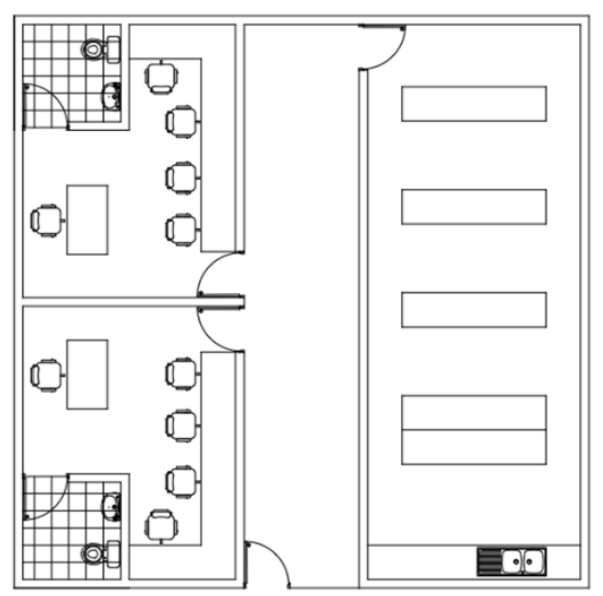

Para la remodelación se requerirán los siguientes materiales:

Tabla 49 Requerimiento de materiales para remodelación

\begin{tabular}{|c|c|c|c|}
\hline Ítems & Cantidad & Características & Proveedor \\
\hline Mayólicas & 120 & Mayólicas, de 1 x 1 metros. & Sodimac \\
\hline Puertas & 2 & Puertas de madera simples, 80 x 20. & Sodimac \\
\hline Persianas & 3 & Horizontales, color blanca. $50 \mathrm{~mm}$. & Sodimac \\
\hline Drywall & 4 & $\begin{array}{l}\text { Divisiones de Drywall de } 2.40 * 1.22 \\
\text { mts. }\end{array}$ & Sodimac \\
\hline Pintura & 6 & $\begin{array}{l}\text { Balde de pintura marca Vencedor de } \\
\text { color blanco }\end{array}$ & Sodimac \\
\hline
\end{tabular}

\subsubsection{Requerimiento de Vehículos, maquinarias, equipos y mobiliario}

Vehículos: Según el funcionamiento de la empresa no se requerirá adquirir ningún vehículo, debido a que se contratará el servicio de transporte para la fruta del centro de acopio al almacén y luego de allí al puerto en donde se embarcará la mercancía.

Maquinarias: Por el momento, horizonte del proyecto (5 años) no se requerirá adquirir ninguna maquinaria, debido a que se alquilará la maquila a la empresa Sunfruits, que tiene un centro de procesamiento en Ica.

Equipos: Los equipos como las computadoras y las radios celulares, están dirigidos para cada trabajador, de manera que estos les ayuden a cumplir más eficientemente con 
su trabajo. Cada responsable de su área contará con su propia computadora. Se está comprando una impresora multifuncional mediana para el uso de todos los trabajadores, pero para la comodidad del gerente se encontrará en su oficina.

Tabla 50 Requerimiento de Equipos

\begin{tabular}{|c|c|c|c|c|c|}
\hline Item & Cantidad & Características & Vida útil & Proveedor & $\begin{array}{c}\text { Precio } \\
\text { Unitario (US\$) }\end{array}$ \\
\hline \multicolumn{6}{|c|}{ Área de Gerencia y Exportaciones } \\
\hline \multirow{3}{*}{ Computadora } & \multirow{3}{*}{2} & Procesador: Intel Celeron Dual-Core 847 & & \multirow{3}{*}{ Avadan PC } & \\
\hline & & Disco Duro: 500 GB & 4 & & \\
\hline & & Memoria RAM: 4 GB & & & 539.68 \\
\hline $\begin{array}{c}\text { Impresora } \\
\text { Multifuncional }\end{array}$ & 1 & HP Advantage 5525 WI-FI Inalámbrica & 4 & $\mathrm{HP}$ & 126.97 \\
\hline Equipos celulares & 2 & 2 aparatos telefónicos & 2 & Movistar & 0.00 \\
\hline Equipos de defensa civil & 1 & $\begin{array}{l}\text { Contiene dos extintores de } 5 \text { kilos de abc } \\
\text { y artículos de primera necesidad }\end{array}$ & 5 & Defensa Civil & 34.95 \\
\hline & & Área de Operaciones & & & \\
\hline Guantes descartables & 100 & Guantes de látex & - & Qualatex & 0.49 \\
\hline Jabas Cosecheras & 880 & $\begin{array}{l}\text { PEAD con protección UV } \\
522 \times 362 \times 315 \text { mm Capac. } 25 \mathrm{KG}\end{array}$ & 5 & Basa & 2.86 \\
\hline
\end{tabular}

Por ley es obligatorio contar con equipos de seguridad, defensa civil exige que hayan extintores en los centros de trabajo para poder prevenir cualquier tipo de desastre.

\section{Mobiliario}

Tabla 51 Requerimiento de Mobiliario Oficina

\begin{tabular}{|c|c|c|c|c|c|}
\hline Item & Cantidad & Características & Vida útil & Proveedor & $\begin{array}{c}\text { Precio } \\
\text { Unitario (US\$) }\end{array}$ \\
\hline \multicolumn{6}{|c|}{ Área de Gerencia } \\
\hline Escritorio & 2 & $\begin{array}{l}\text { Estructura con patas metálicas y melamine } \\
\text { Medidas: } 100 \mathrm{~cm} \times 75 \mathrm{~cm} \times 50 \mathrm{~cm}\end{array}$ & 10 & Muebles Villa & 158.7 \\
\hline Sillas giratorias & 2 & Respaldo y asiento acolchado. Base de Nylon & 10 & Asenti & 44.41 \\
\hline Sillas de visita & 2 & Silla juvenil negro con pistón de Tela. Base de Nylon & 10 & Asenti & 19.02 \\
\hline Archivero & 1 & Cajonera $8 \mathrm{~cm} \times 32 \mathrm{~cm} \times 40 \mathrm{~cm}$ acabado en melamine & 10 & Home collection & 63.49 \\
\hline Útiles de oficina & 1 & Set básico de útiles de oficina & - & Tai Loy & 79.37 \\
\hline
\end{tabular}




\subsubsection{Requerimiento de materia prima}

Tabla 52 Requerimiento Anual de Granadas (primer año)

\begin{tabular}{ccc}
\hline Item & Cantidad en KG & Proveedor \\
\hline Granadas & $39,015.36$ & Ica Pacific SA \\
\hline
\end{tabular}

La cantidad requerida para el primer año de operaciones ya incluye la merma de $15 \%$. Se estará acopiando inicialmente en Ica debido a que es la mayor zona productora de Granadas y por la cercanía que tiene con Lima. Uno de nuestros principales proveedores será Ica Pacific SA y estaremos en constante contacto con SENASA para que nos actualice sobre los productores de granada. Ver anexo $\mathrm{n}^{\mathrm{o}} 7$ en el cual se indica la lista de productores para explotación comercial internacional.

\subsubsection{Requerimiento de insumos para empaque de la fruta}

Tabla 53 Requerimiento Anual de Materias Primas relacionadas al empaque

\begin{tabular}{lccc}
\hline \multicolumn{1}{c}{ Items } & $\begin{array}{c}\text { Cantidad para 4 kgs } \\
\text { de Granada }\end{array}$ & Unidad & Proveedor \\
\hline Etiqueta & 1 por caja & Unidad & Cromagraf \\
Cajas & Caja de cartón de $3.8 \mathrm{kgs}$ & Unidad & Trupal \\
Sticker & 1 por cada caja, Medidas: & Millar & Cromagraf \\
Sticker & $4.1 \mathrm{~cm}$ x $4.7 \mathrm{~cm}$ & Millar & Cromagraf \\
Bolsas Stepac & 1 por cada granada & millar & Fiamma \\
\hline
\end{tabular}

La caja a utilizar es una genérica para $3.8 \mathrm{Kg}$. color blanca litografiada, por cada caja se colocará una etiqueta con la marca y el logo de la empresa, la cual deberá mostrar toda la información necesaria como el lugar de procedencia. Asimismo se colocarán stickers a cada una de las frutas que permitan identificar la marca.

\subsubsection{Mano de obra directa}

Para el acopio de la fruta en el campo del proveedor Ica Pacific SA, la cual cuenta con varios predios como Proyecto Parcela y Santa Filomena en el subsector de 
Santiago en Ica, se contratará a 15 operarios para que trabajen un jornal y reúnan la cantidad necesaria para completar un contenedor.

Tabla 54 Requerimiento de MOD para el primer año

\begin{tabular}{ccc}
\hline Item & Cantidad & $\begin{array}{c}\text { Horas hombre } \\
\text { x contenedor }\end{array}$ \\
\hline Personal de Acopio & 15.00 & 1 Jornal (8 horas) \\
\hline
\end{tabular}

\subsubsection{Factores indirectos de operación}

\subsubsection{Requerimiento de suministros}

Se está considerando lo siguiente como el consumo de agua, luz, internet entre otros para el día a día de las operaciones en las instalaciones y los respectivos requerimientos mensuales.

Tabla 55 Requerimiento de Suministros

\begin{tabular}{llll}
\hline \multicolumn{1}{c}{ Items } & \multicolumn{1}{c}{ Descripción } & Cantidad Mensual & \multicolumn{1}{c}{ Proveedor } \\
\hline Agua & Consumo de Agua m3 & 50 & Emapica \\
Electricidad & Consumo de Energia kw & 350 & Electrodunas \\
Celulares & Radio ilimitado & Tarifa Plana & Entel \\
Telefonía, Internet & Duo fijo & $3 \mathrm{~g}$ de velocidad & Movistar \\
\hline
\end{tabular}

\subsubsection{Requerimiento de servicios indirectos}

En este punto se estará especificando las actividades necesarias para el buen funcionamiento de la empresa. Entre estas se encuentra el transporte y distribución de la mercadería desde Ica Hasta Lima - Callao, y el contador externo que se contratará. 
- Servicios Logísticos: los servicios a requerir serán los servicios logísticos de exportación para lo cual vamos a contratar al operador logístico Kuehne Nagel. quien se encargará del proceso logístico de exportación hasta el puerto.

- Contabilidad: Para la contabilidad de la empresa vamos a subcontratar aun contador con experiencia quien se encargará por periodos de recoger la información de la empresa y de la contabilidad.

\subsection{ESTUDIO DE LA ORGANIZACIÓN}

\subsubsection{Estructura organizativa}

La conformación de la empresa Pome Perú consiste en 3 personas cuyos puestos son escritos más adelante en la tabla 58. Se cuenta con 2 áreas las cuales son: Gerencia General/Administración, y Exportaciones.

Cada área tiene una persona encargada de monitorear el trabajo y asegurarse que se estén cumpliendo los procedimientos adecuadamente, son llamados los responsables de cada área. El Gerente supervisa el funcionamiento de toda la empresa de forma global.

Tabla 56 Datos Generales de la empresa

\begin{tabular}{ll}
\hline Nombre Comercial & Pome Perú \\
Razón Social & Pome Perú S.A.C. \\
RUC & Calle Independencia 193 \\
Dirección & Ica \\
Estado de la Empresa & Activo \\
Actividad de Comercio Exterior & Exportador \\
Página Web & www.pomeperu.com.pe \\
Correo Electrónico & ventas @ pomeperusac.com.pe \\
Teléfono & 989447564 \\
Persona de Contacto & Carla Rubio Valla \\
\hline
\end{tabular}

\subsubsection{Organigrama funcional}

El organigrama de la empresa está compuesto únicamente por 4 personas, es pequeño debido que somos una micro empresa que recién está comenzando operaciones. En los próximos años de funcionamiento se puede tomar en consideración ampliarlo dependiendo de las necesidades de la empresa. En la siguiente figura se 
muestra el organigrama, en el cual se pueden observar las dos áreas centrales y el contador externo.

Figura 38 Organigrama de Pome Perú

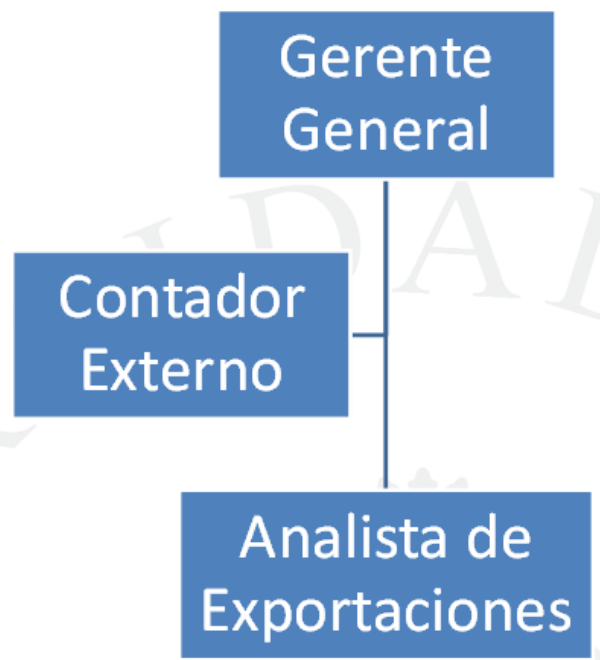

\subsubsection{Descripción del organigrama funcional}

A continuación se describen las funciones y características de los principales puestos de la empresa:

Tabla 57 Descripción de los puestos de trabajo en Pome Perú

\begin{tabular}{|c|c|c|c|c|}
\hline $\begin{array}{c}\mathbf{N}^{\circ} \text { personas en el } \\
\text { cargo }\end{array}$ & Cargo & Funciones & Sueldo & Perfil \\
\hline$\frac{34}{34}$ & Gerente General & $\begin{array}{l}\text { - Llevar control de todas las áreas y planear las } \\
\text { acciones a realizar } \\
\text { - Establecer metas a mediano y largo plazo } \\
\text { para el crecimiento de la empresa } \\
\text { - Reuniones con proveedores y clientes } \\
\text { potenciales }\end{array}$ & 2850 & $\begin{array}{l}\text { - Licenciado en Administración o Negocios } \\
\text { Internacionales. } \\
\text { - Experiencia mínima: } 2 \text { años } \\
\text { - Ser proactivo, emprendedor y leal }\end{array}$ \\
\hline 1 & $\begin{array}{l}\text { Analista de } \\
\text { Exportación }\end{array}$ & $\begin{array}{l}\text { - Realizar la documentación de exportación del } \\
\text { producto y hacer seguimiento a los embarques } \\
\text { - Coordinación del proceso logístico del } \\
\text { producto (desde el acopio hasta el despacho). } \\
\text { - Coordinación con los clientes y } \\
\text { proveedores de servicios }\end{array}$ & 2000 & $\begin{array}{l}\text { - Ser licenciado o graduado en } \\
\text { Administración o Negocios Internacionales. } \\
\text { - Experiencia mínima: } 1 \text { año en } \\
\text { exportaciones } \\
\text { - Capacidad de interrelacionarse con } \\
\text { clientes y proveedores } \\
\text { - Inglés intermedio-Avanzado }\end{array}$ \\
\hline
\end{tabular}

* En el tercer y quinto año, debido a la política de sueldos impuesta por la empresa se aumentarán los sueldos en $15 \%$.

\subsubsection{Visión, misión y valores}




\subsubsection{Visión}

Ser uno de los principales proveedores de Granadas hacia el mercado Europeo, obtener el liderazgo en costos y calidad brindando un producto que satisfaga las exigencias de los consumidores, gracias al esfuerzo conjunto del equipo de trabajo.

\subsubsection{Misión}

Exportar productos agroindustriales de calidad que cumplan con los estándares internacionales respetando y siendo socialmente responsables con todos los grupos de interés alrededor de la empresa.

\subsubsection{Valores}

- Integridad: respetar el código de ética de la empresa

○ Compromiso: Con los proyectos actuales y nuevos que implemente la empresa.

- Puntualidad: Cumplir con las labores a tiempo, además asistir y retirarse del centro laboral a las horas correspondientes al horario de trabajo.

- Excelencia: Las operaciones y procedimientos deben ser completadas de forma precisa tal y como se planean de acuerdo a los requerimientos de la empresa.

\subsection{Estudio Legal}

\subsubsection{Formas Societarias}

La empresa será constituida como una sociedad de tipo S.A.C, la razón por la cual se ha decidido constituir una Sociedad Anónima Cerrada ya que ésta se constituye como mínimo con dos personas y puede llegar a tener hasta 20 socios como máximo. En este caso Pome Perú cuenta con dos socios, Carla Rubio (Socio principal) y Alejandro Rubio. Es recomendable tener acciones en vez de participaciones, debido que de esta manera se puede cotizar en la bolsa de valores.

Los Órganos administrativos son:

- Junta General de accionistas

- Directorio 


\section{- Gerencia}

La base legal en la cual se ampara: Ley General de Sociedades 26887- Artículos del 234 al 248

\subsubsection{Justificación de la forma societaria}

Se considera preferible adoptar esta forma societaria porque:

- Si es una SAC no pasa por la escritura pública (el proceso es más fácil y rápido). Sin embargo, si es una SRL, la transferencia tiene que pasar por Escritura Pública.

- Los socios no responden con su patrimonio personal ante las deudas de la empresa. Tienen responsabilidad limitada.

- El Capital Social está representado por acciones nominativas y se conforma con los aportes (en bienes y/o en efectivo) de los socios.

- Las empresas bajo la modalidad S.A.C. se encuentran mejor respaldadas que otras al momento de solicitar financiamiento.

\subsubsection{Flujograma de creación de la empresa}

\section{Elaboración de la minuta}

Documento previo en el cual los miembros de la sociedad a crear explican su voluntad de constituir la empresa, y en donde se señalan todos los acuerdos respectivos. Consta del pacto social y los estatutos, incluyendo los insertos que se puedan adjuntar a ésta.

\section{Apertura de cuenta bancaria}

Se crea una cuenta de custodia.

\section{Inscripción en Registros Públicos}

Se lleva la escritura pública a los registros públicos para su registro.

\section{Inscripción de RUC}

El RUC (Registro Único de Contribuyentes) es lo que identifica a una persona o a la empresa ante la SUNAT para el pago de los impuestos. Toda persona 
natural o jurídica está obligada a inscribirse en el RUC, de lo contrario serán sancionadas de acuerdo con el Código Tributario, igual que los inscritos en el RUC que no presenten la declaración. Para obtenerlo debemos acudir a la SUNAT, llenar un formulario de justificación, y esperar notificación.

\section{Licencia de funcionamiento}

Se saca a través de la municipalidad del distrito en donde va a estar ubicado el negocio. Los documentos a presentar son:

- Fotocopia del RUC.

- Certificado de Zonificación (zona industrial, zona comercial, zona residencial, etc.).

- Croquis de la ubicación de la empresa.

- Copia de contrato de alquiler o título de propiedad.

- Fotocopia de la escritura pública.

- Recibos de pago por derecho por licencia.

- Formulario de solicitud.

\section{Permiso de Defensa Civil}

Se saca dicho permiso para prevenir y/o reducir el riesgo de un peligro de origen natural o inducido por el hombre, para así prevenir cualquier problema.

\section{Registro de marca}

El registro de marcas en Perú está a cargo de la Dirección de Signos Distintivos del INDECOPI.

Figura 39 Flujograma de Creación de la empresa
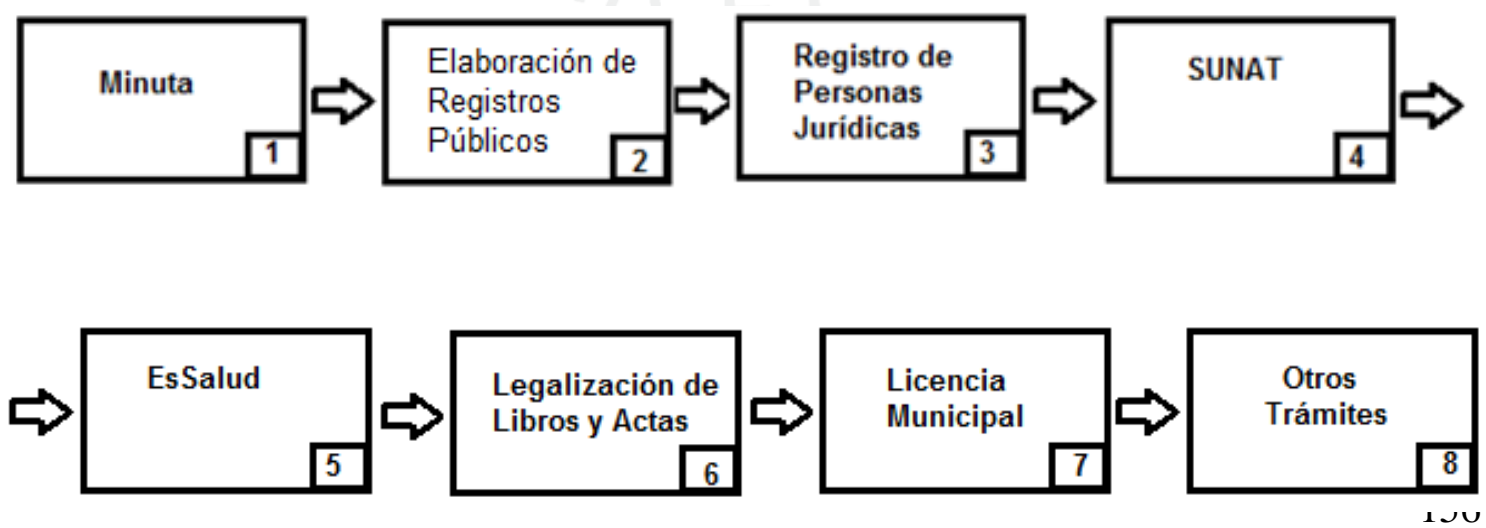


\subsubsection{Legislación arancelaria - tributaria Tributario:}

\section{Impuesto a la Renta: Tercera Categoría}

- La renta neta imponible se obtendrá después de restarle a la renta bruta, los gastos necesarios para el funcionamiento del negocio y otorgamiento del servicio.

- Este impuesto se determinará aplicando una tasa del $30 \%$ sobre la renta neta anual.

- El ejercicio gravable será del 01 de Enero al 31 de Diciembre.(Base Legal: D.S. 054-99-EF)

\section{Impuesto General a las Ventas (IGV)}

- El impuesto a pagar se determina mensualmente deduciendo el impuesto calculado sobre las ventas del periodo menos el total del impuesto pagado en las compras.

- La tasa del impuesto es del $17 \%$ adicionalmente se aplica el $2 \%$ que corresponde al impuesto de promoción municipal, lo que hace un total del 19\%.

- El impuesto debe estar en forma discriminada para que permita la utilización del crédito fiscal. Base Legal: D.S. 055-99-EF).

\section{Impuesto Extraordinario de Solidaridad}

- La sociedad aportará por este concepto una tasa del 5\% del total de la planilla de obreros y empleados.

- El aporte estará también afecto a las gratificaciones de Fiestas Patrias y Navidad.

\section{Carga Impositiva Tributaria Laboral}

\section{De la Empresa:}

- Seguro Social: La empresa aportará a ESSALUD, desde su funcionamiento, el $9 \%$ del total de la planilla de empleados.

\section{Del Trabajador:}


- AFP (Administradora de Fondo de Pensiones): El trabajador aportará a la AFP de su elección lo siguiente:

- $8.00 \%$ aporte obligatorio

$-1.45 \%$ prima de seguro (promedio entre las AFPs)

- $2.50 \%$ comisión variable (promedio entre las AFPs)

- SNP (Sistema Nacional de Pensiones): Aquellos empleados que prefieran el SNP tendrán que hacer una aportación del 13\% de su remuneración asegurable.

- Quinta Categoría: Los empleados que sobrepasen las 7 UIT al año (S/. 3,850 cada una) se les retendrá el 15\% sobre el exceso.

\section{Arancelaria}

- Ad Valorem: (Preferencia Arancelaria SGS con la Unión Europea.

- Específico

- Sobretasa Arancelaria

La empresa no se acogerá a la "Ley General de Aduanas" por no ser un agente de comercio exterior; pero la tendrá en cuenta para la elección de régimen de exportación, régimen aduanero y las posibles sanciones en caso de cometer una infracción. La ley aplicable al tipo de empresa es la "Ley de Sociedades". Teniendo en cuenta lo antes mencionado, la empresa se acogerá como régimen de exportación al "Régimen de Exportación Definitiva", debido a que esta modalidad facilita el despacho para la exportación de mercancías en libre circulación que salen del territorio aduanero para su uso o consumo definitivo en el exterior.

\subsubsection{Legislación ambiental}

La Ley General del Ambiente LEY No 28611 establece las disposiciones generales exigibles a los proyectos de inversión de las empresas. A través de la Legislación Ambiental Peruana se regulan las actividades sectoriales relacionadas al presente proyecto, como la industria y la agricultura. Debido a la naturaleza del proyecto no se afecta la regulación ambiental en materia de industria, ya que las actividades de acopio y producción se realizan en las instalaciones de Ica Pacific SA, la institución que cumple con todas las disposiciones ambientales exigibles. A pesar de 
esto nuestra empresa también debe tomarlo en cuenta debido que nosotros en el futuro planeamos encargarnos de la producción.

Respecto a la legislación ambiental en agricultura, la empresa proveedora de granadas cumple con todas las disposiciones exigidas sobre el manejo integrado de control de plagas, de tal manera que sus plantaciones son tratadas con plaguicidas y sustancias autorizadas, con el fin de volverlas más resistentes a la filoxera y el nematodo, plagas que podrían afectar la calidad del fruto. Además, SENASA a través de la Comisión Nacional de Plaguicidas (CONAP), realiza una evaluación permanente de los plaguicidas y sustancias afines que se utilicen en la siembra.

\subsection{Fundamentos Financieros}

Al analizar la viabilidad del presente plan de negocio se debe tomar en consideración las inversiones que deberán llevarse a cabo para comenzar las operaciones de la empresa. Estas consisten en activos fijos, capital de trabajo gastos pre-operativos. Para Pome Perú su más fuerte inversión se da en el Capital de trabajo.

\subsubsection{Evaluación Económica Financiera}

\subsubsection{Supuestos Financieros}

Pome Perú es una pequeña empresa (MYPE) según la Ley $\mathrm{N}^{\circ} 28015$; DS $\mathrm{N}^{\circ}$ 009-2003 en donde las ventas deben ser desde 150 UIT hasta 1,700 UIT, siendo 1 UIT equivalente a S/ 3,850 al tipo de cambio actual aproximadamente US\$ 1,222.

\section{- Beneficios para los trabajadores}

Tabla 58 Beneficios para los trabajadores en pequeñas empresas 


\begin{tabular}{ll}
\hline Beneficios de los trabajadores & Régimen Laboral Pequeña Empresa \\
\hline Remuneración mínima vital (2014) & S/ 750.00 \\
Compens ación por tiempo de servicios (CTS) & $1 / 2$ sueldo por cada año de trabajo \\
Gratificaciones por Fiestas Patrias y Navidad & $1 / 2$ sueldo en Julio y $1 / 2$ sueldo en Diciembre \\
Seguro Social de Salud & Essalud $9 \%$ (Aportado por empleador) \\
Jornada Máxima & 8 horas o 48 horas semanales \\
Vacaciones & 15 días por año \\
Participación Utilidades & Aplica \\
Sistema Pensionario & 1. SNP/ONP \\
\hline
\end{tabular}

Nota. Fuente: Ministerio de Trabajo y Promoción del Empleo

\section{- Impulso a las micro, pequeñas y medianas empresas}

El régimen Laboral Especial es de naturaleza permanente. La empresa que durante dos años consecutivos supere el nivel de ventas establecido o el número de trabajadores límites establecidos en dicha ley para clasificar a una empresa como Micro o Pequeña Empresa, podrá conservar por un año más el mismo régimen laboral. (El Peruano, 2008)

\subsubsection{Estructura de costos fijos y variables}

\subsubsection{Costos Fijos}

Los costos fijos están compuestos por los sueldos, pago de suministros públicos algunos gastos como los de promoción y contador externo. Se debe notar que estos varían año a año, debido a que se está tomando en consideración la inflación, asimismo la empresa tiene una política de aumento de sueldos.

Tabla 59 Costos Fijos Mensuales y Anuales

\begin{tabular}{|c|c|c|c|c|c|c|c|}
\hline \multirow[b]{2}{*}{ COSTOS FIJOS } & \multirow[b]{2}{*}{$\begin{array}{l}\text { UNIDAD } \\
\text { MESES }\end{array}$} & \multirow[b]{2}{*}{$\begin{array}{c}\text { VALOR UNITARIO } \\
\text { MENSUAL }\end{array}$} & \multirow[b]{2}{*}{ MONTO AÑO 1} & \multirow[b]{2}{*}{ MONTO AÑO 2} & \multirow{2}{*}{$\begin{array}{l}\text { TIVOS } \\
\text { MONTO AÑO } \\
3\end{array}$} & \multirow[b]{2}{*}{ MONTO AÑO 4} & \multirow[b]{2}{*}{ MONTO AÑO 5} \\
\hline & & & & & & & \\
\hline Gerente General & 1 & 904.76 & $10,857.14$ & $11,074.29$ & $13,002.87$ & $13,288.94$ & $15,635.30$ \\
\hline Asistente de Exportaciones & 1 & 634.92 & $7,619.05$ & $7,771.43$ & $9,124.82$ & $9,325.57$ & $10,972.14$ \\
\hline Gratificación & 1 & 128.31 & $1,539.68$ & $1,570.48$ & $1,843.97$ & $1,884.54$ & $2,217.29$ \\
\hline CTS & 1 & 58.63 & 703.55 & 914.83 & $1,064.26$ & $1,097.63$ & $1,279.55$ \\
\hline SIS (Es Salud) $9 \%$ & 1 & 150.12 & $1,801.43$ & $1,837.46$ & $2,157.45$ & 2,204.91 & $2,594.22$ \\
\hline Alquiler & 1 & 634.92 & $7,619.05$ & $7,619.05$ & $7,619.05$ & $7,619.05$ & $7,619.05$ \\
\hline Servicios (Agua y Luz) & 1 & 110.48 & $1,325.71$ & $1,325.71$ & $1,325.71$ & $1,325.71$ & $1,325.71$ \\
\hline Comunicaciones (Teléfono e Internet) & 1 & 63.17 & 758.10 & 758.10 & 758.10 & 758.10 & 758.10 \\
\hline Gastos de Movilidad & 1 & 95.24 & $1,142.86$ & $1,142.86$ & $1,142.86$ & $1,142.86$ & $1,142.86$ \\
\hline $\begin{array}{l}\text { Gasto de Promoción (incluye visita a feria } \\
\text { anual) }\end{array}$ & 1 & 168.33 & $2,020.00$ & $2,140.00$ & $2,510.00$ & $4,120.00$ & $4,220.00$ \\
\hline Contador Externo por tiempo parcial* & 1 & 68.78 & 825.40 & 825.40 & 825.40 & 825.40 & 825.40 \\
\hline Costos Fijos Acumulados & 1 & $3,017.66$ & $36,211.97$ & $36,979.59$ & $41,374.49$ & $43,592.70$ & $48,589.61$ \\
\hline
\end{tabular}




\section{Sueldos}

Para la elaboración de la planilla se debe tomar en cuenta que PomePeru S.A.C. es una pequeña empresa pues sus ventas anuales no superan las 1700 UIT. El sueldo neto para el gerente general es de US\$ 904.76 y para el analista de exportación es de US\$ 634.92. A continuación detallamos la composición de los sueldos. 
Tabla 60 Planilla Mensual

\begin{tabular}{|c|c|c|c|c|c|c|c|c|c|c|c|c|c|}
\hline Cargo & $\begin{array}{l}\text { Sueldo US\$ } \\
\text { Enero }\end{array}$ & $\begin{array}{c}\text { Sueldo US\$ } \\
\text { Febrero }\end{array}$ & $\begin{array}{c}\text { Sueldo US\$ } \\
\text { Marzo }\end{array}$ & $\begin{array}{c}\text { Sueldo US\$ } \\
\text { Abril }\end{array}$ & $\begin{array}{c}\text { Sueldo US\$ } \\
\text { Mayo }\end{array}$ & $\begin{array}{c}\text { Sueldo US\$ } \\
\text { Junio }\end{array}$ & $\begin{array}{c}\text { Sueldo US\$ } \\
\text { Julio }\end{array}$ & $\begin{array}{c}\text { Sueldo US\$ } \\
\text { Agosto }\end{array}$ & $\begin{array}{c}\text { Sueldo US\$ } \\
\text { Setiembre }\end{array}$ & $\begin{array}{l}\text { Sueldo US\$ } \\
\text { Octubre }\end{array}$ & $\begin{array}{l}\text { Sueldo US\$ } \\
\text { Noviembre }\end{array}$ & $\begin{array}{l}\text { Sueldo US\$ } \\
\text { Diciembre }\end{array}$ & Tota Anual \\
\hline Gerente General & 904.76 & 904.76 & 904.76 & 904.76 & 904.76 & 904.76 & 904.76 & 904.76 & 904.76 & 904.76 & 904.76 & 904.76 & $10,857.14$ \\
\hline Analista de exportación & 634.92 & 634.92 & 634.92 & 634.92 & 634.92 & 634.92 & 634.92 & 634.92 & 634.92 & 634.92 & 634.92 & 634.92 & $7,619.05$ \\
\hline Gratificación & & & & & & & 769.84 & & & & & 769.84 & $1,539.68$ \\
\hline Total Sueldo Bruto & $1,539.68$ & $1,539.68$ & $1,539.68$ & $1,539.68$ & $1,539.68$ & $1,539.68$ & $1,539.68$ & $1,539.68$ & $1,539.68$ & $1,539.68$ & $1,539.68$ & $1,539.68$ & $18,476.19$ \\
\hline CTS (Mayo y Noviembre) & & & & & 254.48 & & & & & & 449.07 & & 703.55 \\
\hline Aporte Essalud 9\% & 138.57 & 138.57 & 138.57 & 138.57 & 138.57 & 138.57 & 138.57 & 138.57 & 138.57 & 138.57 & 138.57 & 138.57 & $1,662.86$ \\
\hline Planilla Total Mensual & $1,678.25$ & $1,678.25$ & $1,678.25$ & $1,678.25$ & $1,932.73$ & $1,678.25$ & $1,678.25$ & $1,678.25$ & $1,678.25$ & $1,678.25$ & $2,127.33$ & $1,678.25$ & $20,842.60$ \\
\hline
\end{tabular}

Tabla 61 Planilla Anual

\begin{tabular}{lrrrrr}
\hline Cargo & Sueldo US\$ Año 1 & Sueldo US\$ Año 2 & Sueldo US\$ Año 3 & Sueldo US\$ Año 4 & Sueldo US\$ Año 5 \\
\hline Gerente General & $10,857.14$ & $11,074.29$ & $13,002.9$ & $13,288.9$ \\
Analista de Exportación & $7,619.05$ & $7,771.43$ & $9,124.8$ & $9,325.6$ & $15,635.3$ \\
Gratificación & $1,539.68$ & $1,570.48$ & $1,843.97$ & $1,884.54$ & $2,217.29$ \\
Total & $20,015.87$ & $20,416.19$ & $23,971.67$ & $24,499.05$ & $1,097.63$ \\
CTS & 703.55 & 914.83 & $1,064.26$ & $1,279.55$ \\
Essalud 9\% & $1,801.43$ & $1,837.46$ & $2,157.45$ & $2,204.91$ & $2,594.22$ \\
\hline Planilla Total Anual & $\mathbf{2 2 , 5 2 0 . 8 5}$ & $\mathbf{2 3 , 1 6 8 . 4 8}$ & $\mathbf{2 7 , 1 9 3 . 3 8}$ & $\mathbf{2 7 , 8 0 1 . 5 9}$ & $\mathbf{3 2 , 6 9 8 . 5 0}$ \\
\hline
\end{tabular}

Para la proyección de la planilla de sueldos anual se ha tomado en consideración una inflación de $2 \%$ en promedio anual. Asimismo como se mencionó anteriormente la empresa aumentará los salarios en 15\% en los años 3 y 5 . En el anexo no 8 se detalla el cálculo de la CTS a pagar a los dos trabajadores que están en planilla. 


\section{Costos de Servicios Directos}

La empresa tendrá sus instalaciones en un local comercial alquilado en la ciudad de Ica, el cual estará operativo los 12 meses del año, por lo que se debe desembolsar el alquiler todo el año. Al igual que el alquiler los otros servicios (Agua, Luz, Internet), serán considerados como un pago fijo durante todos los meses en los cuales este operativo el local. En lo que respecta al costo de comunicación está compuesto por la telefonía fija y celular.

Tabla 62 Costos de Servicios Directos

\begin{tabular}{|c|c|c|c|c|c|c|c|c|c|c|c|c|c|}
\hline Concepto & Enero & Febrero & Marzo & Abril & Mayo & Junio & Julio & Agosto & Septiembre & Octubre & Noviembre & Diciembre & Total \\
\hline Agua & 53.33 & 53.33 & 53.33 & 53.33 & 53.33 & 53.33 & 53.33 & 53.33 & 53.33 & 53.33 & 53.33 & 53.33 & 640.00 \\
\hline Eectricidad & 57.14 & 57.14 & 57.14 & 57.14 & 57.14 & 57.14 & 57.14 & 57.14 & 57.14 & 57.14 & 57.14 & 57.14 & 685.71 \\
\hline Alquiler & 634.92 & 634.92 & 634.92 & 634.92 & 634.92 & 634.92 & 634.92 & 634.92 & 634.92 & 634.92 & 634.92 & 634.92 & $7,619.05$ \\
\hline $\begin{array}{l}\text { Comunicaciones } \\
\text { (Teléfono e Internet) }\end{array}$ & 63.17 & 63.17 & 63.17 & 63.17 & 63.17 & 63.17 & 63.17 & 63.17 & 63.17 & 63.17 & 63.17 & 63.17 & 758.10 \\
\hline Gastos de Movilidad & 95.24 & 95.24 & 95.24 & 95.24 & 95.24 & 95.24 & 95.24 & 95.24 & 95.24 & 95.24 & 95.24 & 95.24 & $1,142.86$ \\
\hline Total & 903.81 & 903.81 & 903.81 & 903.81 & 903.81 & 903.81 & 903.81 & 903.81 & 903.81 & 903.81 & 903.81 & 903.81 & $10,845.71$ \\
\hline Total (S/.) & $2,847.00$ & $2,847.00$ & $2,847.00$ & $2,847.00$ & $2,847.00$ & $2,847.00$ & $2,847.00$ & $2,847.00$ & $2,847.00$ & $2,847.00$ & $2,847.00$ & $2,847.00$ & $34,164.00$ \\
\hline
\end{tabular}




\section{- Costos de Promoción}

Los gastos de Promoción que son entre ellos están explicados en la tabla 40 "Presupuesto de Actividades de Marketing", en donde se detallan las actividades a realizarse y su respectivo costo.

Tabla 63 Gasto de Promoción Proyectado

\begin{tabular}{lrrrrr}
\hline & Año 1 & \multicolumn{1}{c}{ Año 2 } & \multicolumn{1}{c}{ Año 3 } & \multicolumn{1}{c}{ Año 4 } & \multicolumn{1}{c}{ Año 5 } \\
\hline Presupuesto Marketing & $2,020.00$ & $2,140.00$ & $2,510.00$ & $4,120.00$ & $4,220.00$ \\
Total Anual & $\mathbf{2 , 0 2 0 . 0 0}$ & $\mathbf{2 , 1 4 0 . 0 0}$ & $\mathbf{2 , 5 1 0 . 0 0}$ & $\mathbf{4 , 1 2 0 . 0 0}$ & $\mathbf{4 , 2 2 0 . 0 0}$ \\
\hline
\end{tabular}

Podemos ver que del año 1 al 5 los gastos de promoción se duplican, esto se debe a que durante los primeros 3 años solo se asistirá a la Feria internacional London Produce como visitantes y para los años 4 y 5 se hará una inversión mayor alquilando un pequeño stand.

\section{- Costos de contador externo}

El contador no estará dentro de la planilla, pero se está incluyendo como un gasto en el cual de todas formas se incurrirá cuando sea necesario.

\subsubsection{Costos variables}

Los costos variables están relacionados directamente con el volumen de ventas, es decir, variarán dependiendo de la cantidad de contenedores, en este caso son Reefer de 40. Para el costeo se consideraron materias primas, empaque y embalaje, almacenamiento, costos logísticos y certificados. Para mayor detalle de los costos variables ver anexo $n^{\circ} 1$, en el cual se adjunta la cotización de la empresa Sunfruit en Ica, la cual se ha contratado para realizar el procesamiento de la fruta. 
Tabla 64 Costos variables

\begin{tabular}{lccr}
\hline ESTRUCTURA DE COSTOS (EN DÓLARES) & \multicolumn{3}{c}{ CONTENEDOR 40' } \\
\hline \multicolumn{1}{c}{ COSTES } \\
& \multicolumn{2}{c}{$\begin{array}{c}\text { CONTENEDOR } \\
\text { 40' PIES }\end{array}$} \\
& $\begin{array}{c}\text { UNIIAD } \\
\mathbf{0 . 6 3 K G}\end{array}$ & CAJAS DE 3.8 KG & \\
\hline Materia Prima & 0.410 & 2.473 & $11,038.87$ \\
Transporte aprovisionamiento & 0.022 & 0.132 & 589.25 \\
Acopio & 0.012 & 0.075 & 333.33 \\
Supervisor de Campo & & & \\
Recepcion, selección, embalaje, etiquetado & 0.002 & 0.011 & 47.62 \\
paletizado y embarque & & & \\
Sellado de Bolsas Xtend & 0.067 & 0.402 & $1,795.95$ \\
Cajas de Cartón (Empaque) & 0.007 & 0.043 & 191.31 \\
Bolsas Xtend & 0.048 & 0.290 & $1,296.35$ \\
Sticker pequeño para cada fruta & 0.022 & 0.132 & 589.96 \\
Etiqueta para el exterior de la caja & 0.011 & 0.066 & 294.62 \\
Etiqueta para pallets & 0.033 & 0.200 & 892.80 \\
Almacenamiento & 0.000 & 0.002 & 8.40 \\
Costos Logisticos & 0.021 & 0.127 & 566.86 \\
Certificado Fitosanitario y Origen & 0.084 & 0.504 & $2,249.50$ \\
Costos Variables Acumulados & 0.002 & 0.015 & 65.00 \\
\hline
\end{tabular}

\section{- Materia Prima}

La materia prima para cada contenedor son las granadas, se estará adquiriendo $15 \%$ adicional a la cantidad necesaria por contenedor debido a la merma.

Tabla 65 Costos de Materiales Directos

\begin{tabular}{|c|c|c|c|}
\hline \multirow{2}{*}{$\begin{array}{l}\text { MATERIALES } \\
\text { DIRECTOS }\end{array}$} & \multicolumn{3}{|c|}{1 CONTENEDOR } \\
\hline & $\begin{array}{l}\text { UNIDAD } \\
\text { 0.65KG }\end{array}$ & CAJA 3.8 KG & 1 CONT 16,963.2 kg \\
\hline Materia Prima: Granadas & 0.410 & 2.47 & $11,038.87$ \\
\hline
\end{tabular}

\section{- Mano de Obra Directa}

En la siguiente tabla podemos observar la mano de obra directa necesaria en nuestro proyecto, que son los operarios encargados del acopio de la fruta para cada contenedor. 
Tabla 66 Costos de Mano de Obra Directa (MOD)

\begin{tabular}{lc}
\hline & Pago por Jornal \\
\hline Acopio & 22.22 \\
$\mathbf{N}^{\circ}$ de Operarios & 15.00 \\
\hline Total (US\$) & 333.33 \\
\hline
\end{tabular}

El pago a los operarios será por jornal y se necesitarán 15 de ellos para completar la cantidad necesaria para un contenedor en un día.

\section{- Costos Logísticos}

En la siguiente tabla definiremos los costos logísticos que se incurrirán para la exportación de un contenedor de 40 pies, en los cuales se incluye el costo de transporte terrestre de Ica a Lima, y luego de ese punto al Callao, del Agente de Aduanas, Agente Naviero.

Tabla 67 Costos Logísticos

\begin{tabular}{lr}
\hline \multicolumn{1}{c}{ Costos Logísticos } & $\mathbf{2 2 4 9 . 5 0}$ \\
\hline Gate Out+ Precintado & 145.00 \\
Costo de Transporte & $1,525.50$ \\
Agenciamiento de Aduanas & 200.00 \\
Tracción Contenedores & 80.00 \\
& \\
Visto Bueno de Exportación & 132.00 \\
Carga & 167.00 \\
\hline
\end{tabular}

\subsubsection{Margen y determinación del precio de venta}

Antes de fijar el precio de venta es importante determinar el costo total por unidad, para a partir de allí poder fijar nuestro margen de ganancia y comparar con los precios de los competidores. La tabla que se muestra a continuación representa tanto los costos variables como fijos unitarios para los cinco primeros años de actividad de Pome Perú. La unidad de medida utilizada para los cálculos es de un contenedor de 40 pies. 
Tabla 68 Costos Fijos y Variables Unitarios

\begin{tabular}{lrrrrr}
\hline Costos & Año 1 & Año 2 & Año 3 & Año 4 & \multicolumn{1}{c}{ Año 5 } \\
\hline CVU & $19,959.82$ & $20,359.01$ & $20,766.20$ & $21,181.52$ & $21,605.15$ \\
CFU & $3,017.66$ & $3,081.63$ & $3,447.87$ & $3,632.73$ & $4,049.13$ \\
CTU & $22,977.48$ & $23,440.65$ & $24,214.07$ & $24,814.24$ & $25,654.28$ \\
M. GANANCIA 26\% & $5,974.15$ & $6,094.57$ & $6,295.66$ & $6,451.70$ & $6,670.11$ \\
\hline PRECIO DE VENTA & $\mathbf{2 8 , 9 5 1 . 6 3}$ & $\mathbf{2 9 , 5 3 5 . 2 2}$ & $\mathbf{3 0 , 5 0 9 . 7 3}$ & $\mathbf{3 1 , 2 6 5 . 9 5}$ & $\mathbf{3 2 , 3 2 4 . 4 0}$ \\
\hline
\end{tabular}

Al realizarse la venta en términos de venta $\mathrm{FOB}$, se está considerando como primera barrera el precio FOB de la oferta nacional el cual se encuentra en el rango de USD\$ 2.1 a 2.9 por kg dependiendo de la empresa. También se tomarán en cuenta los precios de la demanda internacional, por lo que el precio de venta se encontrara situado entre esos parámetros, el precio de venta FOB de un contenedor proveniente de España es aproximadamente US\$29,346.34. Por esta razón es que decidió determinar un margen de ganancia de $26 \%$. (Ver tabla)

Tabla 69 Precio de Venta FOB

\begin{tabular}{|c|c|c|c|c|c|}
\hline \multirow[b]{2}{*}{ Costos } & \multirow[b]{2}{*}{ ¿Quién cobra? } & \multirow[b]{2}{*}{ Fase Logística } & \multicolumn{3}{|c|}{1 CONTENEDOR } \\
\hline & & & $\begin{array}{l}\text { UNIDAD } \\
0.63 \mathrm{KG}\end{array}$ & $\begin{array}{c}\text { САJA } \\
3.8 \mathrm{KG}\end{array}$ & 1 CONT 40' \\
\hline Materia prima & Proveedores & Aprovisionamiento & 0.410 & 2.47 & $11,038.87$ \\
\hline Mano de obra directa & Dpto de Personal & Aprovisionamiento & 0.014 & 0.09 & 380.95 \\
\hline Mano de obra directa (Procesamiento/ Tercerización) & Proveedores & Aprovisionamiento & 0.067 & 0.40 & $1,795.95$ \\
\hline Gastos indirectos de fabricación & Costos Fijos & Aprovisionamiento & 0.112 & 0.68 & $3,017.66$ \\
\hline Transporte de aprovisionamiento & Transportista & Aprovisionamiento & 0.022 & 0.13 & 589.25 \\
\hline Envases y Embalaje & Proveedores & Aprovisionamiento & 0.122 & 0.73 & $3,273.45$ \\
\hline Almacenamiento & Proveedores & Aprovisionamiento & 0.021 & 0.13 & 566.86 \\
\hline Certificaciones & Proveedores & Aprovisionamiento & 0.002 & 0.01 & 65.00 \\
\hline EXW & Incoterm & Internacional & 0.770 & 4.64 & $20,727.98$ \\
\hline Gate Out & Terminal de Vacíos & Internacional & 0.005 & 0.03 & 145.00 \\
\hline Transporte Local & Terminal de Vacíos & Internacional & 0.057 & 0.34 & $1,525.50$ \\
\hline Agenciamiento de aduana & Agente de aduana & Internacional & 0.007 & 0.04 & 200.00 \\
\hline Tracción Contenedores en origen & Agente Marítimo & Internacional & 0.003 & 0.02 & 80.00 \\
\hline Visto Bueno de Exportación & Agente Marítimo & Internacional & 0.005 & 0.03 & 132.00 \\
\hline FAS & Incoterm & Internacional & 0.847 & 5.11 & $22,810.48$ \\
\hline Carga & Agente Marítimo & Internacional & 0.006 & 0.04 & 167.00 \\
\hline FOB Acordado & Incoterm & Internacional & 0.853 & 5.15 & $22,977.48$ \\
\hline Margen de Ganancia & & & 0.22 & 1.34 & $5,974.15$ \\
\hline PRECIO FOB TOTAL (Situación Actual) & & & 1.075 & 6.49 & $28,951.63$ \\
\hline
\end{tabular}

\subsubsection{Proyección de Ventas}

Durante el primer año de operaciones se planea vender 2 contenedores, en el segundo se aumentará la cantidad a 4. A partir del tercer año debido a la mayor 
demanda que por parte del Reino Unido y a conocimiento más amplio del mercado gracias a ferias y actividades promoción, se incrementarán las ventas a 7. Para el cuarto año enviaremos $10 \mathrm{y}$ en el quinto año llegaremos a exportar aproximadamente 12 contenedores de granadas frescas.

Tabla 70 Proyección de Ventas Anual

\begin{tabular}{|c|c|c|c|c|c|c|}
\hline \multicolumn{6}{|l|}{ En Unidades } & \\
\hline Producto & Año 1 & Año 2 & Año 3 & Año 4 & Año 5 & \\
\hline $1 \mathrm{CONT} 40^{\prime}$ & 2 & 4 & 7 & 9 & 12 & \\
\hline En Dólares & 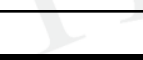 & & & & & \\
\hline $\begin{array}{l}\text { Producto } \\
1 \text { CONT } 40^{\prime}\end{array}$ & $\begin{array}{l}\mathbf{1} \\
57,903\end{array}$ & $\begin{array}{c}\mathbf{2} \\
118,141\end{array}$ & $\begin{array}{r}3 \\
21\end{array}$ & & $\begin{array}{c}4 \\
281,394\end{array}$ & $\begin{array}{c}\mathbf{5} \\
387,893\end{array}$ \\
\hline
\end{tabular}

Asimismo uno de los motivos por los cuales se están aumentando gradualmente los envíos de contenedores se debe a la proyección de crecimiento de la producción de granadas en la región Ica, entre el 2008 y 2013 la misma creció en promedio 68\%.

\subsubsection{Estructura de la inversión}

El proyecto de exportación de la empresa Pome Perú requerirá una inversión en activos fijos de US\$4,169.13, como se podrá observar en la tabla a continuación no hay ninguna inversión de un monto muy grande debido a que se va a contratar el servicio de procesamiento a una empresa en Ica, la cual ya cuenta con bastante experiencia este rubro.

Los activos fijos son bienes que no pueden convertirse en líquidos a corto plazo y son necesarios para el funcionamiento de la empresa y no se destinan a la venta.

Se encuentran afectos a la depreciación, lo que significa que con el tiempo estos pierden su valor pudiendo llegar a cero.

Dentro de los activos fijos también se consideran los equipos que deben ser utilizados para el buen funcionamiento y orden de las instalaciones como lo son los extinguidores, botiquín de salud, luces de seguridad etc. 
Tabla 71 Activos Fijos

\begin{tabular}{|c|c|c|c|c|}
\hline CONCEPTO & U.M. & CANT. & $\begin{array}{c}\text { P.UNIT } \\
\text { US\$ }\end{array}$ & $\begin{array}{c}\text { TOTAL } \\
\text { US\$ }\end{array}$ \\
\hline \multicolumn{5}{|l|}{ I. Maquinaria y equipo } \\
\hline Computadoras & ud & 2 & 539.68 & $1,079.37$ \\
\hline Impres ora multifuncional & ud & 1 & 126.67 & 126.67 \\
\hline Guantes estériles & ud & 100 & 0.49 & 49.00 \\
\hline \multirow[t]{2}{*}{ Jabas Cosecheras } & ud & 780 & 2.86 & $2,228.57$ \\
\hline & & \multicolumn{2}{|c|}{ Sub total \$ } & $3,483.60$ \\
\hline \multicolumn{5}{|l|}{ II. Muebles y enseres } \\
\hline Escritorio & ud & 2 & 158.70 & 317.40 \\
\hline Sillas Oficina (Giratorias) & ud & 2 & 44.41 & 88.83 \\
\hline Sillas Visita & ud & 2 & 19.02 & 38.03 \\
\hline Archiveros & ud & 2 & 63.49 & 126.98 \\
\hline Extintor & ud & 1 & 19.05 & 19.05 \\
\hline Botiquín & $\mathrm{ud}$ & 1 & 15.87 & 15.87 \\
\hline \multirow[t]{2}{*}{ Utiles de oficina } & ud & 1 & 79.37 & 79.37 \\
\hline & & \multicolumn{2}{|c|}{ Sub total \$ } & 685.52 \\
\hline TOTAL ACTIVOS FIJOS & & & & $4,169.13$ \\
\hline
\end{tabular}

Previo al inicio de las actividades de la empresa se incurrirá en los gastos pre-operativos (artículos o servicios) los cuales ascienden a US\$1,714.29 y se detallan en la tabla a continuación:

Tabla 72 Activos Intangibles

\begin{tabular}{|c|c|c|c|c|}
\hline CONCEPTO & U.M. & CANT. & P.UNIT US\$ & $\begin{array}{c}\text { TOTAL } \\
\text { US\$ }\end{array}$ \\
\hline \multicolumn{5}{|l|}{ GASTOS PREOPERATIVOS } \\
\hline Garantía de alquiler & ud & 1 & $1,269.84$ & 1269.84127 \\
\hline Plan de negocio, estudios & ud & 1 & 952.38 & $1,269.84$ \\
\hline Licencias y constitucion de empresa & ud & 1 & 444.44 & 444.44 \\
\hline Remodelación & ud & 1 & 317.46 & 317.46 \\
\hline \multicolumn{4}{|r|}{ Sub total US\$ } & $1,714.29$ \\
\hline TOTAL & & & & 1,714.29 \\
\hline
\end{tabular}

El capital de trabajo de Pome Perú S.A.C es de US\$22,977.48, el cual está compuesto por los costos fijos y variables, representa el $76 \%$ de las inversiones. Este consiste en costos variables y fijos, los primeros dependen del volumen de ventas mientras que los 
segundos son importes mensuales en los cuales la empresa incurre durante todos los meses del año así no haya producción.

Tabla 73 Capital de Trabajo

\begin{tabular}{ccrrr}
\hline CONCEPTO & U.M. CANT. & \multicolumn{1}{c}{$\begin{array}{c}\text { P.UNIT } \\
\mathbf{\$}\end{array}$} & \multicolumn{1}{c}{ TOTAL } \\
\hline CAPITAL DE TRABAJO & & & & \\
\hline Costos variables & mes & 1 & $19,959.82$ & $19,959.82$ \\
Costos y gastos fijos & mes & 1 & $3,017.66$ & $3,017.66$ \\
& & & Sub total \$ & $\mathbf{2 2 , 9 7 7 . 4 8}$ \\
\hline TOTAL CAPITAL DE TRABAJO & & & $\mathbf{2 2 , 9 7 7 . 4 8}$ \\
\hline
\end{tabular}

\subsubsection{Depreciación de Activos Fijos}

La depreciación se refiere a la reducción anual del valor de una propiedad, planta o equipo a causa del uso de los mismos y el paso del tiempo. En el punto 3.3.5 se definió la vida útil de acuerdo a la clasificación de los activos adquiridos para el funcionamiento de negocio. En la siguiente tabla se muestra los montos de la depreciación anual y mensual. Luego en la tabla 75 podemos ver los valores residuales año a año, en el quinto año el valor residual de los activos fijos alcanza los US\$ 420.97.

Tabla 74 Montos en US\$ de la depreciación de Activos

\begin{tabular}{lccrr}
\hline \begin{tabular}{l} 
DEPRECIACION DE ACTIVOS \\
\multicolumn{1}{c}{ Activos Fijos }
\end{tabular} & \% Depreciacion & Vida Util años & Depr. Anual & Depr. Mes \\
\hline & & & & \\
Computadoras & $25 \%$ & 4 & 269.8 & 22.5 \\
Impresora Multifuncional & $25 \%$ & 4 & 31.7 & 2.6 \\
Jabas Cosecheras & $20 \%$ & 5 & 445.7 & 37.1
\end{tabular}

\begin{tabular}{llrrr} 
Escritorio & $10 \%$ & 10 & 31.7 & 2.6 \\
Sillas Oficina & $10 \%$ & 10 & 8.9 & 0.7 \\
Sillas Visita & $10 \%$ & 10 & 3.8 & 0.3 \\
Archiveros & $10 \%$ & 10 & 12.7 & 1.1 \\
Extintor & $20 \%$ & 5 & 3.8 & 0.3 \\
Botiquín & $20 \%$ & 5 & 3.2 & 0.3 \\
& & & & $\mathbf{6 7 . 6 1}$ \\
\hline
\end{tabular}


Tabla 75 Depreciación acumulada de Activos Fijos

\begin{tabular}{crrr}
\hline Año & Depreciación & Depreciación Acumulada & Valor Residual \\
\hline 1 & 811.33 & 0.00 & $3,357.80$ \\
2 & 811.33 & $1,622.66$ & $2,546.47$ \\
3 & 811.33 & $2,433.99$ & $1,735.14$ \\
4 & 811.33 & $3,245.32$ & 923.81 \\
5 & 502.84 & $3,748.16$ & 420.97 \\
\hline
\end{tabular}

\subsubsection{Amortización de Intangibles}

La depreciación de los activos intangibles es conocida como la amortización y funciona de la misma forma que la primera. La vida útil de los intangibles es de 5 años y se deprecian a una tasa de $20 \%$ anual.

Tabla 76 Monto en US\$ de la amortización

\begin{tabular}{ccccc}
\hline Concepto & Tasa & Valor US\$ & $\begin{array}{c}\text { Amortización } \\
\text { Anual }\end{array}$ \\
\hline Amortización & $20 \%$ & $2,984.13$ & 596.83 \\
\hline
\end{tabular}

\subsubsection{Financiamiento de la inversión}

Para efectos del presente proyecto se utilizarán dos fuentes de financiamiento para cubrir los requerimientos de inversión para comenzar las operaciones. La primera es el aporte propio de los socios y la segunda fuente es un préstamo bancario por el $60 \%$ del capital de trabajo. Se ha decidido que el $54.24 \%$ de las inversiones de la empresa sean financiadas mediante aportes de los socios mientras que el $45.76 \%$ restante se obtendrán de un préstamo.

Tabla 77 Estructura de Financiamiento de las inversiones

\begin{tabular}{|c|c|c|c|}
\hline Tipos de Fuentes & APORTE PROPIO PRÉSTAMO BANC. & TOTAL DOLARES & $\%$ \\
\hline \multicolumn{4}{|l|}{ Inversiones } \\
\hline Activos Fijos & $4,169.13$ & $4,169.13$ & $13.8 \%$ \\
\hline Intangibles & $2,984.13$ & $2,984.13$ & $9.9 \%$ \\
\hline Capital de Trabajo & $13,786.49$ & $22,977.48$ & $76.3 \%$ \\
\hline Peso & $54.24 \%$ & & \\
\hline TOTAL INVERSION & $16,344.25$ & $30,130.74$ & $100.0 \%$ \\
\hline
\end{tabular}


El préstamo será solicitado al Agrobanco, debido que Pome Perú no cuenta con todos los recursos propios para financiarse por sí solo. Ver anexo $n^{\circ} 10$ Cronograma de Pagos Préstamo Capital de Trabajo. De acuerdo al portal de transparencia de la SBS, la tasa promedio en moneda extranjera para préstamos a la microempresa es de $20.55 \%$. (SBS, 2015) A continuación se detallan las condiciones:

Tabla 78 Información importante Préstamo Bancario

\begin{tabular}{lr}
\hline \multicolumn{1}{c}{ CONCEPTO } & MONTO \\
\hline Monto a financiar US\$ $\$$ & $13,786.49$ \\
Tasa de interés anual & $21 \%$ \\
Tasa de interés mensual & $1.60 \%$ \\
Periodo de financiamiento (meses) & 42 \\
Periodo de gracia (meses) & 6 \\
Cuota US\$ & 453.43 \\
ITF & $0.01 \%$ \\
\hline
\end{tabular}

\subsubsection{Flujo de Caja}

\subsubsection{Flujo de Caja Económico}

La viabilidad del proyecto es analizada a través del flujo de caja económico, donde se proyectan los fondos generados en cada año. Durante los próximos cinco años, en los primeros dos años se obtienen cifras negativas, lo que puede ser explicado por la menor cantidad de contenedores exportados. A partir del tercer año todos los flujos son positivos y crecientes hasta el último año.

El flujo de caja se caracteriza por mostrar lo que efectivamente ingresa y egresa del negocio, como los ingresos por ventas o el pago de cuentas. Asimismo nos permite obtener las perspectivas de los inversionistas ya que utiliza cada flujo obtenido para calcular tasa de interna de retorno.

En el anexo $n^{\circ} 8$ se pueden apreciar los flujos de caja operativos proyectados para los 5 primeros años de actividad de Pome Perú. 
Tabla 79 Flujo de Caja Económico en US\$

\begin{tabular}{|c|c|c|c|c|c|c|}
\hline & $\mathbf{0}$ & 1 & 2 & 3 & 4 & 5 \\
\hline \multicolumn{7}{|l|}{$\begin{array}{l}\text { INGRESOS } \\
\end{array}$} \\
\hline Ventas & & $57,903.26$ & $118,140.86$ & $213,568.09$ & $281,393.53$ & $387,892.77$ \\
\hline (-) Incobrables (5\%) & & 0.00 & 0.00 & 0.00 & 0.00 & 0.00 \\
\hline Ventas Netas & & $57,903.26$ & $118,140.86$ & $213,568.09$ & $281,393.53$ & $387,892.77$ \\
\hline \multicolumn{7}{|l|}{ FLUJO DE INVERSIONES } \\
\hline Inversiones & $-7,153.25$ & & & & & \\
\hline \multicolumn{7}{|l|}{ I. Maquinaria y equipo } \\
\hline Computadoras & $-1,079.37$ & & & & & \\
\hline Impresora multifuncional & -126.67 & & & & & \\
\hline Guantes estériles & -49.00 & & & & & \\
\hline Jabas Cosecheras & $-2,228.57$ & & & & & \\
\hline \multicolumn{7}{|l|}{ II. Muebles y enseres } \\
\hline Escritorio & -317.40 & & & & & \\
\hline Sillas Oficina & -88.83 & & & & & \\
\hline Sillas Visita & -38.03 & & & & & \\
\hline Archiveros & -126.98 & & & & & \\
\hline Extintor & -19.05 & & & & & \\
\hline Botiquín & -15.87 & & & & & \\
\hline Utiles de oficina & -79.37 & & & & & \\
\hline \multicolumn{7}{|l|}{ III. Gastos Preoperativos } \\
\hline Garantía de alquiler & $-1,269.84$ & & & & & \\
\hline Plan de negocio, estudios & -952.38 & & & & & \\
\hline Licencias y constitucion de empresa & -444.44 & & & & & \\
\hline Remodelación & -317.46 & & & & & \\
\hline \multicolumn{7}{|l|}{ Capital de trabajo } \\
\hline Costos variables & $-19,959.82$ & & & & & \\
\hline Costos y gastos fijos & $-3,017.66$ & & & & & \\
\hline Recuperación capital de trabajo & & & & & & $22,977.48$ \\
\hline \multicolumn{7}{|l|}{ EGRESOS } \\
\hline (-) Costo de Producción & & $39,919.64$ & $81,436.06$ & $145,363.37$ & $190,633.67$ & $259,261.79$ \\
\hline $\begin{array}{l}\text { (-) Gastos Administrativos y Ventas } \\
\text { (-) Valor de Recupero }\end{array}$ & & $36,211.97$ & $36,979.59$ & $41,374.49$ & $43,592.70$ & $48,589.61$ \\
\hline (-) Impuesto a la Renta (30\%) & & 0.00 & 0.00 & 0.00 & $13,727.70$ & $23,682.51$ \\
\hline (+) Depreciación y amortización & & $1,408.16$ & $1,408.16$ & $1,408.16$ & $1,408.16$ & $1,099.66$ \\
\hline FLUJO ECONÓMICO & $30,130.74$ & $16,820.19$ & $1,133.37$ & $28,238.39$ & $34,847.61$ & $80,436.00$ \\
\hline
\end{tabular}

\begin{tabular}{|ll|}
\hline WACC & $15.1941 \%$ \\
VANE & $34,040.79$ \\
TIRE & $33.27 \%$ \\
\hline
\end{tabular}

\subsubsection{Flujo de Caja Financiero}

La empresa Pome Perú financiará el $45.76 \%$ de sus inversiones a través de un préstamo a una entidad bancaria, el monto necesario fue detallado en el punto 3.6.6 el cual fue de US\$13,786.49. Por esta razón es que también se debe hallar el flujo de caja financiero, este considera las distintas salidas de dinero a causa del préstamo. 
Tabla 80 Flujo de Caja Financiero US\$

\begin{tabular}{|c|c|c|c|c|c|c|}
\hline ESTADO DE RESULTADOS & $\mathbf{0}$ & 1 & 2 & 3 & 4 & 5 \\
\hline Préstamo & $13,786.49$ & & & & & \\
\hline FLUJO ECONÓMICO & $-30,130.74$ & $-16,820.19$ & $1,133.37$ & $28,238.39$ & $34,847.61$ & $80,436.00$ \\
\hline Ventas & & $57,903.26$ & $118,140.86$ & $213,568.09$ & $281,393.53$ & $387,892.77$ \\
\hline Costo de Ventas & & $-39,919.64$ & $-81,436.06$ & $-145,363.37$ & $-190,633.67$ & $-259,261.79$ \\
\hline Utilidad Bruta & & $17,983.62$ & $36,704.80$ & $68,204.73$ & $90,759.86$ & $128,630.98$ \\
\hline Gastos Administrativos & & $-36,211.97$ & $-36,979.59$ & $-41,374.49$ & $-43,592.70$ & $-48,589.61$ \\
\hline Depreciación & & $-1,408.16$ & $-1,408.16$ & $-1,408.16$ & $-1,408.16$ & $-1,099.66$ \\
\hline Utilidad Operativa & & $-19,636.50$ & $-1,682.94$ & $25,422.08$ & $45,759.00$ & $78,941.70$ \\
\hline Gastos por interes & & $-2,591.88$ & $-2,084.30$ & $-1,379.37$ & -526.40 & \\
\hline Utilidad. Ant Imp & & $-22,228.38$ & $-3,767.24$ & $24,042.71$ & $45,232.60$ & $78,941.70$ \\
\hline $\operatorname{Imp} 30 \%$ & & - & - & - & $13,569.78$ & $23,682.51$ \\
\hline Ut Neta & & $-22,228.38$ & $-3,767.24$ & $24,042.71$ & $31,662.82$ & $55,259.19$ \\
\hline Amortización & & $-1,453.17$ & $-3,356.83$ & $-4,061.76$ & $-4,914.73$ & \\
\hline FLUJO FINANCIERO & $-16,344.25$ & $-23,681.55$ & $-7,124.07$ & $19,980.95$ & $26,748.09$ & $55,259.19$ \\
\hline
\end{tabular}

El WACC (Costo Promedio Ponderado del capital) hallado en el punto y el flujo de caja financiero hallado en el punto nos ayudarán a determinar la TIRF. En primer lugar el VANF se halló descontando los flujos de los cinco años de operatividad de la empresa a la tasa $15.61 \%$, sumándole el flujo del año 0. Con esta información se obtuvo un VANF de $32,983.21$ y una TIRF de $24.50 \%$.

\subsubsection{Indicadores financieros}

Los indicadores financieros del proyecto, se pueden observar en la tabla $n^{\circ} 81$. Los mismos reflejan el desempeño que va a tener la empresa hasta el quinto año.

Tabla 81 Indicadores Financieros

\begin{tabular}{lc}
\hline \multicolumn{1}{c}{ Indicadores } & Valores \\
\hline TIR E & $33.27 \%$ \\
VAN E & $34,040.79$ \\
WACC & $15.1941 \%$ \\
COK & $15.6108 \%$ \\
\hline
\end{tabular}

\section{Costo de Oportunidad del Capital (COK)}

Para la determinación del Costo de Oportunidad (COK) la tasa de rendimiento mínimo exigida por el inversionista, se utilizó la fórmula de CAPM que se presenta a continuación: 


$$
\mathrm{CAPM}=\mathrm{rf}+\mathrm{b} *(\mathrm{rm}-\mathrm{rf})+\mathrm{rp}
$$

El costo de oportunidad de capital del accionista es de $15.6108 \%$

Los datos necesarios para realizar este cálculo fueron extraídos de diversas fuentes referenciales, $\mathrm{Rf}$ es la tasa libre de riesgo (2.61\%), $\mathrm{Rm}$ es la tasa de riesgo del mercado (15.98\%), B es el beta apalancado (0.84) y el Riesgo país es $1.77 \%$.

\section{Promedio Ponderado del Costo de Capital (WACC)}

El WACC es de $15.1941 \%$ y se calcula multiplicando el peso de los activos aportados por los socios por la tasa de rendimiento exigida por el inversionista más el peso de la inversión financiada por el banco multiplicada por su costo. Se utiliza como tasa al momento de descontar los flujos de efectivo con financiamiento o deuda. La fórmula es a siguiente:

$$
\mathrm{WACC}=\begin{aligned}
& \mathrm{WACC}=\mathrm{rd}^{*} \mathrm{D} /(\mathrm{D}+\mathrm{E})^{*}(1-\mathrm{T})+\mathrm{COK} \\
& *(\mathrm{E} / \mathrm{E}+\mathrm{D})
\end{aligned}
$$

Según nuestro resultado obtenido deberíamos aceptar cualquier inversión que esté por encima de este porcentaje.

\section{Valor Actual Neto Económico (VAN E)}

El valor actual neto económico del proyecto es de US\$34,130.47, esto quiere decir que el valor de la empresa aumenta en US\$ US\$ 34,130.47después de haber cubierto sus costos e inversión. Para hallar este valor se debe utilizar el COK, el cual contiene implícitamente la relación riesgo retorno que existe en el mercado.

\section{Tasa Interna de Retorno Económica (TIR E)}

La TIR económica obtenida es de $33.31 \%$, lo que demuestra que es un proyecto viable y rentable. Se refiere al retorno esperado en función de los rendimientos del mercado de empresas similares al proyecto de evaluación.

\subsubsection{Estados financieros}

\subsubsection{Estado de Ganancias y Pérdidas}


Podemos observar en el Estado de Ganancias y Pérdidas, que durante los dos primeros años de operación la empresa incurre en pérdidas. En el primer año esto se debe a las mayores inversiones que se realizan, luego en el segundo se va recuperando. A partir del tercer año obtenemos resultados positivos crecientes llegando a obtener ganancias por USD\$ 84,969.10 en el quinto año.

El Estado de Ganancias y Pérdidas se ha realizado en Dólares Americanos, solo para fines prácticos, debido que para efectos contables no está permitido la presentación o declaración del documento en moneda extranjera. Se están basando los cálculos en un tipo de cambio referencial promedio de 3.15 por las constantes fluctuaciones que se han presentado durante el 2014 y lo que va del año 2015.

Tabla 82 Estado de Ganancias y Pérdidas en US\$

\begin{tabular}{|c|c|c|c|c|c|c|}
\hline CONCEPTO & $\mathbf{0}$ & 1 & 2 & 3 & 4 & 5 \\
\hline Ventas & & $57,903.26$ & $118,140.86$ & $213,568.09$ & $281,393.53$ & $387,892.77$ \\
\hline (-) Costo de Producción & & $39,919.64$ & $81,436.06$ & $145,363.37$ & $190,633.67$ & $259,261.79$ \\
\hline Utilidad Bruta & & $17,983.62$ & $36,704.80$ & $68,204.73$ & $90,759.86$ & $128,630.98$ \\
\hline (-) Gastos Administrativos y Ventas & & $36,211.97$ & $36,979.59$ & $41,374.49$ & $43,592.70$ & $48,589.61$ \\
\hline EBITDA & & $-18,228.35$ & -274.79 & $26,830.24$ & $47,167.16$ & $80,041.37$ \\
\hline (-) Depreciación y amortización & & $1,408.16$ & $1,408.16$ & $1,408.16$ & $1,408.16$ & $1,099.66$ \\
\hline EBIT & & $-19,636.50$ & $-1,682.94$ & $25,422.08$ & $45,759.00$ & $78,941.70$ \\
\hline (-) Impuesto a la Renta (30\%) & & 0.00 & 0.00 & 0.00 & $13,727.70$ & $23,682.51$ \\
\hline Resultado del Ejercicio & & $-19,636.50$ & $-1,682.94$ & $25,422.08$ & $32,031.30$ & $55,259.19$ \\
\hline Resultado Acumulado & & $-19,636.50$ & $-21,319.44$ & $4,102.6$ & $36,133.94$ & 91,393.13 \\
\hline
\end{tabular}

\subsubsection{Balance General}

Al igual que el Estado de Ganancias, por fines prácticos el balance general se encuentra en moneda extranjera, pero contablemente se rigen bajo la moneda nacional. Por esta razón estos no podrán ser presentados ante la SUNAT. 
Tabla 83 Balance General expresado en US\$

\begin{tabular}{|c|c|c|c|c|c|c|}
\hline CONCEPTO & $\mathbf{0}$ & 1 & 2 & 3 & 4 & 5 \\
\hline \multicolumn{7}{|c|}{ ACTIVO } \\
\hline \multicolumn{7}{|l|}{ Activo Corriente } \\
\hline Caja y Bancos & $22,977.48$ & $4,749.14$ & $4,474.35$ & $31,304.58$ & $78,471.74$ & $144,785.41$ \\
\hline Inventarios & & 0.00 & 0.00 & 0.00 & 0.00 & 0.00 \\
\hline Total Activo Corriente & 22,977.48 & $4,749.14$ & $4,474.35$ & $31,304.58$ & $\mathbf{7 8 , 4 7 1 . 7 4}$ & $144,785.41$ \\
\hline \multicolumn{7}{|l|}{ Activo No Corriente } \\
\hline Inversión Fija Tangible, neto & $4,169.13$ & $3,357.80$ & $2,546.47$ & $1,735.14$ & 923.81 & 420.97 \\
\hline Inversión Fija Intangible, neto & $2,984.13$ & $2,387.30$ & $1,790.48$ & $1,193.65$ & 596.83 & 0.00 \\
\hline Total Activo No Corriente & $7,153.25$ & $5,745.10$ & $4,336.94$ & $2,928.79$ & $1,520.63$ & 420.97 \\
\hline \multicolumn{7}{|l|}{ Redondeo } \\
\hline Total Activo & $30,130.74$ & $10,494.23$ & $8,811.29$ & $34,233.37$ & 79,992.37 & $145,206.37$ \\
\hline \multicolumn{7}{|c|}{ PASIVO } \\
\hline \multicolumn{7}{|l|}{ Pasivo Corriente } \\
\hline Parte Corriente del Prés tamo & & $1,453.17$ & $3,356.83$ & $4,061.76$ & $4,914.73$ & 0.00 \\
\hline Impuesto por pagar & & & & & $13,727.70$ & $23,682.51$ \\
\hline Total Pasivo Corriente & & $1,453.17$ & $3,356.83$ & $4,061.76$ & $18,642.43$ & $23,682.51$ \\
\hline Pasivo No Corriente & $13,786.49$ & $12,333.32$ & $8,976.49$ & $4,914.73$ & 0.00 & 0.00 \\
\hline Total Pasivo No Corriente & $13,786.49$ & $12,333.32$ & $8,976.49$ & $4,914.73$ & 0.00 & 0.00 \\
\hline Total Pasivo & $13,786.49$ & $13,786.49$ & $12,333.32$ & $8,976.49$ & $18,642.43$ & $23,682.51$ \\
\hline 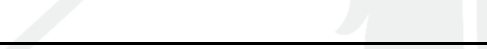 & \multicolumn{3}{|c|}{ PATRIMONIO NETO } & C & & 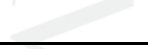 \\
\hline Capital Social & $16,344.25$ & $16,344.25$ & $17,797.42$ & $21,154.25$ & $25,216.01$ & $30,130.74$ \\
\hline Utilidades del periodo & & $-19,636.50$ & $-1,682.94$ & $25,422.08$ & $32,031.30$ & $55,259.19$ \\
\hline Utilidades acumuladas periodo anterior & & & $-19,636.50$ & $-21,319.44$ & $4,102.63$ & $36,133.94$ \\
\hline Total Patrimonio Neto & $16,344.25$ & $-3,292.26$ & $-3,522.03$ & $25,256.88$ & $61,349.94$ & $121,523.86$ \\
\hline Total Pasivo y Patrimonio Neto & $30,130.74$ & $10,494.23$ & $8,811.29$ & $34,233.37$ & 79,992.37 & $145,206.37$ \\
\hline
\end{tabular}

La partida caja y bancos se halló en base al cálculo de los saldos realizados en el flujo de caja económico, el cual se detalla en el anexo $n^{\circ} 9$. 


\section{Conclusiones}

La granada al ser considerada una "Súper Fruta" en los mercados internacionales permite obtener un margen de ganancia mayor, debido a que las personas están dispuestas a desembolsar más dinero por las propiedades saludables que posee. Entre ellas se encuentra la gran concentración de antioxidantes, los cuales previenen enfermedades como el cáncer. Ica cuenta con las condiciones climáticas, la humedad y suelo necesarios para un buen cultivo por lo que aún tiene potencial para desarrollarse y ser más eficiente.

En conclusión la exportación de granadas frescas de la variedad Wonderful producidas en la región Ica son un negocio rentable debido a que la tasa interna de retorno que se obtuvo fue de $33.27 \%$, la cual es mayor al COK de $15.61 \%$.

- En lo que respecta al mercado de destino en el Reino Unido sí se conocen a las granadas y se encuentran disponibles para los consumidores en distintos puntos de venta. El Reino Unido cuenta con una gran diversificación de proveedores mundiales, en el 2014 el Perú se situó en la posición número 6, sin embargo a diferencia de su principal competidor España las importaciones de granadas peruanas por parte del Reino Unido han ido aumentando en los últimos años, en promedio del 2010 al 2014 crecieron 70\%. De la misma forma Holanda, otro competidor importante ha ido disminuyendo sus envíos al Reino Unido El consumo de alimentos saludables como frutas y vegetales es muy valorado en este mercado, el gobierno promueve iniciativas para incrementar los volúmenes, una de ellas es la campaña "5 a day".

- Luego de investigar las principales regiones productoras de granadas, la empresa Pome Perú decidió abastecerse de Ica, por su cercanía a Lima y rendimientos. Esto nos ha permitido incurrir en menores costos y obtener mayores márgenes de ganancia. 
Al situar nuestras oficinas en esta región también podemos tener un mayor control de nuestros proveedores y un lugar cercano donde almacenar la fruta, se recomienda que nuestro asistente de exportaciones trate de permanecer la mayor parte del tiempo allí para un mejor monitoreo de los proveedores. Como se puede observar la empresa incrementa sus envíos gradualmente año a año, en el primer año envía dos contenedores y en el segundo cuatro, pero aun así mantendremos a nuestro personal (gerente y asistente) durante todo el año como para realizar investigación de mercados y búsqueda de potenciales nuevos cliente así como buscar nuevas alternativas de negocio.

Podemos concluir que frente a nuestros competidores como España tenemos la ventaja de la ventana comercial en donde podemos vender mayores volúmenes y más ganancias al poder cobrar un precio referencial más alto. Mientras que Holanda tiene cierta desventaja ante nosotros, porque depende de la producción de terceros al no contar con cultivos de granado. La estrategia de enfoque se utilizará para obtener mayores márgenes de ganancia durante los meses que el mercado se encuentra desabastecido. Los meses en los cuales exportará Pome Perú SAC son entre Marzo a Junio.Se debe aprovechar esta oportunidad para captar la participación de mercado que no pueden abastecer estos mercados en esa época. La estrategia de precio también estará orientada a la competencia, debido a que se toma en consideración el precio FOB referencial para la fijación. 


\section{Recomendaciones}

- Aprovechar las condiciones climáticas y características de la tierra en Ica para así incrementar las exportaciones peruanas de granadas no solo al Reino Unido sino también hacia el mundo.

- Trabajar constantemente en el desarrollo de nuevos productos, es decir no solo mantenernos al margen con materias primas sino aprovechar las propiedades de la granada para la creación de productos con valor agregado como jugos. Esto se realizaría luego del horizonte de tiempo de 5 años.

- Asistir a ferias internacionales primero como visitantes para prospectar y luego considerar la participación con stand. Asimismo participar de actividades como misiones comerciales en las cuales se establecen contactos más directos

- Estar al tanto de las nuevas investigaciones y descubrimientos de las propiedades de las granadas para así tener una herramienta de promoción comercial de la fruta.

- Juntarnos con otros productores de granadas para planificar e implementar estrategias de promoción de la granada peruana en el Reino Unido. Buscar apoyo de la Oficina Económica Comercial de Perú en Londres para realizar actividades en conjunto y para que nos ayuden con información importante del mercado. 


\section{Referencias}

Agencia Andaluza de Promoción Exterior. (Diciembre de 2014). Ficha País Reino

Unido . Obtenido de http://www.extenda.es/web/opencms/archivos/redexterior/ficha_reino_unido.pdf

Agraria.pe. (22 de Abril de 2010). De Soto: Un Régimen Eficiente Y Moderno De

Tierras Mejoraría Producción De La Selva. Obtenido de http://www.agraria.pe/boletines/abril2010/22/index.html

AMPEX. (Noviembre de 2006). Perfil de Mercado de la Granada Fresca. Obtenido de www.ampex.com.pe/down_file.php?f=perfil-granada.pdf\&ruta=perfi

Banco de España . (Febrero de 2012). Obtenido de http://www.bde.es/f/webbde/SES/Secciones/Publicaciones/InformesBoletinesRe vistas/BoletinEconomico/12/Feb/Fich/be1202.pdf

BBC News. (2 de Febrero de 2015). London's population hits 8.6m record high.

Obtenido de http://www.bbc.com/news/uk-england-london-31082941

Central Intelligence Agency - United States of America . (2015). The World Factbook .

Obtenido de https://www.cia.gov/library/publications/the-worldfactbook/geos/pe.html

CEPLAN - Centro Nacional de Planeamiento Extratégico . (Marzo de 2012). Región Ica. Perspectivas para el desarrollo regional al 2021 . Obtenido de http://www.ceplan.gob.pe/sites/default/files/Documentos/4._presentacion_gore_ ica-ceplan.pdf

Corporación Interamericana de Inversiones . (22 de Febrero de 2013). Proyectos

Exportadora Frutícola del Sur. Obtenido de

http://www.iic.org/es/proyectos/project-disclosure/pe3955a-01/exportadorafrut $\%$ C $3 \%$ ADcola-del-sur-sa

Department for Environment, Food \& Rural Affairs . (19 de Setiembre de 2013). Food statistics pocketbook. Obtenido de 
https://www.gov.uk/government/uploads/system/uploads/attachment_data/file/3 15418/foodpocketbook-2013update-29may14.pdf

El Banco Mundial . (2014). Connecting to Compete 2014 Trade Logistics in the Global Economy . Obtenido de http://www.worldbank.org/content/dam/Worldbank/document/Trade/LPI2014.p df

El Banco Mundial . (Junio de 2014). Doing Business. Obtenido de http://espanol.doingbusiness.org/rankings

El Banco Mundial. (2012). Agricultura y desarrollo rural . Obtenido de http://datos.bancomundial.org/indicador

El Comercio. (18 de Noviembre de 2014). MEF cuestiona el drawback por ser una suerte de subsidio ciego. El Comercio . Obtenido de http://elcomercio.pe/economia/peru/mef-cuestiona-drawback-suerte-subsidiociego-noticia-1772161?ref=nota_economia\&ft=contenido

El Peruano. (28 de Junio de 2008). Normas Legales . Obtenido de http://www.elperuano.com.pe/edicion/

Euromonitor International . (July de 2013). Consumer lifestyles in the United Kingdom. Obtenido de http://www.euromonitor.com/

Euromonitor International . (Mayo de 2013). Midlife women: Embracing power and avoiding invisibility in global consumer markets . Obtenido de http://www.euromonitor.com/

Euromonitor International . (06 de Agosto de 2014). Income and Expenditure: United Kingdom. Obtenido de http://www.euromonitor.com/

Euromonitor International . (30 de Enero de 2015). United Kindom: Country Profile . Obtenido de http://www.euromonitor.com/

Euromonitor International. (Junio de 2014). Fruits in the United Kingdom. Obtenido de http://www.euromonitor.com/

European Comission Trade . (2015). Export Helpdesk - Mi exportación. Obtenido de http://exporthelp.europa.eu/thdapp/index.htm

European Food Information Council . (Enero de 2012). Fruit and vegetable consumption in Europe - do Europeans get enough? Obtenido de http://www.eufic.org/article/en/expid/Fruit-vegetable-consumption-Europe/ Fruco PLC . (2015). UK Delivery \& Distribution . Obtenido de http://www.fruco.com/ 
Fundación Chile. (Diciembre de 2009). Granados, Perspectivas y Oportunidades de un Negocio Emergente. Obtenido de http://es.scribd.com/doc/44529052/Estudiode-Granada

Gestión. (12 de Junio de 2012). Chile invierte seis veces más que Perú en investigación y desarrollo tecnológico. Gestión. Obtenido de http://gestion.pe/2012/06/12/tecnologia/chile-invierte-seis-veces-mas-que-peruinvestigacion-y-desarrollo-tecnologico-2004854

Gestión. (14 de Agosto de 2014). Producción peruana de granada crecería 41\% en el 2014, según Maximixe. Gestión. Obtenido de http://gestion.pe/mercados/produccion-peruana-granada-creceria-41-2014segun-maximixe-2105671

Gestiopolis. (16 de Febrero de 2012). Ventajas competitivas del Perú. País que está de moda. Obtenido de http://www.gestiopolis.com/ventajas-competitivas-del-peru/ GOV.UK. (2015). What the government's doing about research and development. Obtenido de https://www.gov.uk/government/policies/research-anddevelopment

Granadas de Elche. (25 de Octubre de 2014). Granadas de Elche pone en marcha una campaña de promoción en los mercados de Madrid para fomentar su consumo. Obtenido de http://granadaselche.com/noticias/granadas-de-elche-pone-enmarcha-una-campana-de-promocion-en-los-mercados-de-madrid-para-fomentarsu-consumo

GranaVida. (2014). La producción de granada mollar sigue subiendo año tras año. Obtenido de http://campodeelche.com/la-produccion-de-granada-mollar-siguesubiendo-ano-tras-ano/

ICEX Oficina Económica y Comercial de España en Londres . (2013). Guía país. Reino Unido 2013. Obtenido de http://www.icex.es/icex/es/navegacionprincipal/todos-nuestros-servicios/informacion-de-mercados/paises/navegacionprincipal/el-mercado/estudios-informes/4436068.html?idPais=GB

INEI - Instituto Nacional de Estadística e Informática. (30 de Junio de 2014). Estado de la Población Peruana 2014. Obtenido de http://www.inei.gob.pe/media/MenuRecursivo/publicaciones_digitales/Est/Lib1 157/libro.pdf 
Instituto Peruano de Economía . (Mayo de 2014 ). Índice de Competitividad Regional INCORE Perú 2014 . Obtenido de http://www.ipe.org.pe/documentos/indice-decompetitividad-regional-incore-peru-2014

International Labour Organization. (2014). Country Profiles. Obtenido de http://www.ilo.org/ilostat/faces/home/statisticaldata/ContryProfileId?_afrLoop= 1045247221371634

Khan, U. (16 de Setiembre de 2008). England is most crowded country in Europe . The Telegraph. Obtenido de http://www.telegraph.co.uk/news/politics/2967374/England-is-most-crowdedcountry-in-Europe.html

Libélula. (15 de Julio de 2011). Diagnóstico de la Agricultura en el Perú. Obtenido de http://www.peruopportunity.org/uploads/posts/34/Diagno_stico_de_la_Agricult ura_en_el_Peru__-_web.pdf

Maynard, G. (4 de Febrero de 2015). The healing power of the pomegranate! Health benefits of superfruit proved. Express. Obtenido de http://www.express.co.uk/life-style/health/556006/Pomegranate-king-superfruit-health-benefits

Messe Berlin. (2015). Fruit Logistica 2016. Obtenido de http://www.fruitlogistica.de/es/APrimeraVista/BreveDescripciN/

Ministerio de Agricultura y Riego . (2007). Sector Agrario . Obtenido de http://www.minagri.gob.pe/portal/objetivos/58-sector-agrario/sectoragrario/659-sector-agrario

Ministerio de Agricultura y Riego . (Noviembre de 2013). El Ministerio de Agricultura y Riego al 2016. Obtenido de http://www.mef.gob.pe/contenidos/inv_publica/docs/novedades/2013/presentaci ones/Ministerio-de-Agricultura-y-Riego.pdf

Ministerio de Agricultura y Riego. (2000). Superficie Agrícola Del Perú, Según Departamento, 1975, 1995 y 2000. Obtenido de www.inei.gob.pe/media/MenuRecursivo/Ambiente2.xls

Ministerio de Agricultura y Riego. (2007). El Comercio Internacional y las posibilidades del Agro Peruano. Obtenido de http://www.minagri.gob.pe/portal/objetivos/22-sector-agrario/visiongeneral/191-el-comercio-internacional 
Ministerio de Comercio Exterior y Turismo . (2013 ). Acuerdo Comercial entre Perú y la Unión Europea. Obtenido de http://www.acuerdoscomerciales.gob.pe/index.php?option=com_content\&view =category\&layout=blog \&id=50\&Itemid $=73$

Ministerio de Defensa. (Abril de 2005). Libro blanco de la Defensa. Obtenido de http://www.mindef.gob.pe/menu/libroblanco/pdf/Capitulo_II.pdf

Ministerio de Economía y Finanzas. (Diciembre de 2012). Perú: Política de Inversión Pública en Ciencia, Tecnología e Innovación 2013-2020. Obtenido de https://www.mef.gob.pe/contenidos/inv_publica/docs/novedades/2013/agosto/Li neamientos_CTI.pdf

Ministerio de Producción. (2014). Plan Nacional de Diversificación Productiva.

Obtenido de http://www.produce.gob.pe/images/stories/Repositorio/publicaciones/plannacional-de-diversificacion-productiva.pdf

Misti Fertilizantes . (2010). Panorama Agronomico y Mercado de Fertilizantes en el Perú . Obtenido de http://www.misti.com.pe/web/images/stories/eventos/Panorama_Agronomico_ Mercado.pdf

Monaghan, A. (12 de Marzo de 2014). British R\&D spending down despite government's innovation strategy. The Guardian . Obtenido de http://www.theguardian.com/technology/2014/mar/12/british-spendingresearch-development-eu-declines

Monaghan, A. (25 de Noviembre de 2014). UK economic recovery to continue into 2016, forecasts OECD . The Guardian. Obtenido de http://www.theguardian.com/business/2014/nov/25/uk-economic-recoverycontinue-2016-oecd

Montoya, A. A. (13 de Marzo de 2015). Instructivo de Packing Granada 2015. Lima. Moulds, J. (31 de Julio de 2012). UK economic outlook slumps on eurozone crisis. The Guardian. Obtenido de http://www.theguardian.com/business/2012/jul/31/ukeconomic-outlook-slumps-eurozone

National Health Service . (2013). Why 5 A DAY? Obtenido de http://www.nhs.uk/Livewell/5ADAY/Pages/Why5ADAY.aspx 
NSF Spain. (2015). Tesco NURTURE. Obtenido de http://www.nsf-cmispain.com/service_intl.asp?service_id=Tesco\%20Nurture888blah88

Oficina Comercial ProChile Los Ángeles. (Agosto de 2012). Estudio de Mercado Granadas Procesadas en EE.UU. . Obtenido de www.prochile.cl

PAPEP-PNUD. (Junio de 2012). Perú: la oportunidad de un nuevo ciclo de desarrollo. Obtenido de http://www.pe.undp.org/content/dam/peru/docs/PeruOportunidadDesarrollo.pdf

Pérez, C. (13 de Febrero de 2015). Alemania y España aceleran el ritmo de recuperación de la zona euro. El País. Obtenido de El País: http://economia.elpais.com/economia/2015/02/13/actualidad/1423813753_5777 58.html

Perú21. (22 de Febrero de 2015). Flash: PBI creció 2.8\% en el 2014 . Perú21. Obtenido de http://peru21.pe/opinion/flash-pbi-crecio-28-2014-2202259

POM Wonderful. (2015). Wonderfully Nutritious. Obtenido de http://www.pomwonderful.com/pomegranate-wellness/wonderfully-nutritious/

Porter, M. (1991). La Ventaja Competitiva de las Naciones . Barcelona: Plaza \& Janes Editores.

Poscosecha. (2010). El Granado I Jornadas nacionales sobre el granado: Producción, economía, industrialización, alimentación y salud,. Obtenido de http://dpvm.umh.es/docs/publicaciones/i\%20jornadas\%20nacionales\%20sobre\% 20el\%20granado.pdf

ProChile Oficina Comercial Londres. (2014). Guía País Reino Unido 2014 . Obtenido de http://www.prochile.gob.cl/wpcontent/blogs.dir/1/files_mf/1397571157RU_Guia_Pais_2014.pdf

ProQuest. (Enero de 2012). Superfruits expand beyond exotic varities . Obtenido de http://www.proquest.com/

Proquest. (s.f.). Superfruits expand beyond exotic varieties. Obtenido de http://www.proquest.com/

Quiles, S. M. (2008). La Fruta Granada uno de los primeros Cultivos del Hombre. Obtenido de http://www.zumodegranada.com/el-resurgimiento-del-primer-frutoque-el-hombre-cultivo/

Reyes, P. (Marzo de 2007). Métodos de Series de Tiempo. Obtenido de www.icicm.com/files/SeriesDeTiempoComp.doc 
Santander Trade Portal . (2014). Normativa de embarques . Obtenido de https://es.santandertrade.com/gestionar-embarques

SBS. (Junio de 2015). Portal de Transparencia SBS . Obtenido de http://www.sbs.gob.pe/

Semana Económica. (22 de Enero de 2015). Moody's corrigió a la baja proyección de crecimiento de la economía peruana. Semana Económica . Obtenido de http://semanaeconomica.com/article/economia/152367-moodys-corrigio-a-labaja-su-proyeccion-de-crecimiento-de-la-economia-peruana/

SIICEX. (Diciembre de 2012). Drawback. Obtenido de http://www.siicex.gob.pe/siicex/portal5ES.asp?_page_=835.83400

Silva-Santisteban, C. T. (Julio de 2010). Paises Bajos (Holanda). Obtenido de http://media.peru.info/PROMO/2010/Europa/Oportunidades\%20Comerciales\%2 0en\%20e1\%20sector\%20agrario\%20en\%20Paises\%20Bajos.pdf

World Economic Forum. (2014). Country/Economic Profiles: United Kingdom. Obtenido de http://reports.weforum.org/global-competitiveness-report-20142015/economies/\#indexId=GCI\&economy=GBR

World Economic Forum. (Setiembre de 2014). The Global Competitiveness Report 2014-2015. Obtenido de http://www.weforum.org/reports/globalcompetitiveness-report-2014-2015

Znews. (7 de Enero de 2010). Pomegranate helps fight breast cancer. Obtenido de http://zeenews.india.com/news/health/health-news/pomegranate-helps-fightbreast-cancer_6548.html 


\section{BIBLIOGRAFÍA}

Czinkota, M. Marketing Internacional: Cengage Learning, 8va edición. México D.F, 2008.

Porter, Michael. La Ventaja Competitiva de las Naciones. Plaza \& Janes Editores, 1991

Proyecto UE-PERU/PENXSector Agricultura y Agroindustria. (2004). “Asistencia técnica para los planes operativos (POS) ”. Perú.

Tokeshi Shirota Alberto. Planifique, Desarrolle y Escriba su Tesis. Fondo de Desarrollo Editorial de la Universidad de Lima, 2008.

Trupal. Protocolo de paletizado para cajas agroindustriales. Elaborado por Rojas Lino, Alan (Desarrollo Trupal S.A.) 
ANEXOS 


\section{ANEXO N ${ }^{\circ}$ 1: COTIZACIÓN SERVICIO DE PROCESO Y ALMACENAMIENTO DE GRANADAS}

\section{sunfruits}

Plan Tarifario Servicio de Conservación Granado - Campaña 2014

(Expresado en Nuevos Soles sin el IGV)

\begin{tabular}{|c|c|c|c|}
\hline ITEM & Descripción & Unidad & $\begin{array}{l}\text { Tarifa En Soles } \\
\text { Europa y Otros }\end{array}$ \\
\hline $\begin{array}{c}\text { Proceso de } \\
\text { Granado }\end{array}$ & $\begin{array}{l}\text { Tarifa de Proceso } \\
\text { Incluye: Recepcion, selección, embalaje, etiquetado paletizad } \\
\text { dias en camara refrigerada. }\end{array}$ & Kilo empacado & 0.2900 \\
\hline Otros & Sellado de bolsa atmosfera controlada en camara & x caja & 0.1350 \\
\hline Reproceso & Maquila de fruta ya procesada en línea & Kilo & 0.2900 \\
\hline Frio & $\begin{array}{l}\text { Servicio de enfriamiento y/o almacenamiento } \\
\text { Nota: Incluye } 7 \text { días de almacenamiento en camara frigorifica }\end{array}$ & $\begin{array}{l}\text { Por caja de } \\
\quad 3.8 \mathrm{Kg}\end{array}$ & 0.4000 \\
\hline \multirow[t]{2}{*}{ Otros } & \multicolumn{3}{|c|}{ 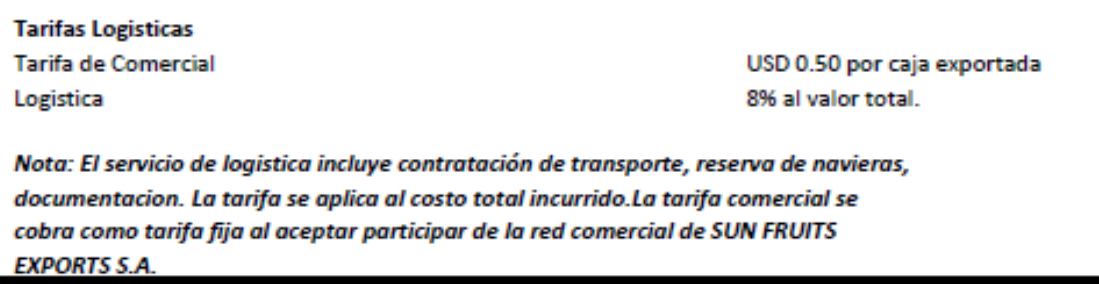 } \\
\hline & \multicolumn{3}{|c|}{$\begin{array}{l}\text { Todas las Tarifas establecidas son en Nuevos Soles donde no se incluye el IGV las } \\
\text { mismas que pueden variar dependiendo de la fecha de firma del contrato. }\end{array}$} \\
\hline
\end{tabular}




\section{ANEXO N 2: DIRECTORIO DE POSIBLES CLIENTES EN EL REINO UNIDO}

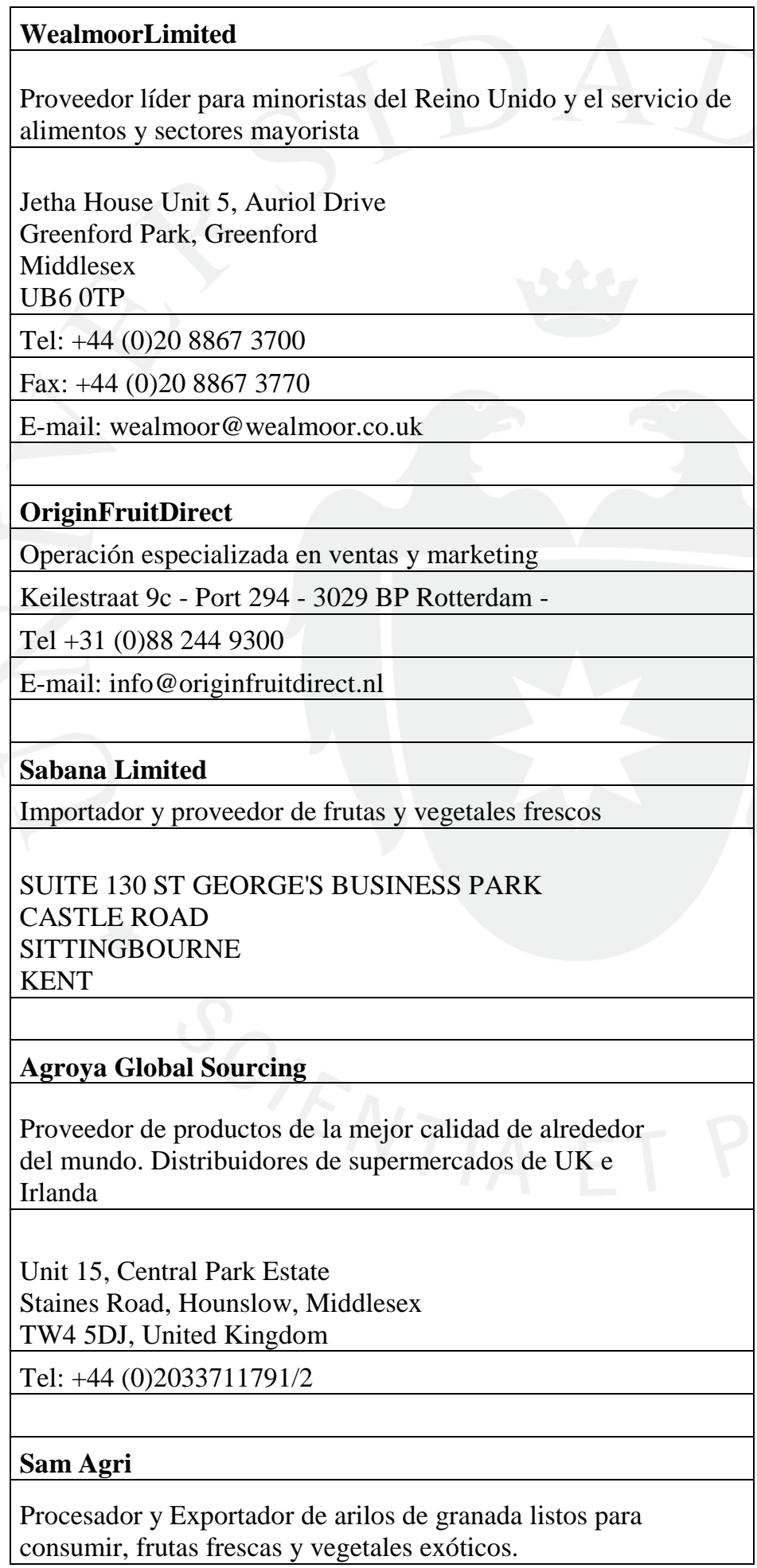


402, Maxx Chambers, Pattigadda,

Begumpet, Hyderabad, Andhra Pradesh-500 003,India

Tel: +91 4027906577 Fax: +91 4027902174

E-mail: info@samagri.com

Poupart Imports

Proveedor de fruta de calidad, cítricos, cerezas, uvas y otros productos a supermercados y al sector no retails de Reino Unido y Europa.

Turnford Place

Great Cambridge Road

TurnfordBroxbourneHerts

EN10 6NH

Tel: 01992473024

E-mail: info@ poupart.co.uk

\section{Prepworld}

Proveedor de packs innovadores de fruta blanda

Court Lodge Farm

Dale Road

Southfleet

Kent DA13 9NQ, United Kingdom

Tel: 01474832569 Fax: 01992666706

\section{Oxford Fruit Company Ltd}

Proveedor e importador especializado en todas las

variedades de fruta fresca y vegetales.

Haddonsacre

Station Road

Offenham

Evesham

Worcs WR11 8JJ

Tel: -44 (0) 01386831110 Fax: +44 (0) 1386831090

E-mail: sales@ oxfordfruit.com

\section{Pacific Produce LTD}

Importador y distribuidor de frutas, vegetales y cìtricos

The Threshing Barn

North Weston

Thame

Oxfordshire, OX9 2HA

Tel: 01865874322

E-mail: info@pacificproduce.co.uk 


\section{ANEXO N³: COTIZACIÓN DE FLETE AGENTE NAVIERO KUEHNE+NAGEL A PUERTO DE TILBURY}

\section{KUEHNE + NAGEL PROPUESTA COMERCIAL}

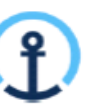

\begin{tabular}{|c|c|c|}
\hline FECHA & VALIDEZ & OFERTA NO. \\
\hline $15 / 04 / 2015$ & $30 / 05 / 2015$ & LIM-CEPE-2797912N \\
\hline \multicolumn{2}{|c|}{ CLIENTE } & \multirow[b]{2}{*}{$\begin{array}{l}\text { Kuehne + Nagel S.A. } \\
\text { Calle Las Begonias } N^{\circ} 441 \\
\text { Oficina 1201-1202, Piso } 12 \\
\text { Lima 27, Perú } \\
\text { Tel.: (51-01) } 6120800 \\
\text { Fax: (51-01) 612 } 0801 \\
\text { www.kn-portal.com }\end{array}$} \\
\hline $\begin{array}{l}\text { Pome Perú } \\
\text { Attn: Mrs. Carla Rubio } \\
\text { Lima-Peru }\end{array}$ & & \\
\hline PRODUCTO: & Carga General, no peligrosa & \\
\hline
\end{tabular}

Estimado/a Mrs. Carla Rubio,

Atendiendo a sus requerimientos a continuación presentamos nuestra propuesta comercial:

\begin{tabular}{|l|l|l|l|}
\hline ORIGEN: & Callao & SERVICIO: & FCL Exportación Marítima \\
\hline DESTINO: & Tilbury & INCOTERM: & CFR \\
\hline
\end{tabular}

\begin{tabular}{|l|l|}
\hline \multicolumn{2}{|c|}{ GASTOS LOCALES } \\
\hline DESCRIPCIÓN & VALORES AFECTOS A IGV \\
\hline KN Handling & S/. $150 / \mathrm{BI}$ \\
\hline BL Fee & USD $35 / \mathrm{BL}$ \\
\hline
\end{tabular}

\begin{tabular}{|l|c|}
\hline \multicolumn{2}{|c|}{ FLETE INTERNACIONAL } \\
\hline DESCRIPCIÓN & VALORES \\
\hline Flete marítimo FCL de exportación de Callao a Tilbury & USD 2800 / 40RF \\
\hline T/T: 24 dias // Salidas Semanales // Servicio directo & \\
\hline$\left.{ }^{*}\right)$ El combustible es un recargo variable y regirá el vigente al momento del embarque
\end{tabular}




\title{
ANEXO N 4: COMUNICACIÓN CON OCEX PERÚ EN EL REINO UNIDO
}

\author{
Contacto William Arteaga - Granadas $\square \quad \operatorname{Recibidos} \times \quad \underline{\underline{G}}$ \\ Carla Rubio <carla.rubio.v@gmail.com> \\ 13 jul. (hace 9 días) \\ para bpaino, ocexloncom - \\ Estimado Bruno,
}

Es un gusto saludarte.

William Arteaga de Promperú me brindó tu contacto, actualmente el es mi asesor de tesis y me recomendó escribirte porque me dijo que tu tienes información muy importante que posiblemente pueda ayudar a enriquecer mi trabajo.

Te comento, actualmente estoy elaborando mi tesis es sobre exportación de granadas frescas al mercado del Reino Unido.

Asimismo como hasta hace poco estuve trabajando en ADEX este año çnocí a Jaime Cárdenas en la Feria Seafood Expo Global en Bruselas y también le comenté brevemente sobre mi proyecto de tesis. Él me dijo que justamente este año estaban realizando un estudio sobre la granada. Sé que eso les va a tomar tiempo, pero si tuvieras alguna información preliminar sobre el mercado o distribución del producto sería de mucha ayuda para mí.

Por otro lado William me sugirió que dentro de mi trabajo en la parte de promoción considere participar de la Feria London Produce, debido que mi mercado de destino para comenzar es solo el Reino Unido. Tú qué opinas? ¿Crees que pueda funcionar esta feria para ofrecer granadas peruanas? Sería de mucha utilidad para mí si podrías brindarme algunos contactos o referencias de potenciales clientes, principalmente distribuidores de fruta fresca. Mi estrategia inicial es venderle a distribuidores porque aun no tengo la capacidad de abastecer por ejemplo a un gran supermercado.

Mucho agradeceré puedas apoyarme con la información que tengas al alcance.

Quedo atenta a tu gentil respuesta.

Mil Gracias por tu apoyo.

Saludos,

$\cdots$

para mí, bpaino

Estimada Carla,

Estamos en este momento trabajando en un estudio de perfil de mercado para la Granada en el Reino Unido, el cual esperamos esté listo para finales de Agosto. Adicionalmente, estamos trabajando un reporte sobre la industria de ventas al por mayor de frutas y verduras frescas en el Reino Unido, el cual estará listo en las próximas semanas. Sería ideal si pudieses esperar para que te facilitemos esta información.

Con respecto al London Produce Show, efectivamente es una feria muy interesante para el tipo de producto con el que quieres trabajar. Nosotros hemos participado en las primeras 2 ediciones y la calidad de los contactos que hemos establecido es muy interesante, definitivamente los actores más importantes de esta industria en el Reino Unido estaban presentes en la feria.

Saludos

\begin{tabular}{|l|l} 
Bruno Paino \\
Oficina Comercial \\
Embajada del Perú en el Reino Unido \\
1 Lyric Square, w6 0NB \\
$+44(0) 2035426970$ \\
bpaino@perutrade-uk.com
\end{tabular}




\section{ANEXO N ${ }^{\circ}$ 5: PROTOCOLO DE PALETIZADO PARA CAJAS AGROINDUSTRIALES}

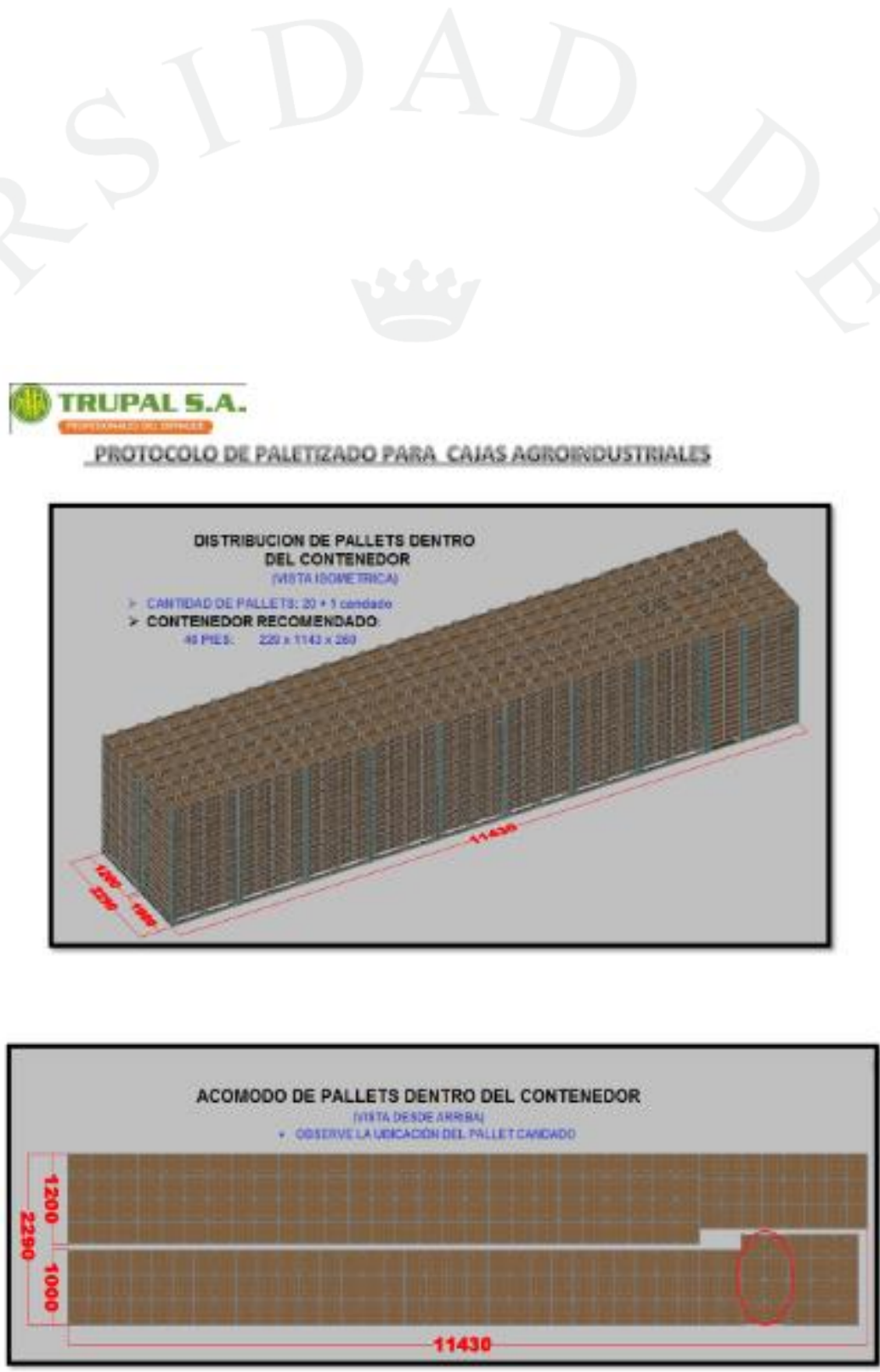




\section{ANEXO N6: SEGMENTACIÓN Y DEMANDA DE GRANADAS EN BASE A LA POBLACIÓN DEL REINO UNIDO}

\begin{tabular}{lrrrrr}
\hline \multicolumn{7}{c}{ Población Objetivo } \\
\hline Grupo Edades & 2015 & 2016 & 2017 & 2018 & 2019 \\
$\mathbf{3 5 - 3 9}$ & $4,056,897$ & $4,147,846$ & $4,247,074$ & $4,336,334$ & $4,363,136$ \\
$\mathbf{4 0 - 4 4}$ & $4,268,410$ & $4,130,359$ & $4,007,345$ & $3,935,276$ & $3,956,897$ \\
$\mathbf{4 5 - 4 9}$ & $4,607,486$ & $4,583,471$ & $4,529,082$ & $4,451,207$ & $4,338,478$ \\
$\mathbf{5 0 - 5 4}$ & $4,547,523$ & $4,606,063$ & $4,636,571$ & $4,635,380$ & $4,615,160$ \\
$\mathbf{5 5 - 5 9}$ & $3,932,151$ & $4,041,373$ & $4,154,911$ & $4,260,783$ & $4,368,089$ \\
$\mathbf{6 0 - 6 4}$ & $3,486,635$ & $3,512,735$ & $3,571,699$ & $3,640,664$ & $3,720,424$ \\
$\mathbf{6 5 - 6 9}$ & $3,604,173$ & $3,623,408$ & $3,460,538$ & $3,382,100$ & $3,351,845$ \\
$\mathbf{7 0 - 7 4}$ & $2,722,333$ & $2,849,019$ & $3,107,597$ & $3,248,493$ & $3,315,494$ \\
Poblacion Total & $31,225,608$ & $31,494,274$ & $31,714,817$ & $31,890,237$ & $32,029,523$ \\
\hline
\end{tabular}

\begin{tabular}{lrrrrr}
\hline Pobl. Objetivo & $31,225,608$ & $31,494,274$ & $31,714,817$ & $31,890,237$ & $32,029,523$ \\
Consumo anual pais & 0.390451865 & 0.391247819 & 0.388706209 & 0.392966104 & 0.393901138 \\
Consumo Pob. Obj KG & $12,192,096.86$ & $12,322,066.02$ & $12,327,746.28$ & $12,531,782.19$ & $12,616,465.56$ \\
Consumo Total Londres & $3,361,767.16$ & $3,403,217.60$ & $3,414,912.89$ & $3,485,847.99$ & $3,526,961.33$ \\
\hline
\end{tabular}

Determinación de participación de mercado en el Reino Unido

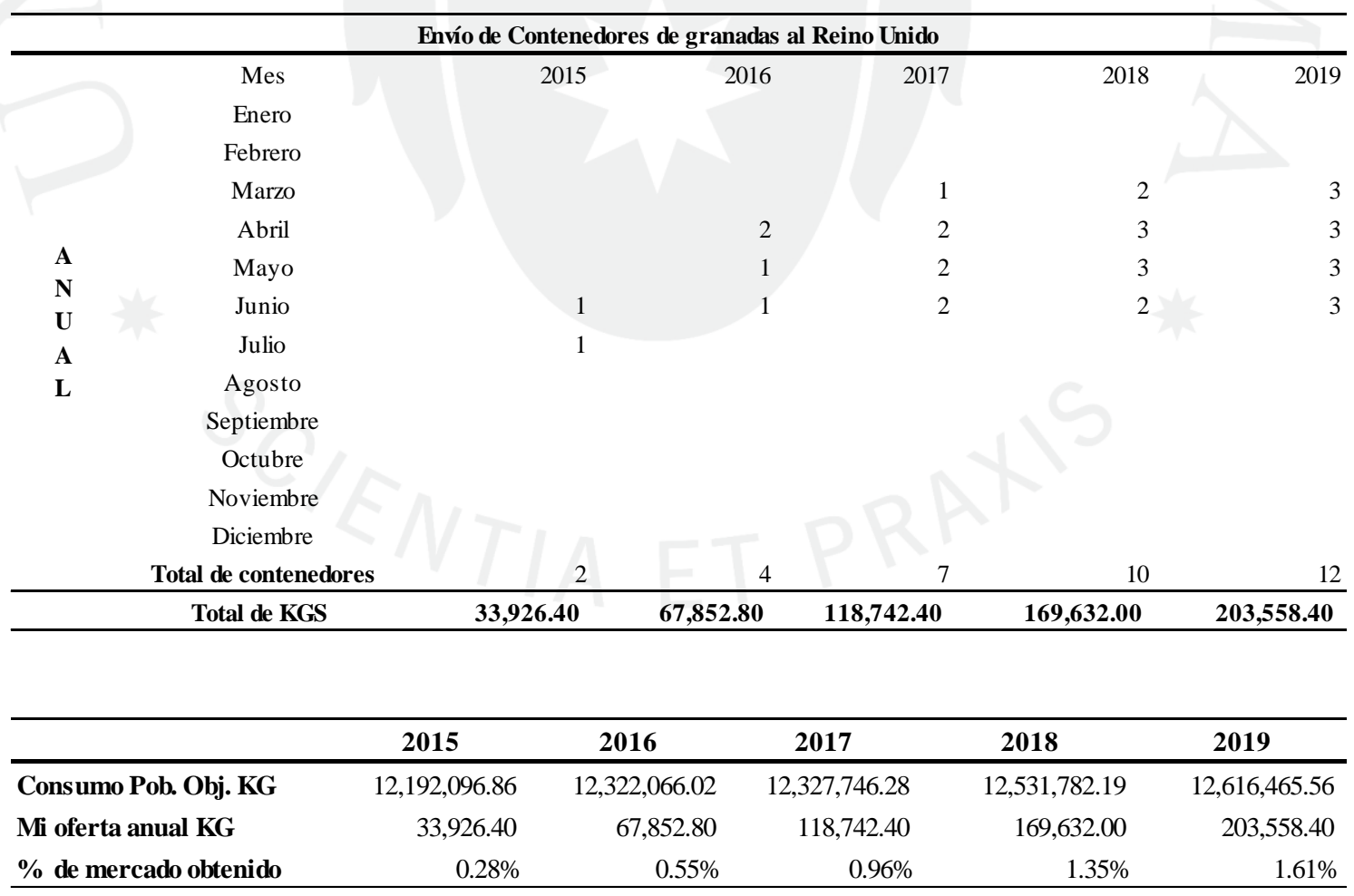




\section{ANEXO No 7: RELACIÓN DE PRODUCTORES DE GRANADA DE EXPLOTACIÓN COMERCIAL CON DESTINO INTERNACIONAL (SENASA)}

\begin{tabular}{|c|c|c|c|c|c|c|c|c|c|c|c|c|}
\hline VALLE & SECTOR & d & CODI_PROD_ & RAZON DEL PRODUCTOR & $\begin{array}{l}\text { CODIGO } \\
\text { PREDIO }\end{array}$ & NOMBRE DE PREDIO & $\begin{array}{c}\text { AREA } \\
\text { PREDIO }\end{array}$ & $\begin{array}{c}\text { NOMBRE } \\
\text { HOSP. }\end{array}$ & $\begin{array}{l}\text { DESC. } \\
\text { CULTIVO }\end{array}$ & \begin{tabular}{|c|} 
AREA \\
HOSPEDAN \\
TE
\end{tabular} & $\begin{array}{l}\text { DENS. } \\
\text { PREDIO }\end{array}$ & $\begin{array}{l}\text { FECHA } \\
\text { INSTAL. }\end{array}$ \\
\hline 04 ICA & 01 ALTA & 02 GUADALU & 00710 & AGRICOLA HERMANAS BERNALES S.A.C. & 03 & $\begin{array}{l}\text { FUNDO VIRGEN DEL ROSARIO } \\
\text { DE YAUCA }\end{array}$ & 4.0000 & GRANADO & Wonderful & 4.0000 & 570.00 & $01 / 06 / 2013$ \\
\hline 04 ICA & 01 ALTA & 02 GUADALC & 01659 & Y \& R AGRICOLA DUSHEDARE E.I.R.L. & 02 & FUNDO JAZMIN & 385.0000 & GRANADO & Wonderful & 8.0000 & 540.00 & $15 / 08 / 2012$ \\
\hline 04 ICA & 01 ALTA & 02 GUADALC & 02060 & EURO S.A. & 01 & FUNDO LOS POBRES & 90.0000 & GRANADO & Wonderful & 10.0000 & 416.00 & $01 / 09 / 2001$ \\
\hline 04 ICA & 01 ALTA & 02 GUADALC & 02060 & EURO S.A. & 01 & FUNDO LOS POBRES & 90.0000 & GRANADO & Wonderful & 11.0000 & 888.00 & $01 / 02 / 2009$ \\
\hline 04 ICA & 01 ALTA & 02 GUADALU & 02060 & EURO S.A. & 01 & FUNDO LOS POBRES & 90.0000 & GRANADO & Wonderful & 7.5000 & 416.00 & $01 / 02 / 2002$ \\
\hline 04 ICA & 03 BAJO & 01 SANTIAG & 00532 & FUNDO SAN LUIS S.A.C. & 02 & FUNDO SAN LUIS & 500.0000 & GRANADO & Wonderful & 50.0000 & 416.00 & $15 / 02 / 2011$ \\
\hline 04 ICA & O3 BAJO & 01 SANTIAG & 09944 & ICA PACIFIC S.A. & 07 & PROYECTO PARCELA & 90.7000 & GRANADO & Wonderful & 37.0700 & 500.00 & $15 / 11 / 2007$ \\
\hline 04 ICA & O3 BAJO & 01 SANTIAG & 09944 & ICA PACIFIC S.A. & 07 & PROYECTO PARCELA & 90.7000 & GRANADO & $\mathrm{S} / \mathrm{N}$ & 24.0200 & 556.00 & $15 / 10 / 2012$ \\
\hline 04 ICA & O3 BAJO & 01 SANTIAG & 09944 & ICA PACIFIC S.A. & 07 & PROYECTO PARCELA & 90.7000 & GRANADO & Wonderful & 22.8000 & 500.00 & $15 / 08 / 2006$ \\
\hline 04 ICA & 03 BAJO & 01 SANTIAG & 09944 & ICA PACIFIC S.A. & 09 & SANTA FILOMENA & 52.1400 & GRANADO & Wonderful & 20.1300 & 500.00 & $01 / 04 / 2007$ \\
\hline 04 ICA & 03 BAJO & 01 SANTIAG & 09944 & ICA PACIFIC S.A. & 09 & SANTA FILOMENA & 52.1400 & GRANADO & Wonderful & 6.1300 & 357.00 & $01 / 03 / 2009$ \\
\hline 04 ICA & 03 BAJO & 01 SANTIAG & 09944 & ICA PACIFIC S.A. & 10 & MACACARA & 53.5400 & GRANADO & Wonderful & 12.4400 & 357.00 & $15 / 03 / 2009$ \\
\hline 04 ICA & 03 BAJO & 01 SANTIAG & 09944 & ICA PACIFIC S.A. & 10 & MACACARA & 53.5400 & GRANADO & Wonderful & 33.8000 & 417.00 & $01 / 12 / 2007$ \\
\hline 04 ICA & 03 BAJO & 01 SANTIAG & 09944 & ICA PACIFIC S.A. & 11 & SANTIAGO APOSTOL & 138.0000 & GRANADO & $S / N$ & 10.6200 & 476.00 & $15 / 09 / 2000$ \\
\hline 04 ICA & O3 BAJO & 01 SANTIAG & 14263 & NORTH BAY PRODUCE S. A. & 03 & SANTIAGO APOSTOL & 163.3400 & GRANADO & Wonderful & 24.1900 & 417.00 & $01 / 11 / 2013$ \\
\hline 04 ICA & 03 BAJO & 01 SANTIAG & 14263 & NORTH BAY PRODUCE S. A. & 03 & SANTIAGO APOSTOL & 163.3400 & GRANADO & Wonderful & 10.1800 & 476.00 & $01 / 11 / 2000$ \\
\hline 04 ICA & O3 BAJO & 01 SANTIAG & 14263 & NORTH BAY PRODUCE S. A. & 03 & SANTIAGO APOSTOL & 163.3400 & GRANADO & Wonderful & 34.8000 & 556.00 & $01 / 11 / 2012$ \\
\hline 04 ICA & 03 BAJO & 02 OCUCAJE & 02244 & INCA GUTIERREZ LAZARO FRANCISCO & 02 & $\mathrm{~S} / \mathrm{N}$ & 7.0000 & GRANADO & $\mathrm{S} / \mathrm{N}$ & 0.0025 & 2.00 & $01 / 02 / 1990$ \\
\hline
\end{tabular}




\section{ANEXO No 8: CÁlCULO ANUAL DE LA CTS A PAGAR}

\begin{tabular}{|c|c|c|c|c|c|c|c|c|c|c|}
\hline \multirow{2}{*}{$\begin{array}{l}\text { Gerente General } \\
\text { Período }\end{array}$} & \multicolumn{2}{|c|}{2015} & \multicolumn{2}{|c|}{2016} & \multicolumn{2}{|c|}{2017} & \multicolumn{2}{|c|}{2018} & \multicolumn{2}{|c|}{2019} \\
\hline & Mayo & Noviembre & Mayo & Noviembre & Mayo & Noviembre & Mayo & Noviembre & Mayo & Noviembre \\
\hline Sueldo Básico & 1425 & 1425 & 1453.5 & 1453.50 & 1706.63 & 1706.63 & 1744.17 & 1744.17 & 2052.13 & 2052.13 \\
\hline Gratificación & - & 237.5 & 237.50 & 242.25 & 242.25 & 284.44 & 284.44 & 290.70 & 290.70 & 342.02 \\
\hline \multirow[t]{2}{*}{ Remuneración Computable } & 1425.00 & 1662.5 & 1691.00 & 1695.75 & 1948.88 & 1991.06 & 2028.61 & 2034.87 & 2342.83 & 2394.15 \\
\hline & \multicolumn{2}{|c|}{2015} & \multicolumn{2}{|c|}{2016} & \multicolumn{2}{|c|}{2017} & \multicolumn{2}{|c|}{2018} & \multicolumn{2}{|c|}{2019} \\
\hline Concepto & Mayo & Noviembre & Mayo & Noviembre & Mayo & Noviembre & Mayo & Noviembre & Mayo & Noviembre \\
\hline Meses Computables & 3 & 6 & 6 & 6 & 6 & 6 & 6 & 6 & 6 & 6 \\
\hline Días computables & 29 & 0 & 0 & 0 & 0 & 0 & 0 & 0 & 0 & 0 \\
\hline CTS a Pagar & 471.04 & 831.25 & 845.50 & 847.88 & 974.44 & 995.53 & 1014.31 & 1017.43 & 1171.41 & 1197.08 \\
\hline Total & \multicolumn{2}{|c|}{1302.29} & \multicolumn{2}{|c|}{1693.38} & \multicolumn{2}{|c|}{1969.97} & \multicolumn{2}{|c|}{2031.74} & \multicolumn{2}{|c|}{2368.49} \\
\hline Analista de Exportaciones & \multicolumn{2}{|c|}{2015} & \multicolumn{2}{|c|}{2016} & \multicolumn{2}{|c|}{2017} & \multicolumn{2}{|c|}{2018} & \multicolumn{2}{|c|}{2019} \\
\hline Período & Mayo & Noviembre & Mayo & Noviembre & Mayo & Noviembre & Mayo & Noviembre & Mayo & Noviembre \\
\hline Sueldo Básico & 1000 & 1000 & 1020 & 1020 & 1197.63 & 1197.63 & 1223.98 & 1223.98 & 1440.09 & 1440.09 \\
\hline Gratificación & - & 166.67 & 166.67 & 170.00 & 170.00 & 199.61 & 199.61 & 204.00 & 204.00 & 240.02 \\
\hline \multirow[t]{2}{*}{ Remuneración Computable } & 1000.00 & 1166.67 & 1186.67 & 1190.00 & 1367.63 & 1397.24 & 1423.59 & 1427.98 & 1644.09 & 1680.11 \\
\hline & \multicolumn{2}{|c|}{2015} & \multicolumn{2}{|c|}{2016} & \multicolumn{2}{|c|}{2017} & \multicolumn{2}{|c|}{2018} & \multicolumn{2}{|c|}{2019} \\
\hline Concepto & Mayo & Noviembre & Mayo & Noviembre & Mayo & Noviembre & Mayo & Noviembre & Mayo & Noviembre \\
\hline Meses Computables & 3 & 6 & 6 & 6 & 6 & 6 & 6 & 6 & 6 & 6 \\
\hline Días computables & 29 & 0 & 0 & 0 & 0 & 0 & 0 & 0 & 0 & 0 \\
\hline CTS a Pagar & 330.56 & 583.33 & 593.33 & 595.00 & 683.82 & 698.62 & 711.79 & 713.99 & 822.04 & 840.05 \\
\hline Total & \multicolumn{2}{|c|}{913.89} & \multicolumn{2}{|c|}{1188.33} & \multicolumn{2}{|c|}{1382.44} & \multicolumn{2}{|c|}{1425.78} & \multicolumn{2}{|c|}{1662.10} \\
\hline
\end{tabular}




\section{ANEXO No 9: FLUJOS DE CAJA OPERATIVO PARA PERÍODO 2015-2019}

\begin{tabular}{|c|c|c|c|c|c|c|c|c|c|c|c|c|c|}
\hline \multicolumn{14}{|c|}{ PRIMER AÑO } \\
\hline CONCEPTO & 1 & 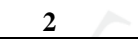 & 3 & 4 & 5 & 6 & 7 & 8 & 9 & 10 & 11 & 12 & Total \\
\hline INGRESOS (A) & 0.00 & 0.00 & 0.00 & 0.00 & $28,951.63$ & $28,951.63$ & 0.00 & 0.00 & 0.00 & 0.00 & 0.00 & 0.00 & $\overline{57,903.26}$ \\
\hline Ventas & 0.00 & 0.00 & 0.00 & 0.00 & $28,951.63$ & $28,951.63$ & 0.00 & 0.00 & 0.00 & 0.00 & 0.00 & 0.00 & \\
\hline EGRESOS (B) & $3,017.66$ & $3,017.66$ & $3,017.66$ & $3,017.66$ & $22,977.48$ & $22,977.48$ & $3,017.66$ & $3,017.66$ & $3,017.66$ & 3,017.66 & $3,017.66$ & $3,017.66$ & $76,131.60$ \\
\hline Costos & $3,017.66$ & $3,017.66$ & $3,017.66$ & $3,017.66$ & $22,977.48$ & $22,977.48$ & $3,017.66$ & $3,017.66$ & $3,017.66$ & $3,017.66$ & $3,017.66$ & $3,017.66$ & \\
\hline Costos Fijos & $3,017.66$ & $3,017.66$ & $3,017.66$ & $3,017.66$ & $3,017.66$ & $3,017.66$ & $3,017.66$ & $3,017.66$ & $3,017.66$ & $3,017.66$ & $3,017.66$ & $3,017.66$ & \\
\hline Costos Variables & 0.00 & 0.00 & 0.00 & 0.00 & $19,959.82$ & $19,959.82$ & & 0.00 & 0.00 & 0.00 & 0.00 & 0.00 & \\
\hline SI & $22,977.48$ & $19,959.82$ & $16,942.15$ & $13,924.49$ & $10,906.83$ & $16,880.97$ & $22,855.12$ & $19,837.45$ & $16,819.79$ & $13,802.13$ & $10,784.46$ & $7,766.80$ & \\
\hline FLUJO NETO (A-B) & $-3,017.66$ & $-3,017.66$ & $-3,017.66$ & $-3,017.66$ & $5,974.15$ & $5,974.15$ & $-3,017.66$ & $-3,017.66$ & $-3,017.66$ & $-3,017.66$ & $-3,017.66$ & $-3,017.66$ & $-18,228.35$ \\
\hline FLUJO NETO: (A-B) + SI & $19,959.82$ & $16,942.15$ & $13,924.49$ & $10,906.83$ & $16,880.97$ & $22,855.12$ & \begin{tabular}{|l|}
$19,837.45$ \\
\end{tabular} & $16,819.79$ & $13,802.13$ & $\begin{array}{l}10,784.46 \\
\end{array}$ & 7,766.80 & $4,749.14$ & \\
\hline
\end{tabular}

\begin{tabular}{|c|c|c|c|c|c|c|c|c|c|c|c|c|c|}
\hline \multirow[b]{2}{*}{ CONCEPTO } & \multirow[b]{2}{*}{1} & \multirow[b]{2}{*}{2} & \multirow[b]{2}{*}{3} & \multirow[b]{2}{*}{4} & \multicolumn{3}{|c|}{ SEGUNDO AÑO } & \multirow[b]{2}{*}{8} & \multirow[b]{2}{*}{9} & \multirow[b]{2}{*}{10} & \multirow[b]{2}{*}{11} & \multirow[b]{2}{*}{12} & \multirow[b]{2}{*}{ Total } \\
\hline & & & & & 5 & 6 & 7 & & & & & & \\
\hline INGRESOS (A) & 0.00 & 0.00 & $29,535.22$ & $29,535.22$ & $29,535.22$ & $29,535.22$ & 0.00 & 0.00 & 0.00 & 0.00 & 0.00 & 0.00 & $118,140.86$ \\
\hline Ventas & 0.00 & 0.00 & $29,535.22$ & $29,535.22$ & $29,535.22$ & $29,535.22$ & 0.00 & 0.00 & 0.00 & 0.00 & 0.00 & 0.00 & \\
\hline EGRESOS (B) & $3,081.63$ & $3,081.63$ & $23,440.65$ & $23,440.65$ & $23,440.65$ & $23,440.65$ & $3,081.63$ & $3,081.63$ & $3,081.63$ & $3,081.63$ & $3,081.63$ & $3,081.63$ & $118,415.65$ \\
\hline Costos & $3,081.63$ & $3,081.63$ & $23,440.65$ & $23,440.65$ & $23,440.65$ & $23,440.65$ & $3,081.63$ & $3,081.63$ & $3,081.63$ & $3,081.63$ & $3,081.63$ & $3,081.63$ & \\
\hline Costos Fijos & $3,081.63$ & $3,081.63$ & $3,081.63$ & $3,081.63$ & $3,081.63$ & $3,081.63$ & $3,081.63$ & $3,081.63$ & $3,081.63$ & $3,081.63$ & $3,081.63$ & $3,081.63$ & \\
\hline Costos Variables & 0.00 & 0.00 & $20,359.01$ & $20,359.01$ & $20,359.01$ & $20,359.01$ & 0.00 & 0.00 & 0.00 & 0.00 & 0.00 & 0.00 & \\
\hline SI & $4,749.14$ & $1,667.50$ & $-1,414.13$ & $4,680.44$ & $10,775.01$ & $16,869.58$ & $22,964.14$ & $19,882.51$ & $16,800.88$ & $13,719.25$ & $10,637.61$ & $7,555.98$ & \\
\hline FLUJO NETO (A-B) & $-3,081.63$ & $-3,081.63$ & $6,094.57$ & $6,094.57$ & $6,094.57$ & $6,094.57$ & $-3,081.63$ & $-3,081.63$ & $-3,081.63$ & $-3,081.63$ & $-3,081.63$ & $-3,081.63$ & -274.79 \\
\hline FLUJO NETO: (A-B) + SI & $1,667.50$ & $-1,414.13$ & $4,680.44$ & $10,775.01$ & $16,869.58$ & $22,964.14$ & $19,882.51$ & $16,800.88$ & $13,719.25$ & $10,637.61$ & $7,555.98$ & $4,474.35$ & \\
\hline
\end{tabular}




\begin{tabular}{|c|c|c|c|c|c|c|c|c|c|c|c|c|c|}
\hline \multirow[b]{2}{*}{ CONCEPTO } & \multicolumn{8}{|c|}{ TERCER AÑO } & \multirow[b]{2}{*}{9} & \multirow[b]{2}{*}{10} & \multirow[b]{2}{*}{11} & \multirow[b]{2}{*}{12} & \multirow[b]{2}{*}{ Total } \\
\hline & 1 & 2 & 3 & 4 & 5 & 6 & 7 & 8 & & & & & \\
\hline INGRESOS (A) & 0.00 & 0.00 & $30,509.73$ & $61,019.45$ & $61,019.45$ & $61,019.45$ & 0.00 & 0.00 & 0.00 & 0.00 & 0.00 & 0.00 & $213,568.09$ \\
\hline Ventas & 0.00 & 0.00 & $30,509.73$ & $61,019.45$ & $61,019.45$ & $61,019.45$ & 0.00 & 0.00 & 0.00 & 0.00 & 0.00 & 0.00 & \\
\hline EGRESOS (B) & $3,447.87$ & $3,447.87$ & $24,214.07$ & $44,980.26$ & $44,980.26$ & $44,980.26$ & $3,447.87$ & $3,447.87$ & $3,447.87$ & $3,447.87$ & $3,447.87$ & $3,447.87$ & $186,737.86$ \\
\hline Costos & $3,447.87$ & $3,447.87$ & $24,214.07$ & $44,980.26$ & $44,980.26$ & $44,980.26$ & $3,447.87$ & $3,447.87$ & $3,447.87$ & $3,447.87$ & $3,447.87$ & $3,447.87$ & \\
\hline Costos Fijos & $3,447.87$ & $3,447.87$ & $3,447.87$ & $3,447.87$ & $3,447.87$ & $3,447.87$ & $3,447.87$ & $3,447.87$ & $3,447.87$ & $3,447.87$ & $3,447.87$ & $3,447.87$ & \\
\hline Costos Variables & 0.00 & 0.00 & $20,766.20$ & $41,532.39$ & $41,532.39$ & $41,532.39$ & 0.00 & 0.00 & 0.00 & 0.00 & 0.00 & 0.00 & \\
\hline SI & $4,474.35$ & $1,026.47$ & $-2,421.40$ & $3,874.26$ & $19,913.45$ & $35,952.64$ & $51,991.83$ & $48,543.95$ & $45,096.08$ & $41,648.21$ & $38,200.33$ & $34,752.46$ & \\
\hline FLUJO NETO (A-B) & $-3,447.87$ & $-3,447.87$ & $6,295.66$ & $16,039.19$ & $16,039.19$ & $16,039.19$ & $-3,447.87$ & $-\mathbf{3 , 4 4 7 . 8 7}$ & $-3,447.87$ & $-3,447.87$ & $-3,447.87$ & $-3,447.87$ & $26,830.24$ \\
\hline FLUJO NETO: (A-B) + SI & $1,026.47$ & $-2,421.40$ & $3,874.26$ & $19,913.45$ & $35,952.64$ & $51,991.83$ & $48,543.95$ & $45,096.08$ & $41,648.21$ & $38,200.33$ & $34,752.46$ & 31,304.58 & \\
\hline
\end{tabular}

\begin{tabular}{|c|c|c|c|c|c|c|c|c|c|c|c|c|c|}
\hline \multirow[b]{2}{*}{ CONCEPTO } & \multirow[b]{2}{*}{1} & \multirow{2}{*}{2} & \multirow[b]{2}{*}{3} & \multirow[b]{2}{*}{4} & \multicolumn{3}{|c|}{ CUARTO AÑO } & \multirow[b]{2}{*}{8} & \multirow[b]{2}{*}{9} & \multirow[b]{2}{*}{10} & \multirow[b]{2}{*}{11} & \multirow[b]{2}{*}{12} & \multirow[b]{2}{*}{ Total } \\
\hline & & & & & 5 & 6 & 7 & & & & & & \\
\hline INGRESOS (A) & 0.00 & 0.00 & $62,531.90$ & $93,797.84$ & $62,531.90$ & $62,531.90$ & 0.00 & 0.00 & 0.00 & 0.00 & 0.00 & 0.00 & $281,393.53$ \\
\hline Ventas & 0.00 & 0.00 & $62,531.90$ & $93,797.84$ & $62,531.90$ & $62,531.90$ & 0.00 & 0.00 & 0.00 & 0.00 & 0.00 & 0.00 & \\
\hline EGRESOS (B) & $3,632.73$ & $3,632.73$ & $45,995.76$ & $67,177.28$ & $45,995.76$ & $45,995.76$ & $3,632.73$ & $3,632.73$ & $3,632.73$ & $3,632.73$ & $3,632.73$ & $3,632.73$ & $234,226.37$ \\
\hline Costos & $3,632.73$ & $3,632.73$ & $45,995.76$ & $67,177.28$ & $45,995.76$ & $45,995.76$ & $3,632.73$ & $3,632.73$ & $3,632.73$ & $3,632.73$ & $3,632.73$ & $3,632.73$ & \\
\hline Costos Fijos & $3,632.73$ & $3,632.73$ & $3,632.73$ & $3,632.73$ & $3,632.73$ & $3,632.73$ & $3,632.73$ & $3,632.73$ & $3,632.73$ & $3,632.73$ & $3,632.73$ & $3,632.73$ & \\
\hline Costos Variables & 0.00 & 0.00 & $42,363.04$ & $63,544.56$ & $42,363.04$ & $42,363.04$ & 0.00 & 0.00 & 0.00 & 0.00 & 0.00 & 0.00 & \\
\hline SI & $31,304.58$ & $27,671.86$ & $24,039.13$ & $40,575.27$ & $67,195.83$ & $83,731.96$ & $100,268.09$ & $96,635.37$ & $93,002.64$ & $89,369.92$ & $85,737.19$ & $82,104.47$ & \\
\hline FLUJO NETO (A-B) & $-3,632.73$ & $-3,632.73$ & $16,536.13$ & $26,620.56$ & $16,536.13$ & $16,536.13$ & $-3,632.73$ & $-3,632.73$ & $-3,632.73$ & $-3,632.73$ & $-3,632.73$ & $-3,632.73$ & $47,167.16$ \\
\hline FLUJO NETO: (A-B) + SI & $27,671.86$ & $24,039.13$ & $40,575.27$ & $67,195.83$ & $83,731.96$ & $100,268.09$ & $96,635.37$ & $93,002.64$ & $89,369.92$ & $85,737.19$ & $82,104.47$ & $78,471.74$ & \\
\hline
\end{tabular}




\begin{tabular}{|c|c|c|c|c|c|c|c|c|c|c|c|c|c|}
\hline \multirow[b]{2}{*}{ CONCEPTO } & \multirow[b]{2}{*}{1} & \multirow[b]{2}{*}{2} & \multirow[b]{2}{*}{3} & \multirow[b]{2}{*}{4} & \multicolumn{3}{|c|}{ QUINTO AÑO } & \multirow[b]{2}{*}{8} & \multirow[b]{2}{*}{9} & & \multirow[b]{2}{*}{12} & \multirow[b]{2}{*}{ Total } \\
\hline & & & & & 5 & 6 & 7 & & & 10 & 11 & & \\
\hline INGRESOS (A) & 0.00 & 0.00 & $96,973.19$ & $96,973.19$ & 96,973.19 & 96,973.19 & 0.00 & 0.00 & 0.00 & 0.00 & 0.00 & 0.00 & $387,892.77$ \\
\hline Ventas & 0.00 & 0.00 & $96,973.19$ & $96,973.19$ & $96,973.19$ & $96,973.19$ & 0.00 & 0.00 & 0.00 & 0.00 & 0.00 & 0.00 & \\
\hline EGRESOS (B) & $4,049.13$ & $4,049.13$ & $68,864.58$ & $68,864.58$ & $68,864.58$ & $68,864.58$ & $4,049.13$ & $4,049.13$ & $4,049.13$ & $4,049.13$ & $4,049.13$ & $4,049.13$ & $307,851.41$ \\
\hline Costos & $4,049.13$ & $4,049.13$ & $68,864.58$ & $68,864.58$ & $68,864.58$ & $68,864.58$ & $4,049.13$ & $4,049.13$ & $4,049.13$ & $4,049.13$ & $4,049.13$ & $4,049.13$ & \\
\hline Costos Fijos & $4,049.13$ & $4,049.13$ & $4,049.13$ & $4,049.13$ & $4,049.13$ & $4,049.13$ & $4,049.13$ & $4,049.13$ & $4,049.13$ & $4,049.13$ & $4,049.13$ & $4,049.13$ & \\
\hline Costos Variables & 0.00 & 0.00 & $64,815.45$ & $64,815.45$ & $64,815.45$ & $64,815.45$ & 0.00 & 0.00 & 0.00 & 0.00 & 0.00 & 0.00 & \\
\hline SI & $78,471.74$ & $74,422.61$ & $70,373.47$ & $98,482.08$ & $126,590.69$ & $154,699.30$ & $182,807.91$ & $178,758.78$ & $174,709.64$ & $170,660.51$ & $166,611.37$ & $162,562.24$ & \\
\hline FLUJO NETO (A-B) & $-4,049.13$ & $-4,049.13$ & $28,108.61$ & $28,108.61$ & $28,108.61$ & $28,108.61$ & $-4,049.13$ & $-4,049.13$ & $-4,049.13$ & $-4,049.13$ & $-4,049.13$ & $-4,049.13$ & $80,041.37$ \\
\hline FLUJO NETO: (A-B) + SI & $74,422.61$ & 70,373.47 & $98,482.08$ & $126,590.69$ & $154,699.30$ & $182,807.91$ & $178,758.78$ & $174,709.64$ & $170,660.51$ & $166,611.37$ & $162,562.24$ & $158,513.11$ & \\
\hline
\end{tabular}




\section{ANEXO N 10: CRONOGRAMA DE PAGOS PRÉSTAMO \\ CAPITAL DE TRABAJO}

\begin{tabular}{|l|l|r|}
\hline Monto a financiar (o préstamo) & US\$\$. & $13,786.49$ \\
\hline Tasa de interés mensual & $\%$ & $1.60 \%$ \\
\hline Periodo de financiamiento & meses & 42 \\
\hline Periodo de gracia & meses & 6 \\
\hline Cuota & US\$ & -453.43 \\
\hline
\end{tabular}

\begin{tabular}{|c|c|c|c|c|c|c|c|}
\hline & Amort & Interes & Cuota & ITF & Total Pago & Saldo & Fn \\
\hline & & & & & & $13,786.49$ & -13786.4894 \\
\hline 1 & 0 & 220.75 & 220.75 & 0.01 & 220.76 & $13,786.49$ & 220.76 \\
\hline 2 & 0 & 220.75 & 220.75 & 0.01 & 220.76 & $13,786.49$ & 220.76 \\
\hline 3 & 0 & 220.75 & 220.75 & 0.01 & 220.76 & 13786.49 & 220.76 \\
\hline 4 & 0 & 220.75 & 220.75 & 0.01 & 220.76 & 13786.49 & 220.76 \\
\hline 5 & 0 & 220.75 & 220.75 & 0.01 & 220.76 & 13786.49 & 220.76 \\
\hline 6 & 0 & 220.75 & 220.75 & 0.01 & 220.76 & 13786.49 & 220.76 \\
\hline 7 & 232.68 & 220.75 & 453.43 & 0.02 & 453.45 & 13553.81 & 453.45 \\
\hline 8 & 236.41 & 217.02 & 453.43 & 0.02 & 453.45 & 13317.40 & 453.45 \\
\hline 9 & 240.19 & 213.24 & 453.43 & 0.02 & 453.45 & 13077.21 & 453.45 \\
\hline 10 & 244.04 & 209.39 & 453.43 & 0.02 & 453.45 & 12833.18 & 453.45 \\
\hline 11 & 247.94 & 205.48 & 453.43 & 0.02 & 453.45 & 12585.23 & 453.45 \\
\hline 12 & 251.91 & 201.51 & 453.43 & 0.02 & 453.45 & 12333.32 & 453.45 \\
\hline 13 & 255.95 & 197.48 & 453.43 & 0.02 & 453.45 & 12077.37 & 453.45 \\
\hline 14 & 260.05 & 193.38 & 453.43 & 0.02 & 453.45 & 11817.32 & 453.45 \\
\hline 15 & 264.21 & 189.22 & 453.43 & 0.02 & 453.45 & 11553.11 & 453.45 \\
\hline 16 & 268.44 & 184.99 & 453.43 & 0.02 & 453.45 & 11284.67 & 453.45 \\
\hline 17 & 272.74 & 180.69 & 453.43 & 0.02 & 453.45 & 11011.93 & 453.45 \\
\hline 18 & 277.11 & 176.32 & 453.43 & 0.02 & 453.45 & 10734.83 & 453.45 \\
\hline 19 & 281.54 & 171.88 & 453.43 & 0.02 & 453.45 & 10453.29 & 453.45 \\
\hline 20 & 286.05 & 167.38 & 453.43 & 0.02 & 453.45 & 10167.24 & 453.45 \\
\hline 21 & 290.63 & 162.80 & 453.43 & 0.02 & 453.45 & 9876.60 & 453.45 \\
\hline 22 & 295.28 & 158.14 & 453.43 & 0.02 & 453.45 & 9581.32 & 453.45 \\
\hline 23 & 300.01 & 153.41 & 453.43 & 0.02 & 453.45 & 9281.31 & 453.45 \\
\hline 24 & 304.82 & 148.61 & 453.43 & 0.02 & 453.45 & 8976.49 & 453.45 \\
\hline 25 & 309.70 & 143.73 & 453.43 & 0.02 & 453.45 & 8666.79 & 453.45 \\
\hline 26 & 314.66 & 138.77 & 453.43 & 0.02 & 453.45 & 8352.14 & 453.45 \\
\hline 27 & 319.69 & 133.73 & 453.43 & 0.02 & 453.45 & 8032.44 & 453.45 \\
\hline 28 & 324.81 & 128.61 & 453.43 & 0.02 & 453.45 & 7707.63 & 453.45 \\
\hline 29 & 330.01 & 123.41 & 453.43 & 0.02 & 453.45 & 7377.62 & 453.45 \\
\hline 30 & 335.30 & 118.13 & 453.43 & 0.02 & 453.45 & 7042.32 & 453.45 \\
\hline 31 & 340.67 & 112.76 & 453.43 & 0.02 & 453.45 & 6701.65 & 453.45 \\
\hline 32 & 346.12 & 107.31 & 453.43 & 0.02 & 453.45 & 6355.53 & 453.45 \\
\hline 33 & 351.66 & 101.76 & 453.43 & 0.02 & 453.45 & 6003.87 & 453.45 \\
\hline 34 & 357.29 & 96.13 & 453.43 & 0.02 & 453.45 & 5646.57 & 453.45 \\
\hline 35 & 363.02 & 90.41 & 453.43 & 0.02 & 453.45 & 5283.56 & 453.45 \\
\hline 36 & 368.83 & 84.60 & 453.43 & 0.02 & 453.45 & 4914.73 & 453.45 \\
\hline 37 & 374.73 & 78.69 & 453.43 & 0.02 & 453.45 & 4540.00 & 453.45 \\
\hline 38 & 380.73 & 72.69 & 453.43 & 0.02 & 453.45 & 4159.26 & 453.45 \\
\hline 39 & 386.83 & 66.60 & 453.43 & 0.02 & 453.45 & 3772.43 & 453.45 \\
\hline 40 & 393.02 & 60.40 & 453.43 & 0.02 & 453.45 & 3379.41 & 453.45 \\
\hline 41 & 399.32 & 54.11 & 453.43 & 0.02 & 453.45 & 2980.09 & 453.45 \\
\hline 42 & 405.71 & 47.72 & 453.43 & 0.02 & 453.45 & 2574.38 & 453.45 \\
\hline 43 & 412.21 & 41.22 & 453.43 & 0.02 & 453.45 & 2162.18 & 453.45 \\
\hline 44 & 418.81 & 34.62 & 453.43 & 0.02 & 453.45 & 1743.37 & 453.45 \\
\hline 45 & 425.51 & 27.91 & 453.43 & 0.02 & 453.45 & 1317.86 & 453.45 \\
\hline 46 & 432.33 & 21.10 & 453.43 & 0.02 & 453.45 & 885.53 & 453.45 \\
\hline 47 & 439.25 & 14.18 & 453.43 & 0.02 & 453.45 & 446.28 & 453.45 \\
\hline 48 & 446.28 & 7.15 & 453.43 & 0.02 & 453.45 & 0.00 & 453.45 \\
\hline
\end{tabular}

